\title{
Migratie van zoetwaterstandvis tussen Noordzeekanaal en omliggende boezems en polders
}

Datarapportage 2019

Auteur(s): $\quad$ A.B. Griffioen 1, \& R. Kroes 2

1 Wageningen Marine Research

2 Universteit van Amsterdam

Wageningen Marine Research

IJmuiden, december 2019

Wageningen Marine Research rapport C126/19 
Keywords: Schubvis, Noordzeekanaal, telemetrie, PIT-tag, migratie

Opdrachtgever: Ecologische Verbindingszone Noordzeekanaal en Ommelanden:

RWS West-Nederland Noord

Provincie Noord-Holland

Hoogheemraadschap Hollands Noorderkwartier

Hoogheemraadschap van Rijnland

Waterschap Amstel, Gooi en Vecht

Sportvisserij Midwest Nederland

Gemeente Amsterdam

Port of Amsterdam

Dit rapport is gratis te downloaden van: https://doi.org/10.18174/509050

Wageningen Marine Research verstrekt geen gedrukte exemplaren van rapporten.

Wageningen Marine Research is ISO 9001:2015 gecertificeerd.

\section{(c) Wageningen Marine Research}

Wageningen Marine Research, instituut binnen de rechtspersoon Stichting

Wageningen Research, hierbij

vertegenwoordigd door Dr. M.C.Th.

Scholten, Algemeen directeur

KvK nr. 09098104,

WMR BTW nr. NL 8113.83.696.B16.

Code BIC/SWIFT address: RABONL2U

IBAN code: NL 73 RABO 0373599285
Wageningen Marine Research aanvaardt geen aansprakelijkheid voor gevolgschade, noch voor schade welke voortvloeit uit toepassingen van de resultaten van werkzaamheden of andere gegevens verkregen van Wageningen Marine Research. Opdrachtgever vrijwaart Wageningen Marine Research van aanspraken van derden in verband met deze toepassing.

Alle rechten voorbehouden. Niets uit deze uitgave mag weergegeven en/of gepubliceerd worden, gefotokopieerd of op enige andere manier gebruikt worden zonder schriftelijke toestemming van de uitgever of auteur. 


\section{Inhoud}

$\begin{array}{llr}1 & \text { Inleiding } & 5\end{array}$

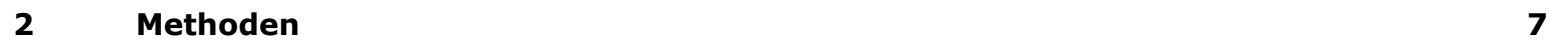

$\begin{array}{lll}2.1 & \text { Locaties en telemetrie } & 7\end{array}$

2.2 Nauerna $r$

$\begin{array}{ll}2.3 \text { Halfweg } & 10\end{array}$

2.4 Kadoelen 12

2.5 Willem I-sluis $\quad 14$

2.6 Oranjesluizen 16

$\begin{array}{llr}3 & \text { Resultaten } & 18\end{array}$

$\begin{array}{lll}3.1 & \text { Nauerna } & 19\end{array}$

$\begin{array}{llr}3.2 & \text { Halfweg } & 22\end{array}$

$\begin{array}{ll}3.3 & \text { Kadoelen } \\ 3.4 & 26\end{array}$

$\begin{array}{lll}3.4 & \text { Willem I-sluis } & 30\end{array}$

$\begin{array}{lll}3.5 & \text { Oranjesluizen } & 33\end{array}$

$4 \quad$ Conclusies en aanbevelingen $\quad 36$

$\begin{array}{llr}5 & \text { Kwaliteitsborging } & 37\end{array}$

$\begin{array}{lr}\text { Literatuur } & 38\end{array}$

$\begin{array}{lr}\text { Verantwoording } & 39\end{array}$

Bijlage 1 Detecties gemalen $\quad 40$

Bijlage $2 \quad$ Voorbeelden migratiepatronen 5 


\section{Samenvatting}

Er wordt in Nederland relatief veel aandacht besteed aan de migratie van trekvissen als aal, zalm, zeeforel en andere soorten. Belangrijke voorbeelden voor Nederland zijn bijvoorbeeld: 'de Kier' bij het Haringvliet ${ }^{1}$, de realisatie van de Vismigratierivier bij Kornwerderzand ${ }^{2}$, de Swimway Vecht ${ }^{3}$ en de vele andere (lokale) initiatieven om de keten van migratie voor vis mogelijk te maken tussen wateren. Ook liggen inmiddels vele migratievoorzieningen in en rond het Noordzeekanaal. Dit is hard nodig omdat veel watersystemen sterk zijn gecompartimenteerd. Aan de ene kant om het land te beschermen tegen overstroming door de zee, de grote rivieren en de grote meren zijn dijken aangelegd. Aan de andere kant om het gebied leefbaar te maken en de landbouw te optimaliseren zijn de watersystemen met behulp van gemalen, dijken, dammen, stuwen en andere kunstwerken in kleine beheersbare eenheden verdeeld en daarmee afgesloten geraakt voor migrerende vissen. Niet alleen 'de bekende' trekvissen zoals de paling of de zalm hebben een migratiedrang om (grote) afstanden te zwemmen, ook zoetwatervissen trekken van het ene water naar het andere. Dit gebeurt om verschillende redenen, zoals bijvoorbeeld voor de paai, migratie naar opgroeigebied, of naar ander water voor de winterrust.

Deze rapportage betreft een datarapportage voor het eerste migratieseizoen in $2019 \mathrm{t} / \mathrm{m} 19$ augustus waar met PIT telemetrie techniek onderzoek gedaan is bij vijf locaties: Gemaal Halfweg, Gemaal Nauerna, Gemaal Kadoelen, Willem I-sluis en Oranjesluizen. In het voorjaar van 2019 zijn 1844 vissen van 15 verschillende soorten gemerkt met PIT tags. Het merendeel daarvan betrof brasem en blankvoorn, maar er is bijvoorbeeld ook snoekbaars en baars gemerkt. Grote snoekbaars en baars zijn ook uitgerust met een van buitenaf zichtbare Floytag voor terugmelding door sport of beroepsvisssers. Om de zwembewegingen in de buurt van de onderzoekslocaties te volgen zijn PIT tag antennes geïnstalleerd bij de vispassages (Halfweg, Nauerna, Kadoelen en Oranjesluizen) of de vismigratievoorziening via rinketten (Willem I). Daarnaast zijn ook de uitstroomzijdes van gemalen afgedekt met antennes (Halfweg, Nauerna en Kadoelen). Het doel van het onderzoek is om het gebruik van vismigratievoorzieningen door vissen te evalueren en daarnaast zwembewegingen tussen het Noordzeekanaal en boezem/polder te volgen.

In totaal zijn tot 19 augustus 2019717 individuele vissen gedetecteerd op een van de antennes met in totaal ruim 1.300.000 detecties. De resultaten laten zien dat de gemerkte brasems op grote schaal (tientallen $\mathrm{km}$ ) migreren in relatief korte tijd. Individuele brasems worden op meerdere locaties gezien door de telemetrie. Ook wordt waargenomen dat gemerkte vissen langdurig in de buurt van een gemaaluitstroom blijven rondzwemmen. In totaal zijn er twee terugmeldingen geweest van sportvisserij die snoekbaars hadden gevangen: een snoekbaars die gemerkt was bij Nauerna (en ook daar gevangen) en een die gemerkt was bij de Oranjesluizen en teruggevangen bij de Entrepothaven (AmsterdamRijnkanaal).

In de volgende maanden gaan we door met het verzamelen van de detecties en blijven we de techniek controleren. Aanbevolen wordt om in het voorjaar van 2020 extra vissen van een merk te voorzien op de locaties waar in 2019 de passages laat zijn opgeleverd of waar er relatief weinig vissen zijn gevangen. Daarnaast wordt aanbevolen om een extra voorjaar te monitoren (2021) om patronen in het migratiegedrag beter inzichtelijk te krijgen en te beoordelen of er sprake is van willekeurige of gerichte migratie, bijvoorbeeld ten behoeve van paai of overwintering.

\footnotetext{
${ }^{1}$ https://www.rijkswaterstaat.nl/water/projectenoverzicht/haringvliet-haringvlietsluizen-op-een-kier/index.aspx

${ }^{2}$ https://deafsluitdijk.nl/projecten/vismigratierivier/

${ }^{3}$ https://www.sportvisserijnederland.nl/actueel/nieuws/20679/swimway-vecht-vismigratie-onderzocht.html
} 


\section{$1 \quad$ Inleiding}

Er wordt in Nederland relatief veel aandacht besteed aan het verbeteren van de migratie van trekvissen als aal, zalm, zeeforel en andere soorten. Belangrijke voorbeelden voor Nederland zijn bijvoorbeeld: 'de Kier' bij het Haringvliet ${ }^{4}$, de realisatie van de Vismigratierivier bij Kornwerderzand ${ }^{5}$, de Swimway Vecht ${ }^{6}$ en de vele andere (lokale) initiatieven om de keten van migratie voor vis mogelijk te maken tussen wateren. Ook liggen inmiddels vele migratievoorzieningen in en rond het Noordzeekanaal (NZK). Dit is hard nodig omdat veel watersystemen sterk zijn gecompartimenteerd. Aan de ene kant om het land te beschermen tegen overstroming door de zee, de grote rivieren en de grote meren zijn dijken aangelegd. Aan de andere kant om het gebied leefbaar te maken en de landbouw te optimaliseren zijn de watersystemen met behulp van gemalen, dijken, dammen, stuwen en andere kunstwerken in kleine beheersbare eenheden verdeeld en daarmee afgesloten geraakt voor migrerende vissen. Niet alleen 'de bekende' trekvissen zoals de paling of de zalm hebben een migratiedrang om (grote) afstanden te zwemmen, ook zoetwatervissen trekken van het ene water naar het andere. Dit gebeurt om verschillende redenen, zoals bijvoorbeeld voor de paai, migratie naar opgroeigebied, of naar ander water voor de winterrust.

Alle waterbeheerders in Europa hebben de opdracht om uiterlijk in 2027 te voldoen aan de doelstellingen van de Europese Kaderrichtlijn Water. Deze doelstellingen omvatten onder meer eisen aan de visgemeenschap. Het streven is in de waterlichamen te komen tot een zo natuurlijk mogelijke, evenwichtige en bestendige visstand waarbij met "natuurlijk" wordt bedoeld: de situatie in een oorspronkelijke, historische situatie of vergelijkbare referentiesituatie. Twee andere belangrijke wettelijke regelingen voor de bescherming en het herstel van trekvispopulaties vormen de Europese Aalverordening (2007) en de Beneluxbeschikking vismigratie (2009). In Nederland wordt daarom gewerkt aan herstel van zout-zoet verbindingen en worden landinwaarts ook herstelmaatregelen getroffen om waterlichamen met elkaar te verbinden en zo vismigratie mogelijk te maken (Kroes et al. 2018).

Het herstel van verbindingen tussen wateren is van groot belang voor vele trekvissoorten en zogeheten standvissen, maar men moet ook denken aan het herstel van paaigronden, foerageer- en opgroeigebieden, het selectief gebruik maken van een estuarium, etc. Uiteindelijk is er meer nodig dan alleen 'vrije vismigratie'. Toch is het herstel van vrije migratie een goede eerste stap die aangepakt moet worden. Het samenwerkingsverband Ecologische Verbindingszone Noordzeekanaal en Ommelanden (EVZ NZK eo) ${ }^{7}$, bestaat uit meerdere waterbeheerders en partners die de handen ineen hebben geslagen voor het herstel van vismigratie in de diverse beheergebieden rond het Noordzeekanaal. Het probleem van versnippering is door de betrokken partijen van het samenwerkingsverband onderkend en in het gezamenlijke areaal zijn de afgelopen jaren diverse maatregelen genomen om vismigratieknelpunten op te lossen of te mitigeren. Samenwerking is hierin noodzakelijk om tot een succesvol resultaat te kunnen komen. Vismigratieroutes doorkruisen vaak meerdere beheergebieden, waardoor maatregelen in het ene gebied directe gevolgen kunnen hebben voor het andere gebied.

In eerdere onderzoek is de migratie van aal en driedoornige stekelbaars onderzocht (Griffioen and Winter 2017, 2018, Griffioen et al. 2019a, Griffioen et al. 2019b, Winter et al. 2019). Het onderzoek beschreven in deze datarapportage richt zich op vissen die niet tussen zoet en zout migreren, maar meer lokaal actief zijn. We noemen deze vissen in deze rapportage 'standvis'. Het doel van dit onderzoek is om te evalueren of deze 'standvissen' gebruik maken van de aangelegde vismigratie voorzieningen en in hoeverre zij heen en weer zwemmen tussen Rijkswater (Noordzeekanaal en Markermeer) en

\footnotetext{
${ }^{4}$ https://www.rijkswaterstaat.nl/water/projectenoverzicht/haringvliet-haringvlietsluizen-op-een-kier/index.aspx

${ }^{5}$ https://deafsluitdijk.nl/projecten/vismigratierivier/

${ }^{6}$ https://www.sportvisserijnederland.nl/actueel/nieuws/20679/swimway-vecht-vismigratie-onderzocht.html

7 Partners: provincie Noord-Holland, Hoogheemraadschap Hollands Noorderkwartier, Hoogheemraadschap van Rijnland, Waterschap Amstel, Gooi en Vecht, Sportvisserij Midwest Nederland, Port of Amsterdam, gemeente Amsterdam en Rijkswaterstaat WestNederland Noord
} 
polders/boezems. Deze (data)rapportage betreft een overzicht van vijf onderzoeklocaties waarbij met PIT telemetrie de migratie van 'standvis' wordt onderzocht. Daarnaast wordt er een overzicht gegeven van het aantal gemerkte vissen en een eerste inzicht in migratiepatronen op basis van detecties $\mathrm{t} / \mathrm{m} 19$ augustus 2019 en van Oranjesluizen t/m 29 augustus 2019. In deze rapportage zijn geen analyses opgenomen. Dit zal aan het einde van het onderzoek worden gedaan (2021).

De uitvoering van het onderzoek kon niet worden gedaan zonder de hulp van de visserij. Wij willen graag Visserij Service Nederland (alle locaties) en Piet Ruijter (Halfweg) bedanken voor hun inzet in dit onderzoek. Verder willen we Ruud Houtkooper bedanken voor het plaatsen van het frame bij gemaal Halfweg. 


\section{$2 \quad$ Methoden}

\section{$2.1 \quad$ Locaties en telemetrie}

Binnen dit onderzoek worden vijf locaties onderzocht met behulp van PIT telemetrie (Figuur 2-1). Daarbij werden in het voorjaar met een zegen vissen gevangen en (onder verdoving) met een tag uitgerust en vervolgens weer vrijgelaten. De vissen zijn voornamelijk aan de Noordzeekanaalzijde (NZK-zijde) gevangen met een zegen. Na het merken (23 of $32 \mathrm{~mm}$ tag) zijn ze ook weer aan deze zijde van de barrière uitgezet. Daar waar er weinig vis is gevangen is er ook op andere plekken gevist (boezemzijde) om voldoende vis te kunnen merken. In de opzet van het onderzoek is ook getracht het sluiscomplex bij Muiden in te richten als onderzoekslocatie. Hier is op last van de beheerder (AGV) om veiligheidsredenen vanaf gezien. Bij de locaties Nauerna, Halfweg en Kadoelen zijn zowel bij de vispassage als bij de uitstroomzijde van het gemaal antennes geplaatst. Op deze manier kan worden nagegaan of vissen via het gemaal vanuit de polder/boezem weer richting het NZK worden uitgemaald. Tevens leveren detecties bij de uitstroomzijde ook inzicht op of vissen nog in het systeem aanwezig zijn als zij zich bij deze zijde van het gemaal ophouden. Een antenne aan de instroomzijde van het gemaal is vanuit veiligheidsoverwegingen niet mogelijk. De werkzaamheden bij de Oranjesluizen worden gedaan door de Universiteit van Amsterdam (Figuur 2-1).

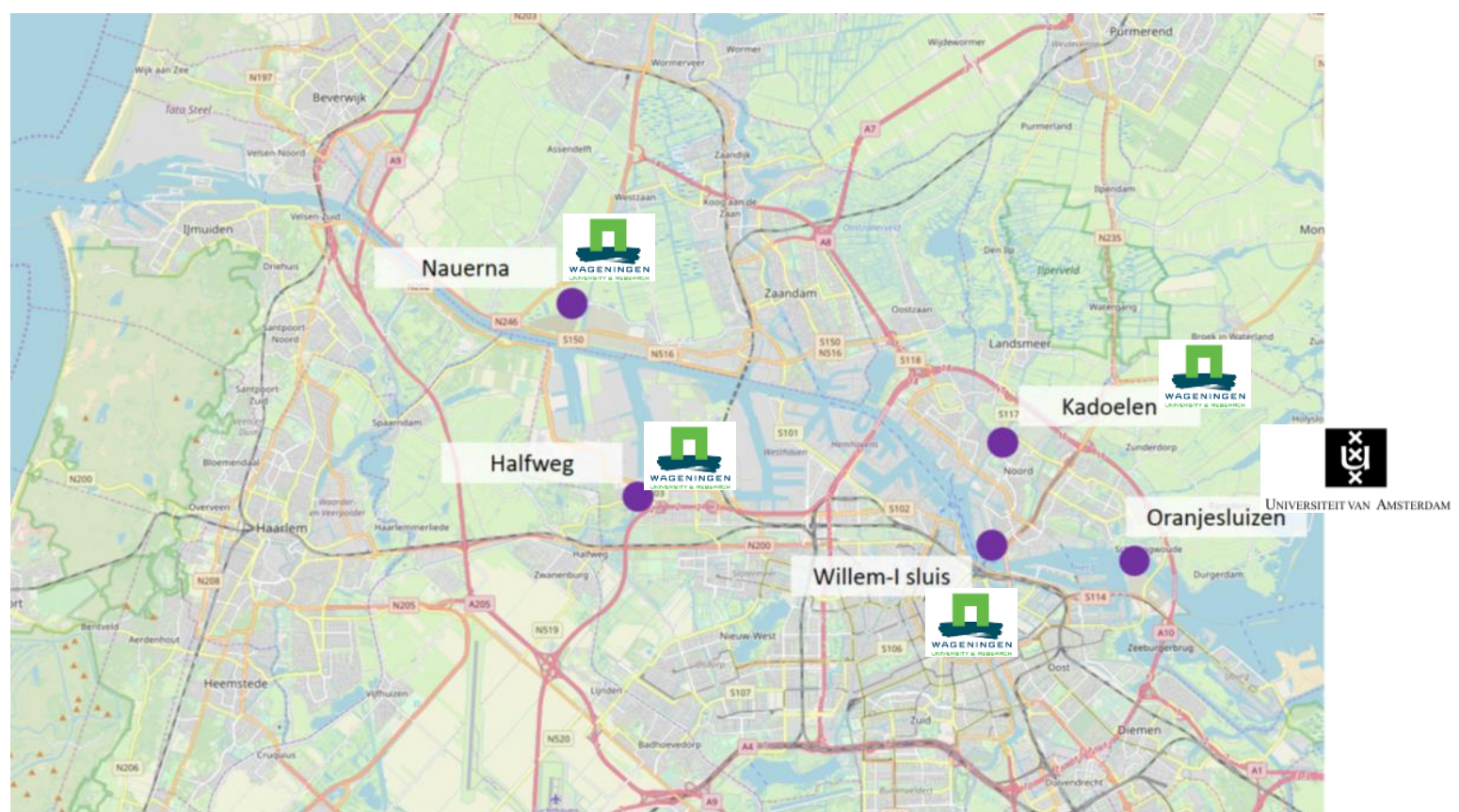

Figuur 2-1 Onderzoeklocaties met PIT telemetrie op vijf locaties die boezem/polder (of Markermeer) verbinden met het Noordzeekanaal. Het onderzoek wordt uitgevoerd met als doel de migratie van zoetwatervis te volgen.

Tabel 1 Totaal aantal gemerkte vissen voor de vijf locaties $(N=1.844)$.

\begin{tabular}{|l|r|r|r|r|r|r|}
\hline & Halfweg & Kadoelen & Nauerna & Oranjesluizen & Willem I Sluis & totaal \\
\hline Baars & 22 & 19 & 4 & 23 & & 68 \\
\hline Blankvoorn & 104 & 5 & 1 & 458 & 5 & 573 \\
\hline Bot & & & 9 & 1 & & 10 \\
\hline Brasem & 177 & 454 & 83 & 277 & 38 & 1029 \\
\hline Dunlipharder & & & & 5 & & 5 \\
\hline Houting & 2 & & & 4 & & 6 \\
\hline Hybride & 1 & & & 2 & & 3 \\
\hline Karper & & 2 & 1 & & & 3 \\
\hline Kolblei & 3 & 3 & 15 & 1 & & 22 \\
\hline Paling & & & 4 & & & 4 \\
\hline Roofblei & & & & 5 & & 5 \\
\hline Ruisvoorn & 1 & & & & & 1 \\
\hline Snoek & 2 & 4 & & 4 & & 10 \\
\hline Snoekbaars & 14 & 24 & 49 & 8 & & 95 \\
\hline Winde & & & & 8 & 1 & 9 \\
\hline Totaal & 326 & 511 & 166 & 796 & 45 & 1844 \\
\hline
\end{tabular}




\section{$2.2 \quad$ Nauerna}

\section{PIT opstelling}

Gemaal Nauerna heeft naast het gemaal een sluis-vispassage die op 17 april 2019 in bedrijf is genomen en vanaf 24 april stabiel functioneerde (pers. meded. S. Westerman, HHNK). Op deze locatie zijn in totaal vier antennes geplaatst: twee in de uitstroom van het gemaal en twee bij de in- en uitgang van de vispassage. De antennes bij het gemaal bestaan uit twee frames van elk ca. 1,8 x 0,8m (2-loop $4 \mathrm{~mm}^{2}$ draad). Bij de vispassage is aan de NZK-zijde een antenne geplaatst en aan de polderzijde ook een (beide ca. 0,6x0,6m, 3-loop 2,5 $\mathrm{mm}^{2}$ draad). Deze zijn in de sponning van de voorziening gehangen. De readers zijn draadloos gesynchroniseerd. Indien een vis richting de ingang van de vispassage zwemt wordt deze eerst door de antenne bij de uitstroom van het gemaal gedetecteerd.

De vispassage NZK-zijde detecteerde vanaf: De vispassage polderzijde vanaf: Gemaal frames oost detecteerde vanaf:
12 maart 2019

12 maart 2019

12 maart 2019, van 9-25 juli geen data door wegvallen stroom

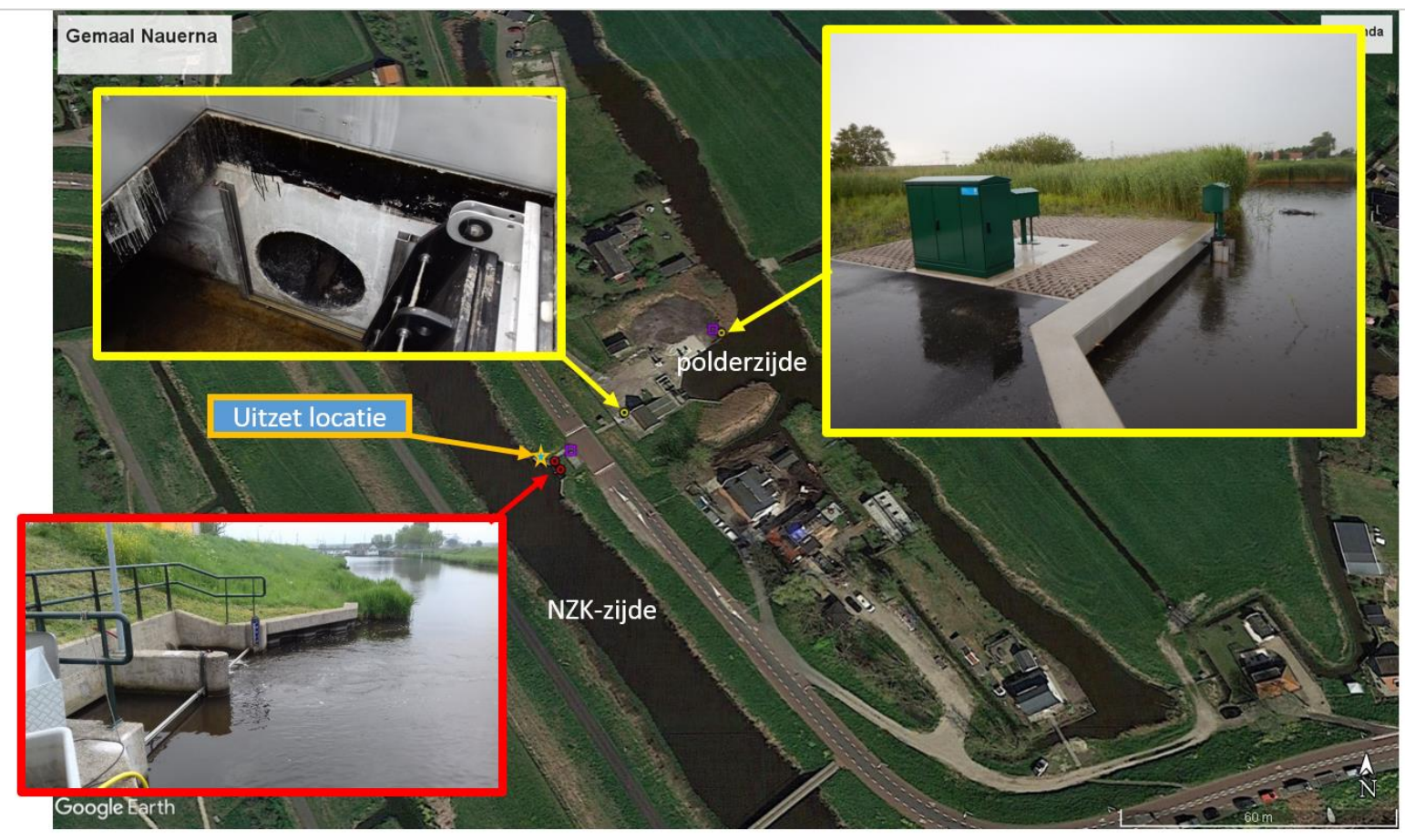

Figuur 2-2 Plaatsing van de antennes voor PIT telemetrie bij gemaal Nauerna. In totaal twee antennes achter het gemaal, een antenne bij de passage NZK-zijde en een antenne bij de vispassage aan de polderzijde.

\section{Testvissen}

Bij gemaal Nauerna zijn in totaal 166 vissen gemerkt en allemaal aan de NZK-zijde uitgezet (Tabel 2). De vangst was erg wisselend met enkele dagen waarop er geen vangst is geweest. In totaal zijn 83 brasems en 49 snoekbaarzen gemerkt en in lager aantal ook kolblei (15 stuks), bot ( 9 stuks), paling ( 4 stuks), baars ( 4 stuks), karper ( 1 vis) en blankvoorn ( 1 vis). Afgezien van 1 bot met een $12 \mathrm{~mm}$ tag en een 1 bot met $23 \mathrm{~mm}$ tag, zijn alle vissen zijn met een $32 \mathrm{~mm}$ tag uitgerust en op normaal zwemgedrag gecontroleerd voordat ze zijn vrijgelaten. De vissen zijn bij de uitstroomzijde van het gemaal losgelaten. 
Tabel 2 Totaal aantal gemerkte vissen bij gemaal Nauerna $(N=166)$.

\begin{tabular}{|c|c|c|c|c|c|c|c|c|c|c|}
\hline & & & & & mean & $\min$ & $\max$ & mean & $\min$ & $\max$ \\
\hline soort & vangstlocatie & uitzetlocatie & datum & $n$ & lengte (mm) & lengte $(\mathrm{mm})$ & lengte $(\mathrm{mm})$ & gewicht (gr) & gewicht (gr) & gewicht (gr) \\
\hline Baars & NZK-zijde & NZK-zijde & $2 / \mathrm{mei}$ & 4 & 232 & 153 & 283 & 191 & 42 & 317 \\
\hline Bot & NZK-zijde & NZK-zijde & 2/mei & 5 & 254 & 136 & 337 & 222 & 28 & 428 \\
\hline Brasem & NZK-zijde & NZK-zijde & 2/mei & 55 & 427 & 213 & 575 & 1021 & 88 & 1980 \\
\hline Kolblei & NZK-zijde & NZK-zijde & $2 / \mathrm{mei}$ & 5 & 240 & 192 & 319 & 217 & 76 & 472 \\
\hline Snoekbaars & NZK-zijde & NZK-zijde & 2/mei & 7 & 417 & 245 & 565 & 614 & 96 & 1426 \\
\hline Brasem & NZK-zijde & NZK-zijde & $7 / \mathrm{mei}$ & 2 & 417 & 413 & 420 & 853 & 826 & 880 \\
\hline Kolblei & NZK-zijde & NZK-zijde & 7/mei & 1 & 291 & 291 & 291 & 340 & 340 & 340 \\
\hline Snoekbaars & NZK-zijde & NZK-zijde & 7/mei & 1 & 534 & 534 & 534 & 1215 & 1215 & 1215 \\
\hline Brasem & NZK-zijde & NZK-zijde & $14 / \mathrm{mei}$ & 15 & 303 & 219 & 473 & 390 & 108 & 1166 \\
\hline Snoekbaars & NZK-zijde & NZK-zijde & $14 / \mathrm{mei}$ & 9 & 401 & 226 & 656 & 723 & 90 & 2182 \\
\hline Bot & NZK-zijde & NZK-zijde & $28 / \mathrm{mei}$ & 4 & 241 & 221 & 276 & 121 & 63 & 165 \\
\hline Brasem & NZK-zijde & NZK-zijde & 28/mei & 11 & 330 & 238 & 495 & 518 & 124 & 1426 \\
\hline Kolblei & NZK-zijde & NZK-zijde & 28/mei & 7 & 183 & 159 & 237 & 82 & 49 & 170 \\
\hline Paling & NZK-zijde & NZK-zijde & $28 / \mathrm{mei}$ & 1 & 532 & 532 & 532 & 303 & 303 & 303 \\
\hline Snoekbaars & NZK-zijde & NZK-zijde & $28 / \mathrm{mei}$ & 32 & 393 & 234 & 611 & 535 & 106 & 1878 \\
\hline
\end{tabular}

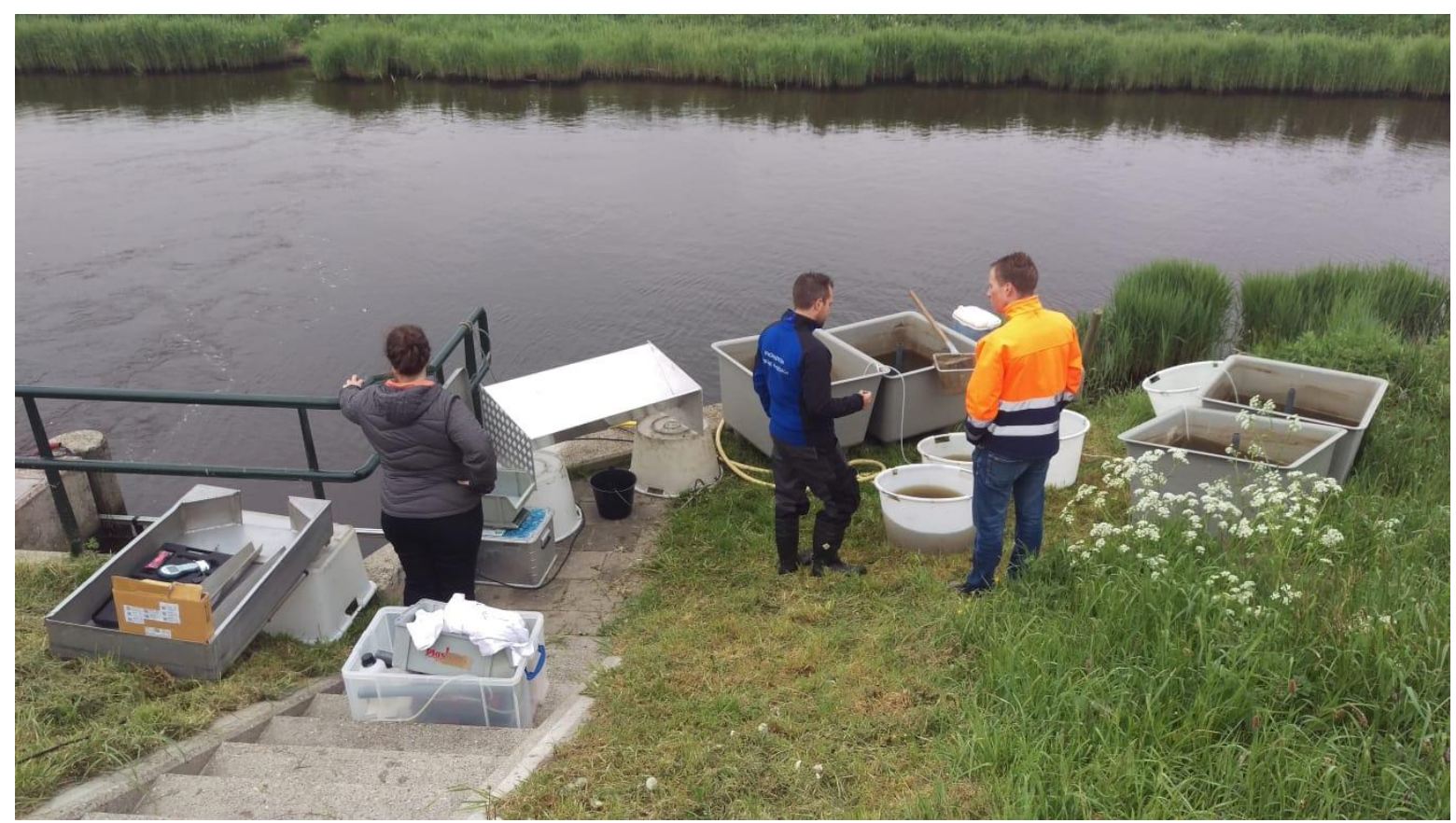

Foto 2. Opstelling voor het merken van de vis bij de uitstroomzijde van gemaal Nauerna (foto: Rens Hensgens). 


\subsection{Halfweg}

\section{PIT opstelling}

Gemaal Halfweg heeft naast het gemaal een "Manshanden" vispassage. Deze bestaat uit een opvoerbak, die vanuit de boezem wordt gevuld met een vijzel. Vanuit de opvoerbak stroom continu water langs het gemaal naar de NZK-zijde en een stroom terug naar de boezem, zodat vis die vanuit het NZK terechtkomt in de opvoerbak richting de boezem kan passeren. Op deze locatie zijn in totaal 15 antennes geplaatst: elf bij het gemaal en vier bij de vispassage. De antennes bij het gemaal bestaan uit drie frames van elk ca. $5 \times 5,5 \mathrm{~m}$. Deze zijn met een kraan in de sponning van elke koker gehangen. Per frame zijn vier antennes gespannen van 0,6×3m met elk circa 0,4m tussenruimte. De draden zijn dubbel gelust met $4 \mathrm{~mm}^{2}$ draad. De ruimte tussen de antennes wordt afgedekt door het bereik van de antenne zelf, zodat er nauwelijks 'dode ruimte' ontstaat. Het frame aan de oostzijde, het frame links in Figuur 2-3, heeft drie antennes ingeschakeld (en dus een 'blinde vlek') omdat aan dezelfde reader ook de antenne van de vispassage is gekoppeld. De readers zijn gesynchroniseerd middels een bekabelde master/slave connectie.

Bij de vispassage is aan de NZK-zijde een antenne geplaatst (ca. 0,9x0,9m, 3-loop 2,5mm² draad) en aan de boezemzijde in totaal drie. Eén kleine antenne (ca. 0,3x0,6m, 3-loop 2,5 $\mathrm{mm}^{2}$ draad) daar waar de vis de vispassage verlaat en twee 'gestapelde' antennes (ca. 2,4x0,6m 2-loop 4mm² draad) voor de instroom van de vijzel.

De vispassage NZK-zijde detecteerde vanaf: De vispassage boezemzijde vanaf:

Het gemaal frame oost detecteerde vanaf:

Het gemaal frame midden en west vanaf:
30 maart 2019

30 maart 2019

24 april 2019 (tussen 19-29 augustus defect door bliksem inslag)

29 mei $2019^{8}$

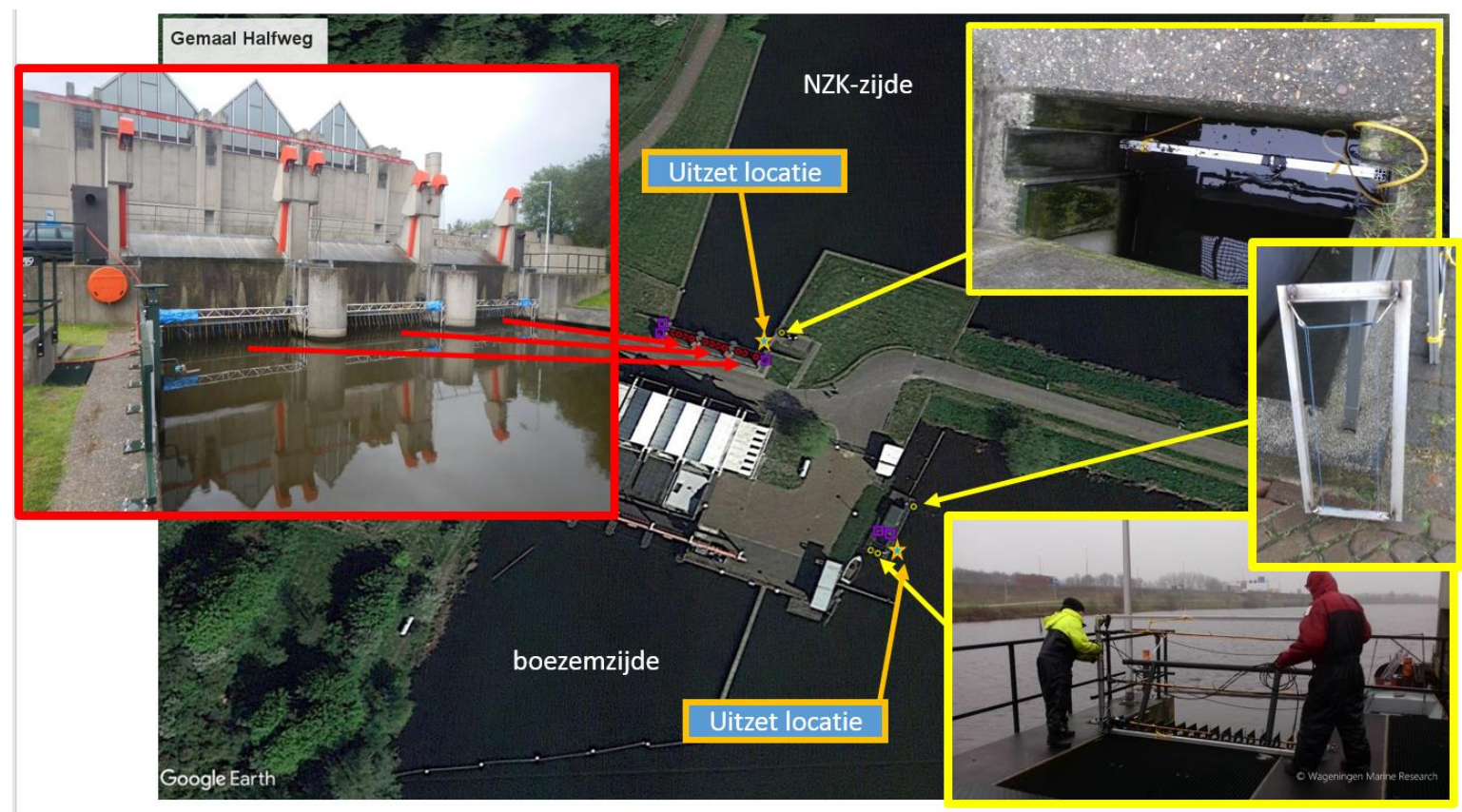

Figuur 2-3 Plaatsing van de antennes voor PIT telemetrie bij gemaal Halfweg. In totaal 11 antennes achter het gemaal, 1 antenne bij de passage NZK zijde en 3 antennes bij de vispassage aan de boezemzijde.

\section{Testvissen}

Bij gemaal Halfweg zijn in totaal 326 vissen gemerkt: 289 zijn gevangen aan de boezemzijde, 14 aan de NZK-zijde en 23 stuks zijn uit de monitoring ${ }^{9}$ van de vispassage (boezemzijde) gehaald (Tabel 3 ). Van de aan de boezemzijde gevangen vissen (incl. die uit de fuikmonitoring van de vispassage) zijn 61

\footnotetext{
${ }^{8}$ Vanwege detectierange en storing van de synchronisatie zijn deze frames ingeschakeld vanaf 29 mei toen de storing was verholpen en de detectierange geoptimaliseerd.

${ }^{9}$ Hoogheemraadschap van Rijnland en Rijkswaterstaat voeren sinds 2014 bij de vispassage te Halfweg in het voorjaar een monitoring uit met behulp van een fuik. Dit wordt uitgevoerd door beroepsvisser P. Ruijter.
} 
weer aan de boezemzijde teruggezet na merken en 251 aan de NZK-zijde (Tabel 3). In totaal zijn 177 brasems en 104 blankvoorns gemerkt en in lager aantal baars (22 stuks), snoekbaars (14 stuks), kolblei (3 stuks), houting ( 2 stuks), snoek ( 2 stuks), ruisvoorn (1 vis) en een cyprinide hybride (1 vis) gemerkt. Alle vissen zijn met een $32 \mathrm{~mm}$ tag uitgerust en op normaal zwemgedrag gecontroleerd voordat ze zijn vrijgelaten. De vissen zijn nabij de ingang van de vispassage losgelaten (ca. 10 meter daarvandaan). Aan de boezemzijde zijn de vissen nabij de vispassage teruggezet.

Tabel 3 Totaal aantal gemerkte vissen bij gemaal Halfweg $(N=326)$.

\begin{tabular}{|c|c|c|c|c|c|c|c|c|c|c|}
\hline & & & & & mean & $\min$ & $\max$ & mean & $\min$ & $\max$ \\
\hline soort & vangstlocatie & uitzetlocatie & datum & $n$ & lengte $(\mathrm{mm})$ & lengte $(\mathrm{mm})$ & lengte $(\mathrm{mm})$ & gewicht (gr) & gewicht (gr) & gewicht (gr) \\
\hline Baars & vispassage & NZK-zijde & $26 / \mathrm{mrt}$ & 11 & 258 & 225 & 367 & 267 & 164 & 782 \\
\hline Blankvoorn & vispassage & NZK-zijde & $26 / \mathrm{mrt}$ & 7 & 199 & 160 & 254 & 103 & 40 & 225 \\
\hline Brasem & vispassage & NZK-zijde & $26 / \mathrm{mrt}$ & 2 & 385 & 218 & 551 & 1112 & 93 & 2130 \\
\hline Snoekbaars & vispassage & NZK-zijde & $26 / \mathrm{mrt}$ & 3 & 497 & 390 & 562 & 1159 & 390 & 1728 \\
\hline Baars & NZK-zijde & NZK-zijde & $26 / \mathrm{mrt}$ & 1 & 214 & 214 & 214 & 145 & 145 & 145 \\
\hline Blankvoorn & NZK-zijde & NZK-zijde & $26 / \mathrm{mrt}$ & 1 & 166 & 166 & 166 & 52 & 52 & 52 \\
\hline Snoek & NZK-zijde & NZK-zijde & $26 / \mathrm{mrt}$ & 1 & 762 & 762 & 762 & & & \\
\hline Snoekbaars & NZK-zijde & NZK-zijde & $26 / \mathrm{mrt}$ & 5 & 543 & 450 & 633 & 1372 & 523 & 2195 \\
\hline Brasem & NZK-zijde & NZK-zijde & 8/apr & 1 & 453 & 453 & 453 & 1316 & 1316 & 1316 \\
\hline Houting & NZK-zijde & NZK-zijde & 8/apr & 2 & 388 & 382 & 394 & 530 & 518 & 542 \\
\hline Snoekbaars & NZK-zijde & NZK-zijde & 8/apr & 1 & 590 & 590 & 590 & 1696 & 1696 & 1696 \\
\hline Snoekbaars & NZK-zijde & NZK-zijde & 30/apr & 2 & 508 & 432 & 584 & 1065 & 519 & 1610 \\
\hline Baars & boezem & boezem & $16 / \mathrm{mei}$ & 3 & 181 & 175 & 190 & 70 & 52 & 86 \\
\hline Blankvoorn & boezem & boezem & $16 / \mathrm{mei}$ & 16 & 206 & 161 & 266 & 121 & 56 & 248 \\
\hline Brasem & boezem & boezem & $16 / \mathrm{mei}$ & 39 & 342 & 227 & 470 & 526 & 90 & 1324 \\
\hline Kolblei & boezem & boezem & $16 / \mathrm{mei}$ & 1 & 252 & 252 & 252 & 266 & 266 & 266 \\
\hline Snoekbaars & boezem & boezem & $16 / \mathrm{mei}$ & 2 & 384 & 253 & 515 & 540 & 106 & 974 \\
\hline Baars & boezem & NZK-zijde & $16 / \mathrm{mei}$ & 3 & 266 & 181 & 376 & 360 & 62 & 858 \\
\hline Blankvoorn & boezem & NZK-zijde & $16 / \mathrm{mei}$ & 13 & 201 & 160 & 287 & 110 & 38 & 312 \\
\hline Brasem & boezem & NZK-zijde & $16 / \mathrm{mei}$ & 7 & 323 & 249 & 411 & 437 & 175 & 928 \\
\hline Kolblei & boezem & NZK-zijde & $16 / \mathrm{mei}$ & 1 & 156 & 156 & 156 & 51 & 51 & 51 \\
\hline Baars & boezem & NZK-zijde & 29/mei & 4 & 303 & 211 & 380 & 473 & 102 & 814 \\
\hline Blankvoorn & boezem & NZK-zijde & 29/mei & 67 & 202 & 108 & 286 & 118 & 50 & 338 \\
\hline Brasem & boezem & NZK-zijde & 29/mei & 128 & 319 & 101 & 495 & 453 & 83 & 1402 \\
\hline Hybride & boezem & NZK-zijde & 29/mei & 1 & 204 & 204 & 204 & 118 & 118 & 118 \\
\hline Kolblei & boezem & NZK-zijde & 29/mei & 1 & 191 & 191 & 191 & 89 & 89 & 89 \\
\hline Ruisvoorn & boezem & NZK-zijde & 29/mei & 1 & 182 & 182 & 182 & 82 & 82 & 82 \\
\hline Snoek & boezem & NZK-zijde & $29 / \mathrm{mei}$ & 1 & 463 & 463 & 463 & 642 & 642 & 642 \\
\hline Snoekbaars & boezem & NZK-zijde & 29/mei & 1 & 700 & 700 & 700 & 2119 & 2119 & 2119 \\
\hline
\end{tabular}

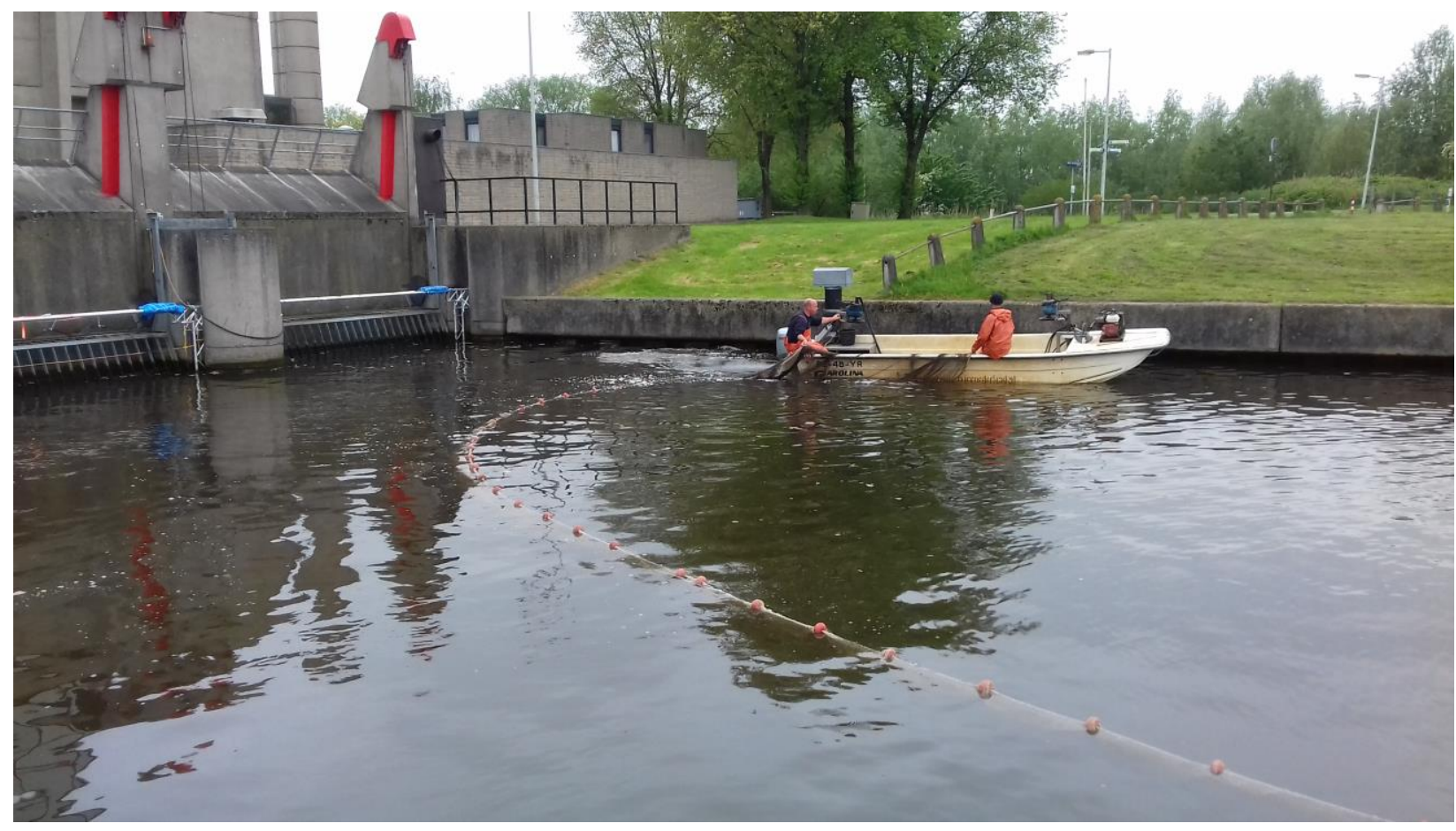

Foto 1. Het vissen met een zegen door Visserij Service Nederland voor het gemaal te Halfweg. 


\section{$2.4 \quad$ Kadoelen}

\section{PIT opstelling}

Gemaal Kadoelen heeft naast het gemaal een sluis-vispassage. Putten ( $2 \times 2 \mathrm{~m})$ aan weerszijden maken daarvan onderdeel uit. Op deze locatie zijn in totaal zes antennes geplaatst: vier in de uitstroom van het gemaal en twee in de putten van de vispassage. De antennes bij het gemaal bestaan uit twee frames van elk ca. 4,2×0,8m (2-loop $4 \mathrm{~mm}^{2}$ draad). Bij de vispassage is aan de NZK-zijde een antenne geplaatst en aan de boezemzijde ook een (beide ca. 0,6x0,8m, 3-loop 2,5 $\mathrm{mm}^{2}$ draad). Deze zijn in de sponning van de voorziening gehangen. De readers zijn draadloos gesynchroniseerd.

De vispassage NZK-zijde detecteerde vanaf: De vispassage polderzijde vanaf:

De frames van het gemaal frames vanaf: september 2017 (voor project uittrek schieraal) september 2017

26 februari 2019

Van 23 t/m 30 april en van 3 t/m 5 mei is er door storing geen detectie geweest bij het gemaal.

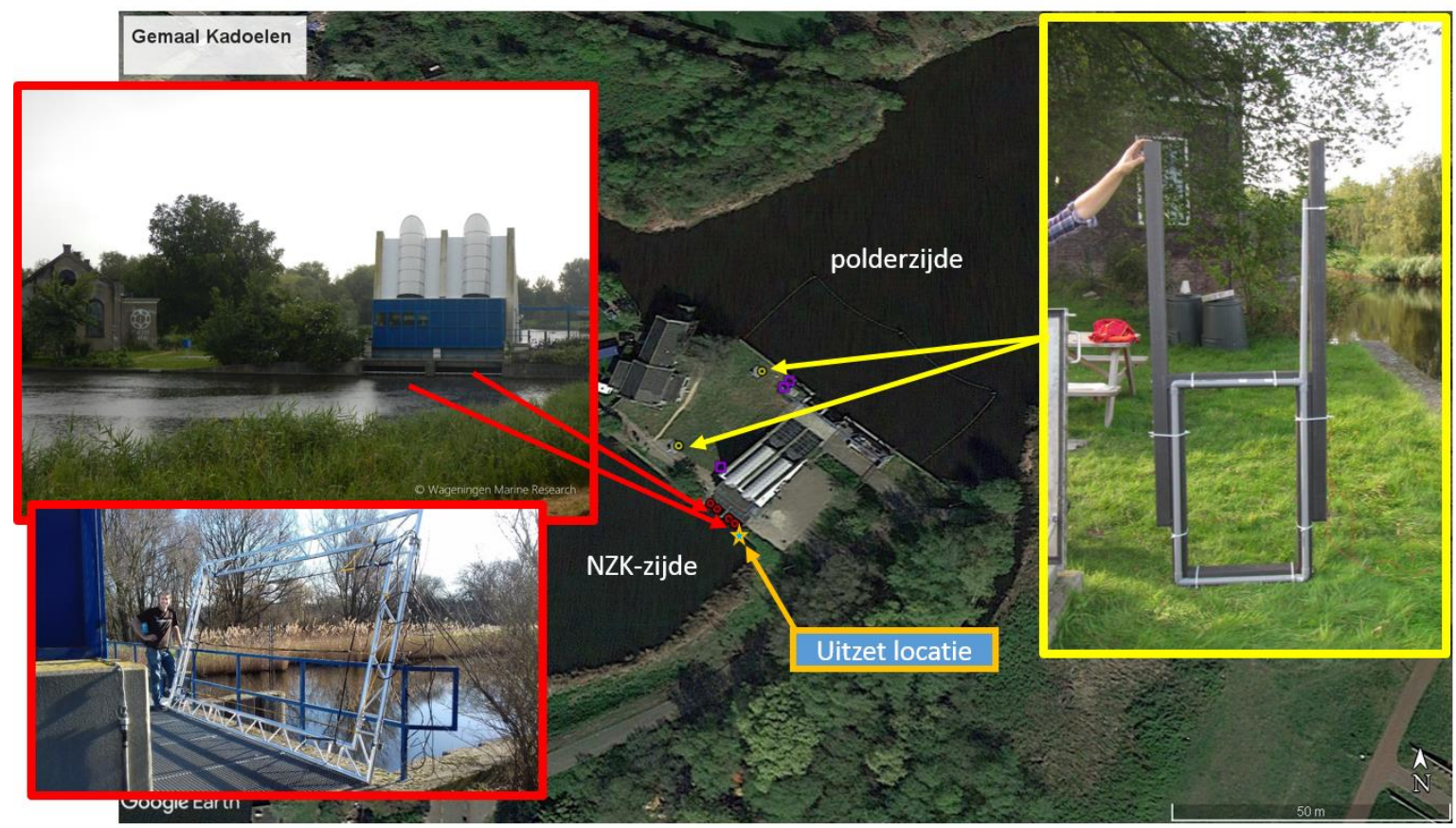

Figuur 2-4 Plaatsing van de antennes voor PIT telemetrie bij gemaal Kadoelen. In totaal vier antennes achter het gemaal, een antenne bij de passage NZK zijde en een antenne bij de vispassage aan de polderzijde.

\section{Testvissen}

Bij gemaal Kadoelen zijn in totaal 511 vissen gevangen in de uitmaalkom van het gemaal. De vissen zijn gemerkt en allemaal aan de NZK-zijde uitgezet (Tabel 4). De vangst was erg wisselend in aantal. In totaal zijn 454 brasems en 24 snoekbaarzen gemerkt en daarnaast ook baars (19 stuks), blankvoorn (5 stuks), snoek (4 stuks), kolblei (3 stuks) en karper ( 2 stuks). Alle vissen zijn met een $32 \mathrm{~mm}$ tag uitgerust en op normaal zwemgedrag gecontroleerd voordat ze zijn vrijgelaten. De vissen zijn bij de gemaal uitstroomzijde losgelaten. 
Tabel 4 Totaal aantal gemerkte vissen bij gemaal Kadoelen $(N=511)$.

\begin{tabular}{|c|c|c|c|c|c|c|c|c|c|c|}
\hline & & & & & mean & $\min$ & $\max$ & mean & $\min$ & $\max$ \\
\hline soort & vangst locatie & uitzetlocatie & datum & $\mathrm{n}$ & lengte $(\mathrm{mm})$ & lengte (mm) & lengte (mm) & gewicht (gr) & gewicht (gr) & gewicht (gr) \\
\hline Baars & NZK-zijde & NZK-zijde & $19 / \mathrm{mrt}$ & 3 & 363 & 293 & 431 & 795 & 342 & 1340 \\
\hline Blankvoorn & NZK-zijde & NZK-zijde & $19 / \mathrm{mrt}$ & 2 & 336 & 296 & 375 & 540 & 332 & 748 \\
\hline Brasem & NZK-zijde & NZK-zijde & $19 / \mathrm{mrt}$ & 140 & 480 & 277 & 610 & 1416 & 614 & 3312 \\
\hline Snoek & NZK-zijde & NZK-zijde & $19 / \mathrm{mrt}$ & 2 & 1018 & 891 & 1145 & & & \\
\hline Snoekbaars & NZK-zijde & NZK-zijde & $19 / \mathrm{mrt}$ & 1 & 562 & 562 & 562 & 1426 & 1426 & 1426 \\
\hline Baars & NZK-zijde & NZK-zijde & 3/apr & 2 & 371 & 321 & 420 & 1023 & 602 & 1444 \\
\hline Blankvoorn & NZK-zijde & NZK-zijde & 3/apr & 2 & 281 & 247 & 314 & 334 & 198 & 470 \\
\hline Brasem & NZK-zijde & NZK-zijde & 3/apr & 235 & 461 & 330 & 593 & 1271 & 171 & 3634 \\
\hline Karper & NZK-zijde & NZK-zijde & 3/apr & 2 & 643 & 541 & 745 & 2660 & 2660 & 2660 \\
\hline Kolblei & NZK-zijde & NZK-zijde & 3/apr & 2 & 281 & 260 & 302 & 324 & 264 & 383 \\
\hline Snoekbaars & NZK-zijde & NZK-zijde & 3/apr & 11 & 530 & 435 & 632 & 1260 & 517 & 2290 \\
\hline Baars & NZK-zijde & NZK-zijde & 15/apr & 14 & 316 & 237 & 442 & 614 & 155 & 1900 \\
\hline Blankvoorn & NZK-zijde & NZK-zijde & 15/apr & 1 & 284 & 284 & 284 & 322 & 322 & 322 \\
\hline Brasem & NZK-zijde & NZK-zijde & 15/apr & 5 & 502 & 442 & 600 & 1782 & 1306 & 3031 \\
\hline Snoek & NZK-zijde & NZK-zijde & 15/apr & 2 & 643 & 495 & 790 & 2433 & 785 & 4081 \\
\hline Snoekbaars & NZK-zijde & NZK-zijde & 15/apr & 10 & 553 & 460 & 662 & 1398 & 750 & 2588 \\
\hline Brasem & NZK-zijde & NZK-zijde & 9/mei & 74 & 439 & 354 & 573 & 1103 & 585 & 2708 \\
\hline Kolblei & NZK-zijde & NZK-zijde & 9/mei & 1 & 294 & 294 & 294 & 442 & 442 & 442 \\
\hline Snoekbaars & NZK-zijde & NZK-zijde & 9/mei & 2 & 537 & 535 & 539 & 1185 & 1175 & 1195 \\
\hline
\end{tabular}

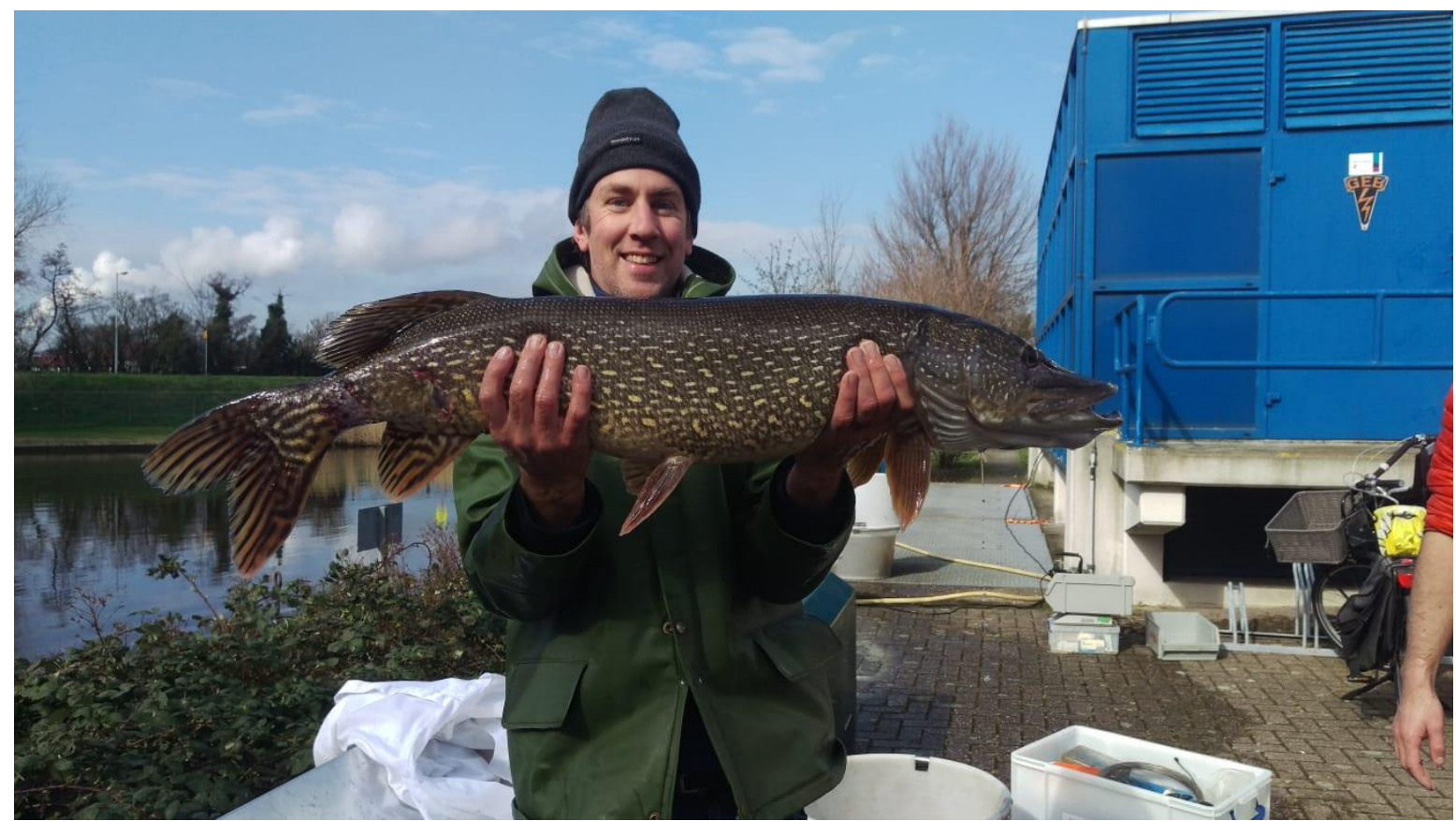

Foto 3. Snoek van $114 \mathrm{~cm}$ gevangen in de maalkom van gemaal Kadoelen. 


\section{$2.5 \quad$ Willem I-sluis}

\section{PIT opstelling}

De Willem I-sluis is voorzien van een vismigratievoorziening via rinketten beheer (Winter et al. 2019). Op deze locatie zijn in totaal zes antennes geplaatst: twee rondom de rinketten van de sluisdeuren aan de NZK-zijde, twee in de kolk en twee rondom de rinketten van de sluisdeuren aan de boezemzijde. De antennes bij de deuren zijn middels RVS-buizen, dyneemadraad en spanbanden rondom de rinketten geplaatst. De antennes zijn ca. 1,5x1,0m (3-loop 2,5 $\mathrm{mm}^{2}$ draad). Het frame in het midden van de kolk heeft twee antenne's van ca. 5,0x0,6m (2-loop $4 \mathrm{~mm}^{2}$ draad). De readers zijn wireless gesynchroniseerd en worden gestoord indien de deuren van de grote kolk worden bediend.

De antennes bij de sluisdeuren detecteren vanaf: september 2017 voor project uittrek schieraal. Aan de boezemzijde zijn de antennes op 5 maart opnieuw aangebracht door duikers.

Frames in de kolk detecteren vanaf: 14 maart (geen volledig bereik) vanaf 25 maart goed bereik.

Van 27 mei tot 11 juni waren de antennes uitgeschakeld door het wegvallen van de stroom.

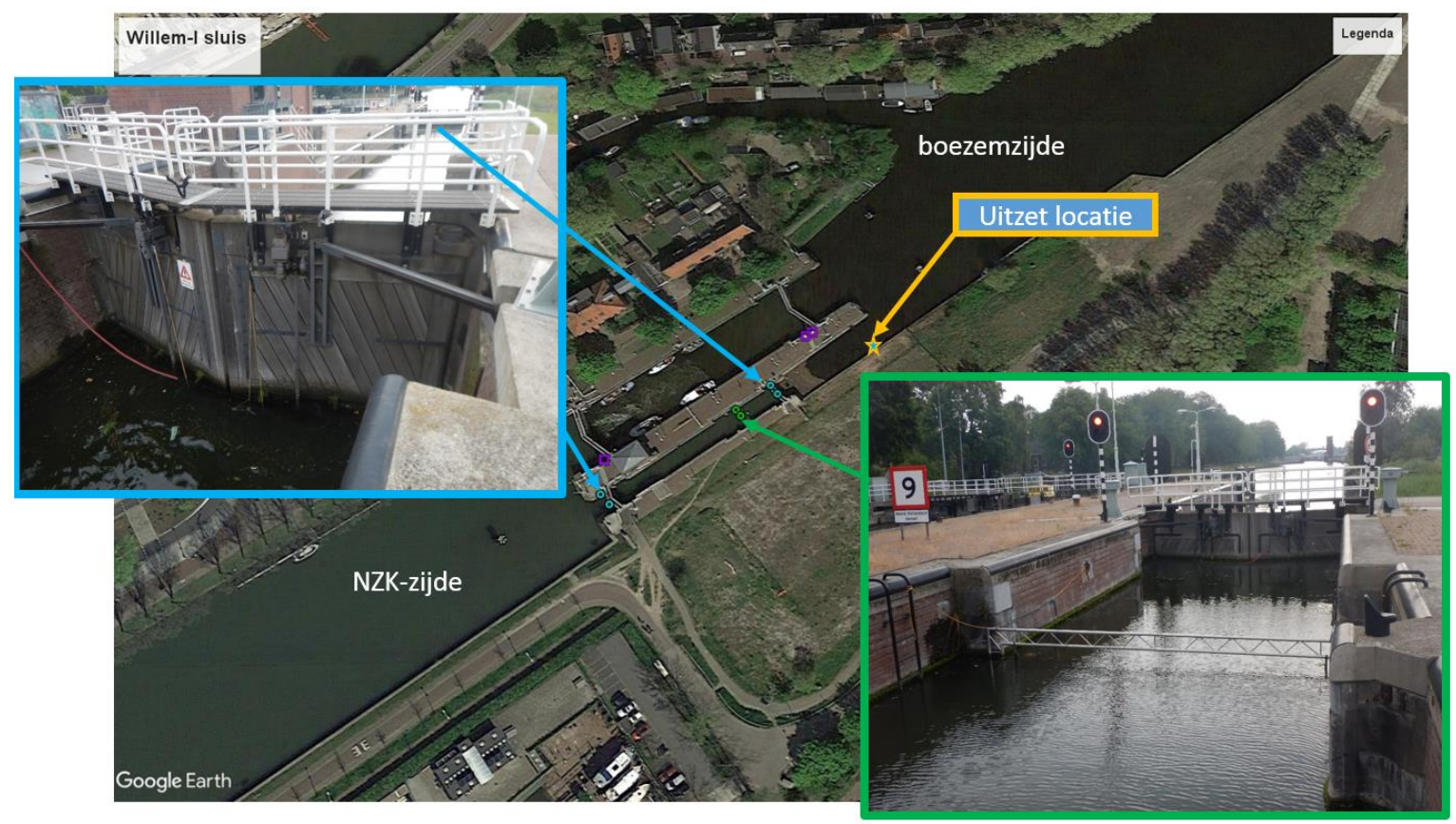

Figuur 2-5 Plaatsing van de antennes voor PIT telemetrie bij de Willem I-sluis. In totaal vier antennes op de sluisdeuren en twee antennes in de kolk.

\section{Testvissen}

Bij de Willem I-sluis zijn in totaal 45 vissen gevangen aan de boezemzijde van de sluis (Tabel 5). In totaal zijn 38 brasems, 5 blankvoorns 1 ruisvoorn en 1 winde gemerkt en losgelaten aan de boezemzijde. Alle vissen zijn met een $32 \mathrm{~mm}$ tag uitgerust en op normaal zwemgedrag gecontroleerd voordat ze zijn vrijgelaten. Al deze vissen waren vrij klein en de visactie aan de boezemzijde ging vooraf aan twee onsuccesvolle visdagen aan de NZK-zijde. Deze vissen zijn ook weer aan de boezemzijde uitgezet (Figuur 2-5). De NZK-zijde is op deze locatie moeilijk te bevissen met de zegen door de diepte van de vaargeul. Om deze reden is een extra keer gevist bij Kadoelen ${ }^{10}$, die op dezelfde boezem is aangesloten. Bij het schieraalonderzoek 2017-2018 is ook veel uitwisseling waargenomen tussen Kadoelen en Willem I-sluis.

\footnotetext{
${ }^{10}$ De bij Kadoelen gevangen vissen zijn gemerkt en allemaal bij Kadoelen aan de NZK-zijde uitgezet. Er is dus een extra 'Kadoelen groep' gemerkt en uitgezet.
} 
Tabel 5 Totaal aantal gevangen en gemerkte vissen bij de Willem I-sluis $(N=45)$.

\begin{tabular}{|l|l|l|l|r|l|l|l|l|l|l|}
\hline & & & & & mean & min & max & mean & min & max \\
\hline soort & vangstlocatie & uitzetlocatie & datum & $\mathbf{n}$ & lengte (mm) & lengte (mm) & lengte (mm) & gewicht (gr) & gewicht (gr) & gewicht (gr) \\
\hline Blankvoorn & boezem & boezem & $24 /$ apr & 5 & 195 & 188 & 203 & 78 & 64 & 87 \\
\hline Brasem & boezem & boezem & $24 /$ apr & 38 & 220 & 165 & 330 & 118 & 38 & 390 \\
\hline Ruisvoorn & boezem & boezem & $24 /$ apr & 1 & 179 & 179 & 179 & 73 & 73 & 73 \\
\hline Winde & boezem & boezem & $24 /$ apr & 1 & 144 & 144 & 144 & 27 & 27 & 27 \\
\hline
\end{tabular}

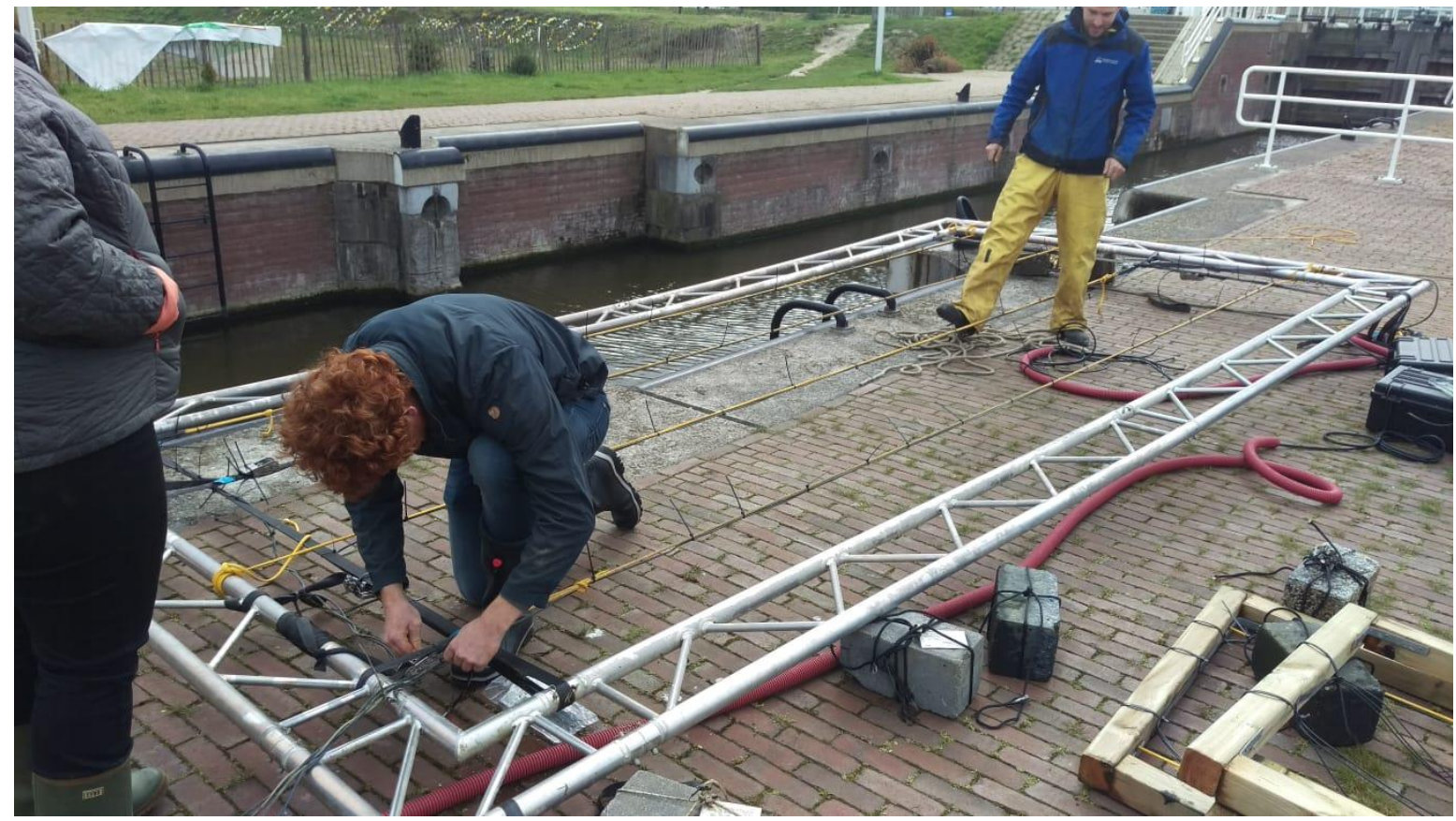

Foto 4. Het aanpassen van de detectielussen op het frame na meerdere testen met verschillende opstellingen. Het frame bestaat hier uit twee antennes van ca. 5x0,6 meter. De ruimte tussen de antennes is zodanig dat er een vrijwel volledig bereik is.

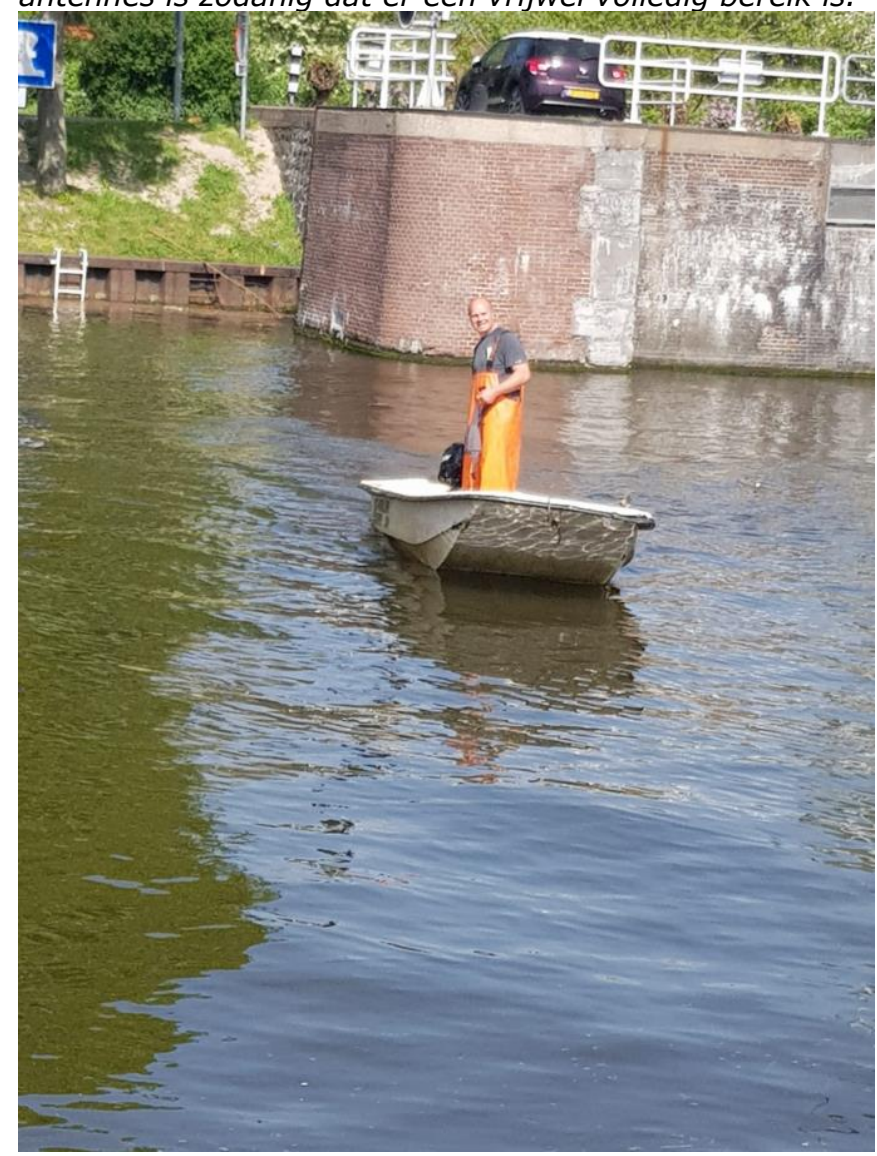

Foto 5. Een ongelukkige voorbijganger liet een tasje in het water vallen welke vakkundig werd teruggevangen voor Bram van Wijk van Visserij Service Nederland. Een sterke aanwijzing dat er goed gevist werd, maar er blijkbaar echt geen vis aanwezig was bij de Willem I-sluis (foto: Rens Hensgens). 


\subsection{Oranjesluizen}

De Oranjesluizen zijn gelegen tussen het Noordzeekanaal en het IJmeer. Het sluiscomplex bevat vier schutsluizen, en twee vispassages die gebouwd zijn in een oud gemaalcomplex (Figuur 2-6). De zuidelijke vispassage is in maart 2019 voorzien van PIT antennes. De vispassage heeft aan de noordwestzijde en de zuidoostzijde een zogenaamde 'vertical slot': een betonconstructie om de stroming door de vispassage te verminderen (Figuur 2-7). Beide vertical slots hebben twee verticale openingen van $50 \mathrm{~cm}$ breed en $200 \mathrm{~cm}$ hoog. Aan de binnen- en buitenzijde van iedere opening is een hardhouten frame geplaatst en gezekerd met spanbanden (afmetingen per frame $\sim 80 \times 230 \mathrm{~cm}, 3-100 p s 4 \mathrm{~mm}^{2}$ draad). In totaal zijn daarmee acht antenneframes geplaatst waarmee naast moment van passeren ook de zwemrichting door de opening in de vertical slots en door de hele vispassage waargenomen kan worden (Figuur 2-7). De antennes worden aangestuurd met twee readers die zijn opgesteld op de vertical slots in weerbestendige houten boxen. De readers zijn draadloos gesynchroniseerd.

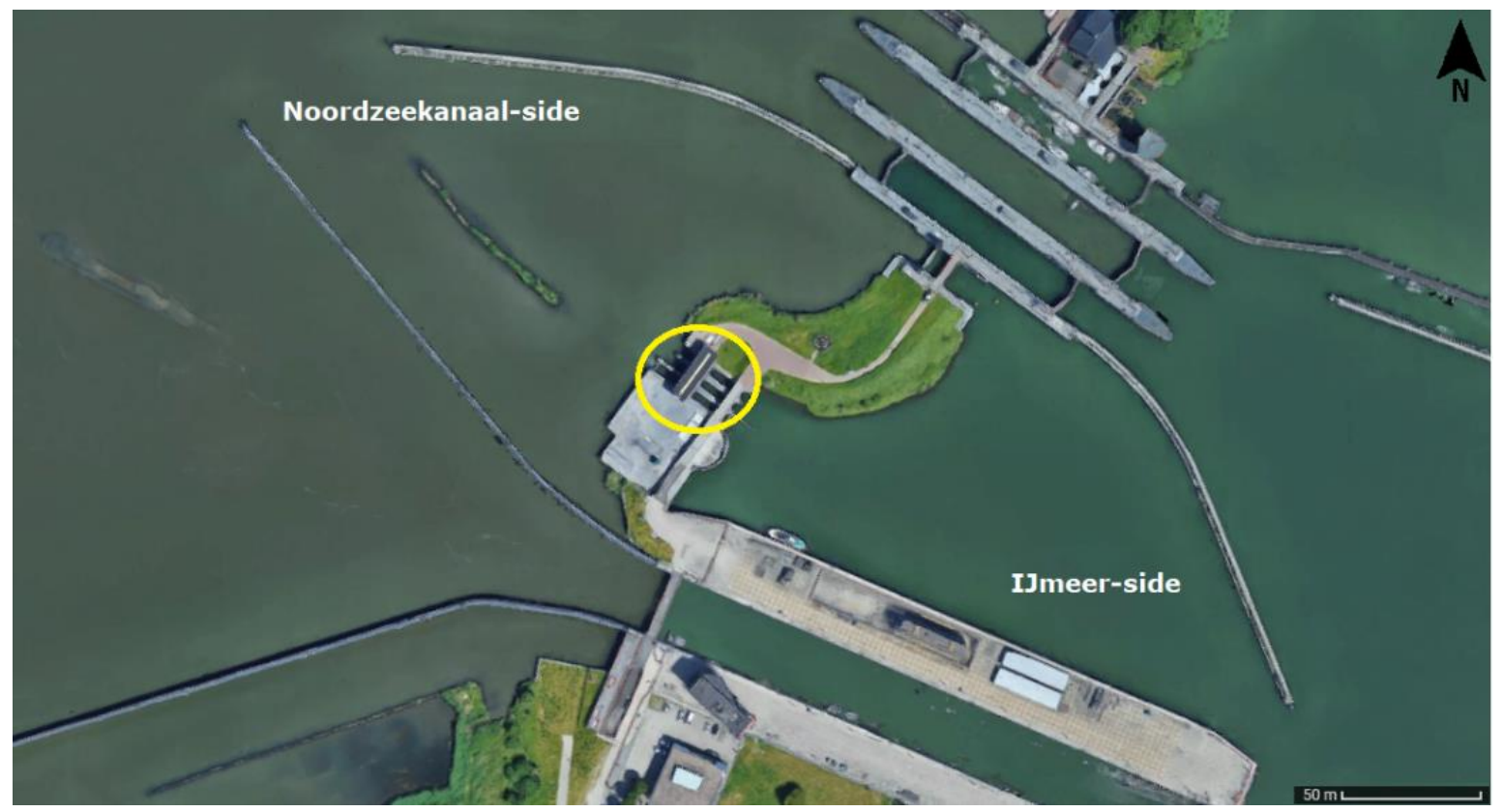

Figuur 2-6 De locatie van de vispassage bij de Oranjesluizen (gele cirkel). De afbeelding laat drie maalgangen zien van het voormalige gemaalcomplex. De zuidelijk maalgang is omgebouwd tot vispassage, de noordelijke wordt gebruikt voor de inlaat van water uit het IJmeer en de middelste is medio 2019 omgebouwd tot een sluis-vispassage. (satelietfoto afkomstig van Google Maps).
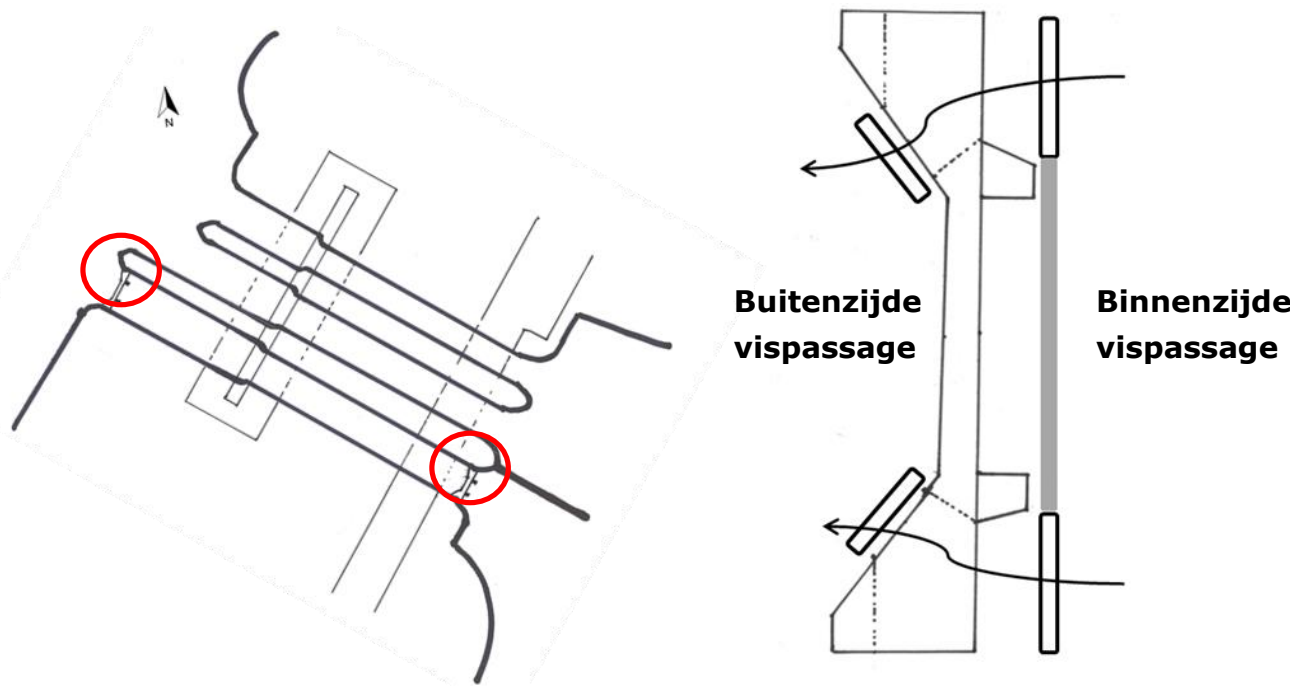

Figuur 2-7 links: Bovenaanzicht van de vispassage met twee vertical slots (rode cirkels). In het midden van iedere maalgang is een schuif aanwezig. De schuif van de vispassage staat open als het peil in het IJmeer hoger is dan het peil in het Noordzeekanaal. Rechts: Schematisch bovenaanzicht van de openingen en antennes van een van de twee vertical slots. De peilen geven de stroomrichting door de openingen in de vertical slots weer. De weerbestendige box (niet zichtbaar) is bovenop de vertical slot geplaatst. 


\section{Testvissen}

Op vier dagen is met een zegen gevist, tweemaal aan de noordwestkant en tweemaal aan de zuidoost kant van het sluiscomplex (Tabel 6). De gevangen vissen zijn voorzien van een $32 \mathrm{~mm}$ PIT tag en aan de vangzijde op ongeveer tien meter van de vispassage weer vrijgelaten. In totaal zijn 796 vissen voorzien van een tag. Aan de zuidoostzijde van de vispassage zijn 419 vissen voorzien van een tag, aan de noordwestzijde 377. Er zijn 12 soorten gevangen: 458 blankvoorns, 277 brasems, gevolgd door baars (23), snoekbaars (8), winde (8), dunlipharder (5), roofblei (5), snoek (4), houting (4), cyprinide hybride (2), kolblei (1) en bot (1).

Tabel 6 Totaal aantal gemerkte vissen bij de Oranjes/uizen $(N=796)$.

\begin{tabular}{|c|c|c|c|c|c|c|c|c|c|c|}
\hline & & & & & mean & $\min$ & $\max$ & mean & $\min$ & $\max$ \\
\hline soort & vangst locatie & uitzetlocatie & datum & $n$ & lengte $(\mathrm{mm})$ & lengte (mm) & lengte (mm) & gewicht (gr) & gewicht (gr) & gewicht (gr) \\
\hline Baars & westzijde & westzijde & 25/apr & 3 & 273 & 234 & 348 & 282 & 174 & 488 \\
\hline Blankvoorn & westzijde & westzijde & 25/apr & 91 & 221 & 170 & 296 & 135 & 52 & 268 \\
\hline Brasem & westzijde & westzijde & 25/apr & 114 & 334 & 209 & 616 & 546 & 90 & 2889 \\
\hline Dunlipharde & westzijde & westzijde & 25/apr & 4 & 674 & 656 & 686 & 2831 & 2550 & 3048 \\
\hline Hybride & westzijde & westzijde & 25/apr & 1 & 354 & 354 & 354 & 473 & 473 & 473 \\
\hline Kolblei & westzijde & westzijde & 25/apr & 1 & 195 & 195 & 195 & 101 & 101 & 101 \\
\hline Roofblei & westzijde & westzijde & 25/apr & 3 & 592 & 533 & 669 & 2828 & 1309 & 4760 \\
\hline Snoek & westzijde & westzijde & 25/apr & 3 & 582 & 466 & 789 & 1706 & 698 & 3605 \\
\hline Snoekbaars & westzijde & westzijde & 25/apr & 8 & 390 & 314 & 440 & 426 & 220 & 548 \\
\hline Winde & westzijde & westzijde & 25/apr & 7 & 485 & 408 & 550 & 1500 & 998 & 2175 \\
\hline Baars & oostzijde & oostzijde & 10/mei & 10 & 213 & 160 & 288 & 126 & 44 & 266 \\
\hline Blankvoorn & oostzijde & oostzijde & $10 / \mathrm{mei}$ & 245 & 203 & 153 & 1991 & 88 & 38 & 824 \\
\hline Brasem & oostzijde & oostzijde & $10 / \mathrm{mei}$ & 31 & 346 & 194 & 524 & 597 & 71 & 2096 \\
\hline Hybride & oostzijde & oostzijde & 10/mei & 1 & 244 & 244 & 244 & 160 & 160 & 160 \\
\hline Baars & westzijde & westzijde & 20/mei & 5 & 266 & 241 & 286 & 255 & 176 & 332 \\
\hline Blankvoorn & westzijde & westzijde & 20/mei & 49 & 226 & 159 & 282 & 150 & 45 & 307 \\
\hline Bot & westzijde & westzijde & 20/mei & 1 & 265 & 265 & 265 & 190 & 190 & 190 \\
\hline Brasem & westzijde & westzijde & 20/mei & 79 & 360 & 189 & 625 & 738 & 57 & 2921 \\
\hline Dunlipharde & westzijde & westzijde & 20/mei & 1 & 655 & 655 & 655 & 2660 & 2660 & 2660 \\
\hline Houting & westzijde & westzijde & 20/mei & 4 & 445 & 385 & 482 & 890 & 616 & 1134 \\
\hline Roofblei & westzijde & westzijde & 20/mei & 1 & 505 & 505 & 505 & 1115 & 1115 & 1115 \\
\hline Snoek & westzijde & westzijde & 20/mei & 1 & 447 & 447 & 447 & 650 & 650 & 650 \\
\hline Winde & westzijde & westzijde & 20/mei & 1 & 480 & 480 & 480 & 1816 & 1816 & 1816 \\
\hline Baars & oostzijde & oostzijde & 24/mei & 5 & 212 & 171 & 274 & 132 & 59 & 270 \\
\hline Blankvoorn & oostzijde & oostzijde & 24/mei & 73 & 220 & 162 & 340 & 129 & 41 & 491 \\
\hline Brasem & oostzijde & oostzijde & 24/mei & 53 & 406 & 200 & 595 & 866 & 412 & 2242 \\
\hline Roofblei & oostzijde & oostzijde & 24/mei & 1 & 353 & 353 & 353 & 387 & 387 & 387 \\
\hline
\end{tabular}




\section{Resultaten}

In deze datarapportage worden tussentijdse resultaten wleergegeven tot en met 19 augustus 2019 en van de Oranjesluizen tot en met 26 augustus 2019. In totaal zijn 717 van de 1.844 gemerkte vissen (39\%) gedetecteerd op een van de antennes met in totaal ruim 1.300.000 detecties. Deze rapportage betreft een data-overzicht en een eerste weergave van migratiepatronen, er zijn geen (uitgebreide) analyses gedaan. De vissen die bij de gemaal uitstroomzijde zijn gedetecteerd (incl. de dag van uitzet ${ }^{11}$ ) zijn gepresenteerd in de bijlage. In de figuren wordt de volgende aanduiding gebruikt:

Osluis O bin/buit

Osluis O buiten

\section{Osluis O binnen}

Osluis $W$ binnen

Osluis $W$ buiten sluis Willem I boezem $(A / B)$

sluis Willem I kolk $(A / B)$ sluis Willem I NZK $(A / B)$ Kadoelen visp. Boezem Kadoelen visp. NZK Kadoelen gemaal park.

Kadoelen gemaal conc.

Halfweg vispassage vijzel Halfweg vispassage boezem Halfweg vispassage NZK Halfweg gemaal west Halfweg gemaal midden Halfweg gemaal oost Nauerna gemaal visp. Nauerna gemaal gem.
Detecties aan de oostzijde van de vispassage. Niet onderscheiden of dit aan de binnenzijde of de buitenzijde is geweest ( 1 antenne gebaseerd op 4 losse antennes).

Oostzijde van de vispassage. Lussen aan IJmeer-zijde en aan de buitenzijde van de vispassage ( 2 antennes).

Oostzijde van de vispassage. Lussen aan IJmeer-zijde en aan de binnenzijde van de vispassage (2 antennes).

Westzijde van de vispassage. Lussen aan de NZK-zijde, aan de binnenkant van de vispassage ( 2 antennes).

Westzijde van de vispassage. Lussen aan de NZK-zijde (2 antennes). Lussen rondom de rinketten. Detecties rondom de rinketten gaan ook door de deur heen, maar beperkt ( 2 antennes).

Lussen in de kolk van de sluis ( 2 antennes)

Lussen aan de NZK-zijde ( 2 antennes)

Lus vispassage aan de boezemzijde ( 1 antenne)

Lus vispassage aan de NZK-zijde (1 antenne)

Kadoelen gemaal met de koker aan de parkeergelegenheid (oostzijde, 2 antennes)

Kadoelen gemaal met de koker aan Concertgemaal zijde (westzijde, 2 antennes)

Lus bij vijzel t.b.v. de vispassage (2 antennes)

Lus bij de 'uitgang' van de vispassage aan de boezemzijde (1 antenne)

Lus bij de 'ingang' van de vispassage aan de NZK-zijde ( 1 antenne)

Westelijke maalkoker van het gemaal (4 antennes)

Maalkoker in het midden van het gemaal (4 antennes)

Oostelijke maalkoker van het gemaal (3 antennes)

Maalkoker die verbonden is met de vispassage (westzijde, 1 antenne) Maalkoker die niet verbonden is met de vispassage (oostzijde, 1 antenne) 


\subsection{Nauerna}

Bij de uitstroomzijde van het gemaal zijn in totaal 91 vissen gedetecteerd: 81 afkomstig van Nauerna, vijf vanuit Halfweg, vier vanuit Kadoelen en één vanuit Oranjesluizen (Bijlage 1). De vispassage Nauerna is in bedrijfgesteld op 17 april en was vanaf 24 april stabiel functionerend. Bij de eerste detecties aan de NZK-zijde van de vispassage was deze dus nog niet actief (Tabel 7). Bij Nauerna zijn bij de vispassage 18 individuele vissen bij de ingang van de passage gedetecteerd (Tabel 7). Daarvan zijn drie vissen ook aan de polder zijde van de passage gedetecteerd: twee brasems (51 en $47 \mathrm{~cm}$ ) en een kolblei $(24 \mathrm{~cm})$. Eén brasem was afkomstig van Halfweg (gemerkt op 29 mei) en twee brasems vanaf Kadoelen (gemerkt op 19 maart). Vissen die zijn gemerkt bij Nauerna worden gezien bij gemaal Halfweg, Kadoelen en de Oranjesluizen (Figuur 3-1). Het is opvallend hoe lang en veelvuldig de vissen worden gedetecteerd die de vispassage Nauerna zijn gepasseerd (Figuur 3-2 en Figuur 3-3). Op 25 mei is een snoekbaars teruggemeld door een sportvisser, die gevangen is bij de jachthaven te Nauerna (Floy Tag: 09706).

Tabel 7 Detecties van vissen bij de vispassage van gemaal Nauerna $(N=18)$. NB. Bij de eerste detecties aan de NZK-zijde van de vispassage op 19 maart was deze nog niet actief.

\begin{tabular}{|c|c|c|c|c|c|c|c|c|c|c|c|}
\hline Datum & Merklocatie & $\operatorname{tag} I D$ & Floytag & Soort & \begin{tabular}{|l|} 
Lengte \\
$(\mathrm{mm})$
\end{tabular} & \begin{tabular}{|l} 
Gewicht \\
(gr)
\end{tabular} & Geslacht & Opm. vis & Vangstlocatie & $\begin{array}{l}\text { Antenne } \\
\text { NZK- } \\
\text { zijde }\end{array}$ & $\begin{array}{l}\text { Antenne } \\
\text { boezem- } \\
\text { zijde }\end{array}$ \\
\hline 19/mrt & Kadoelen & $900 \_230000150074$ & & Brasem & 464 & 1240 & & & maalkom & $x$ & \\
\hline $2 / \mathrm{mei}$ & Nauerna & $900 \_230000150782$ & & Brasem & 351 & 512 & & & Kanaal & $x$ & \\
\hline $2 / \mathrm{mei}$ & Nauerna & $900 \_230000150791$ & & Brasem & 213 & 88 & & & Kanaal & $x$ & \\
\hline $2 / \mathrm{mei}$ & Nauerna & 900_230000150792 & & Brasem & 509 & 1554 & & Wond & Kanaal & $x$ & $x$ \\
\hline $2 / \mathrm{mei}$ & Nauerna & $900 \_230000150822$ & & Brasem & 431 & 1082 & & & Kanaal & $x$ & \\
\hline $2 / \mathrm{mei}$ & Nauerna & 900_230000150839 & & Brasem & 430 & 880 & Man & Paaiuitslag + Wond & Kanaal & $x$ & \\
\hline $2 / \mathrm{mei}$ & Nauerna & $900 \_230000150843$ & & Brasem & 489 & 1510 & & & Kanaal & $x$ & \\
\hline $2 / \mathrm{mei}$ & Nauerna & $900 \_230000150850$ & & Brasem & 480 & 1254 & & & Kanaal & $x$ & \\
\hline $2 / \mathrm{mei}$ & Nauerna & $900 \_230000150851$ & & Brasem & 405 & 807 & Man & Paaiuitslag & Kanaal & $x$ & \\
\hline 14/mei & Nauerna & 900_230000151239 & FT: 09727 & Snoekbaars & 561 & 1649 & & & kanaal & $x$ & \\
\hline $28 / \mathrm{mei}$ & Nauerna & $900 \_230000151686$ & & Kolblei & 237 & 170 & & & kanaal & $x$ & $x$ \\
\hline 29/mei & Halfweg & $900 \_230000151778$ & & Brasem & 309 & 302 & & & Boezemzijde & $x$ & \\
\hline
\end{tabular}




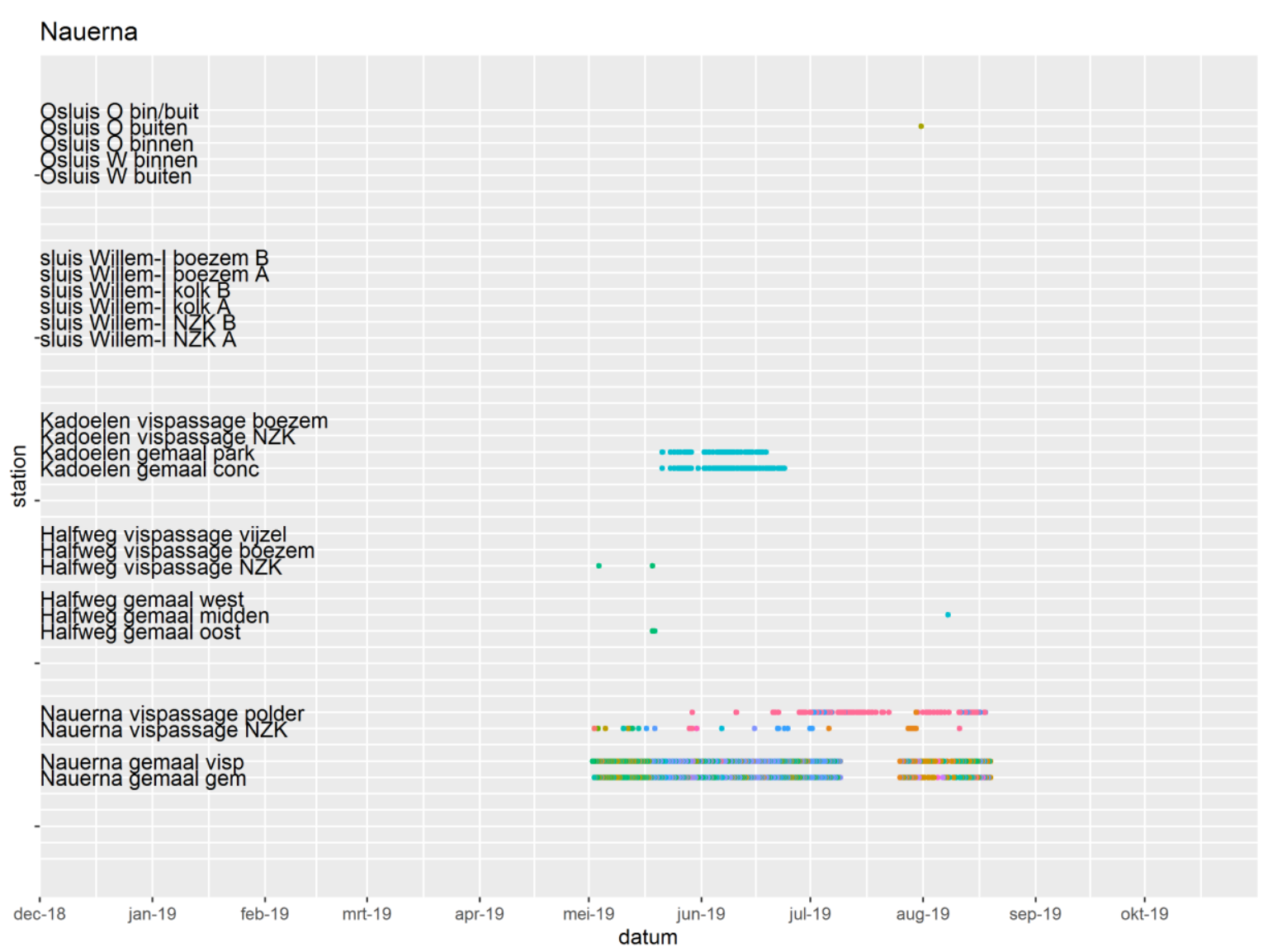

Figuur 3-1 Alle detecties op alle stations van de vissen die oorspronkelijk zijn gevangen, gemerkt en uitgezet bij gemaal Nauerna. NB. in de figuur wordt onderscheid gemaakt in individuen met kleurcodering. Van 9-25 juli was de stroom van de logger van het gemaal uitgeschakeld (zie 'gat' van detecties bij gemaal). 
900_230000151255 Brasem 469 mm 1166 gr Nauerna 14-mei

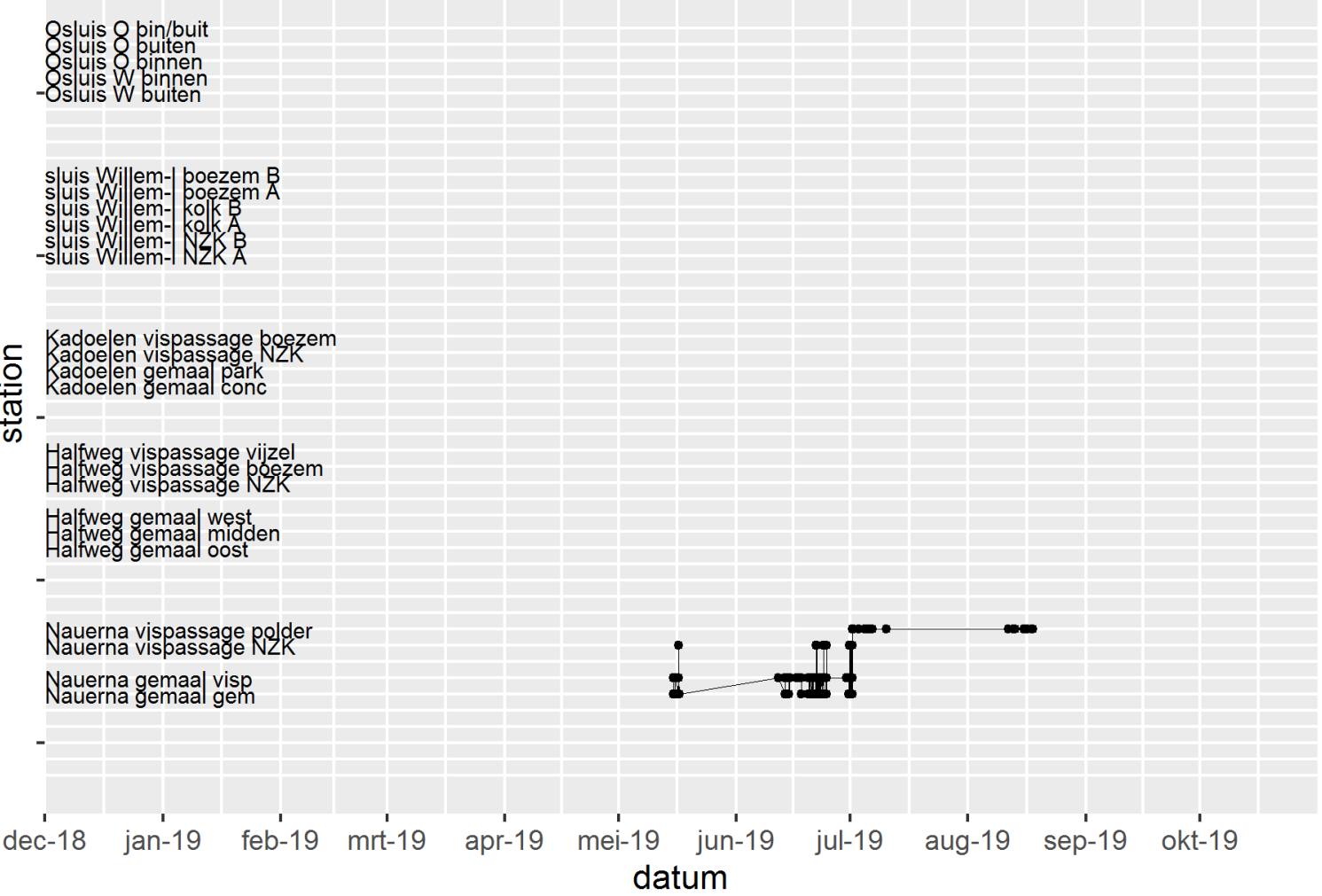

Figuur 3-2 Voorbeeld van een brasem die na herhaalde poging of zoekgedrag de vispassage bij Nauerna is gepasseerd. Na enige tijd duikt de brasem voor meerdere dagen weer op aan de polderzijde van de vispassage.

\section{0_230000151686 Kolblei 237 mm 170 gr Nauerna 28-mei}

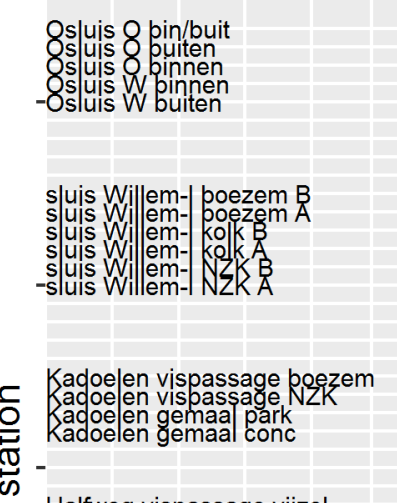

Halfweg vispassage viizel
Halfweg vispassage boem vispassage NZK

Halfweg gemaal west
Halfweg gemaa
midden
Helweg gemaal oost

Nauerna vispassage polder

Nauerna gemaa| visp

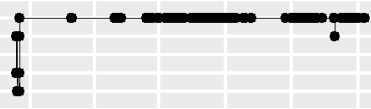

dec-18 jan-19 feb-19 mrt-19 apr-19 mei-19 jun-19 jul-19 aug'-19 sep-19 okt-19 datum

Figuur 3-3 Voorbeeld van een kolbei die vlak na uitzet de vispassage is gepasseerd en vervolgens langdurig in de vispassage blijft rondom de antenne aan de polderzijde. 


\subsection{Halfweg}

Bij het gemaal Halfweg zijn totaal 177 vissen bij het gemaal gedetecteerd waarvan vijf afkomstig van Kadoelen en drie vanuit Nauerna (Bijlage 1). In totaal zijn 79 vissen gedetecteerd bij een antenne van de vispassage (Tabel 8). Het betrof 33 brasems, 35 blankvoorns, zes baarzen, drie snoekbaars, een kolblei en een ruisvoorn. Op twee snoekbaarzen na zijn, van de vissen afkomstig van Halfweg, alle vissen aan de boezemzijde gevangen met de zegen (72 vissen) of afkomstig uit het net van de vispassage monitoring aan de boezemzijde ( 2 baarzen). Drie brasems waren afkomstig van Nauerna $(n=2)$ of Kadoelen $(n=1)$. De vissen hebben ook detecties bij gemaal Nauerna (Figuur 3-4). Er is een voorbeeld waarbij een baars de vispassage volledig lijkt te passeren, maar weer terugzwemt richting het Noordzeekanaal (Figuur 3-5). Veel van de passanten passeren de vispassage vrij snel (dag/dagen) na uitzet (zie bijlage 2), of doen een herhaalde poging na een periode van afwezigheid (Figuur 3-6). Vissen vanuit Kadoelen maken ook bezoeken aan gemaal Halfweg (Figuur 3-7).

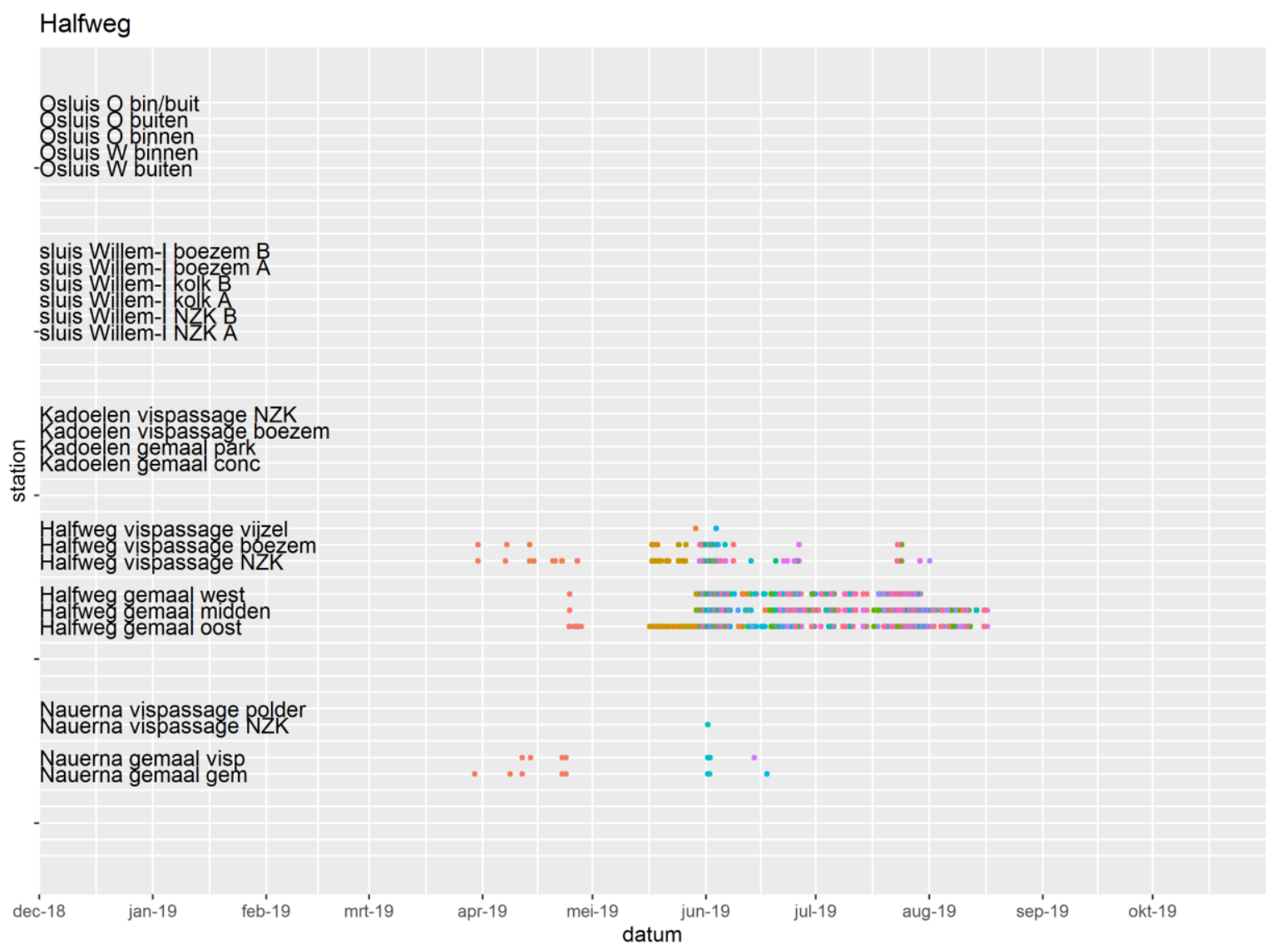

Figuur 3-4 Alle detecties op alle stations van de vissen die oorspronkelijk zijn gevangen, gemerkt en uitgezet bij gemaal Halfweg (NZK-zijde en boezemzijde), NB. in de figuur wordt onderscheid gemaakt in individuen met kleurcodering. De antennes van gemaal-midden en gemaal west zijn vanaf 29 mei ingeschakeld (zie methode). 
900_230000151345 Baars 181 mm 62 gr Halfweg 16-mei

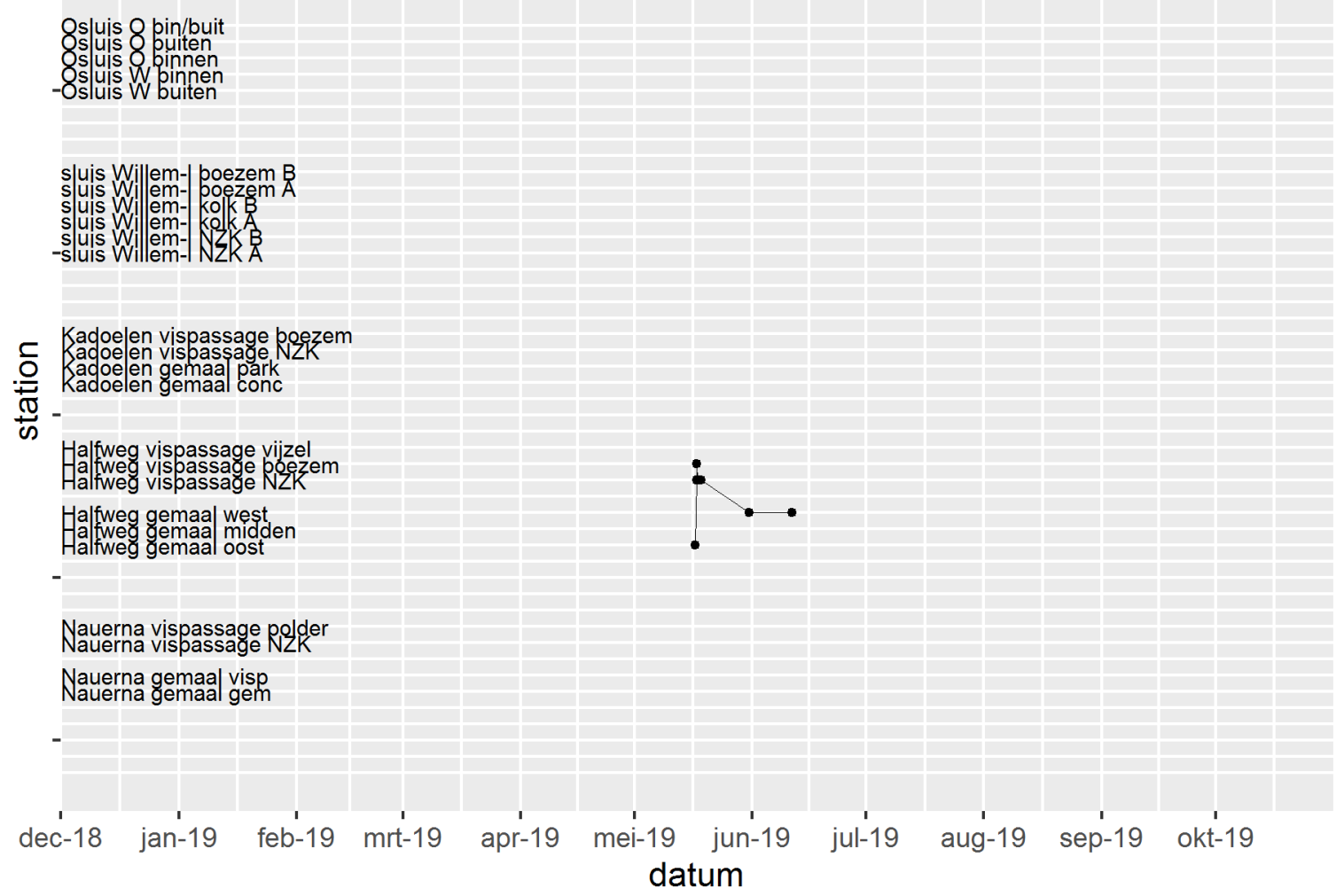

Figuur 3-5 Voorbeeld van een baars die de vispassage is ingezwommen tot aan de boezemzijde, maar uiteindelijk weer via de vispassage is terug gezwommen.

\section{0_230000151723 Brasem 247 mm 150 gr Halfweg 29-mei}

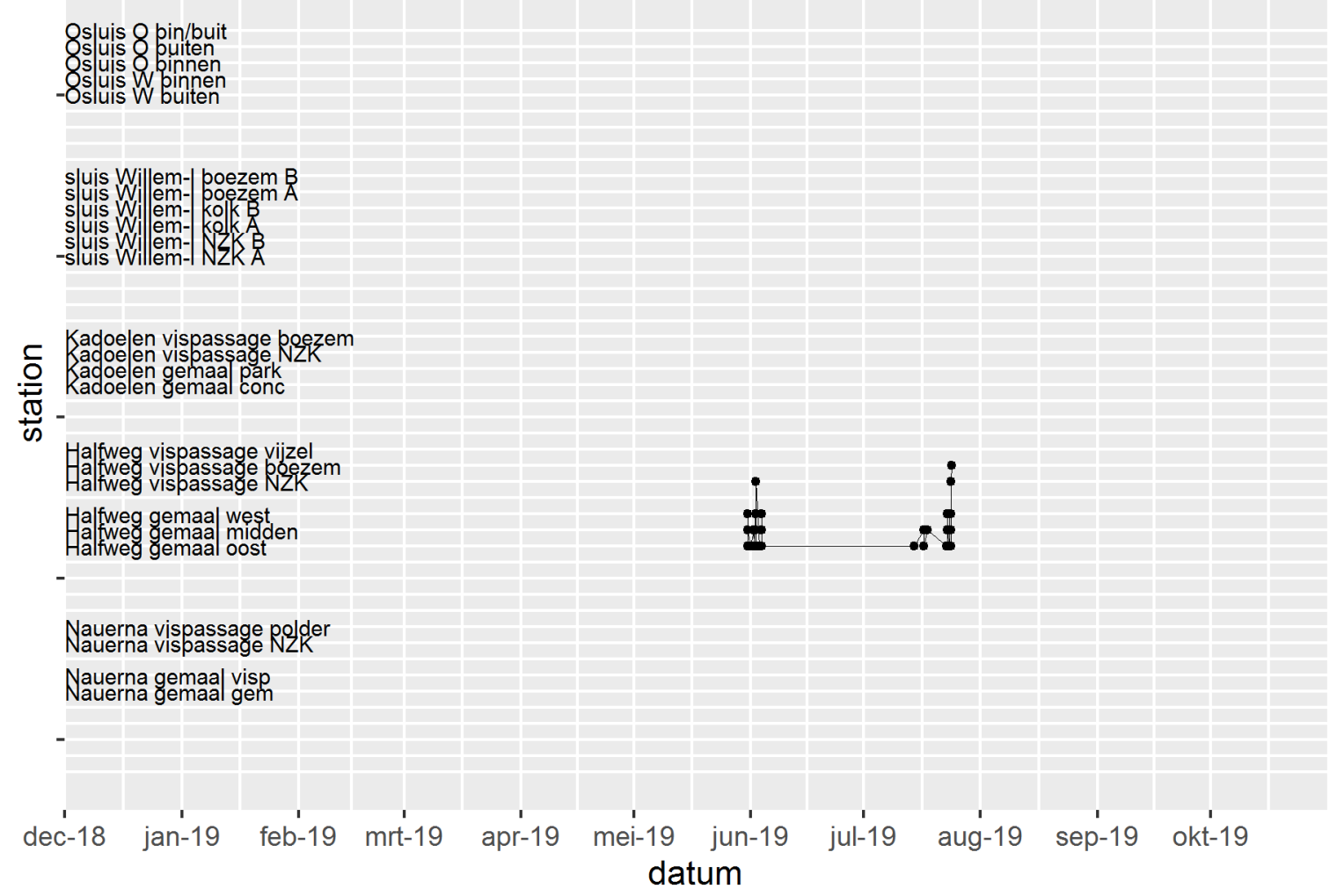

Figuur 3-6 Voorbeeld van een brasem die na een onsuccesvolle poging na 1,5 maand terugkeert en de vispassage alsnog passeert. 
900_230000150353 Brasem 439 mm 973 gr Kadoelen 3-apr

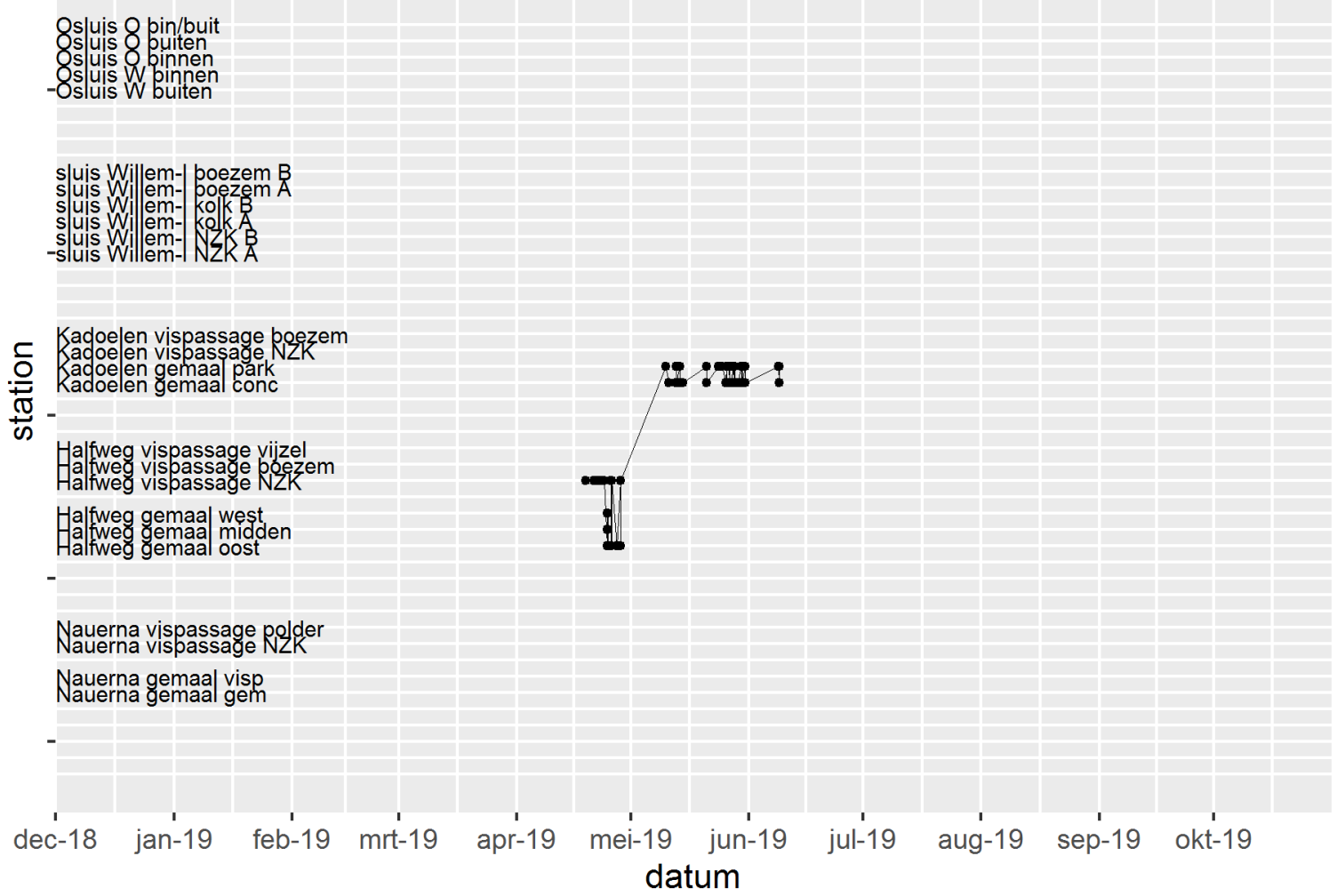

Figuur 3-7 Voorbeeld van een brasem die zijn zoektocht naar boezemgebied lijkt te hebben gestaakt bij Kadoelen (daar gemerkt), is omgekeerd richting Halfweg en daar voor het eerst gedetecteerd, maar was ook daar onsuccesvol en opnieuw naar Kadoelen is vertrokken. Ook daar geen succesvolle passsage. 
Tabel 8 Detecties van vissen bij de vispassage van gemaal Halfweg ( $N=79)$.

\begin{tabular}{|c|c|c|c|c|c|c|c|c|c|c|c|c|}
\hline Datum & Merklocatie & tag ID & floytag & Soort & \begin{tabular}{|l|} 
Lengte \\
$(\mathrm{mm})$
\end{tabular} & \begin{tabular}{|l|} 
Gewicht \\
(gr)
\end{tabular} & Geslacht & Opm. vis & Vangstlocatie & $\begin{array}{l}\text { NZK- } \\
\text { zijde }\end{array}$ & \begin{tabular}{|l|} 
Boezem- \\
zijde
\end{tabular} & $\begin{array}{l}\text { vispas. } \\
\text { Vijzel }\end{array}$ \\
\hline $26 / \mathrm{mrt}$ & Halfweg & 900_230000150171 & FT: 09204 & Snoekbaars & 532 & 1354 & & & NZK-zijde & $x$ & & \\
\hline $26 / \mathrm{mrt}$ & Halfweg & 900_230000150190 & & Baars & 236 & 172 & & Vispassage + uitzet NZK & Vispassage & $x$ & $x$ & \\
\hline $26 / \mathrm{mrt}$ & Halfweg & 900_230000150196 & & Baars & 242 & 222 & & Vispassage + uitzet NZK & Vispassage & $x$ & $\mathrm{x}$ & \\
\hline 3/apr & Kadoelen & 900_230000150353 & & Brasem & 439 & 973 & Man & Paaiuitslag & maalkom & $x$ & & \\
\hline 8/apr & Halfweg & 900_230000150459 & FT: 09226 & Snoekbaars & 590 & 1696 & & & NZK zijde & $x$ & $\mathrm{x}$ & \\
\hline $2 / \mathrm{mei}$ & Nauerna & 900_230000150841 & & Brasem & 478 & 1405 & Man & Paaiuitslag & Kanaal & $x$ & & \\
\hline $2 / \mathrm{mei}$ & Nauerna & 900_230000150844 & & Brasem & 396 & 808 & & & Kanaal & $x$ & & \\
\hline $16 / \mathrm{mei}$ & Halfweg & $900 \_230000151291$ & FT: 09734 & Snoekbaars & 515 & 974 & Man & uitzet boezem & Boezemzijde & & & $x$ \\
\hline $16 / \mathrm{mei}$ & Halfweg & 900_230000151334 & & Blankvoorn & 179 & 71 & & Uitzet NZK & Boezemzijde & $x$ & $\mathrm{x}$ & \\
\hline $16 / \mathrm{mei}$ & Halfweg & 900_230000151335 & & Blankvoorn & 202 & 92 & & Uitzet NZK & Boezemzijde & $x$ & & \\
\hline $16 / \mathrm{mei}$ & Halfweg & 900_230000151336 & & Blankvoorn & 175 & 65 & & Uitzet NZK & Boezemzijde & $x$ & & \\
\hline 16/mei & Halfweg & 900_230000151340 & & Blankvoorn & 164 & 38 & & Uitzet NZK & Boezemzijde & $x$ & $\mathrm{x}$ & \\
\hline $16 / \mathrm{mei}$ & Halfweg & 900_230000151342 & & Brasem & 385 & 648 & & Uitzet NZK & Boezemzijde & $x$ & & \\
\hline $16 / \mathrm{mei}$ & Halfweg & 900_230000151345 & & Baars & 181 & 62 & & Uitzet NZK & Boezemzijde & $\mathrm{x}$ & $\mathrm{x}$ & \\
\hline $16 / \mathrm{mei}$ & Halfweg & 900_230000151349 & & Blankvoorn & 252 & 201 & & Uitzet NZK & Boezemzijde & $x$ & $\mathrm{x}$ & \\
\hline $16 / \mathrm{mei}$ & Halfweg & 900_230000151350 & & Blankvoorn & 227 & 142 & & Uitzet NZK & Boezemzijde & $x$ & & \\
\hline $16 / \mathrm{mei}$ & Halfweg & 900_230000151352 & FT: 09735 & Baars & 376 & 858 & & Uitzet NZK & Boezemzijde & $x$ & $x$ & \\
\hline $16 / \mathrm{mei}$ & Halfweg & 900_230000151353 & & Blankvoorn & 189 & 86 & & Uitzet NZK & Boezemzijde & $x$ & $\mathrm{x}$ & \\
\hline 16/mei & Halfweg & 900_230000151354 & & Blankvoorn & 220 & 130 & & Uitzet NZK & Boezemzijde & $x$ & $\mathrm{x}$ & \\
\hline 16/mei & Halfweg & 900_230000151355 & & Blankvoorn & 225 & 135 & & Uitzet NZK & Boezemzijde & $x$ & $\mathrm{x}$ & \\
\hline $16 / \mathrm{mei}$ & Halfweg & 900_230000151356 & & Blankvoorn & 287 & 312 & & Uitzet NZK + wond & Boezemzijde & $x$ & $\mathrm{x}$ & \\
\hline $29 / \mathrm{mei}$ & Halfweg & 900_230000151691 & & Blankvoorn & 173 & 65 & & Uitzet NZK & Boezemzijde & $x$ & & \\
\hline 29/mei & Halfweg & 900_230000151698 & & Blankvoorn & 218 & 134 & & Uitzet NZK & Boezemzijde & $x$ & $x$ & \\
\hline 29/mei & Halfweg & 900_230000151705 & & Blankvoorn & 186 & 86 & & Uitzet NZK & Boezemzijde & $x$ & & \\
\hline $29 / \mathrm{mei}$ & Halfweg & 900_230000151706 & & Blankvoorn & 202 & 105 & & Uitzet NZK & Boezemzijde & $x$ & $\mathrm{x}$ & \\
\hline 29/mei & Halfweg & 900_230000151717 & & Blankvoorn & 197 & 108 & & Uitzet NZK & Boezemzijde & $x$ & & \\
\hline 29/mei & Halfweg & 900_230000151719 & & Blankvoorn & 171 & 50 & & Uitzet NZK & Boezemzijde & $\mathrm{x}$ & & \\
\hline 29/mei & Halfweg & 900_230000151723 & & Brasem & 247 & 150 & & Uitzet NZK & Boezemzijde & $x$ & $\mathrm{x}$ & \\
\hline 29/mei & Halfweg & 900_230000151729 & & Blankvoorn & 190 & 92 & & Uitzet NZK & Boezemzijde & $\mathrm{x}$ & & \\
\hline 29/mei & Halfweg & $900 \_230000151730$ & & Brasem & 261 & 186 & & Uitzet NZK & Boezemzijde & $x$ & & \\
\hline 29/mei & Halfweg & 900_230000151731 & & Brasem & 207 & 90 & & Uitzet NZK & Boezemzijde & $x$ & $\mathrm{x}$ & \\
\hline 29/mei & Halfweg & 900_230000151732 & & Blankvoorn & 208 & 130 & & Uitzet NZK & Boezemzijde & $x$ & & \\
\hline 29/mei & Halfweg & 900_230000151733 & & Brasem & 384 & 688 & & Uitzet NZK & Boezemzijde & $x$ & & \\
\hline 29/mei & Halfweg & 900_230000151739 & FT: 09976 & Baars & 380 & 814 & & Uitzet NZK & Boezemzijde & $x$ & $x$ & \\
\hline 29/mei & Halfweg & 900_230000151740 & & Blankvoorn & 226 & 157 & & Uitzet NZK & Boezemzijde & $x$ & & \\
\hline $29 / \mathrm{mei}$ & Halfweg & 900_230000151741 & & Brasem & 232 & 136 & & Uitzet NZK & Boezemzijde & $x$ & $\mathrm{x}$ & \\
\hline 29/mei & Halfweg & 900_230000151743 & & Blankvoorn & 286 & 315 & & Uitzet NZK & Boezemzijde & $x$ & $\mathrm{x}$ & \\
\hline 29/mei & Halfweg & 900_230000151747 & & Blankvoorn & 206 & 114 & & Uitzet NZK + wond & Boezemzijde & $x$ & $\mathrm{x}$ & \\
\hline 29/mei & Halfweg & 900_230000151749 & & Brasem & 339 & 408 & & Uitzet NZK & Boezemzijde & $x$ & & \\
\hline 29/mei & Halfweg & 900_230000151750 & & Blankvoorn & 221 & 338 & & Uitzet NZK & Boezemzijde & $x$ & $\mathrm{x}$ & \\
\hline 29/mei & Halfweg & 900_230000151752 & & Blankvoorn & 195 & 96 & & Uitzet NZK & Boezemzijde & $x$ & & \\
\hline 29/mei & Halfweg & 900_230000151753 & & Blankvoorn & 183 & 78 & & Uitzet NZK & Boezemzijde & $\mathrm{x}$ & & \\
\hline 29/mei & Halfweg & 900_230000151761 & FT: 09975 & Baars & 360 & 759 & & Uitzet NZK & Boezemzijde & $x$ & $\mathrm{x}$ & \\
\hline 29/mei & Halfweg & 900_230000151764 & & Blankvoorn & 239 & 163 & & Uitzet NZK & Boezemzijde & $\mathrm{x}$ & $\mathrm{x}$ & \\
\hline 29/mei & Halfweg & $900 \_230000151765$ & & Blankvoorn & 198 & 94 & & Uitzet NZK & Boezemzijde & $x$ & $\mathrm{x}$ & \\
\hline 29/mei & Halfweg & 900_230000151766 & & Blankvoorn & 181 & 73 & & Uitzet NZK + wond & Boezemzijde & $x$ & $\mathrm{x}$ & \\
\hline 29/mei & Halfweg & 900_230000151774 & & Brasem & 495 & 1381 & & Uitzet NZK & Boezemzijde & $x$ & $\mathrm{x}$ & \\
\hline $29 / \mathrm{mei}$ & Halfweg & 900_230000151780 & & Brasem & 267 & 215 & & Uitzet NZK & Boezemzijde & $x$ & & \\
\hline 29/mei & Halfweg & 900_230000151790 & & Kolblei & 191 & 89 & & Uitzet NZK & Boezemzijde & $x$ & & \\
\hline 29/mei & Halfweg & 900_230000151791 & & Brasem & 215 & 104 & & Uitzet NZK & Boezemzijde & $x$ & $\mathrm{x}$ & \\
\hline $29 / \mathrm{mei}$ & Halfweg & 900_230000151797 & & Brasem & 270 & 205 & & Uitzet NZK & Boezemzijde & $x$ & & \\
\hline 29/mei & Halfweg & 900_230000151798 & & Brasem & 402 & 712 & & Uitzet NZK & Boezemzijde & $x$ & & \\
\hline $29 / \mathrm{mei}$ & Halfweg & 900_230000151799 & & Brasem & 484 & 1402 & & Uitzet NZK & Boezemzijde & $x$ & $x$ & $\mathrm{x}$ \\
\hline 29/mei & Halfweg & 900_230000151803 & & Brasem & 280 & 247 & & Uitzet NZK & Boezemzijde & $x$ & & \\
\hline 29/mei & Halfweg & 900_230000151804 & & Brasem & 231 & 133 & & Uitzet NZK & Boezemzijde & $x$ & & \\
\hline 29/mei & Halfweg & 900_230000151807 & & Brasem & 261 & 185 & & Uitzet NZK & Boezemzijde & $x$ & $x$ & \\
\hline 29/mei & Halfweg & 900_230000151809 & & Brasem & 101 & 115 & & Uitzet NZK & Boezemzijde & $\mathrm{x}$ & & \\
\hline 29/mei & Halfweg & 900_230000151824 & & Brasem & 236 & 346 & & Uitzet NZK & Boezemzijde & $\mathrm{x}$ & & \\
\hline 29/mei & Halfweg & 900_230000151833 & & Brasem & 242 & 172 & & Uitzet NZK & Boezemzijde & $\mathrm{x}$ & & \\
\hline $29 / \mathrm{mei}$ & Halfweg & $900 \_230000151834$ & & Blankvoorn & 217 & 125 & & Uitzet NZK & Boezemzijde & $x$ & $\mathrm{x}$ & \\
\hline 29/mei & Halfweg & 900_230000151842 & & Blankvoorn & 213 & 106 & & Uitzet NZK + wond & Boezemzijde & $x$ & & \\
\hline 29/mei & Halfweg & 900_230000151846 & & Brasem & 237 & 137 & & Uitzet NZK & Boezemzijde & $x$ & & \\
\hline $29 / \mathrm{mei}$ & Halfweg & 900_230000151848 & & Blankvoorn & 164 & 54 & & Uitzet NZK & Boezemzijde & $x$ & & \\
\hline 29/mei & Halfweg & 900_230000151849 & & Brasem & 285 & 262 & & Uitzet NZK & Boezemzijde & $x$ & $x$ & \\
\hline 29/mei & Halfweg & 900_230000151851 & & Brasem & 409 & 854 & & Uitzet NZK & Boezemzijde & $x$ & $\mathrm{x}$ & \\
\hline 29/mei & Halfweg & 900_230000151853 & & Brasem & 457 & 1206 & & Uitzet NZK & Boezemzijde & $\mathrm{x}$ & & \\
\hline 29/mei & Halfweg & 900_230000151856 & & Blankvoorn & 230 & 150 & & Uitzet NZK & Boezemzijde & $x$ & $\mathrm{x}$ & \\
\hline 29/mei & Halfweg & 900_230000151859 & & Blankvoorn & 224 & 143 & & Uitzet NZK & Boezemzijde & $x$ & & \\
\hline 29/mei & Halfweg & 900_230000151861 & & Blankvoorn & 215 & 131 & & Uitzet NZK & Boezemzijde & $x$ & & \\
\hline 29/mei & Halfweg & 900_230000151863 & & Brasem & 235 & 125 & & Uitzet NZK & Boezemzijde & $x$ & & \\
\hline 29/mei & Halfweg & 900_230000151864 & & Brasem & 247 & 144 & & Uitzet NZK & Boezemzijde & $x$ & & \\
\hline 29/mei & Halfweg & 900_230000151868 & & Blankvoorn & 275 & 289 & & Uitzet NZK & Boezemzijde & $x$ & & \\
\hline 29/mei & Halfweg & 900_230000151871 & & Brasem & 477 & 1226 & & Uitzet NZK + wond & Boezemzijde & $\mathrm{x}$ & $\mathrm{x}$ & \\
\hline 29/mei & Halfweg & 900_230000151872 & & Ruisvoorn & 182 & 82 & Man & Uitzet NZK & Boezemzijde & $\mathrm{x}$ & $\mathrm{x}$ & \\
\hline $29 / \mathrm{mei}$ & Halfweg & $900 \_230000151880$ & & Brasem & 210 & 93 & & Uitzet NZK & Boezemzijde & $x$ & $\mathrm{x}$ & \\
\hline 29/mei & Halfweg & 900_230000151888 & & Brasem & 238 & 155 & & Uitzet NZK & Boezemzijde & $x$ & & \\
\hline 29/mei & Halfweg & 900_230000151889 & & Brasem & 253 & 179 & & Uitzet NZK & Boezemzijde & $x$ & $\mathrm{x}$ & \\
\hline $29 / \mathrm{mei}$ & Halfweg & 900_230000151894 & & Brasem & 397 & 656 & & Uitzet NZK & Boezemzijde & $x$ & $\mathrm{x}$ & \\
\hline $29 / \mathrm{mei}$ & Halfweg & 900_230000151895 & & Blankvoorn & 172 & 71 & & Uitzet NZK & Boezemzijde & $x$ & $\mathrm{x}$ & \\
\hline
\end{tabular}




\subsection{Kadoelen}

Bij het gemaal zijn 393 vissen gedetecteerd waarvan één brasem die vanuit Nauerna afkomstig was (Bijlage 1). Vanuit Kadoelen worden vissen ook bij andere stations gezien (Figuur 3-8) waaronder bij de Willem I-sluizen (Figuur 3-9). Drie brasems zijn via de vispassage en de boezem bij de Willem I-sluis uitgekomen (vb. Figuur 3-10). Bij Kadoelen zijn bij de vispassage 22 vissen aan de NZK-zijde de passage ingezwommen (Tabel 9). Daarvan zijn 16 vissen ook aan de boezemzijde van de passage gedetecteerd en zijn dus door de koker gezwommen. Alle vissen die de vispassage zijn ingezwommen waren brasems die gemerkt zijn bij Kadoelen. Soms zwemmen de vissen de vispassage ook weer uit (Figuur 3-11). Bij gemaal Kadoelen worden vissen vaak langdurig bij het gemaal waargenomen (Figuur 3-8 en één voorbeeld van 1 brasem Figuur 3-12).

Tabel 9 Detecties van vissen bij de vispassage van gemaal Kadoelen $(N=22)$.

\begin{tabular}{|c|c|c|c|c|c|c|c|c|c|c|}
\hline Datum & Merklocatie & tag ID & Soort & $\begin{array}{l}\text { Lengte } \\
(\mathrm{mm})\end{array}$ & $\begin{array}{l}\text { Gewicht } \\
\text { (gr) }\end{array}$ & Geslacht & Opm. Vis & Vangstlocatie & $\begin{array}{l}\text { Antenne } \\
\text { NZK-zijde }\end{array}$ & $\begin{array}{l}\text { Antenne } \\
\text { boezem-zijde }\end{array}$ \\
\hline $19 / \mathrm{mrt}$ & Kadoelen & 900_230000150021 & Brasem & 477 & 1196 & Man & Paaiuitslag & maalkom & $x$ & $x$ \\
\hline $19 / \mathrm{mrt}$ & Kadoelen & 900_230000150077 & Brasem & 480 & 1210 & & & maalkom & $x$ & \\
\hline 19/mrt & Kadoelen & 900_230000150080 & Brasem & 531 & 1688 & & & maalkom & $x$ & $x$ \\
\hline 19/mrt & Kadoelen & 900_230000150099 & Brasem & 555 & 2400 & Man & Paaiuitslag & maalkom & $x$ & \\
\hline $19 / \mathrm{mrt}$ & Kadoelen & 900_230000150129 & Brasem & 418 & 897 & & & maalkom & $x$ & $x$ \\
\hline $19 / \mathrm{mrt}$ & Kadoelen & 900_230000150134 & Brasem & 532 & 2220 & & & maalkom & $x$ & $x$ \\
\hline 19/mrt & Kadoelen & 900_230000150139 & Brasem & 501 & 1620 & Man & Paaiuitslag & maalkom & $x$ & $x$ \\
\hline 19/mrt & Kadoelen & $900 \_230000150145$ & Brasem & 485 & 1443 & Man & Paaiuitslag & maalkom & $x$ & $x$ \\
\hline 19/mrt & Kadoelen & $900 \_230000150153$ & Brasem & 465 & 1224 & Man & Paaiuitslag & maalkom & $x$ & \\
\hline 3/apr & Kadoelen & 900_230000150296 & Brasem & 462 & 1308 & Man & Paaiuitslag & maalkom & $x$ & \\
\hline 3/apr & Kadoelen & 900_230000150334 & Brasem & 461 & 960 & & & maalkom & $x$ & $x$ \\
\hline 3/apr & Kadoelen & $900 \_230000150351$ & Brasem & 439 & 1033 & & & maalkom & $x$ & $x$ \\
\hline 3/apr & Kadoelen & 900_230000150417 & Brasem & 533 & 2556 & Man & Paaiuitslag & maalkom & $x$ & $x$ \\
\hline 3/apr & Kadoelen & 900_230000150440 & Brasem & 549 & 1840 & Man & Paaiuitslag & maalkom & $x$ & \\
\hline 3/apr & Kadoelen & 900_230000150443 & Brasem & 428 & 1035 & Man & Paaiuitslag & maalkom & $x$ & $x$ \\
\hline 3/apr & Kadoelen & 900_230000150449 & Brasem & 532 & 2194 & & & maalkom & $x$ & $x$ \\
\hline 15/apr & Kadoelen & $900 \_230000150468$ & Brasem & 511 & 1684 & & & maalkom & $x$ & $x$ \\
\hline
\end{tabular}




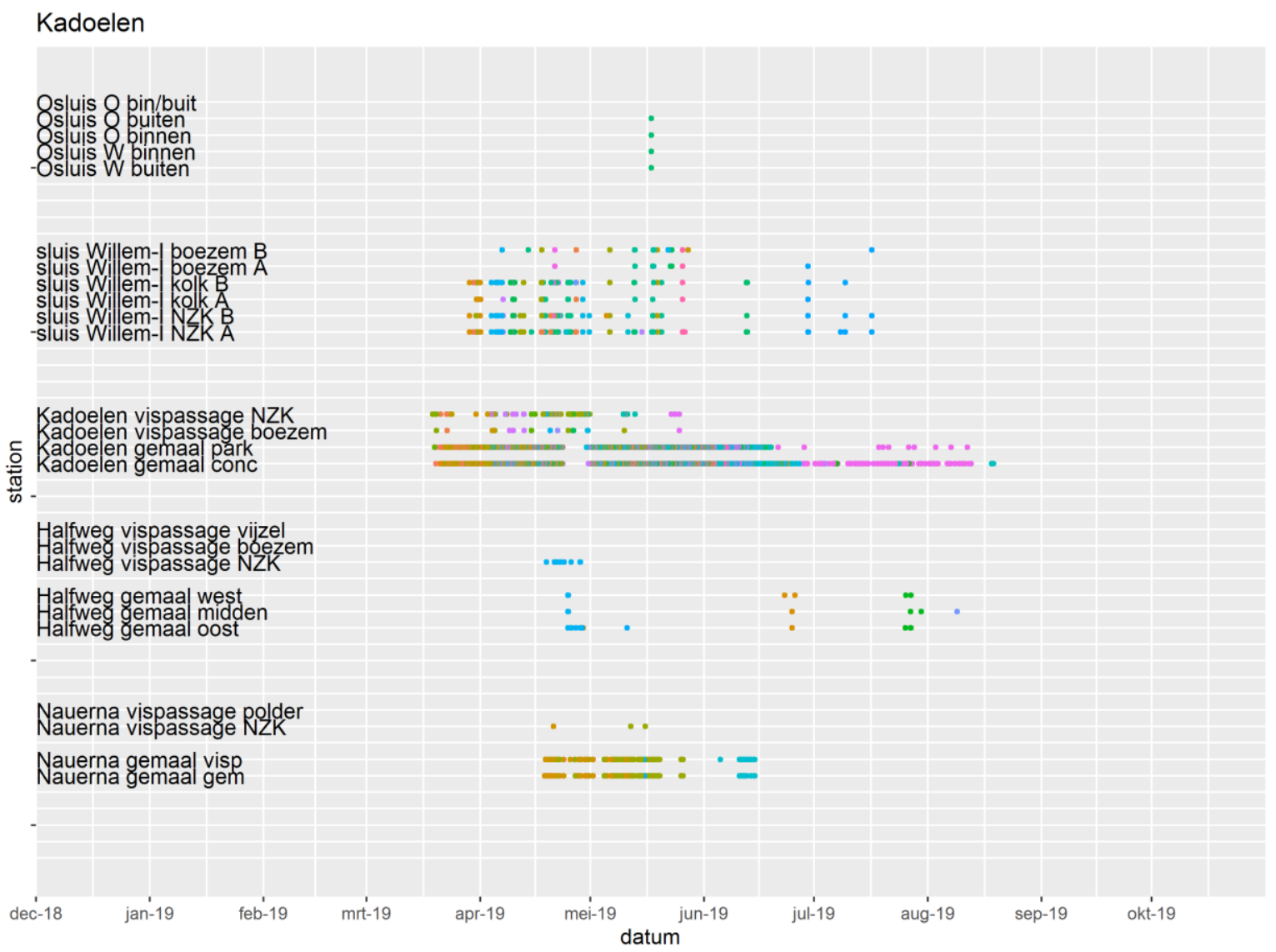

Figuur 3-8 Alle detecties op alle stations van de vissen die oorspronkelijk zijn gevangen, gemerkt en uitgezet bij gemaal Kadoelen. NB. in de figuur wordt onderscheid gemaakt in individuen met kleurcodering.

\section{0_230000150102 Brasem 470 mm 1240 gr Kadoelen 19-mrt}

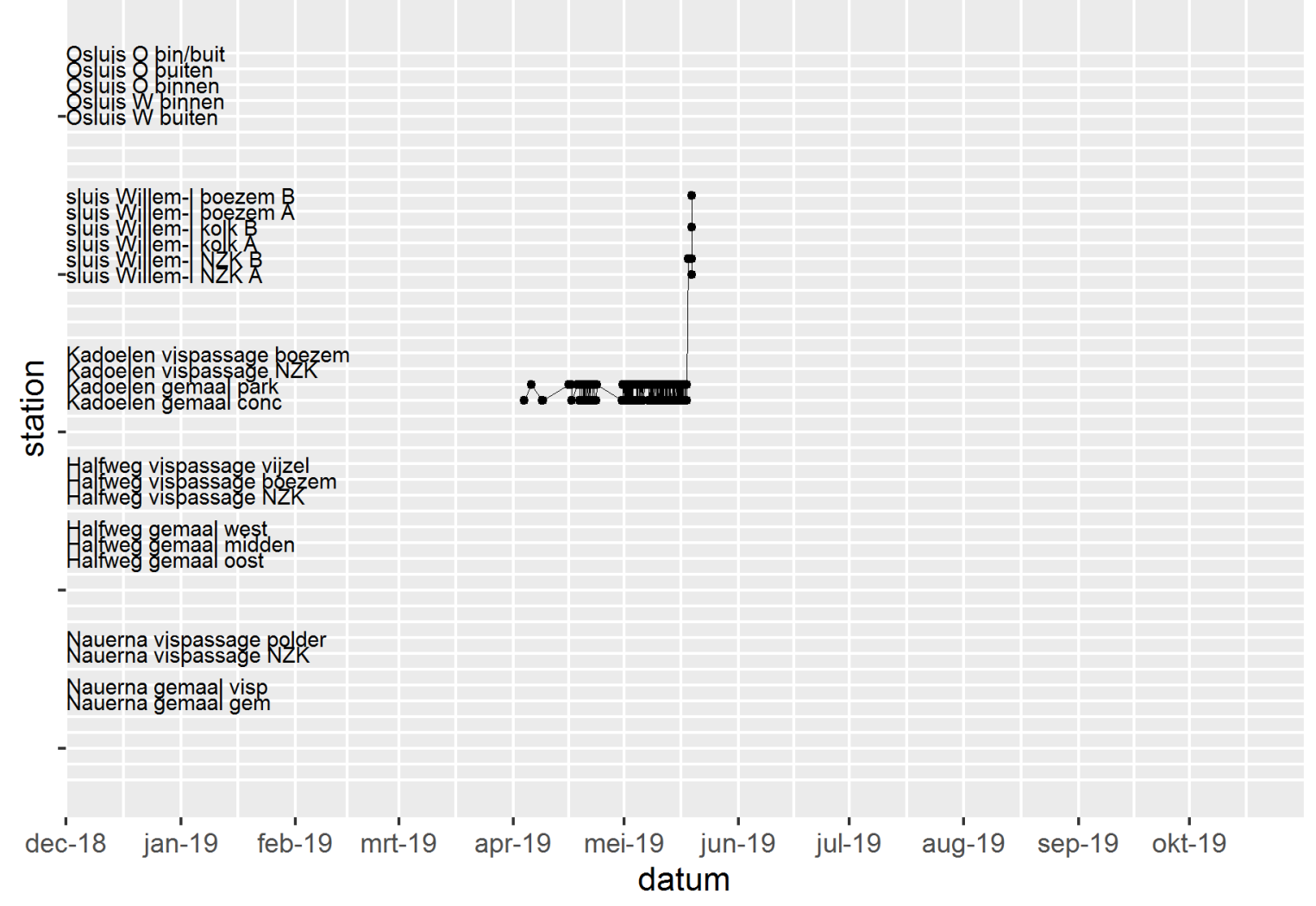

Figuur 3-9 Voorbeeld van een brasem die niet gezien is bij de ingang van de vispassage bij gemaal Kadoelen, maar via het Noordzeekanaal de migratievoorziening bij Willem I-sluis heeft bereikt. 
900_230000150351 Brasem 439 mm 1033 gr Kadoelen 3-apr

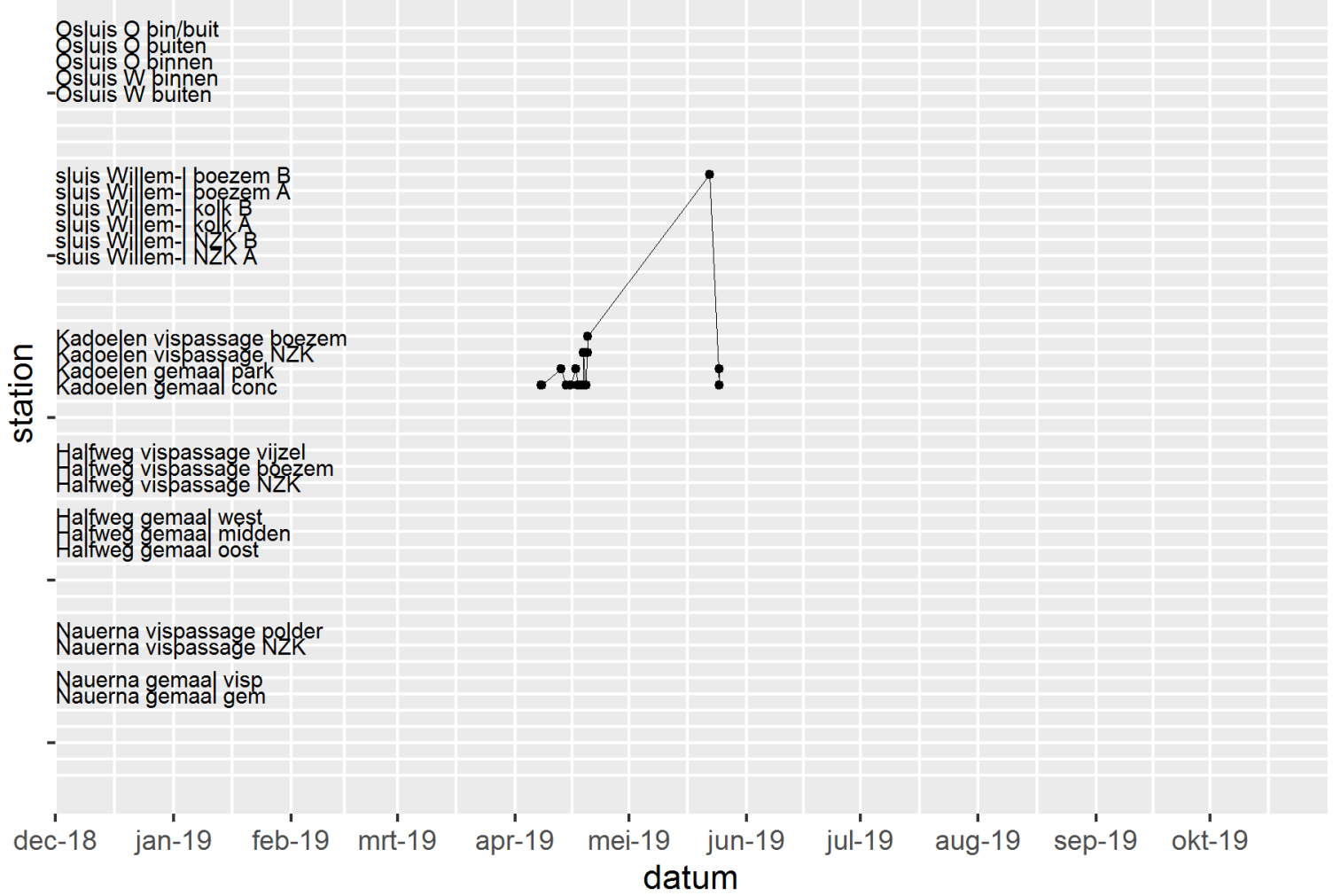

Figuur 3-10 Voorbeeld van een brasem die via de vispassage van Kadoelen naar de Willem I-s/uis is gezwommen en (waarschijnlijk) via de grote kolk van Willem I-sluis weer naar Kadoelen is gezwommen óf via de boezem weer via de pompen van gemaal Kadoelen het Noordzeekanaal is uitgeslagen.

\section{0_230000150139 Brasem 501 mm 1620 gr Kadoelen 19-mrt}

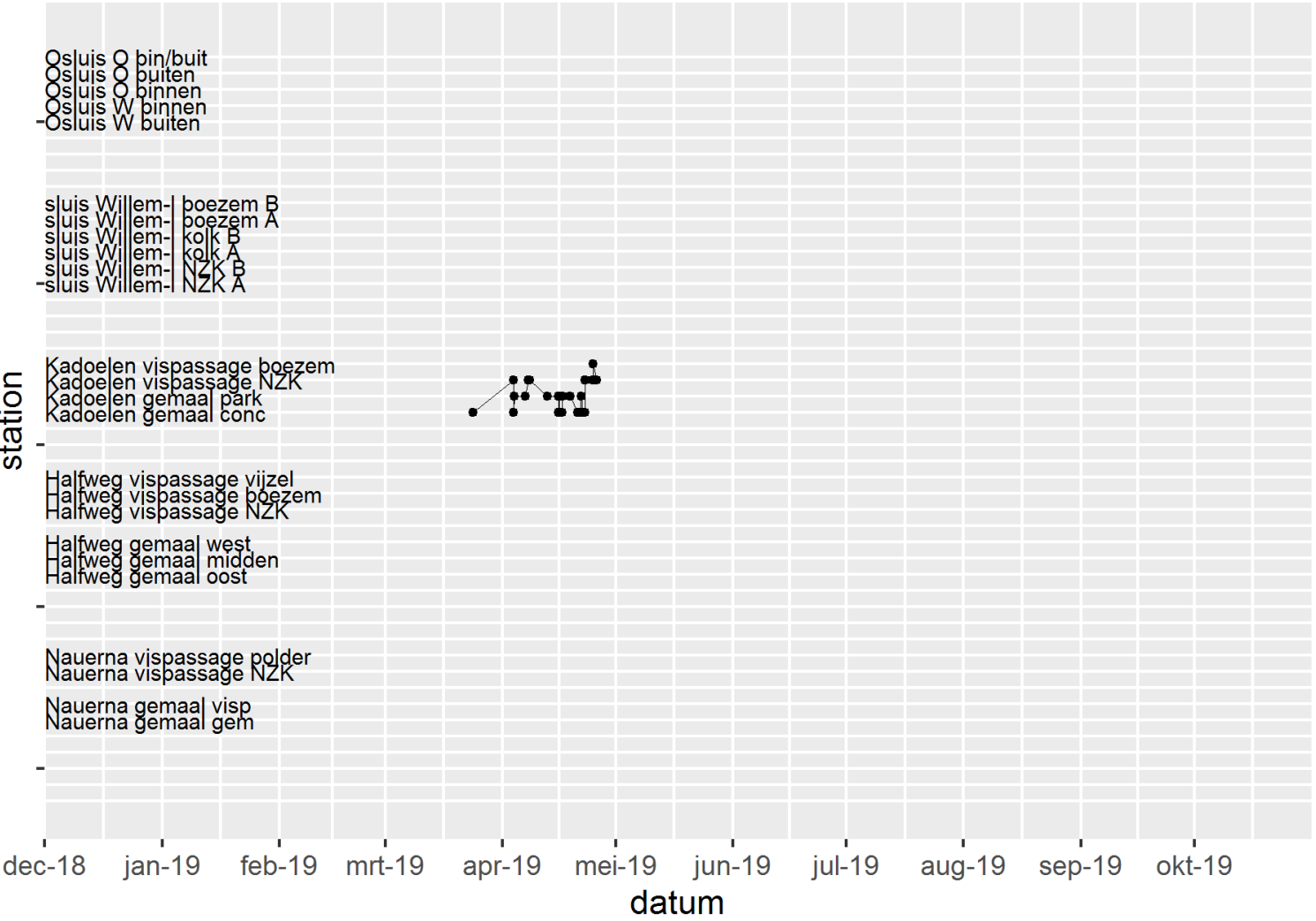

Figuur 3-11 Voorbeeld van een brasem die meerdere keren de vispassage is ingezwommen, met een uiteindelijk succesvolle passage richting de boezem, maar de vispassage weer is uitgezwommen. 
900_230000150028 Brasem 490 mm 1639 gr Kadoelen 19-mrt

8 suis 8 pin/buit

ssuis 8 binnen

- Osluis $W$ buiten

suuis Willem-|poezem B

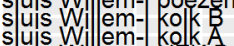

suis Wil em- NZK

-sluis Willem-INZRA

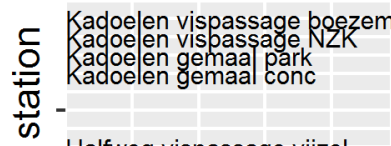

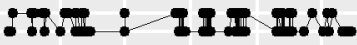

Halfweg vispassage vijzel
Hawweg visassage kizezem
Halfweg vispassage NZK

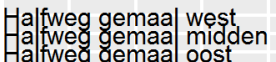

Nauerna vispassage polder

Nauerna gemaal visp

dec-18 jan-19 feb-19 mrt-19 apr-19 mei-19 jun-19 jul-19 aug-19 sep-19 okt-19 datum

Figuur 3-12 Voorbeeld van een brasem die langdurig bij de maalkom van gemaal Kadoelen is waargenomen. 


\subsection{Willem I-sluis}

Bij de Willem I-sluis zijn 35 vissen gedetecteerd bij de vispassage: 33 brasem, 1 karper en 1 baars (Tabel 10). Hiervan zijn er 24 ook daadwerkelijk in de kolk geweest. Deze vissen waren afkomstig van Kadoelen en Oranjesluizen en duiken op aan zowel de boezemzijde (Figuur 3-13, al dan niet na passage van de vispassage bij Kadoelen) als de NZK-zijde (Figuur 3-14). Soms wordt er herhaaldelijk heen en weer gezwommen tussen Kadoelen en Willem I-sluis (Figuur 3-15 en Figuur 3-16). Van de vissen die op locatie zijn gemerkt zijn geen detecties waargenomen.

Tabel 10 Detecties van vissen bij de vispassage van de Willem I-sluis $(N=35)$.

\begin{tabular}{|c|c|c|c|c|c|c|c|c|c|c|c|c|}
\hline Datum & Merklocatie & $\operatorname{tag}$ ID & Floytag & Soort & \begin{tabular}{|l} 
Lengte \\
$(\mathrm{mm})$
\end{tabular} & $\begin{array}{l}\text { Gewicht } \\
\text { (gr) }\end{array}$ & Geslacht & Opm. vis & Vangstlocatie & $\begin{array}{l}\text { Antenne } \\
\text { NZK- } \\
\text { zijde }\end{array}$ & $\begin{array}{l}\text { Antenne } \\
\text { kolk }\end{array}$ & $\begin{array}{l}\text { Antenne } \\
\text { boezem- } \\
\text { zijde }\end{array}$ \\
\hline $19 / \mathrm{mrt}$ & Kadoelen & $900 \_230000150014$ & & Brasem & 466 & 1404 & & & maalkom & $x$ & $x$ & \\
\hline $19 / \mathrm{mrt}$ & Kadoelen & $900 \_230000150067$ & & Brasem & 440 & 1023 & & & maalkom & $x$ & $x$ & \\
\hline $19 / \mathrm{mrt}$ & Kadoelen & $900 \_230000150070$ & & Brasem & 463 & 1250 & & & maalkom & $x$ & & \\
\hline $19 / \mathrm{mrt}$ & Kadoelen & $900 \_230000150085$ & & Brasem & 460 & 1162 & Man & Paaiuitslag & maalkom & & & $x$ \\
\hline $19 / \mathrm{mrt}$ & Kadoelen & $900 \_230000150127$ & & Brasem & 515 & 1570 & & & maalkom & $x$ & $x$ & $x$ \\
\hline $19 / \mathrm{mrt}$ & Kadoelen & $900 \_230000150147$ & & Brasem & 471 & 1307 & & & maalkom & $x$ & $x$ & \\
\hline 3/apr & Kadoelen & 900_230000150240 & & Brasem & 498 & 1387 & Man & Paaiuitslag & maalkom & $x$ & $x$ & \\
\hline 3/apr & Kadoelen & $900 \_230000150247$ & & Brasem & 475 & 1259 & Man & Paaiuitslag & maalkom & & & $x$ \\
\hline 3/apr & Kadoelen & 900_230000150254 & & Brasem & 359 & 500 & Man & Paaiuitslag & maalkom & $x$ & $x$ & \\
\hline 3/apr & Kadoelen & $900 \_230000150259$ & & Brasem & 441 & 1189 & & & maalkom & $x$ & $x$ & \\
\hline 3/apr & Kadoelen & $900 \_230000150278$ & & Brasem & 393 & 758 & & & maalkom & $x$ & $x$ & \\
\hline 3/apr & Kadoelen & 900_230000150316 & & Brasem & 486 & 1353 & Man & Paaiuitslag & maalkom & $x$ & & \\
\hline 3/apr & Kadoelen & $900 \_230000150321$ & & Brasem & 556 & 2281 & & Wond & maalkom & $x$ & & \\
\hline 3/apr & Kadoelen & $900 \_230000150334$ & & Brasem & 461 & 960 & & & maalkom & & & $x$ \\
\hline 3/apr & Kadoelen & $900 \_230000150335$ & & Brasem & 423 & 1002 & Man & Paaiuitslag & maalkom & $x$ & & \\
\hline 3/apr & Kadoelen & $900 \_230000150339$ & & Brasem & 421 & 877 & & & maalkom & $x$ & $x$ & \\
\hline 3/apr & Kadoelen & 900_230000150344 & & Brasem & 421 & 1757 & & & maalkom & $x$ & $x$ & \\
\hline 3/apr & Kadoelen & $900 \_230000150350$ & & Brasem & 496 & 1419 & Man & Paaiuitslag & maalkom & $x$ & $x$ & $x$ \\
\hline 3/apr & Kadoelen & 900_230000150351 & & Brasem & 439 & 1033 & & & maalkom & & & $x$ \\
\hline 3/apr & Kadoelen & $900 \_230000150378$ & & Karper & 745 & NA & & & maalkom & $x$ & $x$ & $x$ \\
\hline 3/apr & Kadoelen & 900_230000150396 & & Brasem & 411 & 630 & Man & Paaiuitslag & maalkom & & $x$ & \\
\hline $10 /$ mei & Oranjesluizen & 900_230000150990 & & Brasem & 439 & 967 & & & Southeast side & $x$ & $x$ & $x$ \\
\hline
\end{tabular}


900_230000150267 Brasem 434 mm 937 gr Kadoelen 3-apr

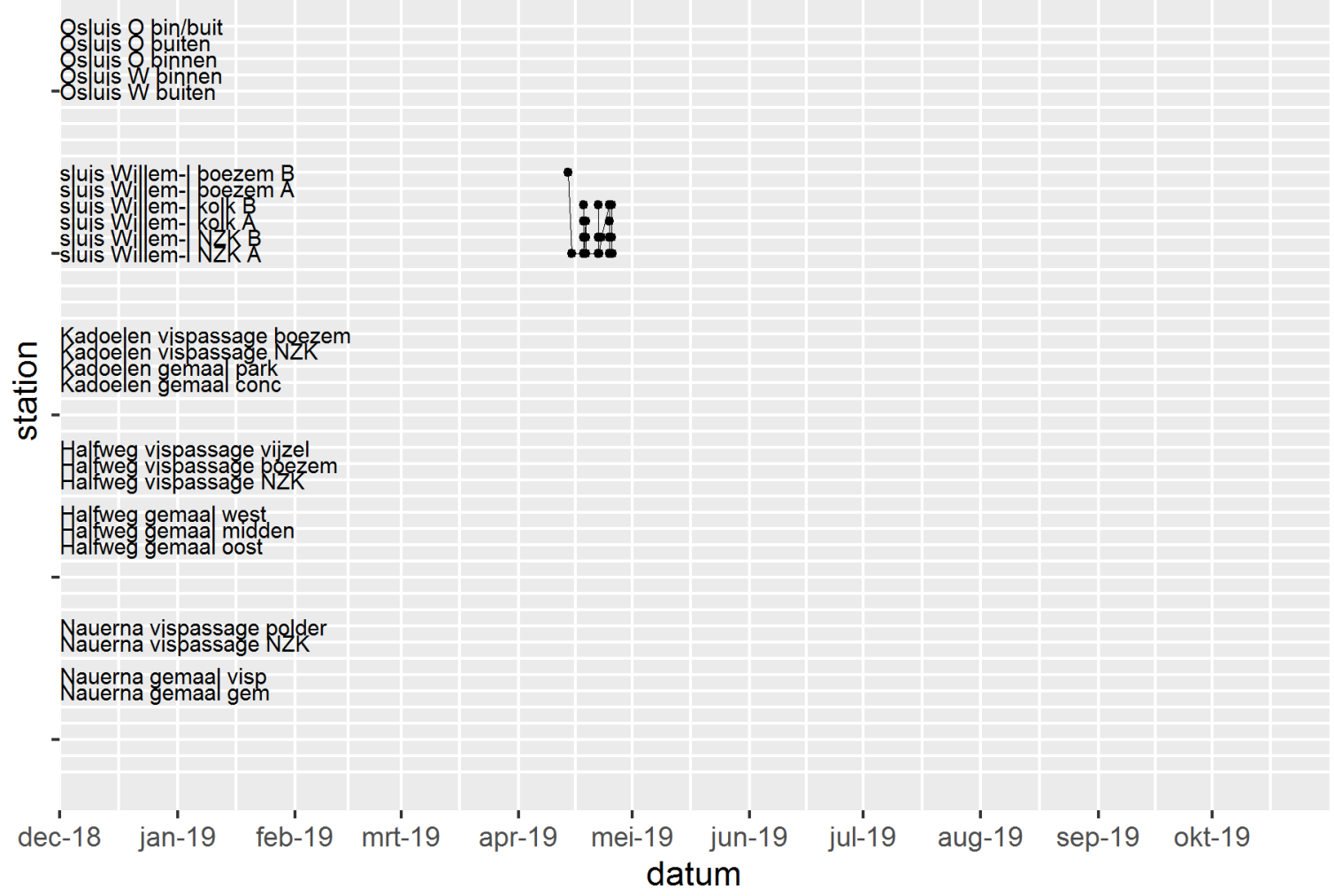

Figuur 3-13 Voorbeeld van een brasem die eerst aan de boezemzijde is gedetecteerd en vervolgens langdurig in de kolk heeft gezwommen of erin en eruit is gezwommen.

\section{0_230000150482 Baars 381 mm 1131 gr Kadoelen 15-apr}

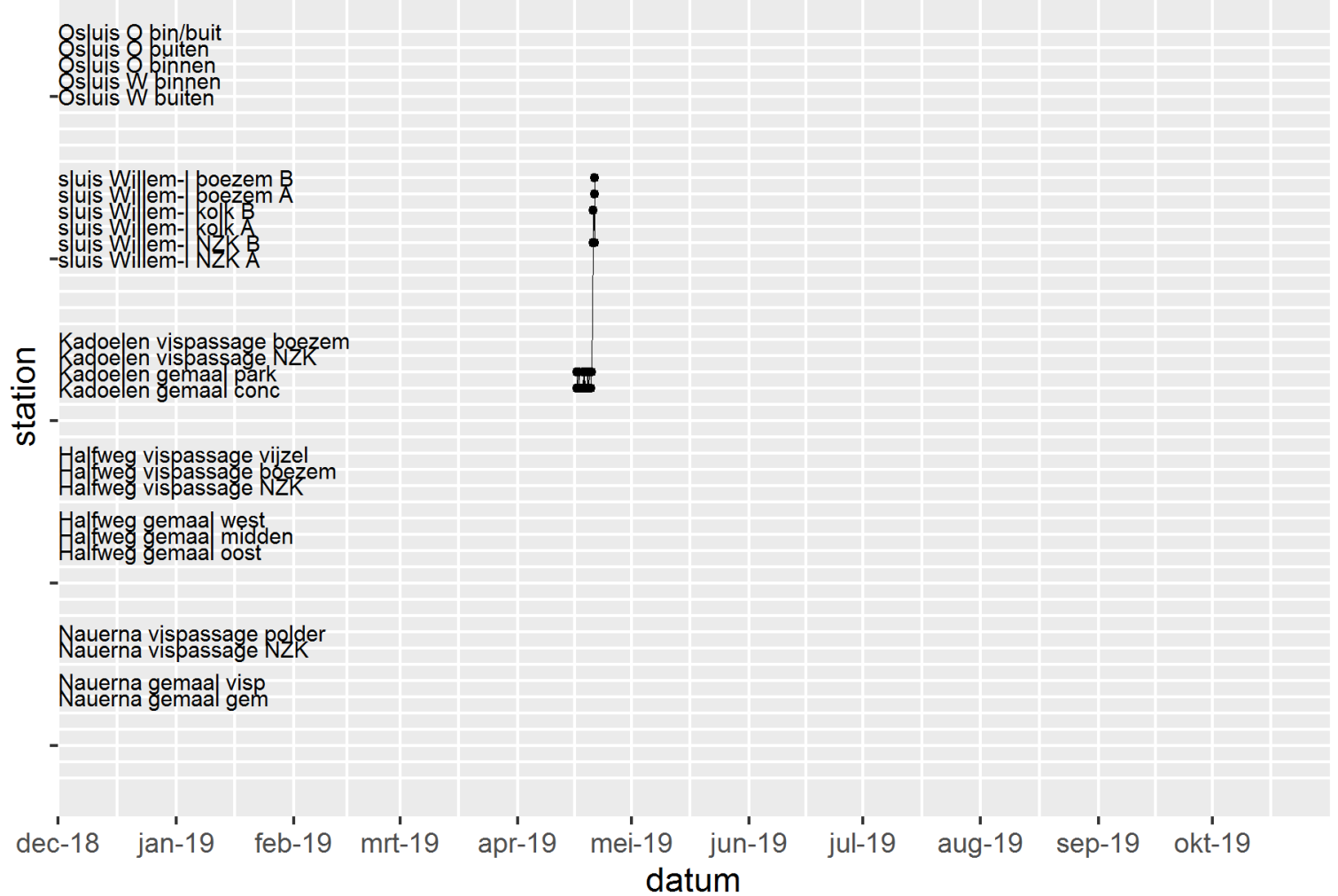

Figuur 3-14 Voorbeeld van een baars die vanaf Kadoelen richting de Willem I-sluis is gezwommen en in de kolk is geweest via de rinketten. 
900_230000150259 Brasem 441 mm 1189 gr Kadoelen 3-apr

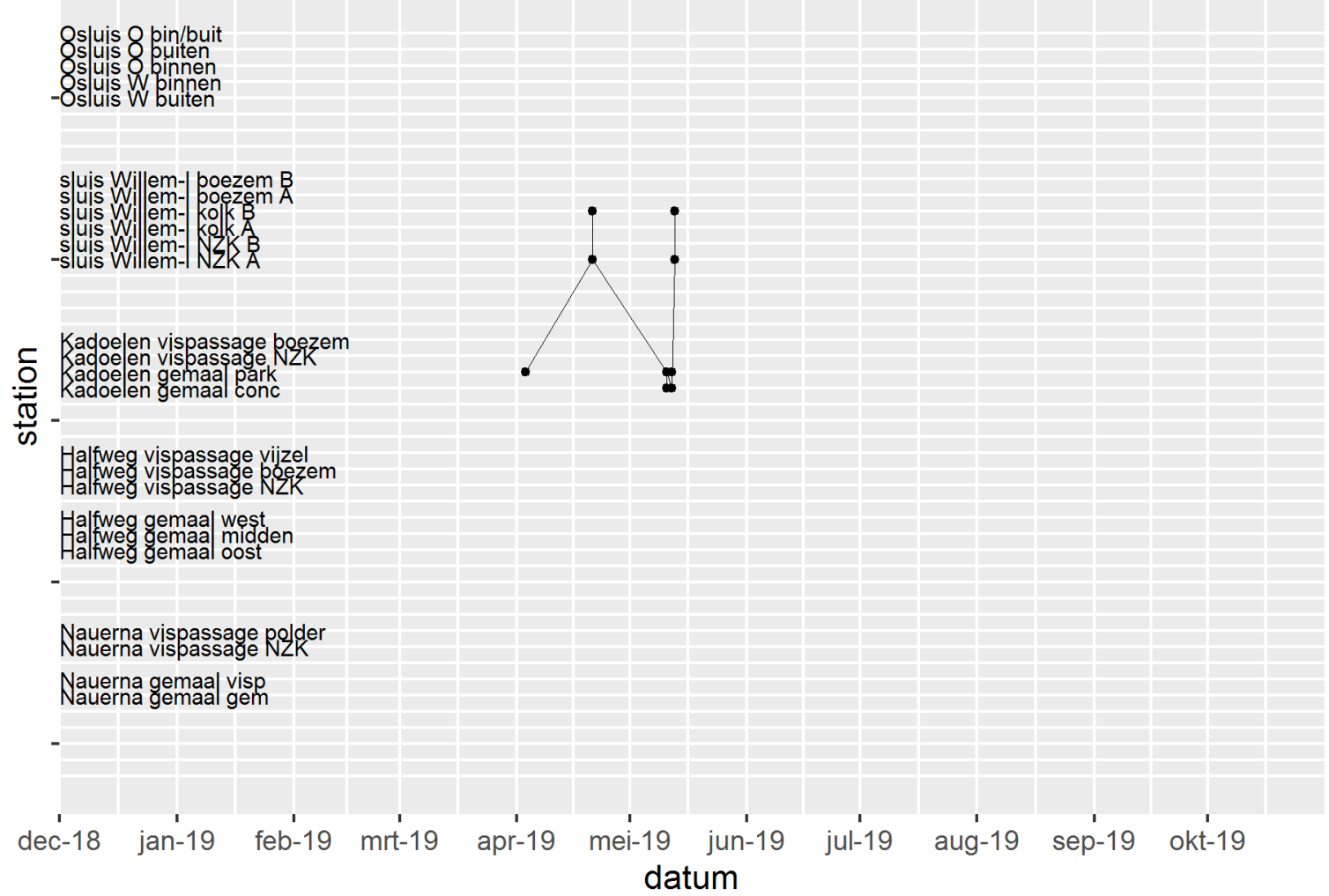

Figuur 3-15 Voorbeeld van een brasem die heen en weer is gezwommen tussen Kadoelen en Willem Isluis. De vis is twee maal in de kolk geweest, maar heeft hem niet gepasseerd.

\section{0_230000150024 Brasem 586 mm 1875 gr Kadoelen 19-mrt}

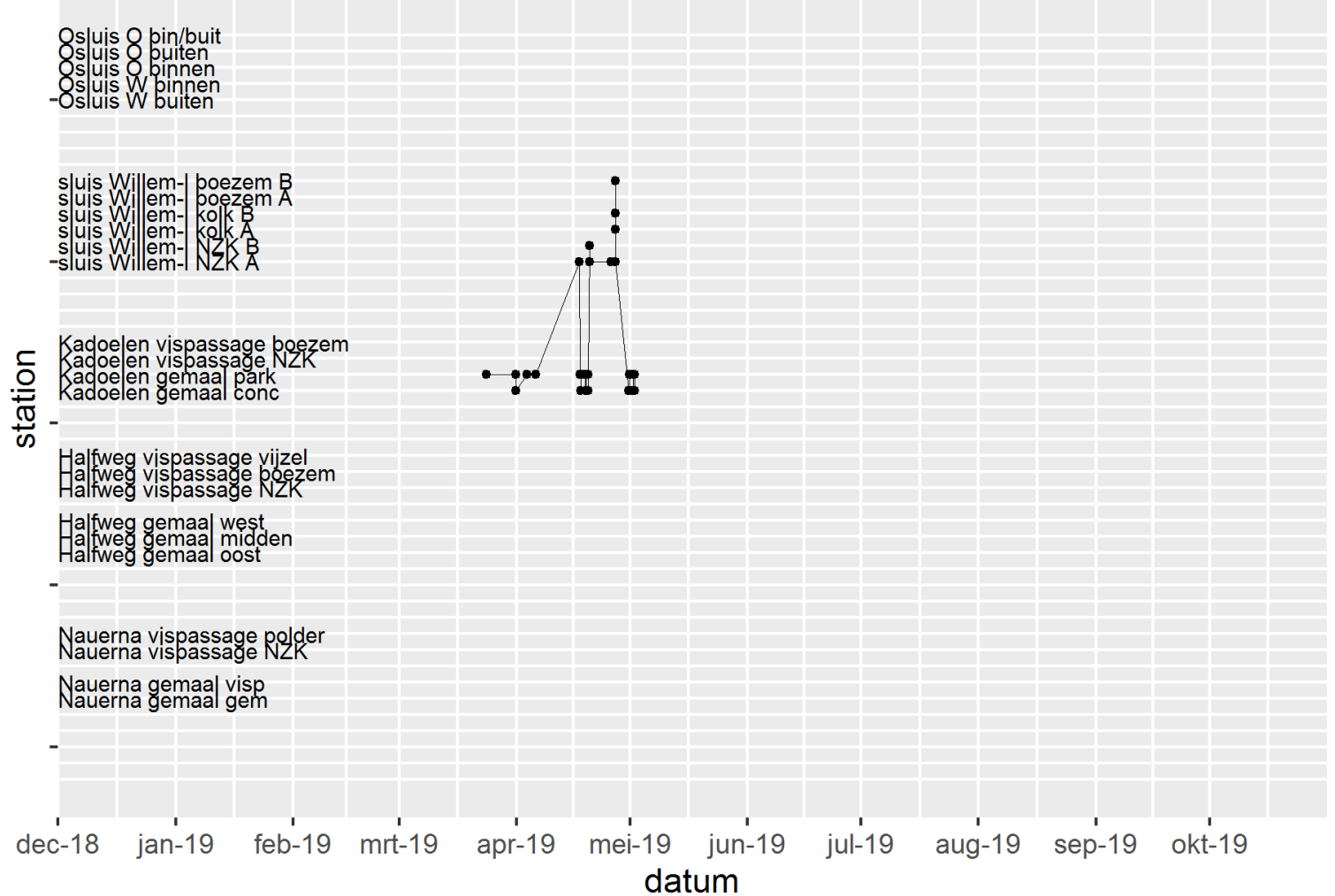

Figuur 3-16 Voorbeeld van een brasem die meerdere malen heen en weer is gezwommen tussen Kadoelen en Willem I-sluis. 


\subsection{Oranjesluizen}

In totaal zijn 45 vissen gedetecteerd door de meetopstelling in de zuidelijke vispassage (Tabel 11). Twee vissen zijn elders gezien bij Willem I-sluis en Nauerna (Figuur 3-17). In totaal zijn 19 vissen aan beide zijden van de vispassage waargenomen (Tabel 11). Eén individu is meerdere keren waargenomen, een blankvoorn van 21,9 cm (Figuur 3-18). Deze blankvoorn heeft in april en mei meerdere keren door de vispassage gezwommen en zwom ook rondjes door de vertical slots aan de zuidoostzijde van de vispassage.

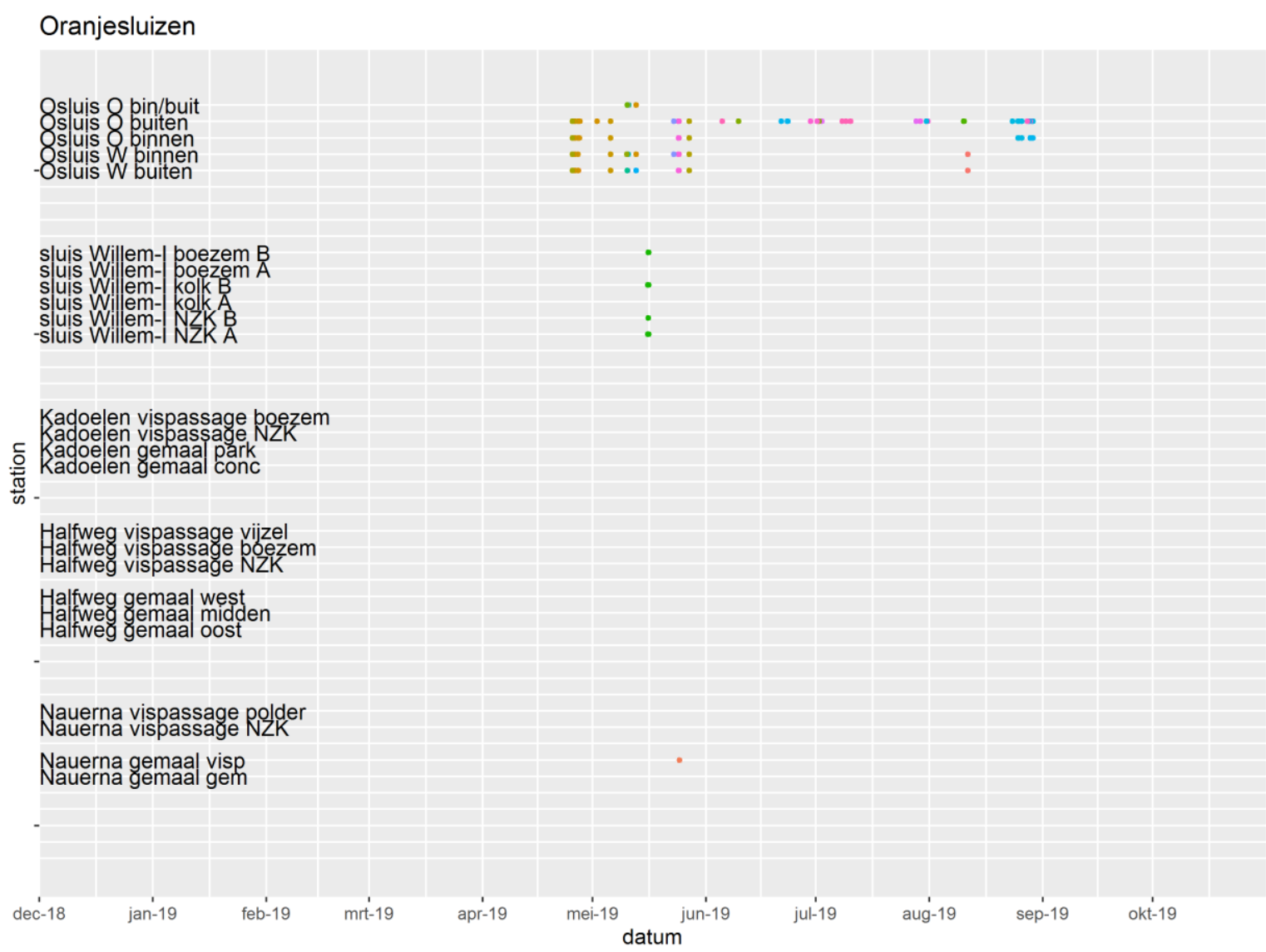

Figuur 3-17 Alle detecties op alle stations van de vissen die oorspronkelijk zijn gevangen, gemerkt en uitgezet bij de Oranjesluizen (oost-zijde en west-zijde).NB. in de figuur wordt onderscheid gemaakt in individuen met kleurcodering. Door een defect aan het systeem kan van een aantal detecties niet worden onderscheiden welke antenne de vis is gedetecteerd. In de figuur is dit aangeduid als 'Osluis O bin/buit'.

Twee van de acht brasems die zijn waargenomen bij de antennes zijn afkomstig van respectievelijk Nauerna en Kadoelen. De brasem van Nauerna is bovendien enkel aan de buitenzijde/IJ-meerzijde van de vispassage waargenomen (Figuur 3-1). Dit individu moet een andere route dan de vispassage genomen hebben om daar waargenomen te kunnen worden. Het vermoeden is dat deze brasem door de naastgelegen sluizen naar buiten is gezwommen.

Uit de voorlopige gegevens blijkt nog dat de meeste detecties plaatsvinden binnen enkele dagen na taggen. De laatste volledige passage vond bovendien plaats op 24 mei. Daarna zijn voornamelijk detecties gedaan van brasem, roofblei en blankvoorn, waarbij de laatste blankvoorn detecties afkomstig lijken van een schooltje dat tegelijk gevangen en gemerkt is.

Op 20 mei 2019 is een baars teruggevangen in de zegenvisserij (900_230000150463, gemerkt bij Kadoelen op 15 april 2019 26cm, 202gr). Deze baars is niet waargenomen bij de vispassage. 
Tabel 11 Detecties van vissen bij de vispassage van de Oranjes/uizen ( $N=45)$.

\begin{tabular}{|c|c|c|c|c|c|c|c|c|c|c|c|c|c|c|}
\hline Datum & Merklocatie & tagID & Floytag & Soort & $\begin{array}{l}\text { Lengte } \\
(\mathrm{mm})\end{array}$ & $\begin{array}{l}\text { Gewicht } \\
\text { (gr) }\end{array}$ & Geslacht & Opm. vis & Vangstlocatie & \begin{tabular}{|l|} 
west \\
binnen
\end{tabular} & \begin{tabular}{|l|} 
west \\
buiten
\end{tabular} & \begin{tabular}{|l|} 
oost \\
binnen
\end{tabular} & \begin{tabular}{|l|} 
oost \\
buiten
\end{tabular} & \begin{tabular}{|l} 
oost \\
binnen/ \\
buiten*
\end{tabular} \\
\hline \begin{tabular}{|l|l}
$3-a p r$ & $K$ \\
\end{tabular} & Kadoelen & 900_230000150255 & & Brasem & 408 & 780 & & & maalkom & $x$ & $x$ & $x$ & $x$ & \\
\hline \begin{tabular}{|l|l}
$25-a p r$ & $C$ \\
\end{tabular} & O'sluis & $900 \_230000150596$ & & Hybride & 354 & 473 & & Paaiuitslag & noord & & $x$ & & & \\
\hline \begin{tabular}{|l|c|}
$25-a p r$ & $C$ \\
\end{tabular} & O'sluis & 900_230000150601 & & Blankvoorn & 241 & 163 & & & noord & $x$ & $x$ & $x$ & $x$ & \\
\hline \begin{tabular}{|l|c}
$25-a p r$ & $C$ \\
\end{tabular} & O'sluis & 900_230000150677 & & Blankvoorn & 200 & 90 & & & noord & $x$ & $x$ & $x$ & $x$ & \\
\hline \begin{tabular}{|l|l}
$25-a p r$ & $C$ \\
\end{tabular} & O'sluis & 900_230000150704 & & Blankvoorn & 175 & 52 & & & noord & $x$ & $x$ & $x$ & $x$ & \\
\hline \begin{tabular}{|l|c|}
$25-a p r$ & $C$ \\
\end{tabular} & O'sluis & $900 \_230000150772$ & & Winde & 490 & 1552 & & & natuur oever & $x$ & $x$ & $x$ & $x$ & \\
\hline $25-a p r$ & O'sluis & $900 \_230000150777$ & & Dunlipharder & 656 & 2968 & & & natuur oever & $x$ & $x$ & $\mathrm{x}$ & $x$ & \\
\hline \begin{tabular}{|l|l}
$2-m e i$ & $N$ \\
\end{tabular} & Nauerna & $900 \_230000150807$ & & Brasem & 470 & 1285 & Man & Paaiuitslag & Kanaal & & & & $x$ & \\
\hline 10-mei & O'sluis & $900 \_230000150950$ & & Brasem & 421 & 1093 & & & zuid oost & $x$ & & & & \\
\hline 10-mei & O'sluis & $900 \_230000150951$ & 9716 & Baars & 240 & 161 & & & zuid oost & & & & $x$ & \\
\hline 10-mei & O'sluis & $900 \_230000151028$ & & Blankvoorn & 186 & 79 & & & zuid oost & $x$ & & & & \\
\hline 10-mei & O'sluis & $900 \_230000151048$ & & Blankvoorn & 164 & 47 & & & zuid oost & & & & & $x$ \\
\hline 10-mei C & O'sluis & $900 \_230000151052$ & & Brasem & 267 & 211 & & & zuid oost & $x$ & $x$ & & & \\
\hline 10-mei & O'sluis & 900_230000151095 & & Blankvoorn & 200 & 87 & & & zuid oost & $x$ & & & & $x$ \\
\hline 10-mei & O'sluis & $900 \_230000151107$ & & Blankvoorn & 164 & 47 & & & zuid oost & $x$ & $x$ & & & $x$ \\
\hline 10-mei & O'sluis & $900 \_230000151114$ & & Blankvoorn & 178 & 78 & & & zuid oost & $x$ & $x$ & & & \\
\hline 10-mei & O'sluis & $900 \_230000151127$ & & Blankvoorn & 200 & 95 & & & zuid oost & $x$ & & & & $x$ \\
\hline \begin{tabular}{|l|c|}
$10-m e i$ \\
$C$
\end{tabular} & O'sluis & 900_230000151129 & & Blankvoorn & 205 & 91 & & & zuid oost & $x$ & $x$ & & & \\
\hline 10-mei & O'sluis & 900_230000151143 & & Blankvoorn & 186 & 71 & & & zuid oost & & & $x$ & $x$ & \\
\hline \begin{tabular}{|l|l}
$10-m e i$ & \\
\end{tabular} & O'sluis & $900 \_230000151149$ & & Blankvoorn & 179 & 60 & & & zuid oost & & & $x$ & $x$ & \\
\hline 10-mei & O'sluis & $900 \_230000151150$ & & Blankvoorn & 190 & 68 & & & zuid oost & $x$ & $x$ & & & $x$ \\
\hline 10-mei & O'sluis & $900 \_230000151162$ & & Blankvoorn & 165 & 49 & & & zuid oost & $x$ & $x$ & & & \\
\hline \begin{tabular}{|l|l}
$24-m e i$ \\
\end{tabular} & O'sluis & $900 \_230000151514$ & & Brasem & 525 & 1482 & Man & Paaiuitslag & zuid oost & & & & $x$ & \\
\hline 24-mei & O'sluis & 900_230000151524 & & Brasem & 320 & 412 & & & zuid oost & $x$ & $x$ & $x$ & $x$ & \\
\hline 24-mei & O'sluis & $900 \_230000151540$ & & Blankvoorn & 200 & 100 & & & zuid oost & & & & $x$ & \\
\hline 24-mei & O'sluis & $900 \_230000151543$ & & Blankvoorn & 249 & 188 & & & zuid oost & & & & $x$ & \\
\hline 24-mei & O'sluis & $900 \_230000151545$ & & Brasem & 530 & 1558 & Man & Paaiuitslag & zuid oost & & & & $x$ & \\
\hline 24-mei & O'sluis & $900 \_230000151596$ & & Blankvoorn & 199 & 86 & & & zuid oost & $x$ & $x$ & $x$ & $x$ & \\
\hline 24-mei C & O'sluis & $900 \_230000151619$ & & Blankvoorn & 205 & 95 & & & zuid oost & $x$ & $x$ & $\mathrm{x}$ & $x$ & \\
\hline 24 & 0 & 900230000151630 & & 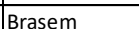 & 430 & 889 & & & $t$ & 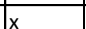 & & 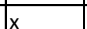 & $\mathrm{x}$ & \\
\hline
\end{tabular}

*door een defect aan het systeem kan van een aantal detecties niet worden onderscheiden welke antenne de vis is gedetecteerd. 
900_230000150692 Blankvoorn 219 mm 140 gr Oranjesluizen 25-apr
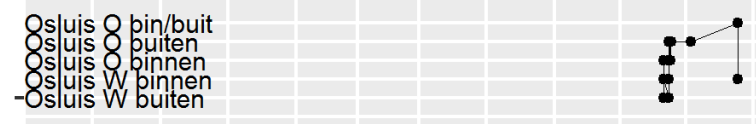

sluis Willem-| boezem $B$

suls Wi em- kolk

sluis Willem- NZK

ᄃ Kadoelen vispassage poezem

은 Kadoelen gemaal park

$\frac{\pi}{\omega}$

Halfweg vispassage vijzel

Ha|fweg vispassage vijzel
Halfweg vispassage boezem
Halfweg vispassage NZK

Halfweg gemaal west

Halfweg gemaal oost

Nauerna vispassage polder

Nauerna gemaa| visp

dec-18 jan-19 feb-19 mrt-19 apr-19 mei-19 jun-19 jul-19 aug-19 sep-19 okt-19 datum

Figuur 3-18 Voorbeeld van een blankvoorn die meerdere malen in de vispassage heen en weer is gezwommen. 


\section{$4 \quad$ Conclusies en aanbevelingen}

Deze rapportage biedt een overzicht van de experimentele opzet, het aantal gemerkte vissen en een overzicht van de eerste detecties. Daarnaast geeft het ook een eerste inzicht in de reikwijdte van de migratie van standvis in en om het NZK. Vooral brasems duiken in het hele kanaal op. Deze vissen lijken op grote schaal (10-tallen $\mathrm{km}$ ) te migreren in relatief korte tijd. De resultaten laten zien dat vissen langdurig in de buurt van de uitstroom van een gemaal blijven. Dit wordt op alle drie de locaties met een gemaal gezien. In totaal zijn er twee terugmeldingen geweest van sportvissers die snoekbaars hebben gevangen: op 25 mei een snoekbaars afkomstig van Nauerna en teruggevangen bij Nauerna en één afkomstig bij de Oranjesluizen en teruggevangen bij de Entrepothaven (Amsterdam-Rijnkanaal). Deze vissen zijn relatief in de buurt van hun merklocatie ook weer teruggevangen. Ook is in de zegenvisserij t.b.v. van het merken een baars teruggevangen afkomstig van Kadoelen en teruggevangen bij Oranjesluizen. Deze baars heeft enkele kilometers gezwommen.

In de volgende maanden zullen WMR en UVA (Oranjesluizen) detecties blijven verzamelen en de techniek controleren. Helaas zijn er meerdere voorbeelden waarbij de stroom (in onwetendheid of als gevolg van storing) was afgesloten bij detectiestations. Om deze redenen zijn er (op meer plekken) contactgegevens achtergelaten met een melding om de stekkers niet te verwijderen.

\section{Aanbevelingen}

Op de locatie Willem I-sluis zijn aan de NZK-zijde geen vissen gevangen. Doordat er veelvuldig vissen heen en weer zwemmen binnen Waterlands Boezem tussen Kadoelen en Willem I-sluis is het aan te bevelen om nogmaals bij Kadoelen te vissen en zo de testgroep te vergroten. Daarnaast is het aan te bevelen om aan de boezemzijde (verderop in het kanaal) van de Willem I-sluis te proberen grotere vissen te vangen en andere soorten dan brasem.

De vispassage bij Nauerna is relatief laat opgeleverd gedurende het onderzoek (eind april). Uit de analyse blijkt dat er slechts drie vissen de passage zijn gepasseerd. Het is onduidelijk of dit ligt aan het ontbreken van een motivatie van migratie (paaitijd was voorbij) of dat de vispassage onvoldoende attractief is. Om hier duidelijkheid in te krijgen wordt aanbevolen het onderzoek uit te breiden met meer vissen die eerder in het seizoen worden gevangen.

Bij Halfweg zijn nauwelijks vissen gevangen aan de NZK-zijde. Vrijwel alle vissen zijn afkomstig van de boezemzijde. Het is aan te bevelen hier nogmaals enkele pogingen te doen waarbij eventuele zijsloten (aan de NZK-zijde) bij Halfweg ook worden geprobeerd.

In het algemeen is het aan te bevelen om het onderzoek uit te breiden met meerdere visdagen en langere periode van detecties waarbij een volgende paaimigratie ook kan worden gevolgd (2021). Op deze manier kan ook rekening worden gehouden met de variatie in omstandigheden en kunnen migratiepatronen worden gevolgd. Zo kan, naast de vraag of vissen gebruik maken van vispassages, beter inzicht worden verkregen in de vraag of de migratiepatronen het gevolg zijn van dispersie of van gerichte paaimigratie. 


\section{$5 \quad$ Kwaliteitsborging}

Wageningen Marine Research beschikt over een ISO 9001:2015 gecertificeerd kwaliteitsmanagementsysteem. Dit certificaat is geldig tot 15 december 2021. De organisatie is gecertificeerd sinds 27 februari 2001. De certificering is uitgevoerd door DNV GL.

Het chemisch laboratorium te IJmuiden beschikt over een EN-ISO/IEC 17025:2017 accreditatie voor testlaboratoria met nummer L097. Deze accreditatie is geldig tot 1 april 2021 en is voor het eerst verleend op 27 maart 1997; deze accreditatie is verleend door de Raad voor Accreditatie. Het chemisch laboratorium heeft hierdoor aangetoond in staat te zijn op technisch bekwame wijze valide resultaten te leveren en te werken volgens de ISO17025 norm. De scope (L097) met de geaccrediteerde analysemethoden is te vinden op de website van de Raad voor Accreditatie (www.rva.nl).

Op grond van deze accreditatie is het kwaliteitskenmerk $\mathrm{Q}$ toegekend aan de resultaten van die componenten die op de scope staan vermeld, mits aan alle kwaliteitseisen is voldaan. Het kwaliteitskenmerk Q staat vermeld in de tabellen met de onderzoeksresultaten. Indien het kwaliteitskenmerk $Q$ niet staat vermeld is de reden hiervan vermeld.

De kwaliteit van de analysemethoden wordt op verschillende manieren gewaarborgd. De juistheid van de analysemethoden wordt regelmatig getoetst door deelname aan ringonderzoeken waaronder die georganiseerd door QUASIMEME. Indien geen ringonderzoek voorhanden is, wordt een tweede lijnscontrole uitgevoerd. Tevens wordt bij iedere meetserie een eerstelijnscontrole uitgevoerd. Naast de lijnscontroles wordende volgende algemene kwaliteitscontroles uitgevoerd:

- Blanco onderzoek.

- Terugvinding (recovery).

- $\quad$ Interne standaard voor borging opwerkmethode.

- Injectie standard.

- Gevoeligheid.

Bovenstaande controles staan beschreven in Wageningen Marine Research werkvoorschrift ISW 2.10.2.105.

Indien gewenst kunnen gegevens met betrekking tot de prestatiekenmerken van de analysemethoden bij het chemisch laboratorium worden opgevraagd.

Indien sprake is van onbeheerste kwaliteit worden passende maatregelen genomen. 


\section{Literatuur}

Griffioen, A. B., D. Burggraaf, O. A. v. Keeken, and H. V. Winter. 2019a. Evaluatie vismigratievoorziening Kleine Sluis IJmuiden voor schieraal. Wageningen Marine Research, IJmuiden.

Griffioen, A. B., and H. V. Winter. 2017. Schieraal uittrek Noordzeekanaal 2016 - een merk-terugvangst experiment met fuikvangsten. Wageningen University \& Research Rapport C050/17.

Griffioen, A. B., and H. V. Winter. 2018. Glasaal bij het sluiscomplex van IJmuiden - Een pilotstudie ter voorbereiding van eenonderzoek naar het gedrag, voorkomen en passage van glasaal bij het sluiscomplex te IJmuiden., Wageningen University \& Research rapport C001/18.

Griffioen, A. B., H. V. Winter, O. A. v. Keeken, and B. v. Houten. 2019b. Intrek van glasaal en driedoornige stekelbaars in het Noordzeekanaal voorjaar 2018. Wageningen Marine Research rapport C054/19.

Kroes, M., P. Philipsen, and H. Wanningen. 2018. Nederland Leeft Met Vismigratie 2017. Actualisatie landelijke database vismigratie., In opdracht van Rijkswaterstaat, Sportvisserij Nederland, Wageningen Marine Research/Ministerie van LNV, Planbureau voor de leefomgeving.

Winter, H. V., O. A. v. Keeken, J. Brockötter, and A. B. Griffioen. 2019. Migratiepatronen en -knelpunten tijdens uittrek van schieraal uit Noordzeekanaal en ommelanden, inclusief Markermeer. Wageningen Marine Research rapport C053/19. 


\section{Verantwoording}

Rapport C126/19

Projectnummer: 4316100136

Dit rapport is met grote zorgvuldigheid tot stand gekomen. De wetenschappelijke kwaliteit is intern getoetst door een collega-onderzoeker en het verantwoordelijk lid van het managementteam van Wageningen Marine Research

Akkoord:

J. Vrooman, MSc

Collega Onderzoeker

Handtekening:

Datum:

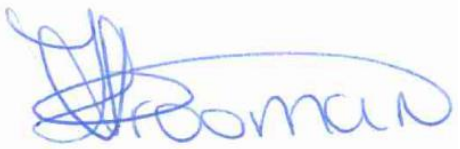

11 december 2019

Akkoord:

Drs. J. Asjes

Manager Integratie

Handtekening:

Datum:

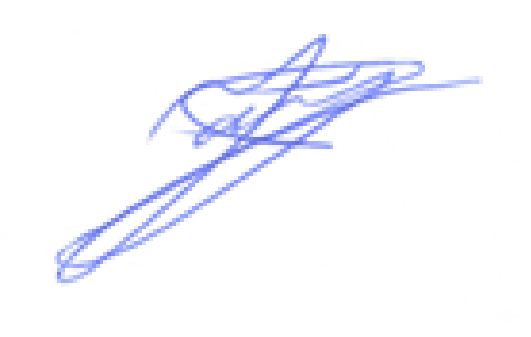

11 december 2019 


\section{Bijlage 1 Detecties gemalen}

Tabel A gedetecteerde vissen bij gemaal Nauerna gesorteerd naar locatie waar de vissen zijn gemerkt. NB. Tabel is inclusief detecties op dag van uitzet.

\begin{tabular}{|c|c|c|c|c|c|c|}
\hline Datum & Locatie gemerkt & tag ID & Soort & $\begin{array}{l}\text { Lengte } \\
(\mathrm{mm})\end{array}$ & $\begin{array}{l}\text { Gewicht } \\
\text { (gr) }\end{array}$ & Gemaal \\
\hline 26-mrt-19 & Halfweg & 900_230000150181 & Blankvoorn & 254 & 225 & $x$ \\
\hline 26-mrt-19 & Halfweg & 900_230000150197 & Blankvoorn & 223 & 144 & $x$ \\
\hline $5 / 29 / 2019$ & Halfweg & 900_230000151778 & Brasem & 309 & 302 & $x$ \\
\hline $5 / 29 / 2019$ & Halfweg & 900_230000151794 & Brasem & 326 & 407 & $x$ \\
\hline $5 / 29 / 2019$ & Halfweg & 900_230000151844 & Brasem & 279 & 240 & $x$ \\
\hline 19-mrt-19 & Kadoelen & 900_230000150074 & Brasem & 464 & 1240 & $x$ \\
\hline 19-mrt-19 & Kadoelen & 900_230000150130 & Brasem & 461 & 1142 & $x$ \\
\hline $4 / 3 / 2019$ & Kadoelen & 900_230000150318 & Brasem & 564 & 1247 & $x$ \\
\hline $4 / 3 / 2019$ & Kadoelen & 900_230000150367 & Brasem & 474 & 1360 & $x$ \\
\hline $5 / 2 / 2019$ & Nauerna & 900_230000150782 & Brasem & 351 & 512 & $x$ \\
\hline $5 / 2 / 2019$ & Nauerna & 900_230000150785 & Brasem & 253 & 161 & $x$ \\
\hline $5 / 2 / 2019$ & Nauerna & 900_230000150788 & Brasem & 502 & 1544 & $x$ \\
\hline $5 / 2 / 2019$ & Nauerna & 900_230000150790 & Brasem & 444 & 1042 & $x$ \\
\hline $5 / 2 / 2019$ & Nauerna & 900_230000150791 & Brasem & 213 & 88 & $x$ \\
\hline $5 / 2 / 2019$ & Nauerna & 900_230000150792 & Brasem & 509 & 1554 & $x$ \\
\hline $5 / 2 / 2019$ & Nauerna & 900_230000150793 & Brasem & 473 & 1140 & $x$ \\
\hline $5 / 2 / 2019$ & Nauerna & 900_230000150796 & Brasem & 509 & 1496 & $x$ \\
\hline $5 / 2 / 2019$ & Nauerna & 900_230000150797 & Brasem & 444 & 1073 & $x$ \\
\hline $5 / 2 / 2019$ & Nauerna & 900_230000150798 & Brasem & 475 & 1245 & $x$ \\
\hline $5 / 2 / 2019$ & Nauerna & 900_230000150799 & Brasem & 441 & 922 & $x$ \\
\hline $5 / 2 / 2019$ & Nauerna & 900_230000150801 & Brasem & 483 & 1520 & $x$ \\
\hline $5 / 2 / 2019$ & Nauerna & 900_230000150802 & Brasem & 524 & 1690 & $x$ \\
\hline $5 / 2 / 2019$ & Nauerna & 900_230000150803 & Brasem & 500 & 1572 & $x$ \\
\hline $5 / 2 / 2019$ & Nauerna & 900_230000150805 & Brasem & 510 & 1760 & $x$ \\
\hline $5 / 2 / 2019$ & Nauerna & 900_230000150806 & Brasem & 472 & 1325 & $x$ \\
\hline $5 / 2 / 2019$ & Nauerna & 900_230000150807 & Brasem & 470 & 1285 & $x$ \\
\hline $5 / 2 / 2019$ & Nauerna & 900_230000150809 & Brasem & 427 & 906 & $x$ \\
\hline $5 / 2 / 2019$ & Nauerna & 900_230000150810 & Brasem & 405 & 993 & $x$ \\
\hline $5 / 2 / 2019$ & Nauerna & 900_230000150811 & Brasem & 411 & 850 & $x$ \\
\hline $5 / 2 / 2019$ & Nauerna & 900_230000150812 & Brasem & 476 & 1262 & $x$ \\
\hline $5 / 2 / 2019$ & Nauerna & 900_230000150815 & Brasem & 415 & 900 & $x$ \\
\hline $5 / 2 / 2019$ & Nauerna & 900_230000150816 & Brasem & 420 & 969 & $x$ \\
\hline $5 / 2 / 2019$ & Nauerna & 900_230000150822 & Brasem & 431 & 1082 & $x$ \\
\hline $5 / 2 / 2019$ & Nauerna & 900_230000150824 & Brasem & 392 & 766 & $x$ \\
\hline $5 / 2 / 2019$ & Nauerna & 900_230000150826 & Brasem & 456 & 1268 & $x$ \\
\hline $5 / 2 / 2019$ & Nauerna & 900_230000150829 & Snoekbaars & 426 & 540 & $x$ \\
\hline $5 / 2 / 2019$ & Nauerna & 900_230000150830 & Brasem & 241 & 152 & $x$ \\
\hline $5 / 2 / 2019$ & Nauerna & 900_230000150837 & Paling & 537 & 95 & $x$ \\
\hline $5 / 2 / 2019$ & Nauerna & 900_230000150838 & Brasem & 436 & 999 & $x$ \\
\hline
\end{tabular}




\begin{tabular}{|c|c|c|c|c|c|c|}
\hline Datum & Locatie gemerkt & tag ID & Soort & $\begin{array}{l}\text { Lengte } \\
(\mathrm{mm})\end{array}$ & $\begin{array}{l}\text { Gewicht } \\
\text { (gr) }\end{array}$ & Gemaal \\
\hline $5 / 2 / 2019$ & Nauerna & 900_230000150839 & Brasem & 430 & 880 & $x$ \\
\hline $5 / 2 / 2019$ & Nauerna & 900_230000150840 & Brasem & 575 & 1208 & $x$ \\
\hline $5 / 2 / 2019$ & Nauerna & 900_230000150841 & Brasem & 478 & 1405 & $x$ \\
\hline $5 / 2 / 2019$ & Nauerna & 900_230000150843 & Brasem & 489 & 1510 & $x$ \\
\hline $5 / 2 / 2019$ & Nauerna & 900_230000150845 & Brasem & 534 & 1980 & $x$ \\
\hline $5 / 2 / 2019$ & Nauerna & 900_230000150848 & Brasem & 499 & 1473 & $x$ \\
\hline $5 / 2 / 2019$ & Nauerna & 900_230000150849 & Brasem & 505 & 1625 & $x$ \\
\hline $5 / 2 / 2019$ & Nauerna & 900_230000150850 & Brasem & 480 & 1254 & $x$ \\
\hline $5 / 2 / 2019$ & Nauerna & 900_230000150851 & Brasem & 405 & 807 & $x$ \\
\hline $5 / 2 / 2019$ & Nauerna & 900_230000150852 & Brasem & 491 & 1457 & $x$ \\
\hline $5 / 2 / 2019$ & Nauerna & 900_230000150853 & Brasem & 462 & 1038 & $x$ \\
\hline $5 / 2 / 2019$ & Nauerna & 900_230000150854 & Baars & 153 & 42 & $x$ \\
\hline $5 / 14 / 2019$ & Nauerna & 900_230000151239 & Snoekbaars & 561 & 1649 & $x$ \\
\hline $5 / 14 / 2019$ & Nauerna & 900_230000151241 & Brasem & 263 & 194 & $x$ \\
\hline $5 / 14 / 2019$ & Nauerna & 900_230000151242 & Snoekbaars & 402 & 439 & $x$ \\
\hline $5 / 14 / 2019$ & Nauerna & 900_230000151243 & Snoekbaars & 541 & 1259 & $x$ \\
\hline $5 / 14 / 2019$ & Nauerna & 900_230000151245 & Snoekbaars & 291 & 205 & $x$ \\
\hline $5 / 14 / 2019$ & Nauerna & 900_230000151246 & Snoekbaars & 371 & 356 & $x$ \\
\hline $5 / 14 / 2019$ & Nauerna & 900_230000151249 & Snoekbaars & 270 & 139 & $x$ \\
\hline $5 / 14 / 2019$ & Nauerna & 900_230000151251 & Brasem & 276 & 230 & $x$ \\
\hline $5 / 14 / 2019$ & Nauerna & 900_230000151252 & Snoekbaars & 295 & 190 & $x$ \\
\hline $5 / 14 / 2019$ & Nauerna & 900_230000151254 & Brasem & 345 & 392 & $x$ \\
\hline $5 / 14 / 2019$ & Nauerna & 900_230000151255 & Brasem & 469 & 1166 & $x$ \\
\hline $5 / 14 / 2019$ & Nauerna & 900_230000151257 & Brasem & 473 & 975 & $x$ \\
\hline $5 / 14 / 2019$ & Nauerna & 900_230000151258 & Brasem & 224 & 124 & $x$ \\
\hline $5 / 14 / 2019$ & Nauerna & 900_230000151259 & Karper & 454 & 1500 & $x$ \\
\hline $5 / 14 / 2019$ & Nauerna & 900_230000151262 & Brasem & 220 & 116 & $x$ \\
\hline $5 / 14 / 2019$ & Nauerna & 900_230000151263 & Brasem & 237 & 129 & $x$ \\
\hline $5 / 14 / 2019$ & Nauerna & 900_230000151264 & Brasem & 413 & 844 & $x$ \\
\hline $5 / 14 / 2019$ & Nauerna & 900_230000151266 & Kolblei & 266 & 291 & $x$ \\
\hline $5 / 14 / 2019$ & Nauerna & 900_230000151267 & Brasem & 435 & 981 & $x$ \\
\hline $5 / 28 / 2019$ & Nauerna & 900_230000151638 & Snoekbaars & 530 & 1120 & $x$ \\
\hline $5 / 28 / 2019$ & Nauerna & 900_230000151645 & Snoekbaars & 364 & 340 & $x$ \\
\hline $5 / 28 / 2019$ & Nauerna & 900_230000151646 & Snoekbaars & 277 & 155 & $x$ \\
\hline $5 / 28 / 2019$ & Nauerna & 900_230000151658 & Snoekbaars & 611 & 1878 & $x$ \\
\hline $5 / 28 / 2019$ & Nauerna & 900_230000151660 & Snoekbaars & 496 & 180 & $x$ \\
\hline $5 / 28 / 2019$ & Nauerna & 900_230000151662 & Snoekbaars & 316 & 230 & $\mathrm{x}$ \\
\hline $5 / 28 / 2019$ & Nauerna & 900_230000151663 & Kolblei & 200 & 111 & $x$ \\
\hline $5 / 28 / 2019$ & Nauerna & 900_230000151666 & Brasem & 281 & 246 & $x$ \\
\hline $5 / 28 / 2019$ & Nauerna & 900_230000151667 & Brasem & 495 & 1258 & $x$ \\
\hline $5 / 28 / 2019$ & Nauerna & 900_230000151669 & Brasem & 238 & 124 & $x$ \\
\hline $5 / 28 / 2019$ & Nauerna & 900_230000151673 & Bot & 240 & 165 & $x$ \\
\hline $5 / 28 / 2019$ & Nauerna & 900_230000151674 & Brasem & 459 & 1276 & $x$ \\
\hline $5 / 28 / 2019$ & Nauerna & 900_230000151675 & Kolblei & 171 & 59 & $x$ \\
\hline $5 / 28 / 2019$ & Nauerna & 900_230000151677 & Brasem & 293 & 263 & $x$ \\
\hline $5 / 28 / 2019$ & Nauerna & 900_230000151681 & Brasem & 299 & 277 & $\mathrm{x}$ \\
\hline
\end{tabular}




\begin{tabular}{|l|l|l|l|l|l|l|}
\hline Datum & Locatie gemerkt & tag ID & Soort & $\begin{array}{l}\text { Lengte } \\
\text { (mm) }\end{array}$ & $\begin{array}{l}\text { Gewicht } \\
\text { (gr) }\end{array}$ & Gemaal \\
\hline $5 / 28 / 2019$ & Nauerna & $900 \_230000151684$ & Kolblei & 159 & 54 & $\mathrm{x}$ \\
\hline $5 / 28 / 2019$ & Nauerna & $900 \_230000151686$ & Kolblei & 237 & 170 & $\mathrm{x}$ \\
\hline $5 / 28 / 2019$ & Nauerna & $900 \_230000151687$ & Brasem & 474 & 1426 & $\mathrm{x}$ \\
\hline $5 / 28 / 2019$ & Nauerna & $900 \_230000151688$ & Snoekbaars & 564 & 1496 & $\mathrm{x}$ \\
\hline $5 / 28 / 2019$ & Nauerna & $900 \_230000151690$ & Bot & 221 & 116 & $\mathrm{x}$ \\
\hline 4/25/2019 & Oranjesluizen & $900 \_230000150586$ & Brasem & 294 & 280 & $\mathrm{x}$ \\
\hline
\end{tabular}


Tabel B gedetecteerde vissen bij gemaal Halfweg gesorteerd naar locatie waar de vissen zijn gemerkt. NB. Tabel is inclusief detecties op dag van uitzet.

\begin{tabular}{|c|c|c|c|c|c|c|}
\hline Datum & Locatie gemerkt & $\operatorname{tag}$ ID & Soort & $\begin{array}{l}\text { Lengte } \\
(\mathrm{mm})\end{array}$ & $\begin{array}{l}\text { Gewicht } \\
\text { (gr) }\end{array}$ & Gemaal \\
\hline 26-mrt-19 & Halfweg & 900_230000150171 & Snoekbaars & 532 & 1354 & $x$ \\
\hline 26-mrt-19 & Halfweg & 900_230000150190 & Baars & 236 & 172 & $x$ \\
\hline 26-mrt-19 & Halfweg & 900_230000150199 & Snoek & 762 & & $x$ \\
\hline $4 / 8 / 2019$ & Halfweg & 900_230000150459 & Snoekbaars & 590 & 1696 & $x$ \\
\hline $4 / 30 / 2019$ & Halfweg & $900 \_230000150778$ & Snoekbaars & 584 & 1610 & $x$ \\
\hline $5 / 16 / 2019$ & Halfweg & 900_230000151270 & Brasem & 406 & 90 & $x$ \\
\hline $5 / 16 / 2019$ & Halfweg & 900_230000151334 & Blankvoorn & 179 & 71 & $x$ \\
\hline $5 / 16 / 2019$ & Halfweg & 900_230000151335 & Blankvoorn & 202 & 92 & $x$ \\
\hline $5 / 16 / 2019$ & Halfweg & 900_230000151336 & Blankvoorn & 175 & 65 & $x$ \\
\hline $5 / 16 / 2019$ & Halfweg & 900_230000151339 & Brasem & 273 & 210 & $x$ \\
\hline $5 / 16 / 2019$ & Halfweg & 900_230000151341 & Brasem & 411 & 928 & $x$ \\
\hline $5 / 16 / 2019$ & Halfweg & 900_230000151342 & Brasem & 385 & 648 & $x$ \\
\hline $5 / 16 / 2019$ & Halfweg & 900_230000151343 & Brasem & 249 & 175 & $x$ \\
\hline $5 / 16 / 2019$ & Halfweg & 900_230000151344 & Brasem & 304 & 329 & $x$ \\
\hline $5 / 16 / 2019$ & Halfweg & 900_230000151345 & Baars & 181 & 62 & $x$ \\
\hline $5 / 16 / 2019$ & Halfweg & 900_230000151346 & Brasem & 339 & 466 & $x$ \\
\hline $5 / 16 / 2019$ & Halfweg & $900 \_230000151348$ & Blankvoorn & 160 & 45 & $x$ \\
\hline $5 / 16 / 2019$ & Halfweg & 900_230000151349 & Blankvoorn & 252 & 201 & $x$ \\
\hline $5 / 16 / 2019$ & Halfweg & $900 \_230000151350$ & Blankvoorn & 227 & 142 & $x$ \\
\hline $5 / 16 / 2019$ & Halfweg & 900_230000151351 & Brasem & 302 & 304 & $x$ \\
\hline $5 / 16 / 2019$ & Halfweg & $900 \_230000151353$ & Blankvoorn & 189 & 86 & $x$ \\
\hline $5 / 16 / 2019$ & Halfweg & 900_230000151354 & Blankvoorn & 220 & 130 & $x$ \\
\hline $5 / 16 / 2019$ & Halfweg & 900_230000151355 & Blankvoorn & 225 & 135 & $x$ \\
\hline $5 / 16 / 2019$ & Halfweg & 900_230000151356 & Blankvoorn & 287 & 312 & $x$ \\
\hline $5 / 29 / 2019$ & Halfweg & 900_230000151691 & Blankvoorn & 173 & 65 & $x$ \\
\hline $5 / 29 / 2019$ & Halfweg & 900_230000151693 & Blankvoorn & 243 & 191 & $x$ \\
\hline $5 / 29 / 2019$ & Halfweg & 900_230000151695 & Brasem & 363 & 514 & $x$ \\
\hline $5 / 29 / 2019$ & Halfweg & $900 \_230000151697$ & Blankvoorn & 190 & 82 & $x$ \\
\hline $5 / 29 / 2019$ & Halfweg & 900_230000151698 & Blankvoorn & 218 & 134 & $x$ \\
\hline $5 / 29 / 2019$ & Halfweg & 900_230000151703 & Brasem & 200 & 83 & $x$ \\
\hline $5 / 29 / 2019$ & Halfweg & 900_230000151705 & Blankvoorn & 186 & 86 & $x$ \\
\hline $5 / 29 / 2019$ & Halfweg & 900_230000151706 & Blankvoorn & 202 & 105 & $x$ \\
\hline $5 / 29 / 2019$ & Halfweg & $900 \_230000151707$ & Blankvoorn & 266 & 256 & $x$ \\
\hline $5 / 29 / 2019$ & Halfweg & 900_230000151709 & Blankvoorn & 183 & 82 & $x$ \\
\hline $5 / 29 / 2019$ & Halfweg & 900_230000151710 & Blankvoorn & 182 & 63 & $x$ \\
\hline $5 / 29 / 2019$ & Halfweg & 900_230000151711 & Blankvoorn & 176 & 75 & $x$ \\
\hline $5 / 29 / 2019$ & Halfweg & 900_230000151714 & Brasem & 386 & 714 & $x$ \\
\hline $5 / 29 / 2019$ & Halfweg & 900_230000151715 & Brasem & 392 & 780 & $x$ \\
\hline $5 / 29 / 2019$ & Halfweg & $900 \_230000151717$ & Blankvoorn & 197 & 108 & $x$ \\
\hline $5 / 29 / 2019$ & Halfweg & 900_230000151718 & Blankvoorn & 108 & 52 & $x$ \\
\hline $5 / 29 / 2019$ & Halfweg & 900_230000151719 & Blankvoorn & 171 & 50 & $x$ \\
\hline $5 / 29 / 2019$ & Halfweg & 900_230000151720 & Brasem & 365 & 570 & $x$ \\
\hline $5 / 29 / 2019$ & Halfweg & 900_230000151721 & Brasem & 259 & 180 & $x$ \\
\hline $5 / 29 / 2019$ & Halfweg & $900 \quad 230000151723$ & Brasem & 247 & 150 & $x$ \\
\hline
\end{tabular}




\begin{tabular}{|c|c|c|c|c|c|c|}
\hline Datum & Locatie gemerkt & tag ID & Soort & $\begin{array}{l}\text { Lengte } \\
(\mathrm{mm})\end{array}$ & $\begin{array}{l}\text { Gewicht } \\
\text { (gr) }\end{array}$ & Gemaal \\
\hline $5 / 29 / 2019$ & Halfweg & 900_230000151724 & Brasem & 384 & 709 & $x$ \\
\hline $5 / 29 / 2019$ & Halfweg & 900_230000151725 & Brasem & 386 & 680 & $x$ \\
\hline $5 / 29 / 2019$ & Halfweg & 900_230000151726 & Snoek & 463 & 642 & $x$ \\
\hline $5 / 29 / 2019$ & Halfweg & 900_230000151727 & Blankvoorn & 163 & 62 & $x$ \\
\hline $5 / 29 / 2019$ & Halfweg & 900_230000151728 & Blankvoorn & 193 & 96 & $x$ \\
\hline $5 / 29 / 2019$ & Halfweg & 900_230000151729 & Blankvoorn & 190 & 92 & $x$ \\
\hline $5 / 29 / 2019$ & Halfweg & 900_230000151730 & Brasem & 261 & 186 & $x$ \\
\hline $5 / 29 / 2019$ & Halfweg & $900 \_230000151731$ & Brasem & 207 & 90 & $x$ \\
\hline $5 / 29 / 2019$ & Halfweg & $900 \_230000151732$ & Blankvoorn & 208 & 130 & $x$ \\
\hline $5 / 29 / 2019$ & Halfweg & $900 \_230000151733$ & Brasem & 384 & 688 & $x$ \\
\hline $5 / 29 / 2019$ & Halfweg & 900_230000151734 & Brasem & 389 & 609 & $x$ \\
\hline $5 / 29 / 2019$ & Halfweg & 900_230000151735 & Brasem & 305 & 327 & $x$ \\
\hline $5 / 29 / 2019$ & Halfweg & 900_230000151736 & Blankvoorn & 175 & 83 & $x$ \\
\hline $5 / 29 / 2019$ & Halfweg & 900_230000151738 & Brasem & 360 & 607 & $x$ \\
\hline $5 / 29 / 2019$ & Halfweg & 900_230000151739 & Baars & 380 & 814 & $x$ \\
\hline $5 / 29 / 2019$ & Halfweg & $900 \_230000151740$ & Blankvoorn & 226 & 157 & $x$ \\
\hline $5 / 29 / 2019$ & Halfweg & 900_230000151741 & Brasem & 232 & 136 & $x$ \\
\hline $5 / 29 / 2019$ & Halfweg & 900_230000151742 & Brasem & 263 & 188 & $x$ \\
\hline $5 / 29 / 2019$ & Halfweg & 900_230000151744 & Blankvoorn & 210 & 135 & $x$ \\
\hline $5 / 29 / 2019$ & Halfweg & $900 \_230000151745$ & Brasem & 266 & 198 & $x$ \\
\hline $5 / 29 / 2019$ & Halfweg & 900_230000151747 & Blankvoorn & 206 & 114 & $x$ \\
\hline $5 / 29 / 2019$ & Halfweg & 900_230000151749 & Brasem & 339 & 408 & $x$ \\
\hline $5 / 29 / 2019$ & Halfweg & 900_230000151752 & Blankvoorn & 195 & 96 & $x$ \\
\hline $5 / 29 / 2019$ & Halfweg & 900_230000151753 & Blankvoorn & 183 & 78 & $x$ \\
\hline $5 / 29 / 2019$ & Halfweg & 900_230000151754 & Blankvoorn & 157 & 50 & $x$ \\
\hline $5 / 29 / 2019$ & Halfweg & 900_230000151755 & Brasem & 396 & 767 & $x$ \\
\hline $5 / 29 / 2019$ & Halfweg & 900_230000151758 & Baars & 211 & 102 & $x$ \\
\hline $5 / 29 / 2019$ & Halfweg & 900_230000151759 & Brasem & 272 & 256 & $x$ \\
\hline $5 / 29 / 2019$ & Halfweg & 900_230000151761 & Baars & 360 & 759 & $x$ \\
\hline $5 / 29 / 2019$ & Halfweg & 900_230000151762 & Blankvoorn & 183 & 75 & $x$ \\
\hline $5 / 29 / 2019$ & Halfweg & 900_230000151764 & Blankvoorn & 239 & 163 & $x$ \\
\hline $5 / 29 / 2019$ & Halfweg & 900_230000151765 & Blankvoorn & 198 & 94 & $x$ \\
\hline $5 / 29 / 2019$ & Halfweg & 900_230000151766 & Blankvoorn & 181 & 73 & $x$ \\
\hline $5 / 29 / 2019$ & Halfweg & 900_230000151767 & Brasem & 231 & 121 & $x$ \\
\hline $5 / 29 / 2019$ & Halfweg & 900_230000151769 & Blankvoorn & 170 & 69 & $x$ \\
\hline $5 / 29 / 2019$ & Halfweg & 900_230000151771 & Snoekbaars & 700 & 2119 & $x$ \\
\hline $5 / 29 / 2019$ & Halfweg & 900_230000151773 & Brasem & 399 & 771 & $x$ \\
\hline $5 / 29 / 2019$ & Halfweg & 900_230000151774 & Brasem & 495 & 1381 & $x$ \\
\hline $5 / 29 / 2019$ & Halfweg & 900_230000151775 & Brasem & 276 & 270 & $x$ \\
\hline $5 / 29 / 2019$ & Halfweg & 900_230000151777 & Brasem & 363 & 572 & $x$ \\
\hline $5 / 29 / 2019$ & Halfweg & 900_230000151779 & Brasem & 316 & 334 & $x$ \\
\hline $5 / 29 / 2019$ & Halfweg & 900_230000151780 & Brasem & 267 & 215 & $x$ \\
\hline $5 / 29 / 2019$ & Halfweg & 900_230000151781 & Brasem & 232 & 113 & $x$ \\
\hline $5 / 29 / 2019$ & Halfweg & 900_230000151782 & Brasem & 231 & 126 & $x$ \\
\hline $5 / 29 / 2019$ & Halfweg & 900_230000151784 & Brasem & 468 & 1367 & $x$ \\
\hline $5 / 29 / 2019$ & Halfweg & 900_230000151786 & Brasem & 425 & 720 & $x$ \\
\hline
\end{tabular}




\begin{tabular}{|c|c|c|c|c|c|c|}
\hline Datum & Locatie gemerkt & tag ID & Soort & $\begin{array}{l}\text { Lengte } \\
(\mathrm{mm})\end{array}$ & $\begin{array}{l}\text { Gewicht } \\
\text { (gr) }\end{array}$ & Gemaal \\
\hline $5 / 29 / 2019$ & Halfweg & 900_230000151789 & Blankvoorn & 199 & 101 & $x$ \\
\hline $5 / 29 / 2019$ & Halfweg & 900_230000151790 & Kolblei & 191 & 89 & $x$ \\
\hline $5 / 29 / 2019$ & Halfweg & 900_230000151791 & Brasem & 215 & 104 & $x$ \\
\hline $5 / 29 / 2019$ & Halfweg & 900_230000151792 & Brasem & 402 & 726 & $x$ \\
\hline $5 / 29 / 2019$ & Halfweg & 900_230000151793 & Brasem & 138 & 148 & $x$ \\
\hline $5 / 29 / 2019$ & Halfweg & 900_230000151794 & Brasem & 326 & 407 & $x$ \\
\hline $5 / 29 / 2019$ & Halfweg & 900_230000151796 & Brasem & 258 & 181 & $x$ \\
\hline $5 / 29 / 2019$ & Halfweg & 900_230000151797 & Brasem & 270 & 205 & $x$ \\
\hline $5 / 29 / 2019$ & Halfweg & 900_230000151798 & Brasem & 402 & 712 & $x$ \\
\hline $5 / 29 / 2019$ & Halfweg & 900_230000151799 & Brasem & 484 & 1402 & $x$ \\
\hline $5 / 29 / 2019$ & Halfweg & 900_230000151800 & Blankvoorn & 196 & 104 & $x$ \\
\hline $5 / 29 / 2019$ & Halfweg & 900_230000151802 & Blankvoorn & 216 & 140 & $x$ \\
\hline $5 / 29 / 2019$ & Halfweg & 900_230000151803 & Brasem & 280 & 247 & $x$ \\
\hline $5 / 29 / 2019$ & Halfweg & 900_230000151804 & Brasem & 231 & 133 & $x$ \\
\hline $5 / 29 / 2019$ & Halfweg & 900_230000151805 & Blankvoorn & 177 & 79 & $x$ \\
\hline $5 / 29 / 2019$ & Halfweg & 900_230000151807 & Brasem & 261 & 185 & $x$ \\
\hline $5 / 29 / 2019$ & Halfweg & 900_230000151809 & Brasem & 101 & 115 & $x$ \\
\hline $5 / 29 / 2019$ & Halfweg & 900_230000151810 & Brasem & 257 & 191 & $x$ \\
\hline $5 / 29 / 2019$ & Halfweg & 900_230000151812 & Brasem & 385 & 626 & $x$ \\
\hline $5 / 29 / 2019$ & Halfweg & $900 \_230000151813$ & Brasem & 267 & 221 & $x$ \\
\hline $5 / 29 / 2019$ & Halfweg & 900_230000151814 & Blankvoorn & 181 & 65 & $x$ \\
\hline $5 / 29 / 2019$ & Halfweg & 900_230000151815 & Brasem & 206 & 83 & $x$ \\
\hline $5 / 29 / 2019$ & Halfweg & 900_230000151816 & Blankvoorn & 231 & 125 & $x$ \\
\hline $5 / 29 / 2019$ & Halfweg & 900_230000151817 & Blankvoorn & 164 & 68 & $x$ \\
\hline $5 / 29 / 2019$ & Halfweg & 900_230000151818 & Blankvoorn & 230 & 145 & $x$ \\
\hline $5 / 29 / 2019$ & Halfweg & 900_230000151819 & Blankvoorn & 161 & 50 & $x$ \\
\hline $5 / 29 / 2019$ & Halfweg & 900_230000151820 & Brasem & 308 & 363 & $x$ \\
\hline $5 / 29 / 2019$ & Halfweg & 900_230000151821 & Brasem & 343 & 537 & $x$ \\
\hline $5 / 29 / 2019$ & Halfweg & 900_230000151822 & Brasem & 269 & 205 & $x$ \\
\hline $5 / 29 / 2019$ & Halfweg & 900_230000151823 & Brasem & 366 & 620 & $x$ \\
\hline $5 / 29 / 2019$ & Halfweg & 900_230000151824 & Brasem & 236 & 346 & $x$ \\
\hline $5 / 29 / 2019$ & Halfweg & 900_230000151827 & Brasem & 231 & 133 & $x$ \\
\hline $5 / 29 / 2019$ & Halfweg & 900_230000151830 & Brasem & 248 & 161 & $x$ \\
\hline $5 / 29 / 2019$ & Halfweg & 900_230000151833 & Brasem & 242 & 172 & $x$ \\
\hline $5 / 29 / 2019$ & Halfweg & 900_230000151834 & Blankvoorn & 217 & 125 & $x$ \\
\hline $5 / 29 / 2019$ & Halfweg & 900_230000151838 & Brasem & 264 & 185 & $x$ \\
\hline $5 / 29 / 2019$ & Halfweg & 900_230000151839 & Brasem & 280 & 199 & $x$ \\
\hline $5 / 29 / 2019$ & Halfweg & 900_230000151844 & Brasem & 279 & 240 & $x$ \\
\hline $5 / 29 / 2019$ & Halfweg & 900_230000151845 & Brasem & 365 & 547 & $x$ \\
\hline $5 / 29 / 2019$ & Halfweg & 900_230000151846 & Brasem & 237 & 137 & $x$ \\
\hline $5 / 29 / 2019$ & Halfweg & 900_230000151848 & Blankvoorn & 164 & 54 & $x$ \\
\hline $5 / 29 / 2019$ & Halfweg & 900_230000151849 & Brasem & 285 & 262 & $x$ \\
\hline $5 / 29 / 2019$ & Halfweg & 900_230000151850 & Brasem & 449 & 1082 & $x$ \\
\hline $5 / 29 / 2019$ & Halfweg & 900_230000151851 & Brasem & 409 & 854 & $x$ \\
\hline $5 / 29 / 2019$ & Halfweg & 900_230000151852 & Brasem & 409 & 805 & $x$ \\
\hline $5 / 29 / 2019$ & Halfweg & 900_230000151853 & Brasem & 457 & 1206 & $x$ \\
\hline
\end{tabular}




\begin{tabular}{|c|c|c|c|c|c|c|}
\hline Datum & Locatie gemerkt & tag ID & Soort & $\begin{array}{l}\text { Lengte } \\
(\mathrm{mm})\end{array}$ & $\begin{array}{l}\text { Gewicht } \\
\text { (gr) }\end{array}$ & Gemaal \\
\hline $5 / 29 / 2019$ & Halfweg & 900_230000151856 & Blankvoorn & 230 & 150 & $x$ \\
\hline $5 / 29 / 2019$ & Halfweg & 900_230000151857 & Brasem & 271 & 223 & $x$ \\
\hline $5 / 29 / 2019$ & Halfweg & 900_230000151858 & Brasem & 277 & 254 & $x$ \\
\hline $5 / 29 / 2019$ & Halfweg & 900_230000151859 & Blankvoorn & 224 & 143 & $x$ \\
\hline $5 / 29 / 2019$ & Halfweg & 900_230000151860 & Blankvoorn & 217 & 122 & $x$ \\
\hline $5 / 29 / 2019$ & Halfweg & 900_230000151861 & Blankvoorn & 215 & 131 & $x$ \\
\hline $5 / 29 / 2019$ & Halfweg & 900_230000151862 & Blankvoorn & 211 & 114 & $x$ \\
\hline $5 / 29 / 2019$ & Halfweg & $900 \_230000151863$ & Brasem & 235 & 125 & $x$ \\
\hline $5 / 29 / 2019$ & Halfweg & 900_230000151864 & Brasem & 247 & 144 & $x$ \\
\hline $5 / 29 / 2019$ & Halfweg & $900 \_230000151865$ & Brasem & 377 & 566 & $x$ \\
\hline $5 / 29 / 2019$ & Halfweg & 900_230000151866 & Brasem & 436 & 1019 & $x$ \\
\hline $5 / 29 / 2019$ & Halfweg & 900_230000151867 & Brasem & 345 & 565 & $x$ \\
\hline $5 / 29 / 2019$ & Halfweg & 900_230000151868 & Blankvoorn & 275 & 289 & $x$ \\
\hline $5 / 29 / 2019$ & Halfweg & 900_230000151869 & Brasem & 365 & 517 & $x$ \\
\hline $5 / 29 / 2019$ & Halfweg & 900_230000151870 & Brasem & 400 & 770 & $x$ \\
\hline $5 / 29 / 2019$ & Halfweg & 900_230000151871 & Brasem & 477 & 1226 & $x$ \\
\hline $5 / 29 / 2019$ & Halfweg & 900_230000151872 & Ruisvoorn & 182 & 82 & $x$ \\
\hline $5 / 29 / 2019$ & Halfweg & 900_230000151873 & Brasem & 419 & 791 & $x$ \\
\hline $5 / 29 / 2019$ & Halfweg & 900_230000151875 & Brasem & 411 & 829 & $x$ \\
\hline $5 / 29 / 2019$ & Halfweg & $900 \_230000151876$ & Brasem & 365 & 668 & $x$ \\
\hline $5 / 29 / 2019$ & Halfweg & 900_230000151878 & Brasem & 280 & 251 & $x$ \\
\hline $5 / 29 / 2019$ & Halfweg & 900_230000151879 & Brasem & 269 & 208 & $x$ \\
\hline $5 / 29 / 2019$ & Halfweg & 900_230000151880 & Brasem & 210 & 93 & $x$ \\
\hline $5 / 29 / 2019$ & Halfweg & 900_230000151882 & Brasem & 286 & 266 & $x$ \\
\hline $5 / 29 / 2019$ & Halfweg & 900_230000151883 & Brasem & 451 & 1164 & $x$ \\
\hline $5 / 29 / 2019$ & Halfweg & 900_230000151884 & Brasem & 249 & 170 & $x$ \\
\hline $5 / 29 / 2019$ & Halfweg & 900_230000151886 & Blankvoorn & 241 & 200 & $x$ \\
\hline $5 / 29 / 2019$ & Halfweg & 900_230000151887 & Brasem & 422 & 888 & $x$ \\
\hline $5 / 29 / 2019$ & Halfweg & 900_230000151888 & Brasem & 238 & 155 & $x$ \\
\hline $5 / 29 / 2019$ & Halfweg & 900_230000151889 & Brasem & 253 & 179 & $x$ \\
\hline $5 / 29 / 2019$ & Halfweg & 900_230000151891 & Brasem & 433 & 1091 & $x$ \\
\hline $5 / 29 / 2019$ & Halfweg & 900_230000151895 & Blankvoorn & 172 & 71 & $x$ \\
\hline $5 / 29 / 2019$ & Halfweg & 900_230000151897 & Brasem & 339 & 458 & $x$ \\
\hline 19-mrt-19 & Kadoelen & 900_230000150064 & Brasem & 461 & 1098 & $x$ \\
\hline $4 / 3 / 2019$ & Kadoelen & 900_230000150224 & Brasem & 496 & 1430 & $x$ \\
\hline $4 / 3 / 2019$ & Kadoelen & 900_230000150353 & Brasem & 439 & 973 & $x$ \\
\hline $4 / 3 / 2019$ & Kadoelen & 900_230000150367 & Brasem & 474 & 1360 & $x$ \\
\hline $4 / 3 / 2019$ & Kadoelen & 900_230000150402 & Brasem & 503 & 1593 & $x$ \\
\hline $5 / 2 / 2019$ & Nauerna & 900_230000150841 & Brasem & 478 & 1405 & $x$ \\
\hline $5 / 2 / 2019$ & Nauerna & 900_230000150853 & Brasem & 462 & 1038 & $x$ \\
\hline $5 / 7 / 2019$ & Nauerna & $900 \_230000150869$ & Brasem & 413 & 880 & $\mathrm{x}$ \\
\hline
\end{tabular}


Tabel C gedetecteerde vissen bij gemaal Kadoelen gesorteerd naar locatie waar de vissen zijn gemerkt. NB. Tabel is inclusief detecties op dag van uitzet.

\begin{tabular}{|c|c|c|c|c|c|c|}
\hline Datum & Locatie gemerkt & tag ID & Soort & $\begin{array}{l}\text { Lengte } \\
(\mathrm{mm})\end{array}$ & \begin{tabular}{|l|} 
Gewicht \\
(gr)
\end{tabular} & Gemaal \\
\hline 19-mrt-19 & Kadoelen & 900_230000150008 & Brasem & 487 & 1318 & $x$ \\
\hline 19-mrt-19 & Kadoelen & 900_230000150009 & Brasem & 606 & 3160 & $x$ \\
\hline 19-mrt-19 & Kadoelen & $900 \_230000150010$ & Brasem & 435 & 977 & $x$ \\
\hline 19-mrt-19 & Kadoelen & 900_230000150011 & Brasem & 481 & 1587 & $x$ \\
\hline 19-mrt-19 & Kadoelen & 900_230000150012 & Brasem & 585 & 3200 & $x$ \\
\hline 19-mrt-19 & Kadoelen & 900_230000150013 & Brasem & 580 & 2457 & $x$ \\
\hline 19-mrt-19 & Kadoelen & 900_230000150014 & Brasem & 466 & 1404 & $x$ \\
\hline 19-mrt-19 & Kadoelen & 900_230000150015 & Brasem & 570 & 1291 & $x$ \\
\hline 19-mrt-19 & Kadoelen & 900_230000150016 & Brasem & 472 & 1464 & $x$ \\
\hline 19-mrt-19 & Kadoelen & 900_230000150017 & Brasem & 458 & 984 & $x$ \\
\hline 19-mrt-19 & Kadoelen & 900_230000150018 & Brasem & 513 & 1760 & $x$ \\
\hline 19-mrt-19 & Kadoelen & 900_230000150019 & Brasem & 421 & 982 & $x$ \\
\hline 19-mrt-19 & Kadoelen & 900_230000150020 & Brasem & 515 & 1734 & $x$ \\
\hline 19-mrt-19 & Kadoelen & 900_230000150022 & Brasem & 509 & 1598 & $x$ \\
\hline 19-mrt-19 & Kadoelen & 900_230000150024 & Brasem & 586 & 1875 & $x$ \\
\hline 19-mrt-19 & Kadoelen & 900_230000150027 & Brasem & 277 & 1402 & $x$ \\
\hline 19-mrt-19 & Kadoelen & 900_230000150028 & Brasem & 490 & 1639 & $x$ \\
\hline 19-mrt-19 & Kadoelen & 900_230000150029 & Brasem & 486 & 1425 & $x$ \\
\hline 19-mrt-19 & Kadoelen & 900_230000150031 & Brasem & 440 & 990 & $x$ \\
\hline 19-mrt-19 & Kadoelen & 900_230000150033 & Brasem & 460 & 1202 & $x$ \\
\hline 19-mrt-19 & Kadoelen & 900_230000150040 & Brasem & 499 & 1476 & $x$ \\
\hline 19-mrt-19 & Kadoelen & 900_230000150041 & Brasem & 465 & 1183 & $x$ \\
\hline 19-mrt-19 & Kadoelen & 900_230000150042 & Brasem & 533 & 1993 & $x$ \\
\hline 19-mrt-19 & Kadoelen & 900_230000150043 & Brasem & 572 & 2576 & $x$ \\
\hline 19-mrt-19 & Kadoelen & 900_230000150044 & Brasem & 480 & 1360 & $x$ \\
\hline 19-mrt-19 & Kadoelen & 900_230000150045 & Brasem & 431 & 952 & $x$ \\
\hline $19-m r t-19$ & Kadoelen & 900_230000150046 & Brasem & 486 & 1470 & $x$ \\
\hline 19-mrt-19 & Kadoelen & $900 \_230000150048$ & Brasem & 488 & 1270 & $x$ \\
\hline 19-mrt-19 & Kadoelen & 900_230000150049 & Brasem & 483 & 1558 & $x$ \\
\hline 19-mrt-19 & Kadoelen & 900_230000150050 & Brasem & 457 & 1236 & $x$ \\
\hline 19-mrt-19 & Kadoelen & 900_230000150051 & Brasem & 435 & 1030 & $x$ \\
\hline 19-mrt-19 & Kadoelen & 900_230000150053 & Brasem & 451 & 1065 & $x$ \\
\hline 19-mrt-19 & Kadoelen & 900_230000150055 & Brasem & 498 & 1490 & $x$ \\
\hline 19-mrt-19 & Kadoelen & 900_230000150056 & Brasem & 460 & 1152 & $x$ \\
\hline 19-mrt-19 & Kadoelen & 900_230000150057 & Brasem & 421 & 1661 & $x$ \\
\hline 19-mrt-19 & Kadoelen & 900_230000150059 & Brasem & 455 & 1010 & $x$ \\
\hline 19-mrt-19 & Kadoelen & 900_230000150060 & Brasem & 458 & 1030 & $x$ \\
\hline 19-mrt-19 & Kadoelen & 900_230000150062 & Brasem & 505 & 1420 & $x$ \\
\hline 19-mrt-19 & Kadoelen & 900_230000150063 & Brasem & 435 & 968 & $x$ \\
\hline 19-mrt-19 & Kadoelen & 900_230000150064 & Brasem & 461 & 1098 & $x$ \\
\hline 19-mrt-19 & Kadoelen & 900_230000150065 & Snoek & 891 & & $x$ \\
\hline 19-mrt-19 & Kadoelen & 900_230000150067 & Brasem & 440 & 1023 & $x$ \\
\hline 19-mrt-19 & Kadoelen & 900_230000150070 & Brasem & 463 & 1250 & $x$ \\
\hline 19-mrt-19 & Kadoelen & 900_230000150071 & Brasem & 500 & 1428 & $x$ \\
\hline
\end{tabular}




\begin{tabular}{|c|c|c|c|c|c|c|}
\hline Datum & Locatie gemerkt & tag ID & Soort & \begin{tabular}{|l} 
Lengte \\
$(\mathrm{mm})$
\end{tabular} & $\begin{array}{l}\text { Gewicht } \\
\text { (gr) }\end{array}$ & Gemaal \\
\hline 19-mrt-19 & Kadoelen & 900_230000150072 & Brasem & 492 & 1557 & $x$ \\
\hline $19-m r t-19$ & Kadoelen & $900 \_230000150073$ & Brasem & 481 & 1420 & $x$ \\
\hline 19-mrt-19 & Kadoelen & $900 \_230000150075$ & Brasem & 475 & 1337 & $x$ \\
\hline 19-mrt-19 & Kadoelen & $900 \_230000150077$ & Brasem & 480 & 1210 & $x$ \\
\hline $19-m r t-19$ & Kadoelen & 900_230000150078 & Brasem & 467 & 1360 & $x$ \\
\hline 19-mrt-19 & Kadoelen & $900 \_230000150079$ & Brasem & 461 & 1290 & $x$ \\
\hline 19-mrt-19 & Kadoelen & 900_230000150080 & Brasem & 531 & 1688 & $x$ \\
\hline $19-m r t-19$ & Kadoelen & 900_230000150081 & Brasem & 516 & 1792 & $x$ \\
\hline 19-mrt-19 & Kadoelen & 900_230000150082 & Brasem & 471 & 1236 & $x$ \\
\hline 19-mrt-19 & Kadoelen & $900 \_230000150083$ & Brasem & 610 & 3097 & $x$ \\
\hline $19-m r t-19$ & Kadoelen & 900_230000150084 & Brasem & 530 & 1852 & $x$ \\
\hline 19-mrt-19 & Kadoelen & $900 \_230000150087$ & Baars & 366 & 702 & $x$ \\
\hline 19-mrt-19 & Kadoelen & $900 \_230000150088$ & Brasem & 519 & 1481 & $x$ \\
\hline $19-m r t-19$ & Kadoelen & $900 \_230000150089$ & Snoekbaars & 562 & 1426 & $x$ \\
\hline 19-mrt-19 & Kadoelen & $900 \_230000150090$ & Blankvoorn & 296 & 332 & $x$ \\
\hline 19-mrt-19 & Kadoelen & 900_230000150091 & Baars & 431 & 1340 & $x$ \\
\hline 19-mrt-19 & Kadoelen & 900_230000150094 & Brasem & 515 & 1590 & $x$ \\
\hline 19-mrt-19 & Kadoelen & 900_230000150096 & Brasem & 531 & 1805 & $x$ \\
\hline 19-mrt-19 & Kadoelen & 900_230000150097 & Brasem & 510 & 1375 & $x$ \\
\hline $19-m r t-19$ & Kadoelen & 900_230000150099 & Brasem & 555 & 2400 & $x$ \\
\hline 19-mrt-19 & Kadoelen & $900 \_230000150101$ & Brasem & 472 & 1214 & $x$ \\
\hline 19-mrt-19 & Kadoelen & 900_230000150102 & Brasem & 470 & 1240 & $x$ \\
\hline 19-mrt-19 & Kadoelen & 900_230000150104 & Brasem & 431 & 830 & $x$ \\
\hline 19-mrt-19 & Kadoelen & 900_230000150108 & Brasem & 451 & 1018 & $x$ \\
\hline $19-m r t-19$ & Kadoelen & 900_230000150109 & Brasem & 451 & 1080 & $x$ \\
\hline 19-mrt-19 & Kadoelen & 900_230000150110 & Brasem & 496 & 1664 & $x$ \\
\hline 19-mrt-19 & Kadoelen & $900 \_230000150111$ & Brasem & 425 & 736 & $x$ \\
\hline 19-mrt-19 & Kadoelen & 900_230000150112 & Brasem & 531 & 1855 & $x$ \\
\hline $19-m r t-19$ & Kadoelen & $900 \_230000150113$ & Brasem & 432 & 966 & $x$ \\
\hline 19-mrt-19 & Kadoelen & $900 \_230000150114$ & Brasem & 508 & 1995 & $x$ \\
\hline $19-m r t-19$ & Kadoelen & 900_230000150118 & Brasem & 587 & 2445 & $x$ \\
\hline 19-mrt-19 & Kadoelen & $900 \_230000150120$ & Brasem & 500 & 1478 & $x$ \\
\hline 19-mrt-19 & Kadoelen & $900 \_230000150121$ & Brasem & 475 & 1170 & $x$ \\
\hline 19-mrt-19 & Kadoelen & 900_230000150123 & Brasem & 508 & 1465 & $x$ \\
\hline 19-mrt-19 & Kadoelen & $900 \_230000150124$ & Brasem & 457 & 1034 & $x$ \\
\hline 19-mrt-19 & Kadoelen & $900 \_230000150126$ & Brasem & 491 & 1392 & $x$ \\
\hline $19-m r t-19$ & Kadoelen & 900_230000150128 & Brasem & 490 & 1488 & $x$ \\
\hline 19-mrt-19 & Kadoelen & $900 \_230000150129$ & Brasem & 418 & 897 & $x$ \\
\hline 19-mrt-19 & Kadoelen & 900_230000150131 & Brasem & 485 & 1352 & $x$ \\
\hline 19-mrt-19 & Kadoelen & 900_230000150132 & Brasem & 426 & 950 & $x$ \\
\hline 19-mrt-19 & Kadoelen & $900 \_230000150134$ & Brasem & 532 & 2220 & $x$ \\
\hline 19-mrt-19 & Kadoelen & $900 \_230000150135$ & Brasem & 465 & 1175 & $x$ \\
\hline 19-mrt-19 & Kadoelen & 900_230000150136 & Brasem & 421 & 960 & $x$ \\
\hline 19-mrt-19 & Kadoelen & $900 \_230000150137$ & Brasem & 512 & 1741 & $x$ \\
\hline 19-mrt-19 & Kadoelen & $900 \_230000150138$ & Brasem & 400 & 825 & $x$ \\
\hline $19-m r t-19$ & Kadoelen & $900 \quad 230000150139$ & Brasem & 501 & 1620 & $x$ \\
\hline
\end{tabular}




\begin{tabular}{|c|c|c|c|c|c|c|}
\hline Datum & Locatie gemerkt & $\operatorname{tag} I D$ & Soort & $\begin{array}{l}\text { Lengte } \\
(\mathrm{mm})\end{array}$ & \begin{tabular}{|l|} 
Gewicht \\
(gr)
\end{tabular} & Gemaal \\
\hline 19-mrt-19 & Kadoelen & 900_230000150143 & Brasem & 480 & 1353 & $x$ \\
\hline 19-mrt-19 & Kadoelen & 900_230000150144 & Brasem & 426 & 903 & $x$ \\
\hline 19-mrt-19 & Kadoelen & 900_230000150146 & Brasem & 538 & 2190 & $x$ \\
\hline 19-mrt-19 & Kadoelen & 900_230000150147 & Brasem & 471 & 1307 & $x$ \\
\hline 19-mrt-19 & Kadoelen & 900_230000150149 & Brasem & 470 & 1192 & $x$ \\
\hline 19-mrt-19 & Kadoelen & 900_230000150151 & Brasem & 452 & 1342 & $x$ \\
\hline 19-mrt-19 & Kadoelen & 900_230000150152 & Brasem & 545 & 2413 & $x$ \\
\hline 19-mrt-19 & Kadoelen & 900_230000150153 & Brasem & 465 & 1224 & $x$ \\
\hline 19-mrt-19 & Kadoelen & 900_230000150154 & Brasem & 495 & 1240 & $x$ \\
\hline 19-mrt-19 & Kadoelen & 900_230000150155 & Brasem & 510 & 1604 & $x$ \\
\hline 19-mrt-19 & Kadoelen & 900_230000150156 & Brasem & 510 & 1277 & $x$ \\
\hline 19-mrt-19 & Kadoelen & 900_230000150157 & Brasem & 481 & 1505 & $x$ \\
\hline 19-mrt-19 & Kadoelen & 900_230000150158 & Brasem & 520 & 1680 & $x$ \\
\hline 19-mrt-19 & Kadoelen & 900_230000150159 & Brasem & 461 & 1046 & $x$ \\
\hline 19-mrt-19 & Kadoelen & $900 \_230000150161$ & Brasem & 496 & 1404 & $x$ \\
\hline 19-mrt-19 & Kadoelen & 900_230000150162 & Brasem & 480 & 1177 & $x$ \\
\hline 19-mrt-19 & Kadoelen & 900_230000150163 & Brasem & 451 & 1177 & $x$ \\
\hline 19-mrt-19 & Kadoelen & 900_230000150164 & Brasem & 491 & 1380 & $x$ \\
\hline $4 / 3 / 2019$ & Kadoelen & 900_230000150205 & Brasem & 496 & 1318 & $x$ \\
\hline $4 / 3 / 2019$ & Kadoelen & 900_230000150207 & Brasem & 434 & 976 & $x$ \\
\hline $4 / 3 / 2019$ & Kadoelen & $900 \_230000150208$ & Brasem & 498 & 1998 & $x$ \\
\hline $4 / 3 / 2019$ & Kadoelen & 900_230000150209 & Brasem & 421 & 930 & $x$ \\
\hline $4 / 3 / 2019$ & Kadoelen & 900_230000150210 & Brasem & 459 & 1150 & $x$ \\
\hline $4 / 3 / 2019$ & Kadoelen & 900_230000150211 & Brasem & 416 & 994 & $x$ \\
\hline $4 / 3 / 2019$ & Kadoelen & 900_230000150212 & Brasem & 436 & 814 & $x$ \\
\hline $4 / 3 / 2019$ & Kadoelen & 900_230000150213 & Brasem & 413 & 969 & $x$ \\
\hline $4 / 3 / 2019$ & Kadoelen & 900_230000150215 & Brasem & 431 & 1099 & $x$ \\
\hline $4 / 3 / 2019$ & Kadoelen & 900_230000150217 & Brasem & 436 & 1138 & $x$ \\
\hline $4 / 3 / 2019$ & Kadoelen & $900 \_230000150219$ & Brasem & 526 & 1844 & $x$ \\
\hline $4 / 3 / 2019$ & Kadoelen & 900_230000150220 & Brasem & 467 & 1126 & $x$ \\
\hline $4 / 3 / 2019$ & Kadoelen & 900_230000150221 & Brasem & 513 & 1414 & $x$ \\
\hline $4 / 3 / 2019$ & Kadoelen & 900_230000150222 & Brasem & 472 & 989 & $x$ \\
\hline $4 / 3 / 2019$ & Kadoelen & 900_230000150223 & Brasem & 507 & 1842 & $x$ \\
\hline 4/3/2019 & Kadoelen & 900_230000150224 & Brasem & 496 & 1430 & $x$ \\
\hline $4 / 3 / 2019$ & Kadoelen & 900_230000150226 & Brasem & 467 & 1214 & $x$ \\
\hline $4 / 3 / 2019$ & Kadoelen & $900 \_230000150228$ & Brasem & 432 & 949 & $x$ \\
\hline $4 / 3 / 2019$ & Kadoelen & 900_230000150229 & Brasem & 491 & 1408 & $x$ \\
\hline $4 / 3 / 2019$ & Kadoelen & 900_230000150230 & Brasem & 461 & 1406 & $x$ \\
\hline $4 / 3 / 2019$ & Kadoelen & 900_230000150231 & Brasem & 462 & 1203 & $x$ \\
\hline $4 / 3 / 2019$ & Kadoelen & 900_230000150232 & Brasem & 524 & 1641 & $x$ \\
\hline $4 / 3 / 2019$ & Kadoelen & 900_230000150233 & Brasem & 507 & 1501 & $x$ \\
\hline $4 / 3 / 2019$ & Kadoelen & 900_230000150234 & Brasem & 448 & 1211 & $x$ \\
\hline $4 / 3 / 2019$ & Kadoelen & 900_230000150235 & Brasem & 462 & 1338 & $x$ \\
\hline $4 / 3 / 2019$ & Kadoelen & $900 \_230000150236$ & Brasem & 448 & 1107 & $x$ \\
\hline $4 / 3 / 2019$ & Kadoelen & 900_230000150237 & Brasem & 490 & 1390 & $x$ \\
\hline $4 / 3 / 2019$ & Kadoelen & $900 \quad 230000150238$ & Brasem & 415 & 824 & $x$ \\
\hline
\end{tabular}




\begin{tabular}{|c|c|c|c|c|c|c|}
\hline Datum & Locatie gemerkt & tag ID & Soort & \begin{tabular}{|l|} 
Lengte \\
$(\mathrm{mm})$
\end{tabular} & \begin{tabular}{|l|} 
Gewicht \\
(gr)
\end{tabular} & Gemaal \\
\hline $4 / 3 / 2019$ & Kadoelen & 900_230000150239 & Brasem & 426 & 1105 & $x$ \\
\hline $4 / 3 / 2019$ & Kadoelen & 900_230000150241 & Brasem & 543 & 2031 & $x$ \\
\hline $4 / 3 / 2019$ & Kadoelen & 900_230000150242 & Brasem & 480 & 1465 & $x$ \\
\hline $4 / 3 / 2019$ & Kadoelen & 900_230000150243 & Brasem & 489 & 765 & $x$ \\
\hline $4 / 3 / 2019$ & Kadoelen & 900_230000150244 & Brasem & 517 & 1883 & $x$ \\
\hline $4 / 3 / 2019$ & Kadoelen & 900_230000150245 & Brasem & 499 & 1373 & $x$ \\
\hline $4 / 3 / 2019$ & Kadoelen & 900_230000150247 & Brasem & 475 & 1259 & $x$ \\
\hline $4 / 3 / 2019$ & Kadoelen & 900_230000150248 & Brasem & 439 & 1113 & $x$ \\
\hline $4 / 3 / 2019$ & Kadoelen & 900_230000150249 & Brasem & 500 & 1535 & $x$ \\
\hline $4 / 3 / 2019$ & Kadoelen & 900_230000150250 & Brasem & 409 & 774 & $x$ \\
\hline $4 / 3 / 2019$ & Kadoelen & 900_230000150251 & Brasem & 456 & 1249 & $x$ \\
\hline $4 / 3 / 2019$ & Kadoelen & 900_230000150252 & Brasem & 502 & 1403 & $x$ \\
\hline $4 / 3 / 2019$ & Kadoelen & 900_230000150254 & Brasem & 359 & 500 & $x$ \\
\hline $4 / 3 / 2019$ & Kadoelen & 900_230000150255 & Brasem & 408 & 780 & $x$ \\
\hline $4 / 3 / 2019$ & Kadoelen & $900 \_230000150257$ & Brasem & 430 & 838 & $x$ \\
\hline $4 / 3 / 2019$ & Kadoelen & 900_230000150258 & Brasem & 466 & 1374 & $x$ \\
\hline $4 / 3 / 2019$ & Kadoelen & 900_230000150259 & Brasem & 441 & 1189 & $x$ \\
\hline $4 / 3 / 2019$ & Kadoelen & 900_230000150261 & Brasem & 482 & 1471 & $x$ \\
\hline $4 / 3 / 2019$ & Kadoelen & 900_230000150262 & Brasem & 440 & 1021 & $x$ \\
\hline $4 / 3 / 2019$ & Kadoelen & $900 \_230000150263$ & Brasem & 441 & 910 & $x$ \\
\hline $4 / 3 / 2019$ & Kadoelen & $900 \_230000150264$ & Brasem & 465 & 1145 & $\mathrm{x}$ \\
\hline $4 / 3 / 2019$ & Kadoelen & 900_230000150265 & Brasem & 473 & 1241 & $x$ \\
\hline $4 / 3 / 2019$ & Kadoelen & 900_230000150266 & Brasem & 496 & 1393 & $x$ \\
\hline $4 / 3 / 2019$ & Kadoelen & 900_230000150268 & Brasem & 347 & 441 & $x$ \\
\hline $4 / 3 / 2019$ & Kadoelen & 900_230000150269 & Brasem & 401 & 755 & $x$ \\
\hline $4 / 3 / 2019$ & Kadoelen & $900 \_230000150271$ & Brasem & 473 & 1277 & $x$ \\
\hline $4 / 3 / 2019$ & Kadoelen & 900_230000150272 & Brasem & 431 & 986 & $\mathrm{x}$ \\
\hline $4 / 3 / 2019$ & Kadoelen & 900_230000150273 & Brasem & 440 & 939 & $x$ \\
\hline $4 / 3 / 2019$ & Kadoelen & $900 \_230000150274$ & Brasem & 533 & 2234 & $x$ \\
\hline $4 / 3 / 2019$ & Kadoelen & $900 \_230000150275$ & Brasem & 496 & 1574 & $x$ \\
\hline $4 / 3 / 2019$ & Kadoelen & 900_230000150276 & Brasem & 437 & 1139 & $x$ \\
\hline $4 / 3 / 2019$ & Kadoelen & 900_230000150277 & Brasem & 472 & 1338 & $x$ \\
\hline $4 / 3 / 2019$ & Kadoelen & 900_230000150278 & Brasem & 393 & 758 & $x$ \\
\hline $4 / 3 / 2019$ & Kadoelen & 900_230000150279 & Brasem & 432 & 913 & $x$ \\
\hline $4 / 3 / 2019$ & Kadoelen & $900 \_230000150280$ & Brasem & 530 & 1830 & $x$ \\
\hline $4 / 3 / 2019$ & Kadoelen & 900_230000150281 & Brasem & 421 & 868 & $\mathrm{x}$ \\
\hline $4 / 3 / 2019$ & Kadoelen & 900_230000150283 & Brasem & 456 & 1155 & $x$ \\
\hline $4 / 3 / 2019$ & Kadoelen & $900 \_230000150285$ & Brasem & 433 & 1079 & $x$ \\
\hline $4 / 3 / 2019$ & Kadoelen & 900_230000150286 & Brasem & 481 & 1371 & $x$ \\
\hline $4 / 3 / 2019$ & Kadoelen & 900_230000150287 & Brasem & 482 & 1326 & $x$ \\
\hline $4 / 3 / 2019$ & Kadoelen & $900 \_230000150288$ & Brasem & 456 & 1418 & $x$ \\
\hline $4 / 3 / 2019$ & Kadoelen & 900_230000150289 & Brasem & 501 & 1391 & $x$ \\
\hline $4 / 3 / 2019$ & Kadoelen & 900_230000150291 & Brasem & 434 & 868 & $x$ \\
\hline $4 / 3 / 2019$ & Kadoelen & $900 \_230000150293$ & Brasem & 444 & 1017 & $x$ \\
\hline $4 / 3 / 2019$ & Kadoelen & 900_230000150294 & Brasem & 431 & 923 & $x$ \\
\hline $4 / 3 / 2019$ & Kadoelen & 900230000150296 & Brasem & 462 & 1308 & $x$ \\
\hline
\end{tabular}




\begin{tabular}{|c|c|c|c|c|c|c|}
\hline Datum & Locatie gemerkt & tag ID & Soort & $\begin{array}{l}\text { Lengte } \\
(\mathrm{mm})\end{array}$ & \begin{tabular}{|l|} 
Gewicht \\
(gr)
\end{tabular} & Gemaal \\
\hline $4 / 3 / 2019$ & Kadoelen & 900_230000150297 & Brasem & 504 & 1730 & $x$ \\
\hline $4 / 3 / 2019$ & Kadoelen & 900_230000150298 & Brasem & 461 & 1059 & $x$ \\
\hline 4/3/2019 & Kadoelen & 900_230000150299 & Brasem & 412 & 808 & $x$ \\
\hline $4 / 3 / 2019$ & Kadoelen & 900_230000150300 & Brasem & 450 & 1113 & $x$ \\
\hline $4 / 3 / 2019$ & Kadoelen & 900_230000150301 & Brasem & 423 & 802 & $x$ \\
\hline $4 / 3 / 2019$ & Kadoelen & 900_230000150302 & Brasem & 544 & 3211 & $x$ \\
\hline $4 / 3 / 2019$ & Kadoelen & 900_230000150303 & Brasem & 530 & 1895 & $x$ \\
\hline $4 / 3 / 2019$ & Kadoelen & 900_230000150304 & Brasem & 417 & 894 & $x$ \\
\hline $4 / 3 / 2019$ & Kadoelen & 900_230000150305 & Brasem & 513 & 1743 & $x$ \\
\hline $4 / 3 / 2019$ & Kadoelen & 900_230000150306 & Brasem & 471 & 1410 & $x$ \\
\hline $4 / 3 / 2019$ & Kadoelen & 900_230000150307 & Brasem & 516 & 1357 & $x$ \\
\hline $4 / 3 / 2019$ & Kadoelen & 900_230000150308 & Brasem & 500 & 1918 & $x$ \\
\hline $4 / 3 / 2019$ & Kadoelen & 900_230000150309 & Brasem & 570 & 2302 & $x$ \\
\hline $4 / 3 / 2019$ & Kadoelen & 900_230000150311 & Brasem & 393 & 701 & $x$ \\
\hline $4 / 3 / 2019$ & Kadoelen & $900 \_230000150313$ & Brasem & 448 & 1132 & $x$ \\
\hline $4 / 3 / 2019$ & Kadoelen & 900_230000150314 & Brasem & 563 & 2231 & $x$ \\
\hline $4 / 3 / 2019$ & Kadoelen & 900_230000150315 & Brasem & 504 & 1395 & $x$ \\
\hline $4 / 3 / 2019$ & Kadoelen & 900_230000150316 & Brasem & 486 & 1353 & $x$ \\
\hline $4 / 3 / 2019$ & Kadoelen & 900_230000150317 & Brasem & 365 & 607 & $x$ \\
\hline $4 / 3 / 2019$ & Kadoelen & $900 \_230000150318$ & Brasem & 564 & 1247 & $x$ \\
\hline $4 / 3 / 2019$ & Kadoelen & 900_230000150319 & Brasem & 434 & 997 & $x$ \\
\hline $4 / 3 / 2019$ & Kadoelen & 900_230000150320 & Brasem & 521 & 1723 & $x$ \\
\hline $4 / 3 / 2019$ & Kadoelen & 900_230000150321 & Brasem & 556 & 2281 & $x$ \\
\hline $4 / 3 / 2019$ & Kadoelen & 900_230000150322 & Brasem & 491 & 1518 & $x$ \\
\hline $4 / 3 / 2019$ & Kadoelen & 900_230000150323 & Brasem & 453 & 1172 & $x$ \\
\hline $4 / 3 / 2019$ & Kadoelen & 900_230000150324 & Brasem & 457 & 1116 & $x$ \\
\hline 4/3/2019 & Kadoelen & 900_230000150325 & Brasem & 415 & 825 & $x$ \\
\hline $4 / 3 / 2019$ & Kadoelen & 900_230000150326 & Brasem & 501 & 1678 & $x$ \\
\hline $4 / 3 / 2019$ & Kadoelen & $900 \_230000150327$ & Brasem & 453 & 1267 & $x$ \\
\hline $4 / 3 / 2019$ & Kadoelen & 900_230000150328 & Brasem & 387 & 743 & $x$ \\
\hline $4 / 3 / 2019$ & Kadoelen & 900_230000150330 & Brasem & 502 & 1812 & $x$ \\
\hline $4 / 3 / 2019$ & Kadoelen & 900_230000150331 & Brasem & 507 & 1570 & $x$ \\
\hline $4 / 3 / 2019$ & Kadoelen & 900_230000150332 & Brasem & 526 & 1130 & $x$ \\
\hline $4 / 3 / 2019$ & Kadoelen & 900_230000150333 & Brasem & 515 & 1726 & $x$ \\
\hline $4 / 3 / 2019$ & Kadoelen & 900_230000150334 & Brasem & 461 & 960 & $x$ \\
\hline $4 / 3 / 2019$ & Kadoelen & 900_230000150335 & Brasem & 423 & 1002 & $x$ \\
\hline $4 / 3 / 2019$ & Kadoelen & 900_230000150336 & Brasem & 454 & 1095 & $x$ \\
\hline 4/3/2019 & Kadoelen & 900_230000150337 & Brasem & 543 & 2436 & $x$ \\
\hline $4 / 3 / 2019$ & Kadoelen & 900_230000150338 & Brasem & 510 & 1814 & $x$ \\
\hline 4/3/2019 & Kadoelen & 900_230000150339 & Brasem & 421 & 877 & $x$ \\
\hline $4 / 3 / 2019$ & Kadoelen & 900_230000150341 & Brasem & 467 & 1349 & $x$ \\
\hline $4 / 3 / 2019$ & Kadoelen & 900_230000150342 & Brasem & 454 & 1134 & $x$ \\
\hline 4/3/2019 & Kadoelen & 900_230000150343 & Brasem & 447 & 1205 & $x$ \\
\hline 4/3/2019 & Kadoelen & $900 \_230000150347$ & Brasem & 511 & 1750 & $x$ \\
\hline $4 / 3 / 2019$ & Kadoelen & 900_230000150348 & Brasem & 462 & 1318 & $x$ \\
\hline $4 / 3 / 2019$ & Kadoelen & $900 \quad 230000150349$ & Brasem & 451 & 1229 & $x$ \\
\hline
\end{tabular}




\begin{tabular}{|c|c|c|c|c|c|c|}
\hline Datum & Locatie gemerkt & tag ID & Soort & \begin{tabular}{|l|} 
Lengte \\
$(\mathrm{mm})$
\end{tabular} & \begin{tabular}{|l|} 
Gewicht \\
(gr)
\end{tabular} & Gemaal \\
\hline $4 / 3 / 2019$ & Kadoelen & $900 \_230000150350$ & Brasem & 496 & 1419 & $x$ \\
\hline $4 / 3 / 2019$ & Kadoelen & 900_230000150351 & Brasem & 439 & 1033 & $x$ \\
\hline $4 / 3 / 2019$ & Kadoelen & 900_230000150353 & Brasem & 439 & 973 & $x$ \\
\hline $4 / 3 / 2019$ & Kadoelen & 900_230000150354 & Brasem & 473 & 3634 & $x$ \\
\hline $4 / 3 / 2019$ & Kadoelen & 900_230000150355 & Brasem & 406 & 830 & $x$ \\
\hline $4 / 3 / 2019$ & Kadoelen & 900_230000150357 & Brasem & 577 & 2864 & $x$ \\
\hline $4 / 3 / 2019$ & Kadoelen & 900_230000150358 & Brasem & 482 & 1554 & $x$ \\
\hline $4 / 3 / 2019$ & Kadoelen & 900_230000150359 & Brasem & 489 & 1384 & $x$ \\
\hline $4 / 3 / 2019$ & Kadoelen & 900_230000150361 & Brasem & 467 & 1300 & $x$ \\
\hline $4 / 3 / 2019$ & Kadoelen & 900_230000150364 & Brasem & 496 & 1796 & $x$ \\
\hline $4 / 3 / 2019$ & Kadoelen & 900_230000150365 & Brasem & 525 & 1613 & $x$ \\
\hline $4 / 3 / 2019$ & Kadoelen & 900_230000150366 & Brasem & 532 & 2066 & $x$ \\
\hline $4 / 3 / 2019$ & Kadoelen & 900_230000150369 & Brasem & 418 & 898 & $x$ \\
\hline $4 / 3 / 2019$ & Kadoelen & 900_230000150370 & Brasem & 545 & 1218 & $x$ \\
\hline $4 / 3 / 2019$ & Kadoelen & $900 \_230000150371$ & Brasem & 443 & 961 & $x$ \\
\hline $4 / 3 / 2019$ & Kadoelen & 900_230000150372 & Brasem & 396 & 801 & $x$ \\
\hline $4 / 3 / 2019$ & Kadoelen & 900_230000150373 & Brasem & 502 & 1470 & $x$ \\
\hline $4 / 3 / 2019$ & Kadoelen & 900_230000150374 & Brasem & 480 & 1636 & $x$ \\
\hline $4 / 3 / 2019$ & Kadoelen & 900_230000150375 & Brasem & 510 & 1674 & $x$ \\
\hline $4 / 3 / 2019$ & Kadoelen & $900 \_230000150376$ & Brasem & 434 & 960 & $x$ \\
\hline $4 / 3 / 2019$ & Kadoelen & $900 \_230000150380$ & Snoekbaars & 577 & 1620 & $\mathrm{x}$ \\
\hline $4 / 3 / 2019$ & Kadoelen & 900_230000150383 & Snoekbaars & 450 & 611 & $x$ \\
\hline $4 / 3 / 2019$ & Kadoelen & 900_230000150384 & Snoekbaars & 532 & 1297 & $x$ \\
\hline $4 / 3 / 2019$ & Kadoelen & 900_230000150385 & Snoekbaars & 572 & 1341 & $x$ \\
\hline $4 / 3 / 2019$ & Kadoelen & 900_230000150386 & Snoekbaars & 570 & 1583 & $x$ \\
\hline $4 / 3 / 2019$ & Kadoelen & $900 \_230000150388$ & Snoekbaars & 600 & 1869 & $x$ \\
\hline $4 / 3 / 2019$ & Kadoelen & 900_230000150389 & Snoekbaars & 481 & 844 & $\mathrm{x}$ \\
\hline $4 / 3 / 2019$ & Kadoelen & 900_230000150390 & Snoekbaars & 435 & 517 & $x$ \\
\hline $4 / 3 / 2019$ & Kadoelen & 900_230000150391 & Baars & 420 & 1444 & $x$ \\
\hline $4 / 3 / 2019$ & Kadoelen & 900_230000150392 & Baars & 321 & 602 & $x$ \\
\hline $4 / 3 / 2019$ & Kadoelen & 900_230000150394 & Blankvoorn & 314 & 470 & $x$ \\
\hline $4 / 3 / 2019$ & Kadoelen & 900_230000150395 & Kolblei & 302 & 383 & $x$ \\
\hline $4 / 3 / 2019$ & Kadoelen & 900_230000150396 & Brasem & 411 & 630 & $x$ \\
\hline $4 / 3 / 2019$ & Kadoelen & 900_230000150397 & Brasem & 529 & 2293 & $x$ \\
\hline $4 / 3 / 2019$ & Kadoelen & 900_230000150398 & Brasem & 396 & 744 & $x$ \\
\hline $4 / 3 / 2019$ & Kadoelen & 900_230000150401 & Brasem & 511 & 2034 & $\mathrm{x}$ \\
\hline $4 / 3 / 2019$ & Kadoelen & 900_230000150402 & Brasem & 503 & 1593 & $x$ \\
\hline $4 / 3 / 2019$ & Kadoelen & 900_230000150403 & Brasem & 581 & 2774 & $x$ \\
\hline $4 / 3 / 2019$ & Kadoelen & 900_230000150404 & Brasem & 490 & 1404 & $x$ \\
\hline $4 / 3 / 2019$ & Kadoelen & 900_230000150406 & Brasem & 491 & 1350 & $x$ \\
\hline $4 / 3 / 2019$ & Kadoelen & $900 \_230000150408$ & Brasem & 430 & 1020 & $x$ \\
\hline $4 / 3 / 2019$ & Kadoelen & 900_230000150409 & Brasem & 401 & 766 & $x$ \\
\hline 4/3/2019 & Kadoelen & 900_230000150410 & Brasem & 479 & 1349 & $x$ \\
\hline $4 / 3 / 2019$ & Kadoelen & $900 \_230000150413$ & Brasem & 397 & 733 & $x$ \\
\hline $4 / 3 / 2019$ & Kadoelen & 900_230000150414 & Brasem & 425 & 925 & $x$ \\
\hline $4 / 3 / 2019$ & Kadoelen & $900 \quad 230000150415$ & Brasem & 396 & 794 & $x$ \\
\hline
\end{tabular}




\begin{tabular}{|c|c|c|c|c|c|c|}
\hline Datum & Locatie gemerkt & tag ID & Soort & \begin{tabular}{|l}
$\begin{array}{l}\text { Lengte } \\
(\mathrm{mm})\end{array}$ \\
\end{tabular} & \begin{tabular}{|l|}
$\begin{array}{l}\text { Gewicht } \\
\text { (gr) }\end{array}$ \\
\end{tabular} & Gemaal \\
\hline $4 / 3 / 2019$ & Kadoelen & 900_230000150416 & Brasem & 422 & 906 & $x$ \\
\hline $4 / 3 / 2019$ & Kadoelen & $900 \_230000150417$ & Brasem & 533 & 2556 & $x$ \\
\hline $4 / 3 / 2019$ & Kadoelen & 900_230000150418 & Brasem & 463 & 1164 & $x$ \\
\hline $4 / 3 / 2019$ & Kadoelen & 900_230000150419 & Brasem & 569 & 3331 & $x$ \\
\hline $4 / 3 / 2019$ & Kadoelen & 900_230000150420 & Brasem & 420 & 817 & $x$ \\
\hline $4 / 3 / 2019$ & Kadoelen & 900_230000150421 & Brasem & 464 & 1320 & $x$ \\
\hline $4 / 3 / 2019$ & Kadoelen & $900 \_230000150422$ & Brasem & 435 & 1037 & $x$ \\
\hline $4 / 3 / 2019$ & Kadoelen & 900_230000150425 & Brasem & 485 & 1534 & $x$ \\
\hline $4 / 3 / 2019$ & Kadoelen & $900 \_230000150426$ & Brasem & 477 & 1170 & $x$ \\
\hline $4 / 3 / 2019$ & Kadoelen & 900_230000150428 & Brasem & 459 & 1195 & $x$ \\
\hline $4 / 3 / 2019$ & Kadoelen & 900_230000150429 & Brasem & 435 & 1040 & $x$ \\
\hline $4 / 3 / 2019$ & Kadoelen & 900_230000150430 & Brasem & 417 & 819 & $x$ \\
\hline $4 / 3 / 2019$ & Kadoelen & 900_230000150431 & Brasem & 388 & 667 & $x$ \\
\hline $4 / 3 / 2019$ & Kadoelen & 900_230000150433 & Brasem & 417 & 1106 & $x$ \\
\hline $4 / 3 / 2019$ & Kadoelen & $900 \_230000150434$ & Brasem & 440 & 1012 & $x$ \\
\hline $4 / 3 / 2019$ & Kadoelen & 900_230000150435 & Brasem & 449 & 1096 & $x$ \\
\hline $4 / 3 / 2019$ & Kadoelen & 900_230000150437 & Brasem & 467 & 1296 & $x$ \\
\hline $4 / 3 / 2019$ & Kadoelen & 900_230000150438 & Brasem & 431 & 886 & $x$ \\
\hline $4 / 3 / 2019$ & Kadoelen & 900_230000150439 & Brasem & 411 & 847 & $x$ \\
\hline $4 / 3 / 2019$ & Kadoelen & $900 \_230000150440$ & Brasem & 549 & 1840 & $x$ \\
\hline $4 / 3 / 2019$ & Kadoelen & 900_230000150442 & Brasem & 445 & 1021 & $x$ \\
\hline $4 / 3 / 2019$ & Kadoelen & 900_230000150443 & Brasem & 428 & 1035 & $x$ \\
\hline $4 / 3 / 2019$ & Kadoelen & 900_230000150444 & Brasem & 496 & 1404 & $x$ \\
\hline $4 / 3 / 2019$ & Kadoelen & 900_230000150445 & Brasem & 427 & 1012 & $x$ \\
\hline $4 / 3 / 2019$ & Kadoelen & 900_230000150448 & Brasem & 482 & 1624 & $x$ \\
\hline $4 / 3 / 2019$ & Kadoelen & 900_230000150449 & Brasem & 532 & 2194 & $x$ \\
\hline $4 / 3 / 2019$ & Kadoelen & $900 \_230000150450$ & Brasem & 493 & 1406 & $\mathrm{x}$ \\
\hline $4 / 3 / 2019$ & Kadoelen & 900_230000150451 & Brasem & 398 & 763 & $x$ \\
\hline $4 / 3 / 2019$ & Kadoelen & $900 \_230000150452$ & Brasem & 467 & 1306 & $x$ \\
\hline $4 / 3 / 2019$ & Kadoelen & 900_230000150454 & Brasem & 481 & 1524 & $x$ \\
\hline $4 / 3 / 2019$ & Kadoelen & 900_230000150455 & Brasem & 501 & 1035 & $x$ \\
\hline $4 / 3 / 2019$ & Kadoelen & 900_230000150457 & Brasem & 514 & 1353 & $x$ \\
\hline $4 / 15 / 2019$ & Kadoelen & 900_230000150463 & Baars & 260 & 202 & $x$ \\
\hline $4 / 15 / 2019$ & Kadoelen & 900_230000150464 & Blankvoorn & 284 & 322 & $x$ \\
\hline $4 / 15 / 2019$ & Kadoelen & $900 \_230000150466$ & Brasem & 496 & 1580 & $x$ \\
\hline $4 / 15 / 2019$ & Kadoelen & $900 \_230000150468$ & Brasem & 511 & 1684 & $\mathrm{x}$ \\
\hline $4 / 15 / 2019$ & Kadoelen & 900_230000150469 & Snoekbaars & 460 & 750 & $x$ \\
\hline $4 / 15 / 2019$ & Kadoelen & $900 \_230000150470$ & Snoekbaars & 537 & 1249 & $x$ \\
\hline $4 / 15 / 2019$ & Kadoelen & 900_230000150471 & Snoekbaars & 547 & 1224 & $x$ \\
\hline $4 / 15 / 2019$ & Kadoelen & 900_230000150472 & Snoekbaars & 543 & 1341 & $x$ \\
\hline $4 / 15 / 2019$ & Kadoelen & $900 \_230000150474$ & Snoek & 790 & 4081 & $x$ \\
\hline $4 / 15 / 2019$ & Kadoelen & $900 \_230000150476$ & Snoekbaars & 549 & 1035 & $x$ \\
\hline $4 / 15 / 2019$ & Kadoelen & 900_230000150477 & Snoekbaars & 558 & 1311 & $x$ \\
\hline $4 / 15 / 2019$ & Kadoelen & $900 \_230000150478$ & Snoek & 495 & 785 & $x$ \\
\hline $4 / 15 / 2019$ & Kadoelen & 900_230000150479 & Snoekbaars & 621 & 2171 & $x$ \\
\hline $4 / 15 / 2019$ & Kadoelen & $900 \quad 230000150480$ & Baars & 299 & 399 & $x$ \\
\hline
\end{tabular}




\begin{tabular}{|c|c|c|c|c|c|c|}
\hline Datum & Locatie gemerkt & tag ID & Soort & \begin{tabular}{|l} 
Lengte \\
$(\mathrm{mm})$
\end{tabular} & $\begin{array}{l}\text { Gewicht } \\
\text { (gr) }\end{array}$ & Gemaal \\
\hline $4 / 15 / 2019$ & Kadoelen & 900_230000150482 & Baars & 381 & 1131 & $x$ \\
\hline $4 / 15 / 2019$ & Kadoelen & $900 \_230000150483$ & Baars & 442 & 1900 & $x$ \\
\hline $4 / 15 / 2019$ & Kadoelen & $900 \_230000150484$ & Baars & 317 & 522 & $x$ \\
\hline $4 / 15 / 2019$ & Kadoelen & $900 \_230000150486$ & Baars & 385 & 1025 & $x$ \\
\hline $4 / 15 / 2019$ & Kadoelen & 900_230000150487 & Baars & 336 & 752 & $x$ \\
\hline $4 / 15 / 2019$ & Kadoelen & $900 \_230000150489$ & Baars & 299 & 378 & $x$ \\
\hline $4 / 15 / 2019$ & Kadoelen & 900_230000150490 & Baars & 305 & 506 & $x$ \\
\hline $4 / 15 / 2019$ & Kadoelen & 900_230000150491 & Baars & 237 & 155 & $x$ \\
\hline $4 / 15 / 2019$ & Kadoelen & 900_230000150492 & Baars & 310 & 450 & $x$ \\
\hline $4 / 15 / 2019$ & Kadoelen & 900_230000150493 & Snoekbaars & 495 & 899 & $x$ \\
\hline $4 / 15 / 2019$ & Kadoelen & 900_230000150494 & Snoekbaars & 557 & 1414 & $x$ \\
\hline $5 / 9 / 2019$ & Kadoelen & $900 \_230000150873$ & Brasem & 466 & 585 & $x$ \\
\hline $5 / 9 / 2019$ & Kadoelen & 900_230000150874 & Brasem & 392 & 712 & $x$ \\
\hline $5 / 9 / 2019$ & Kadoelen & $900 \_230000150875$ & Brasem & 461 & 1030 & $x$ \\
\hline $5 / 9 / 2019$ & Kadoelen & $900 \_230000150876$ & Brasem & 532 & 1581 & $x$ \\
\hline $5 / 9 / 2019$ & Kadoelen & 900_230000150877 & Brasem & 464 & 1184 & $x$ \\
\hline $5 / 9 / 2019$ & Kadoelen & $900 \_230000150878$ & Brasem & 364 & 605 & $x$ \\
\hline $5 / 9 / 2019$ & Kadoelen & 900_230000150881 & Brasem & 514 & 1684 & $x$ \\
\hline $5 / 9 / 2019$ & Kadoelen & 900_230000150884 & Brasem & 421 & 1032 & $x$ \\
\hline $5 / 9 / 2019$ & Kadoelen & $900 \_230000150888$ & Brasem & 489 & 1345 & $x$ \\
\hline $5 / 9 / 2019$ & Kadoelen & $900 \_230000150889$ & Brasem & 457 & 1123 & $x$ \\
\hline $5 / 9 / 2019$ & Kadoelen & 900_230000150890 & Brasem & 419 & 945 & $x$ \\
\hline $5 / 9 / 2019$ & Kadoelen & 900_230000150892 & Brasem & 432 & 1050 & $x$ \\
\hline $5 / 9 / 2019$ & Kadoelen & 900_230000150893 & Brasem & 446 & 1250 & $x$ \\
\hline $5 / 9 / 2019$ & Kadoelen & 900_230000150895 & Brasem & 457 & 1134 & $x$ \\
\hline $5 / 9 / 2019$ & Kadoelen & $900 \_230000150896$ & Brasem & 418 & 1090 & $x$ \\
\hline $5 / 9 / 2019$ & Kadoelen & $900 \_230000150897$ & Snoekbaars & 535 & 1175 & $x$ \\
\hline $5 / 9 / 2019$ & Kadoelen & 900_230000150898 & Brasem & 428 & 1041 & $x$ \\
\hline $5 / 9 / 2019$ & Kadoelen & $900 \_230000150899$ & Brasem & 404 & 914 & $x$ \\
\hline $5 / 9 / 2019$ & Kadoelen & 900_230000150900 & Brasem & 402 & 707 & $x$ \\
\hline $5 / 9 / 2019$ & Kadoelen & 900_230000150901 & Brasem & 520 & 1740 & $x$ \\
\hline $5 / 9 / 2019$ & Kadoelen & 900_230000150902 & Brasem & 414 & 857 & $x$ \\
\hline $5 / 9 / 2019$ & Kadoelen & $900 \_230000150903$ & Brasem & 390 & 635 & $x$ \\
\hline $5 / 9 / 2019$ & Kadoelen & 900_230000150904 & Brasem & 404 & 836 & $x$ \\
\hline $5 / 9 / 2019$ & Kadoelen & 900_230000150905 & Brasem & 498 & 1605 & $x$ \\
\hline $5 / 9 / 2019$ & Kadoelen & $900 \_230000150906$ & Brasem & 488 & 1498 & $x$ \\
\hline $5 / 9 / 2019$ & Kadoelen & 900_230000150907 & Brasem & 402 & 1446 & $x$ \\
\hline $5 / 9 / 2019$ & Kadoelen & 900_230000150908 & Brasem & 450 & 1223 & $x$ \\
\hline $5 / 9 / 2019$ & Kadoelen & 900_230000150909 & Brasem & 412 & 920 & $x$ \\
\hline $5 / 9 / 2019$ & Kadoelen & 900_230000150910 & Brasem & 482 & 1376 & $x$ \\
\hline $5 / 9 / 2019$ & Kadoelen & 900_230000150911 & Brasem & 439 & 890 & $x$ \\
\hline $5 / 9 / 2019$ & Kadoelen & $900 \_230000150912$ & Brasem & 438 & 1038 & $x$ \\
\hline $5 / 9 / 2019$ & Kadoelen & 900_230000150913 & Brasem & 425 & 1020 & $x$ \\
\hline $5 / 9 / 2019$ & Kadoelen & $900 \_230000150914$ & Brasem & 376 & 651 & $x$ \\
\hline $5 / 9 / 2019$ & Kadoelen & 900_230000150915 & Brasem & 520 & 1501 & $x$ \\
\hline $5 / 9 / 2019$ & Kadoelen & 900230000150916 & Brasem & 412 & 808 & $x$ \\
\hline
\end{tabular}




\begin{tabular}{|c|c|c|c|c|c|c|}
\hline Datum & Locatie gemerkt & $\operatorname{tag} I D$ & Soort & $\begin{array}{l}\text { Lengte } \\
(\mathrm{mm})\end{array}$ & \begin{tabular}{|l|} 
Gewicht \\
(gr)
\end{tabular} & Gemaal \\
\hline $5 / 9 / 2019$ & Kadoelen & 900_230000150917 & Brasem & 479 & 1347 & $x$ \\
\hline $5 / 9 / 2019$ & Kadoelen & 900_230000150918 & Brasem & 386 & 705 & $x$ \\
\hline $5 / 9 / 2019$ & Kadoelen & 900_230000150920 & Brasem & 388 & 760 & $x$ \\
\hline $5 / 9 / 2019$ & Kadoelen & 900_230000150921 & Brasem & 398 & 861 & $x$ \\
\hline $5 / 9 / 2019$ & Kadoelen & 900_230000150922 & Brasem & 502 & 1555 & $x$ \\
\hline $5 / 9 / 2019$ & Kadoelen & 900_230000150923 & Brasem & 414 & 965 & $x$ \\
\hline $5 / 9 / 2019$ & Kadoelen & 900_230000150924 & Brasem & 527 & 1941 & $x$ \\
\hline $5 / 9 / 2019$ & Kadoelen & 900_230000150927 & Brasem & 433 & 990 & $x$ \\
\hline $5 / 9 / 2019$ & Kadoelen & 900_230000150928 & Brasem & 451 & 1061 & $x$ \\
\hline $5 / 9 / 2019$ & Kadoelen & 900_230000150929 & Brasem & 451 & 1166 & $x$ \\
\hline $5 / 9 / 2019$ & Kadoelen & 900_230000150930 & Brasem & 460 & 1355 & $x$ \\
\hline $5 / 9 / 2019$ & Kadoelen & 900_230000150932 & Brasem & 421 & 1091 & $x$ \\
\hline $5 / 9 / 2019$ & Kadoelen & 900_230000150933 & Brasem & 413 & 998 & $x$ \\
\hline $5 / 9 / 2019$ & Kadoelen & 900_230000150934 & Brasem & 513 & 1691 & $x$ \\
\hline $5 / 9 / 2019$ & Kadoelen & 900_230000150935 & Brasem & 415 & 849 & $x$ \\
\hline $5 / 9 / 2019$ & Kadoelen & 900_230000150936 & Brasem & 431 & 974 & $x$ \\
\hline $5 / 9 / 2019$ & Kadoelen & 900_230000150937 & Brasem & 470 & 1197 & $x$ \\
\hline $5 / 9 / 2019$ & Kadoelen & 900_230000150938 & Brasem & 499 & 1128 & $x$ \\
\hline $5 / 9 / 2019$ & Kadoelen & 900_230000150940 & Brasem & 394 & 790 & $x$ \\
\hline $5 / 9 / 2019$ & Kadoelen & 900_230000150941 & Brasem & 394 & 702 & $x$ \\
\hline $5 / 9 / 2019$ & Kadoelen & 900_230000150942 & Brasem & 573 & 2708 & $x$ \\
\hline $5 / 9 / 2019$ & Kadoelen & 900_230000150943 & Brasem & 459 & 1483 & $x$ \\
\hline $5 / 9 / 2019$ & Kadoelen & 900_230000150944 & Brasem & 522 & 1378 & $x$ \\
\hline $5 / 9 / 2019$ & Kadoelen & 900_230000150945 & Brasem & 381 & 730 & $x$ \\
\hline $5 / 9 / 2019$ & Kadoelen & 900_230000150946 & Brasem & 426 & 1030 & $x$ \\
\hline $5 / 9 / 2019$ & Kadoelen & 900_230000150947 & Brasem & 356 & 598 & $x$ \\
\hline $5 / 7 / 2019$ & Nauerna & 900_230000150869 & Brasem & 413 & 880 & $x$ \\
\hline
\end{tabular}




\section{Bijlage 2 Voorbeelden migratiepatronen}

Migratie patronen van vissen die óf een vispassage zijn ingezwommen, grotere afstanden hebben gezwommen of andere interessante migratie patronen laten zien. Dit zijn andere vissen die al zijn besproken in de rapportage.

NB. Hfst. 3 voor uitleg van de aanduidingen in de figuren.

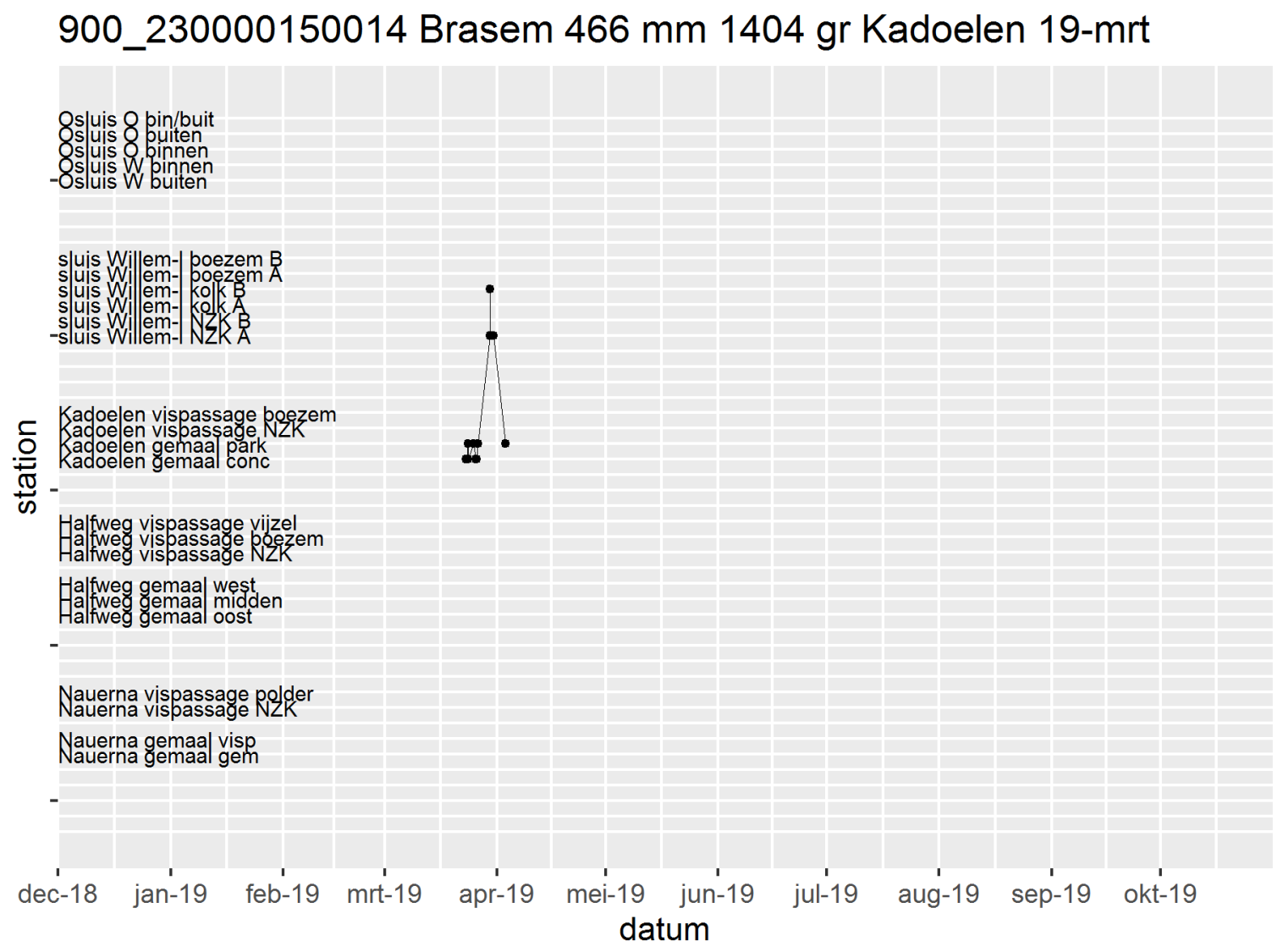


900_230000150046 Brasem 486 mm 1470 gr Kadoelen 19-mrt

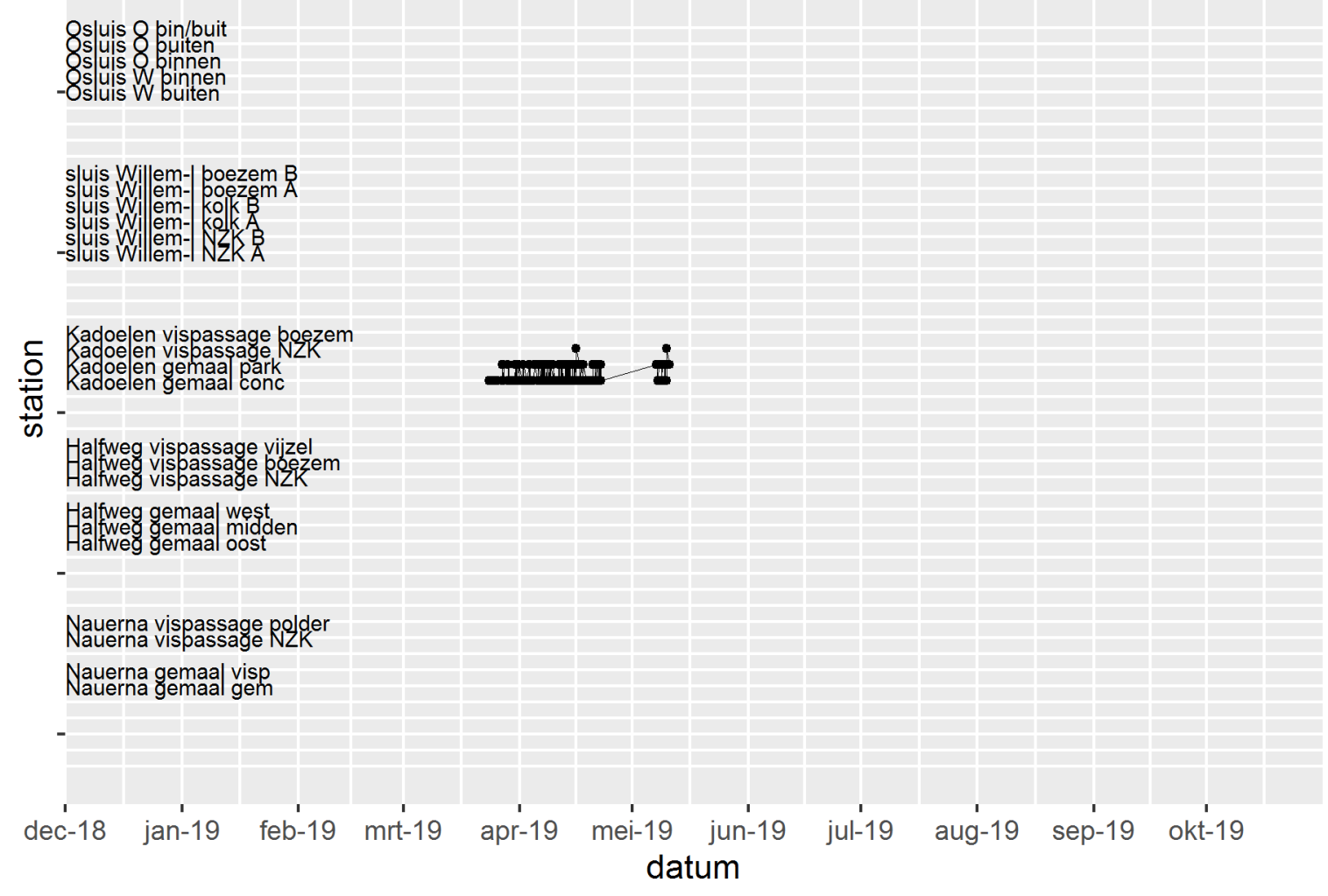

900_230000150064 Brasem 461 mm 1098 gr Kadoelen 19-mrt

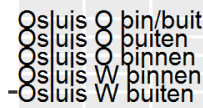

s|uis Willem-| poezem $B$

uis W

-sluis Willem-1 NZK A

ᄃ Kadoelen vispassage boezem

으 Kadoelen gemaa park

की

Halfweg vispassage viizel
Haweg vispassage bo bem
Halfweg vispassage NZK

Halfweg gemaal west

Nauerna vispassage polder

Nauerna gemaa| visp

dec-18 jan-19 feb-19 mrt-19 apr-19 mei-19 jun-19 jul-19 aug-19 sep-19 okt-19 datum 
900_230000150067 Brasem 440 mm 1023 gr Kadoelen 19-mrt

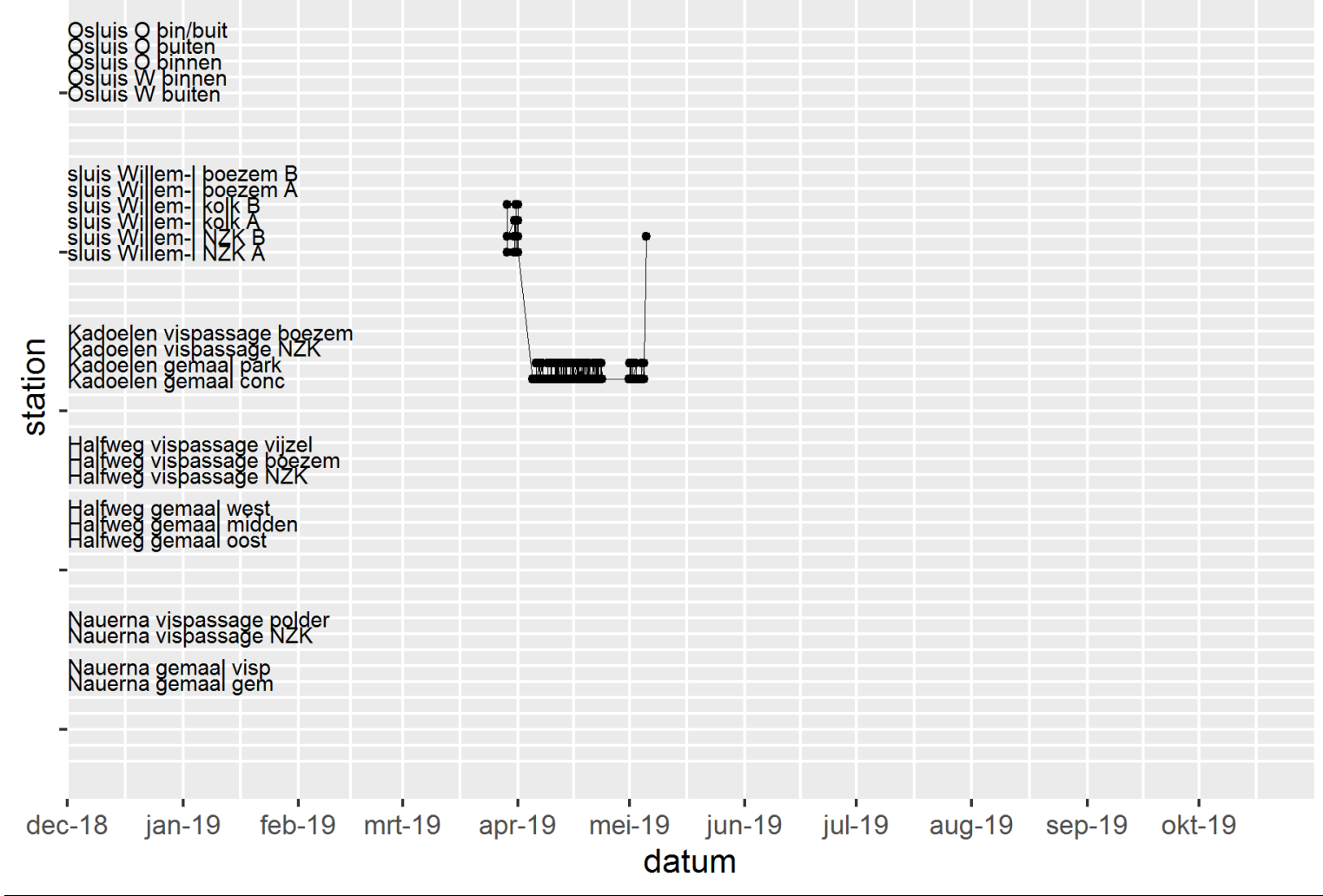

900_230000150074 Brasem 464 mm 1240 gr Kadoelen 19-mrt

Ostuis 8 pin/buit

8 s uis 8 binnen

-8 sluis $W$ buiten

sluis Wil|em-| poezem B

uis W em- kolk

-sluis Willem-I NZK

ᄃ Kadoeen vispassage poezem

으 Kadoelen gemaal conc

$\frac{\pi}{\infty}$

Halfweg vispassage vijzel

Halfweg vispassage pogem

Halfweg gemaa| west

Nauerna vispassage polder

Nauerna gemaal visp

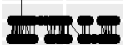

dec-18 jan-19 feb-19 mrt-19 apr-19 mei-19 jun-19 jul-19 aug-19 sep-19 okt-19 datum 
900_230000150080 Brasem 531 mm 1688 gr Kadoelen 19-mrt

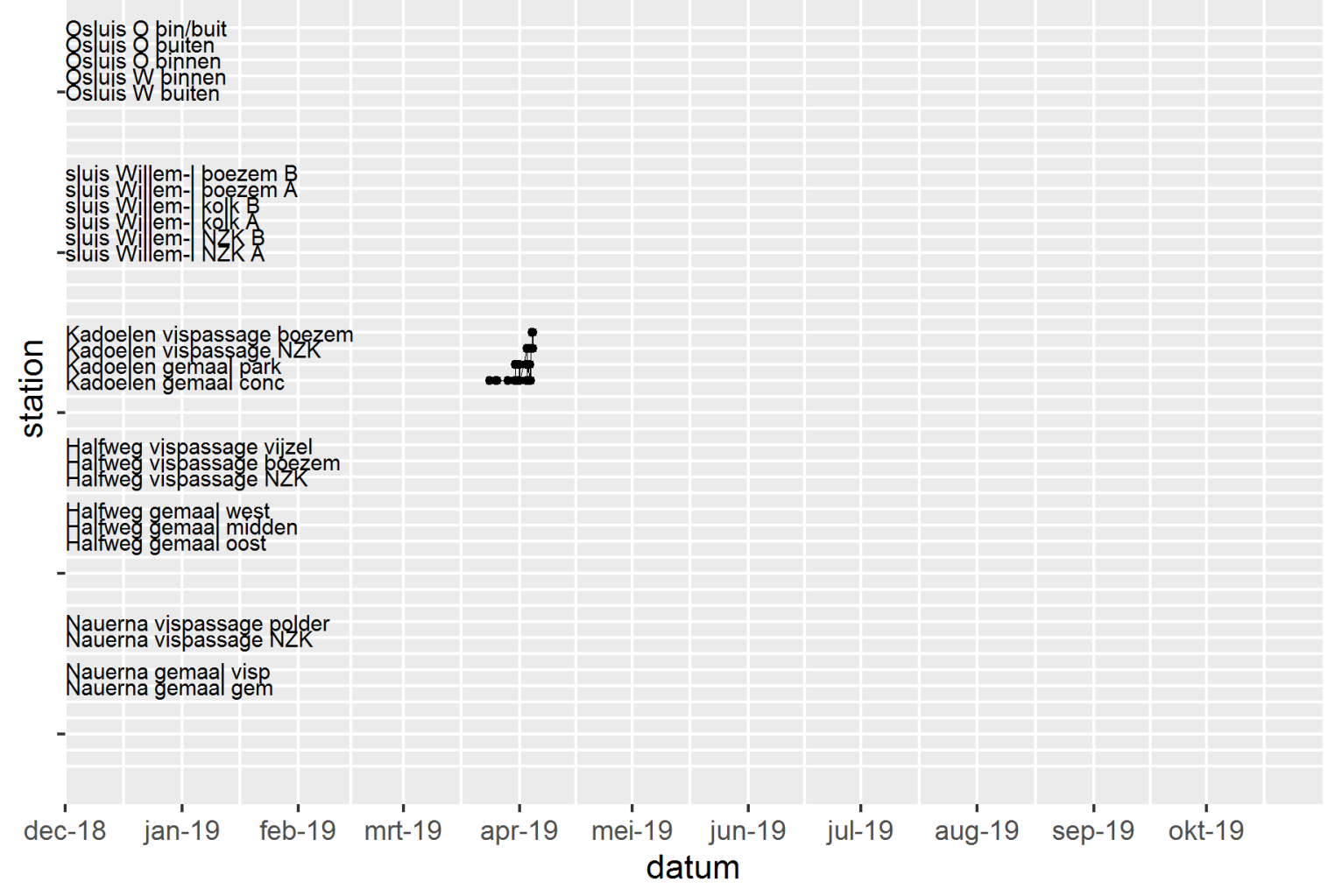

900_230000150102 Brasem 470 mm 1240 gr Kadoelen 19-mrt

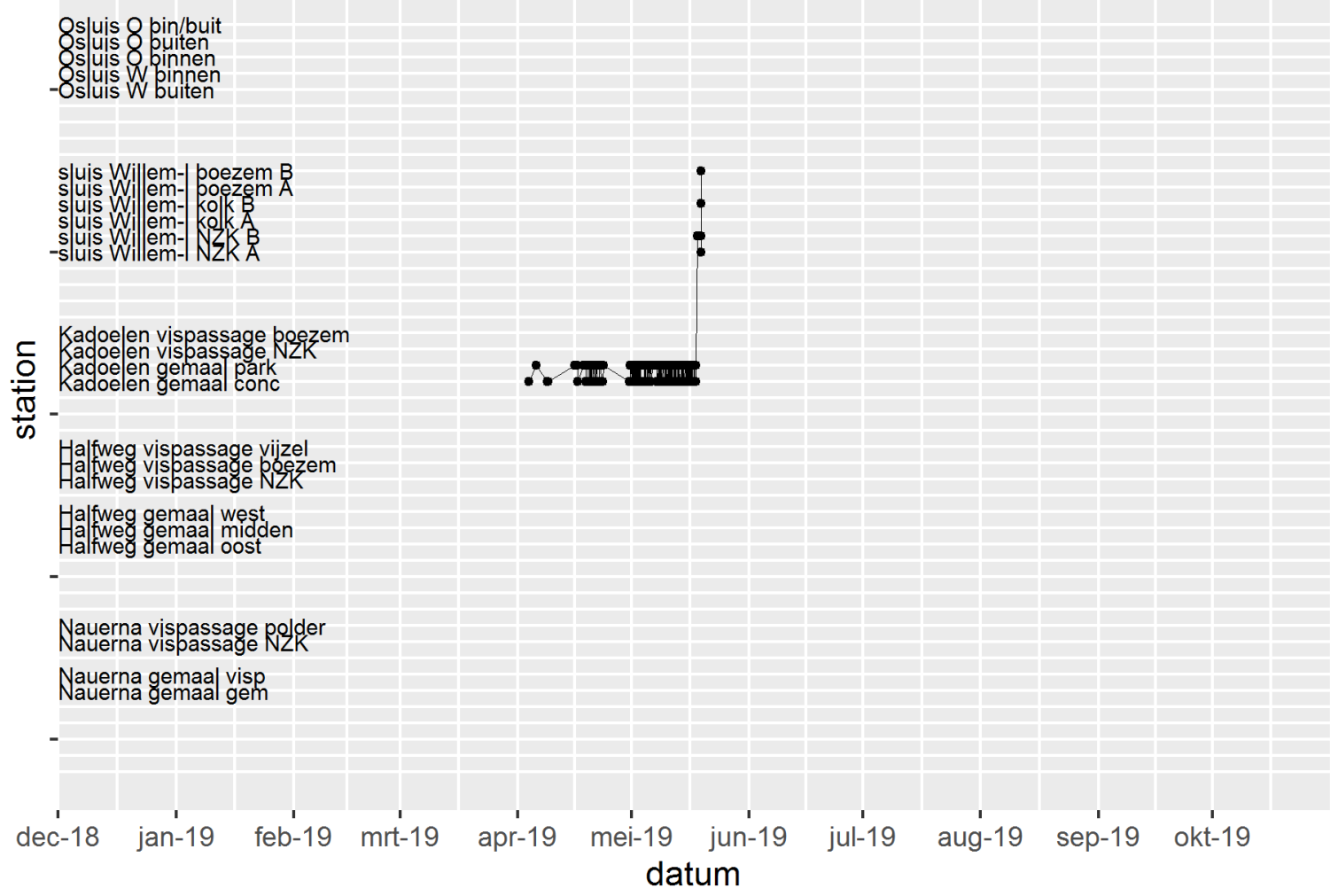


900_230000150121 Brasem 475 mm 1170 gr Kadoelen 19-mrt

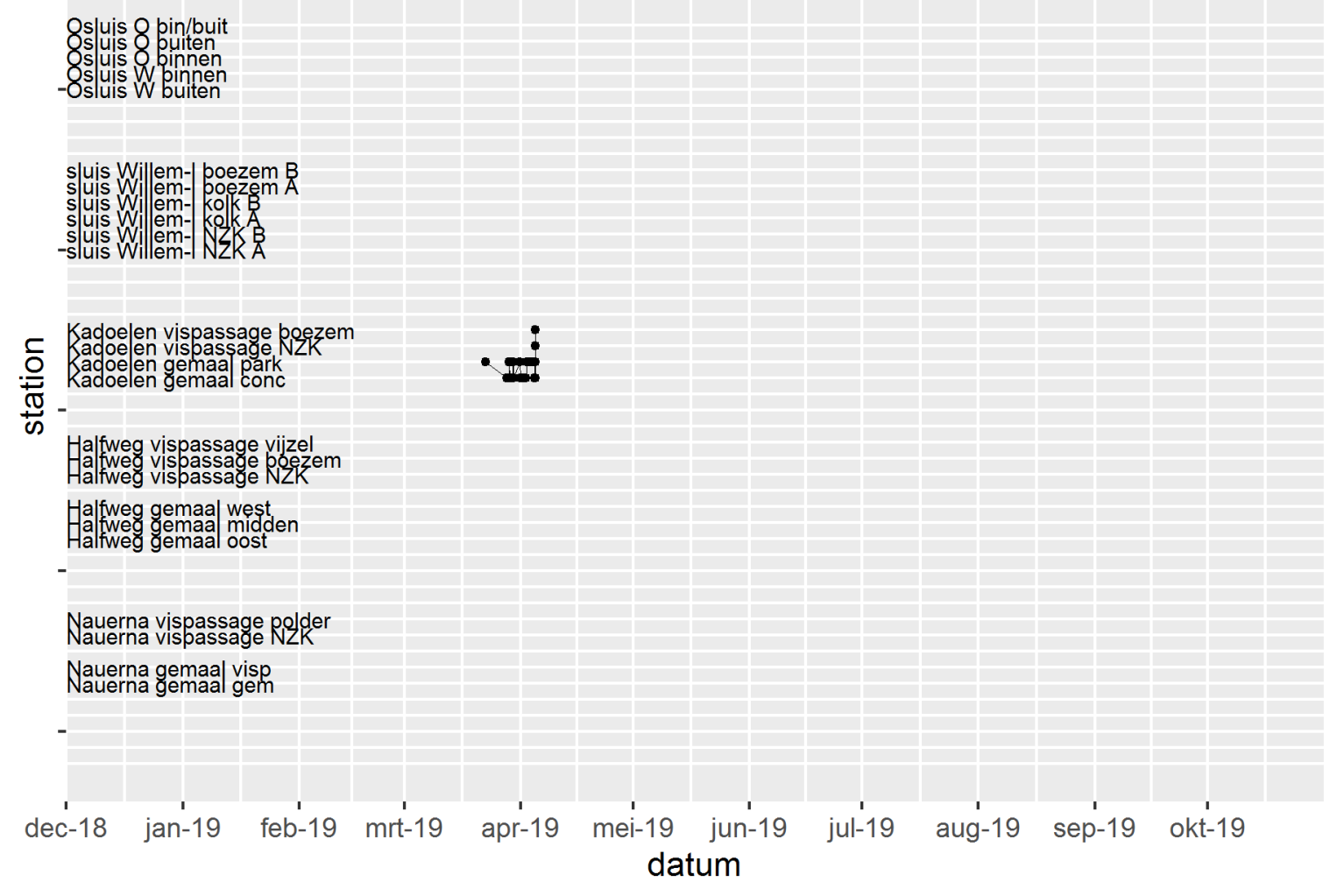

900_230000150127 Brasem 515 mm 1570 gr Kadoelen 19-mrt

Ostuis 8 pin/buit

8 s uis 8 binnen

-8 sluis $W$ buiten

suis Willem-|poezem B

uis W. em- kolke

uis Wil em-

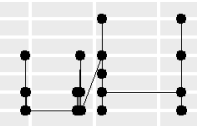

ᄃ. Kadoelen vispassage beezem

음

goe en vemaa park

$+$

Halfweg vispassage vijzel

Halfweg vispassage boezem

Halfweg gemaal west

Nauerna vispassage polder

Nauerna gemaal visp

dec-18 jan-19 feb-19 mrt-19 apr-19 mei-19 jun-19 jul-19 aug-19 sep-19 okt-19 datum 
900_230000150129 Brasem 418 mm 897 gr Kadoelen 19-mrt

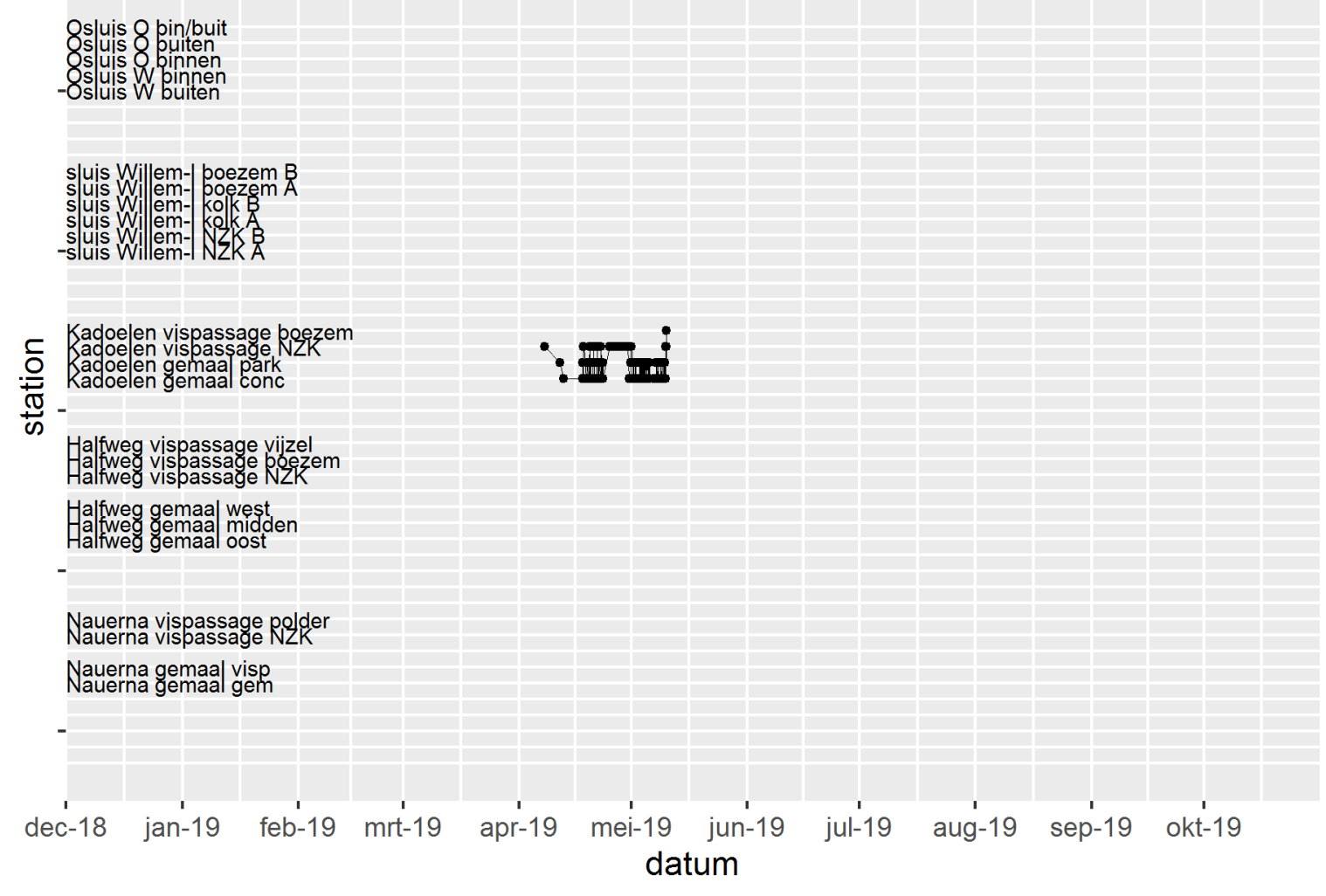

900_230000150139 Brasem 501 mm 1620 gr Kadoelen 19-mrt

8stuis 8 pin/buit

ssuss binnen

-8 sluis $W$ butiten

sluis Willem-|boezem B

uis Wi em- kolk

-sluis Willem-1 NZK A

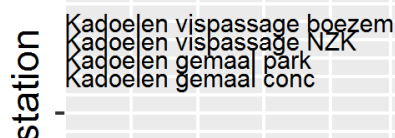

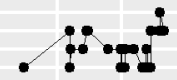

Halifweg vispassage vijzel
Ha|weg vispassage boem
Halfweg vispassage NZK

Halfweg gemaal west

Nauerna vispassage polder

Nauerna gemaal visp

dec-18 jan-19 feb-19 mrt-19 apr-19 mei-19 jun-19 jul-19 aug-19 sep-19 okt-19 datum 
900_230000150147 Brasem 471 mm 1307 gr Kadoelen 19-mrt

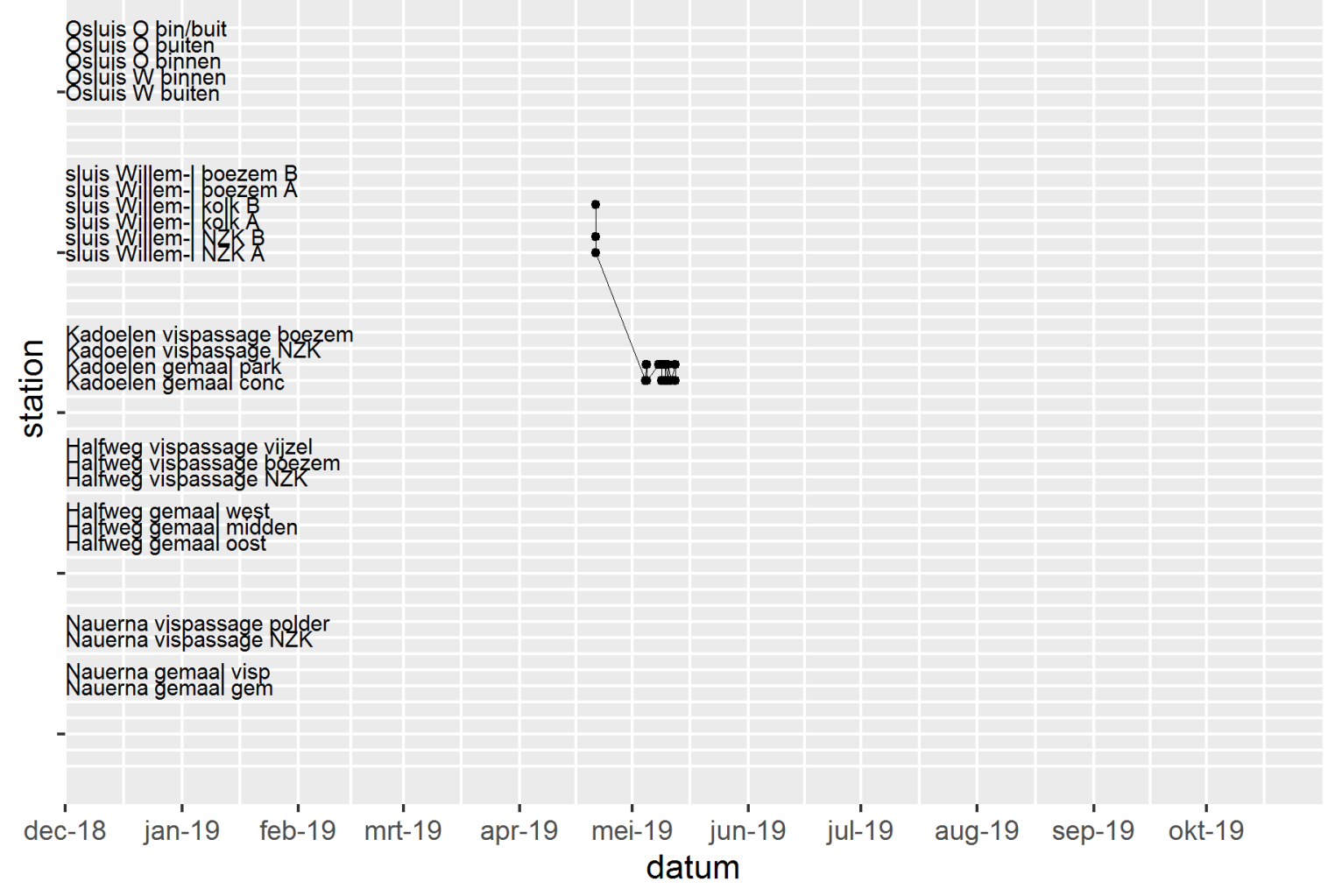

900_230000150190 Baars 236 mm 172 gr Halfweg 26-mrt

8stuis 8 pin/buit

8 suis binnen

- Osluis $W$ buiten

sluis Willem-|boezem B

suis W em- kol k

-sluis Willem-1 NZK A

ᄃ Kadoelen vispassage poezem

으 Kadoelen gemaal park

$\frac{\pi}{C}$

Halfweg vispassage vijzel
Ha|tweg vspassage poezem
Halfweg vispassage NZK

Halfweg gemaa west

Haliweg gemaal oost

Nauerna vispassage polder

Nauerna gemaal visp

dec-18 jan-19 feb-19 mrt-19 apr-19 mei-19 jun-19 jul-19 aug-19 sep-19 okt-19 datum 
900_230000150792 Brasem 509 mm 1554 gr Nauerna 2-mei

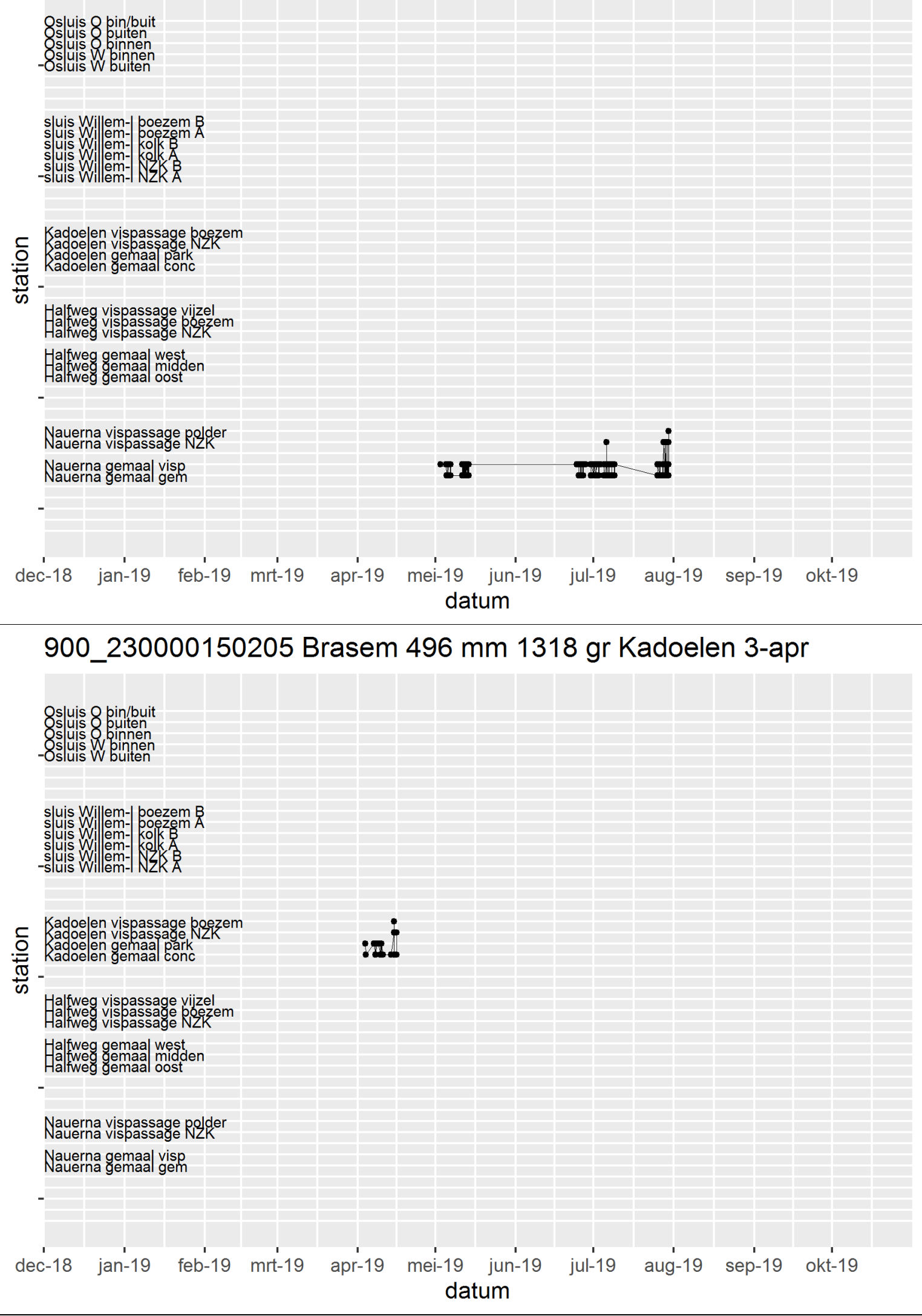


900_230000150208 Brasem 498 mm 1998 gr Kadoelen 3-apr

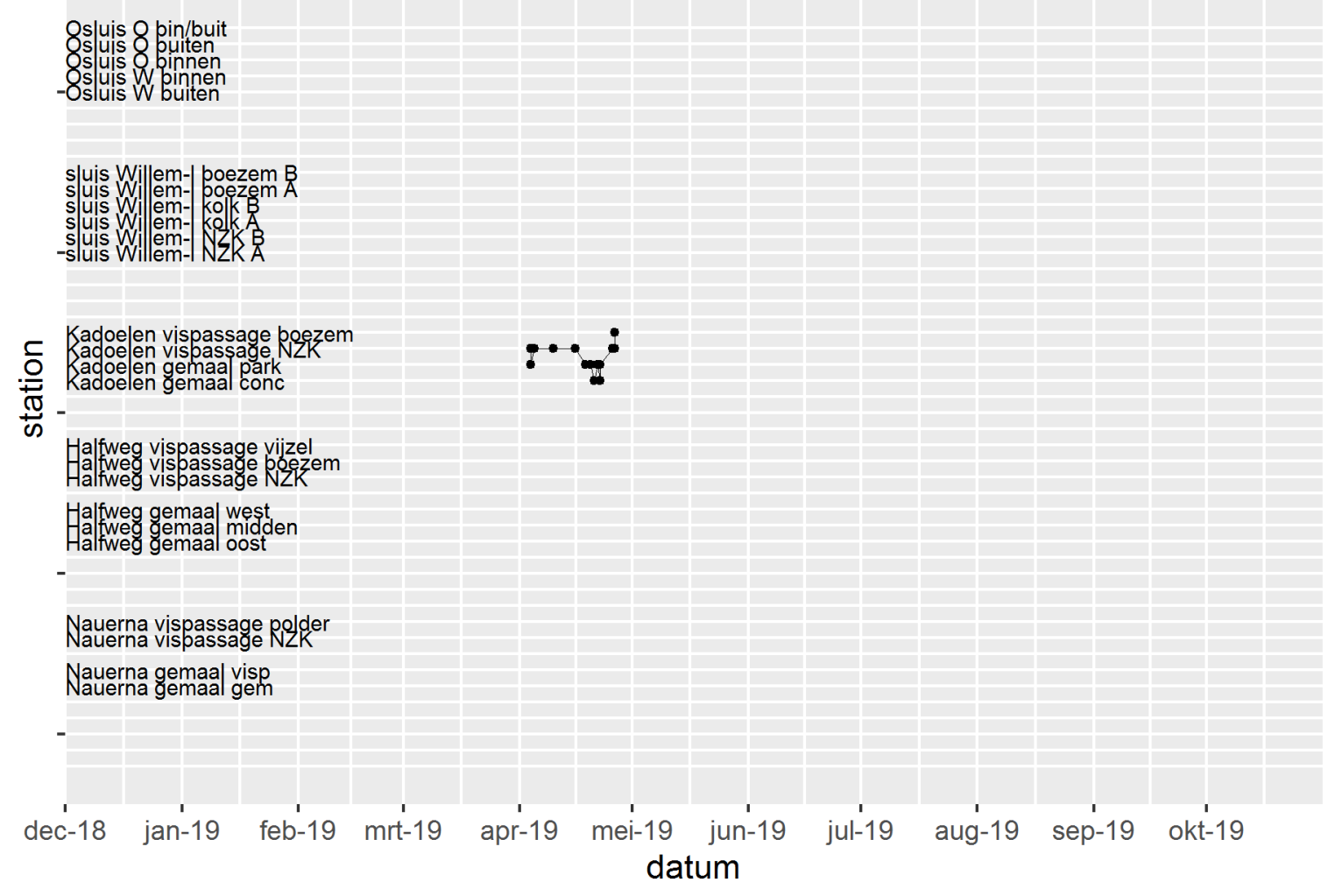

900_230000150224 Brasem 496 mm 1430 gr Kadoelen 3-apr

8stuis 8 pin/buit

8 suis binnen

- Osluis $W$ buiten

sluis Willem-|boezem B

uis W

s suis Willem- NZK

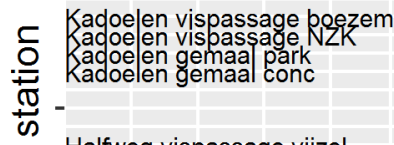

Halfiveg vispassage vijzel
Ha|fweg vispassage boemzem
Halfweg vispassage NZK

Halfweg gemaal west

Nauerna vispassage polder
Nauerna vispassage NZK

Nauerna gemaal visp

dec-18 jan-19 feb-19 mrt-19 apr-19 mei-19 jun-19 jul-19 aug-19 sep-19 okt-19 datum 
900_230000150240 Brasem 498 mm 1387 gr Kadoelen 3-apr

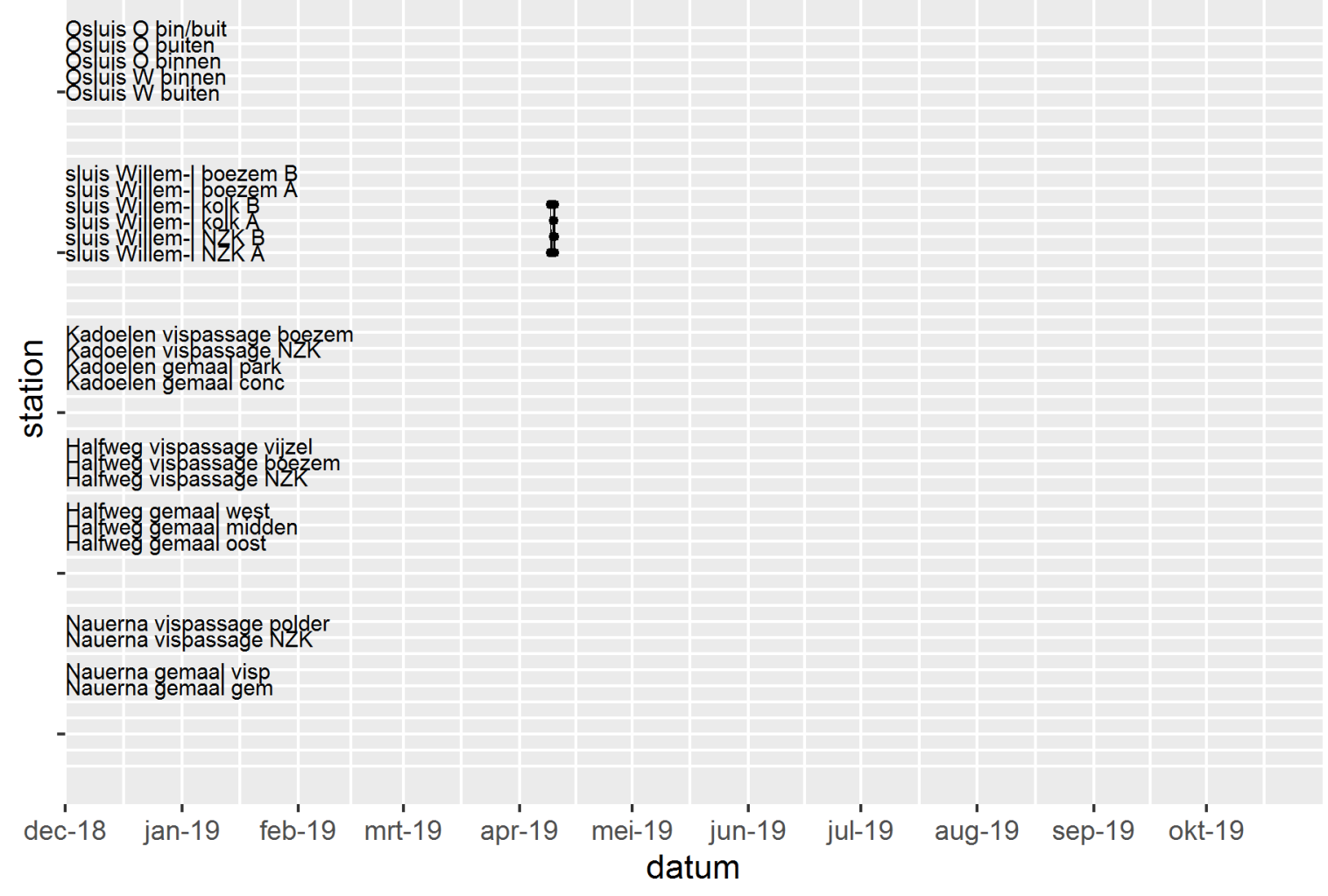

900_230000150247 Brasem 475 mm 1259 gr Kadoelen 3-apr

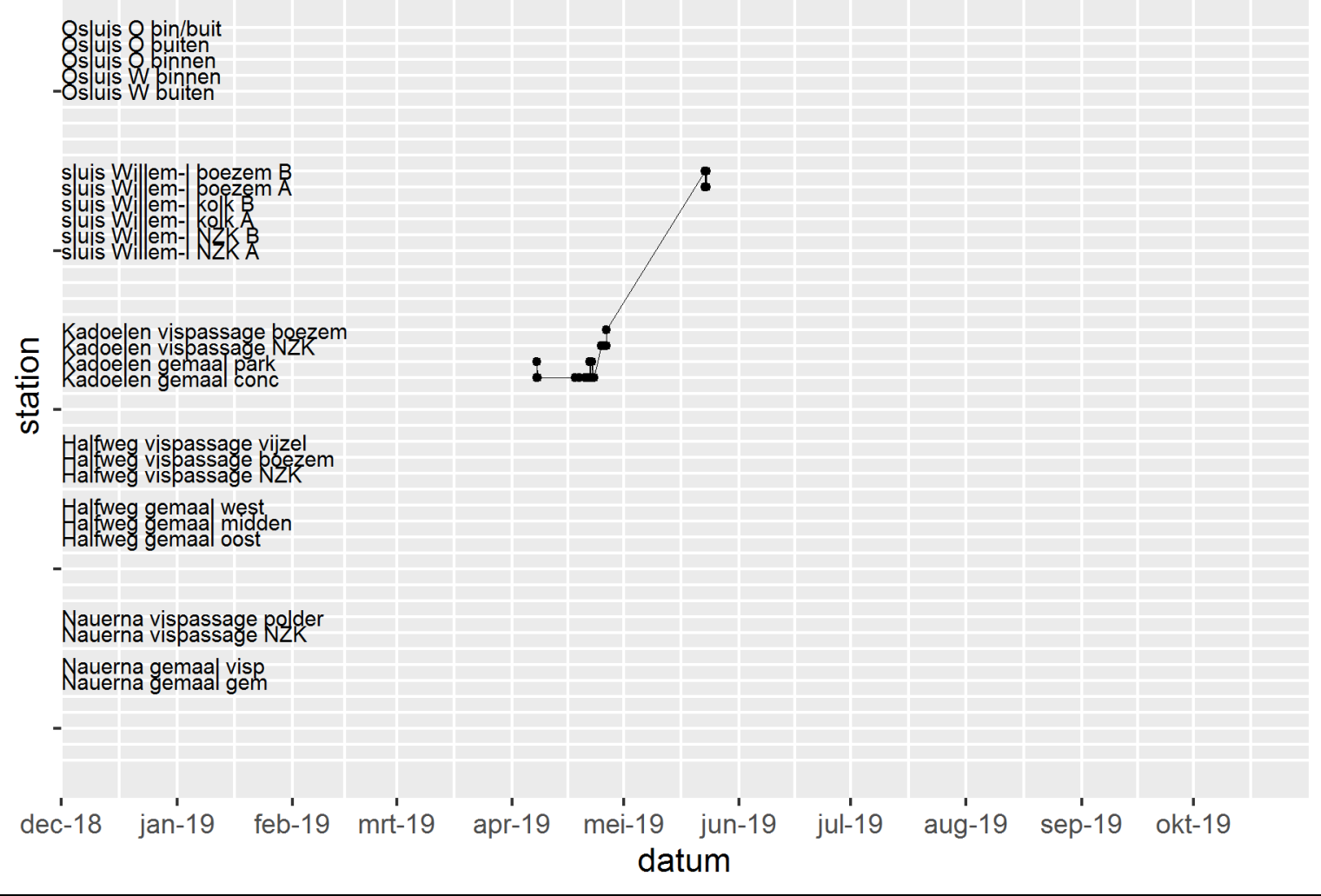


900_230000150254 Brasem 359 mm 500 gr Kadoelen 3-apr

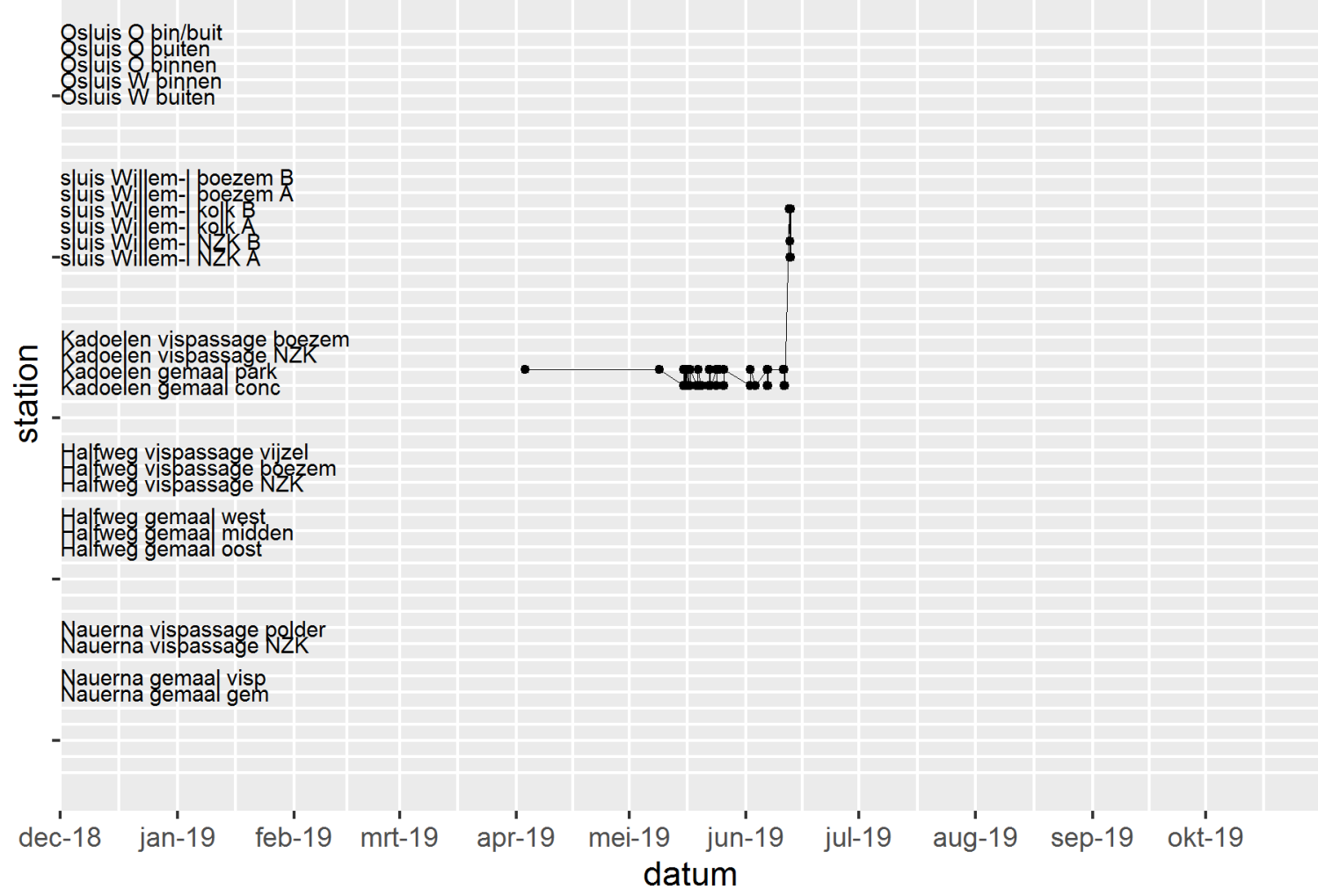

900_230000150259 Brasem 441 mm 1189 gr Kadoelen 3-apr

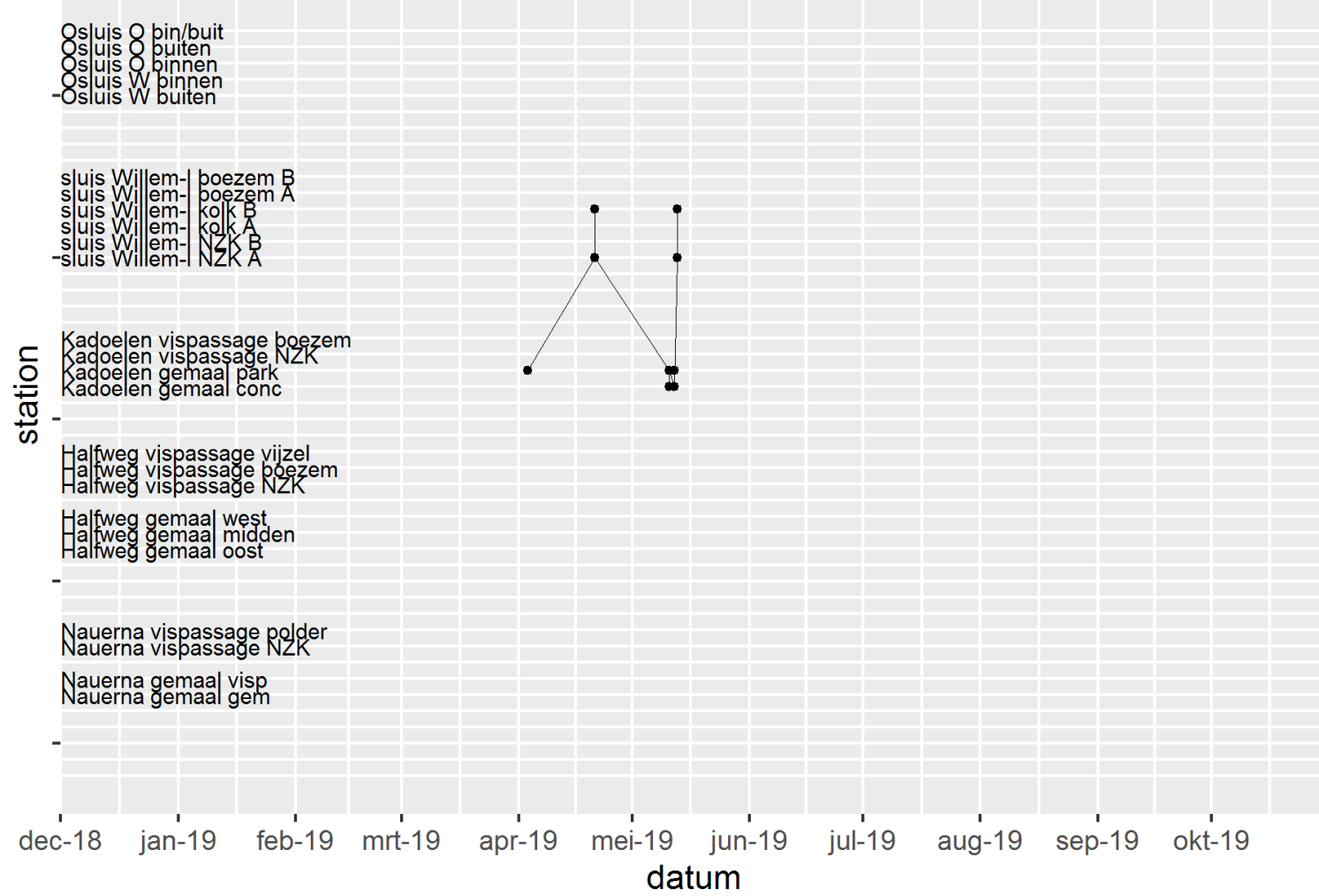


900_230000150267 Brasem 434 mm 937 gr Kadoelen 3-apr

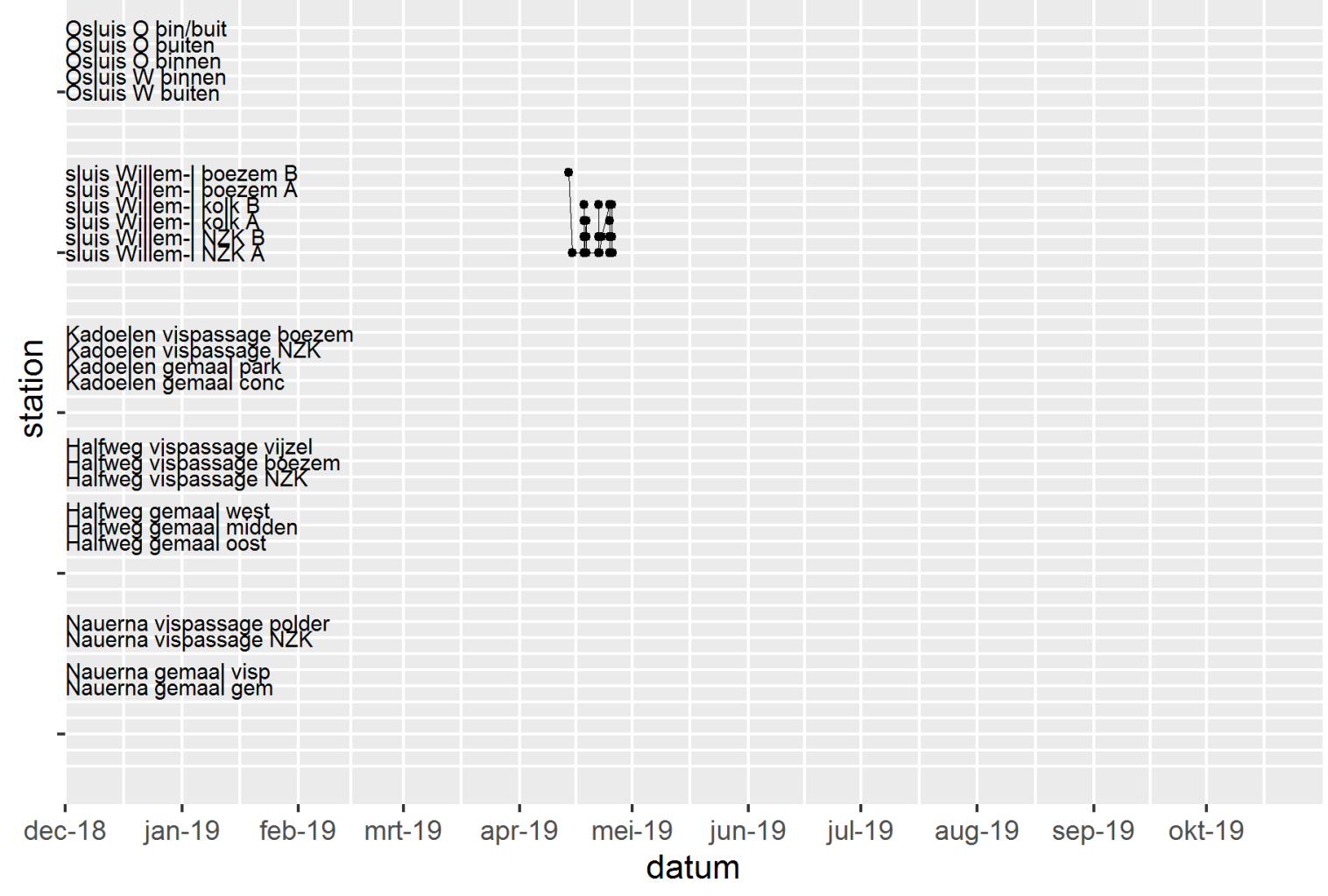

900_230000150271 Brasem 473 mm 1277 gr Kadoelen 3-apr

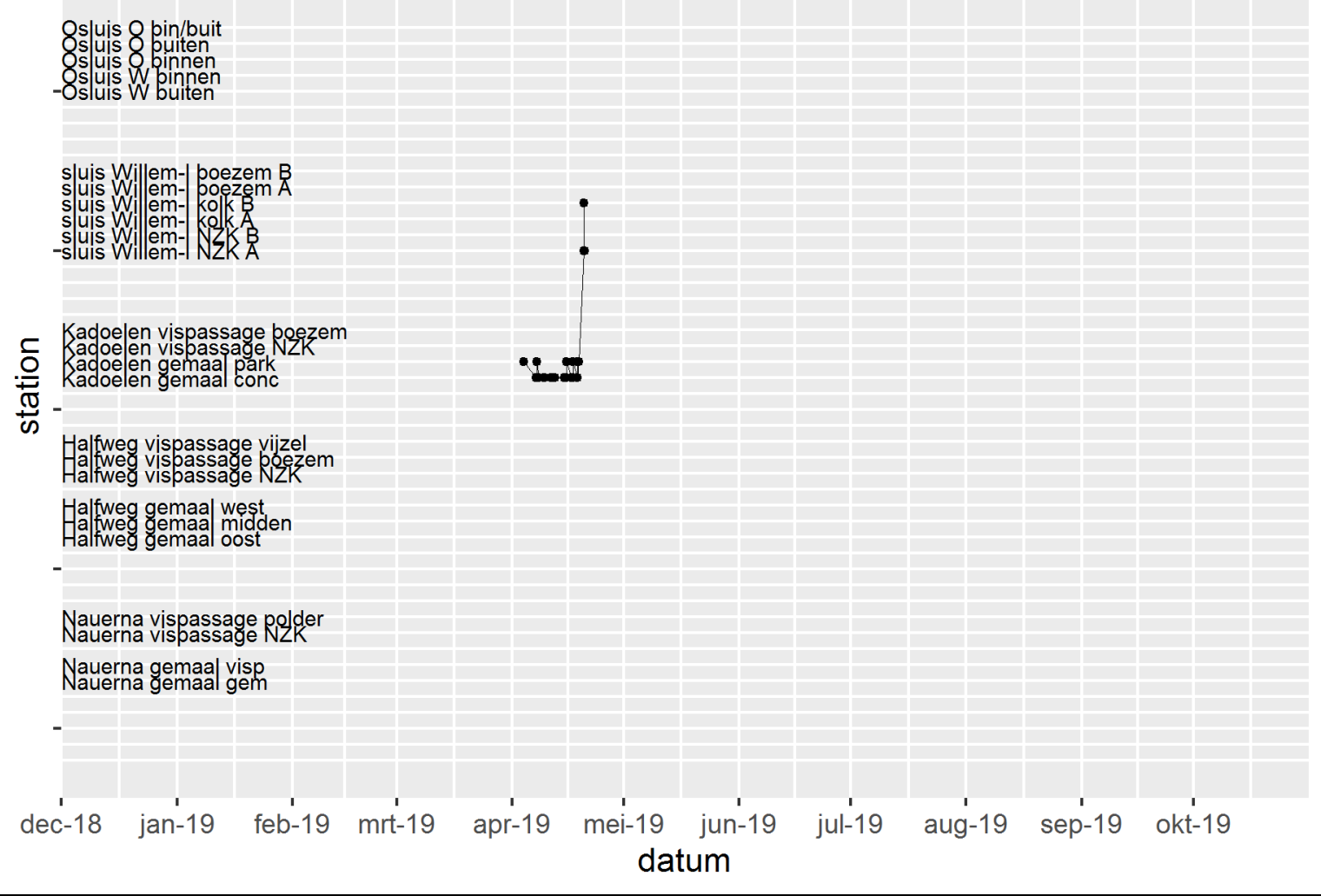


900_230000150278 Brasem 393 mm 758 gr Kadoelen 3-apr

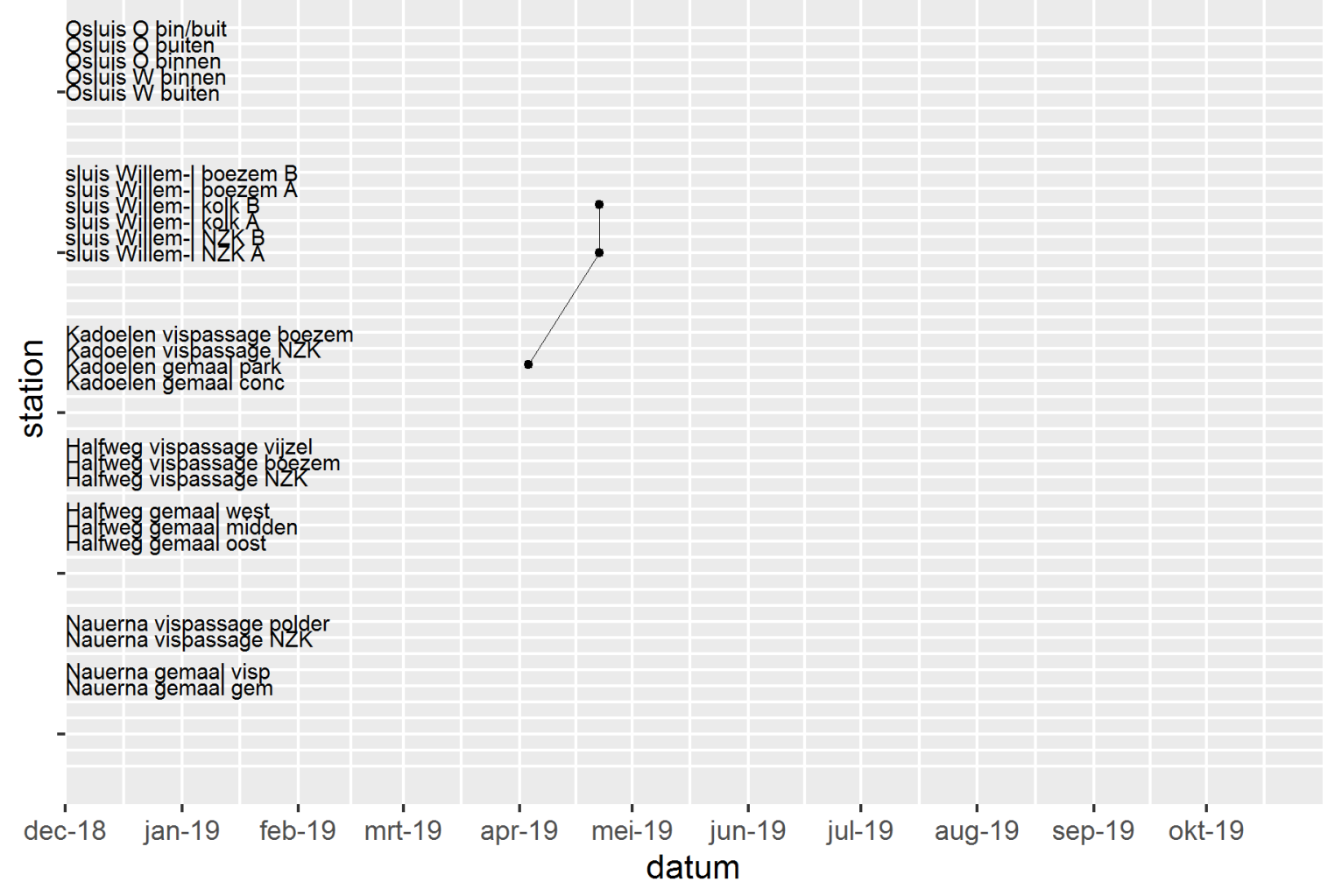

900_230000150306 Brasem 471 mm 1410 gr Kadoelen 3-apr

8stuis 8 pin/buit

8 suis binnen

- Osluis $W$ buiten

sluis Willem-|boezem B

suls W em- kolze

-sluis Willem-I NZK

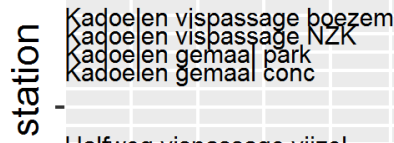

Iร.

Halfweg vispassage vijzel
Halfweg vispassage bijezem
Halfweg vispassage NZK

Halfweg gemaa west

Nauerna vispassage polder
Nauerna vispassage NZK

Nauerna gemaal visp

dec-18 jan-19 feb-19 mrt-19 apr-19 mei-19 jun-19 jul-19 aug-19 sep-19 okt-19 datum 
900_230000150316 Brasem 486 mm 1353 gr Kadoelen 3-apr

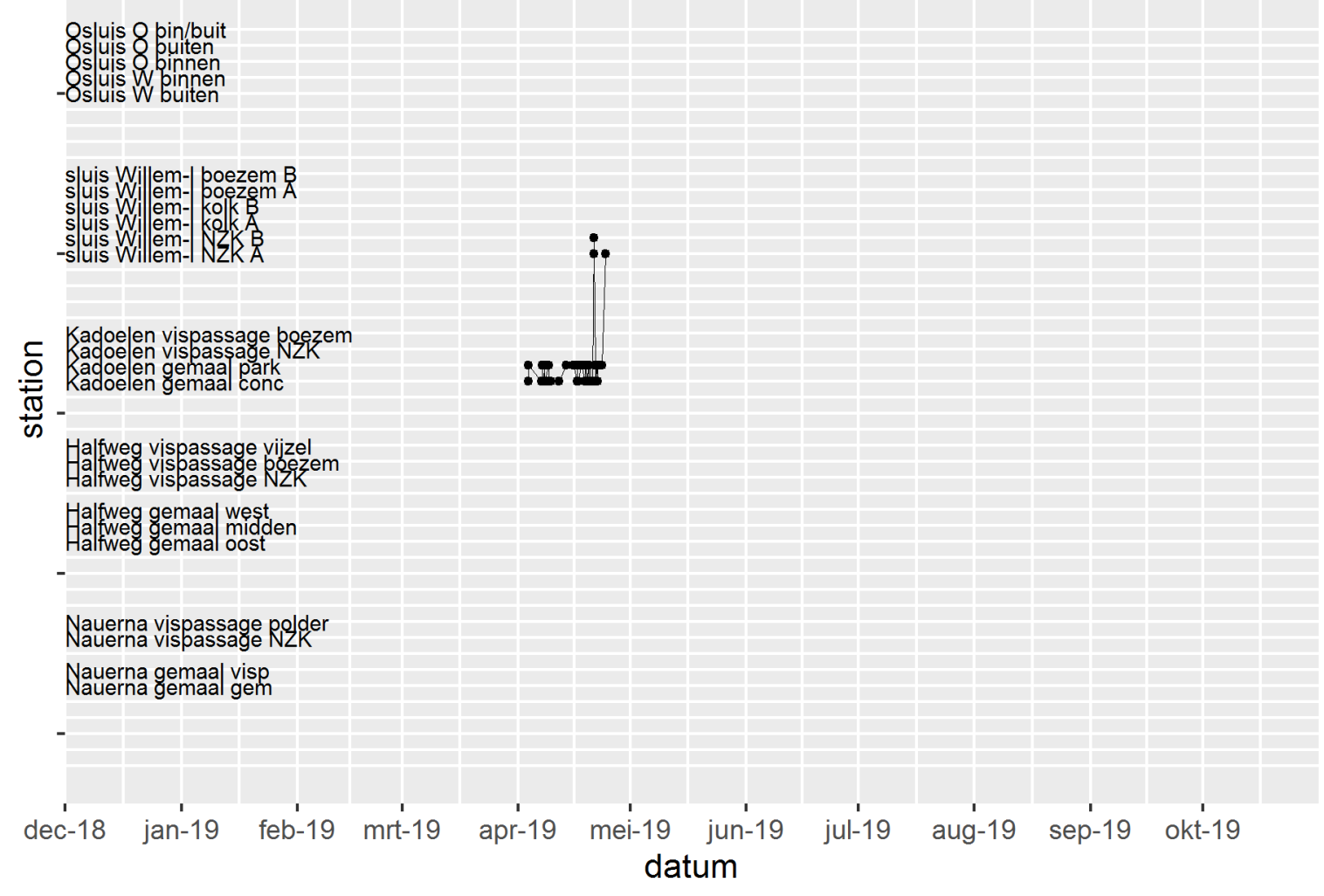

900_230000150318 Brasem 564 mm 1247 gr Kadoelen 3-apr

8stuis 8 pin/buit

8 s uis 8 binnen

- Osluis $W$ buiten

sluis Willem-|boezem B

suls W em- kolkz

s suis Willem- NZK

ᄃ Kadoelen vispassage poezem

aㅡoelen gemaal conc

III range?

क

Halfweg vispassage vijzel

Halfweg vispassage NZK

Halfweg gemaal west

Nauerna vispassage polder

Nauerna gemaal visp

dec-18 jan-19 feb-19 mrt-19 apr-19 mei-19 jun-19 jul-19 aug-19 sep-19 okt-19 datum 
900_230000150321 Brasem 556 mm 2281 gr Kadoelen 3-apr

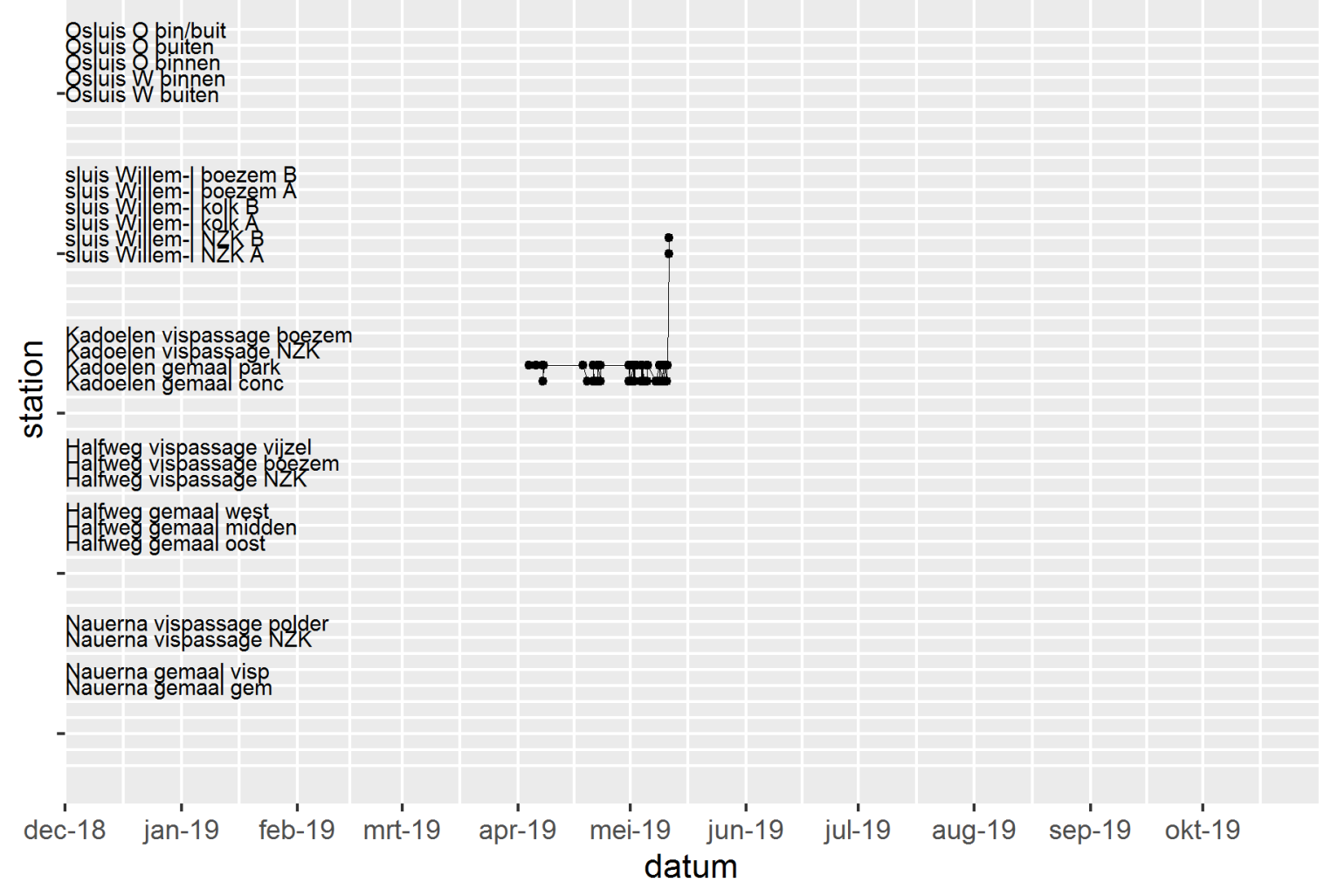

900_230000150334 Brasem 461 mm 960 gr Kadoelen 3-apr

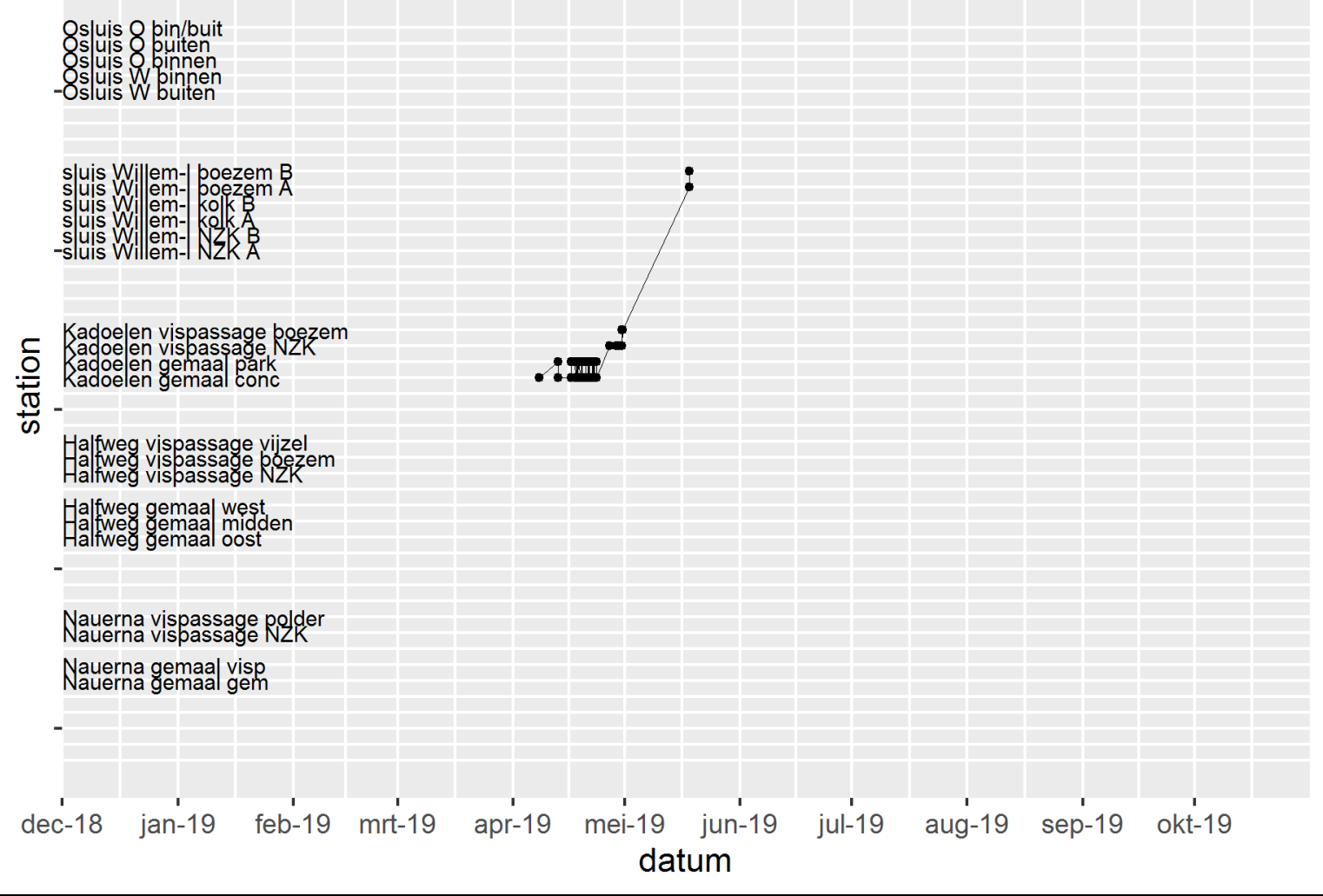


900_230000150335 Brasem 423 mm 1002 gr Kadoelen 3-apr

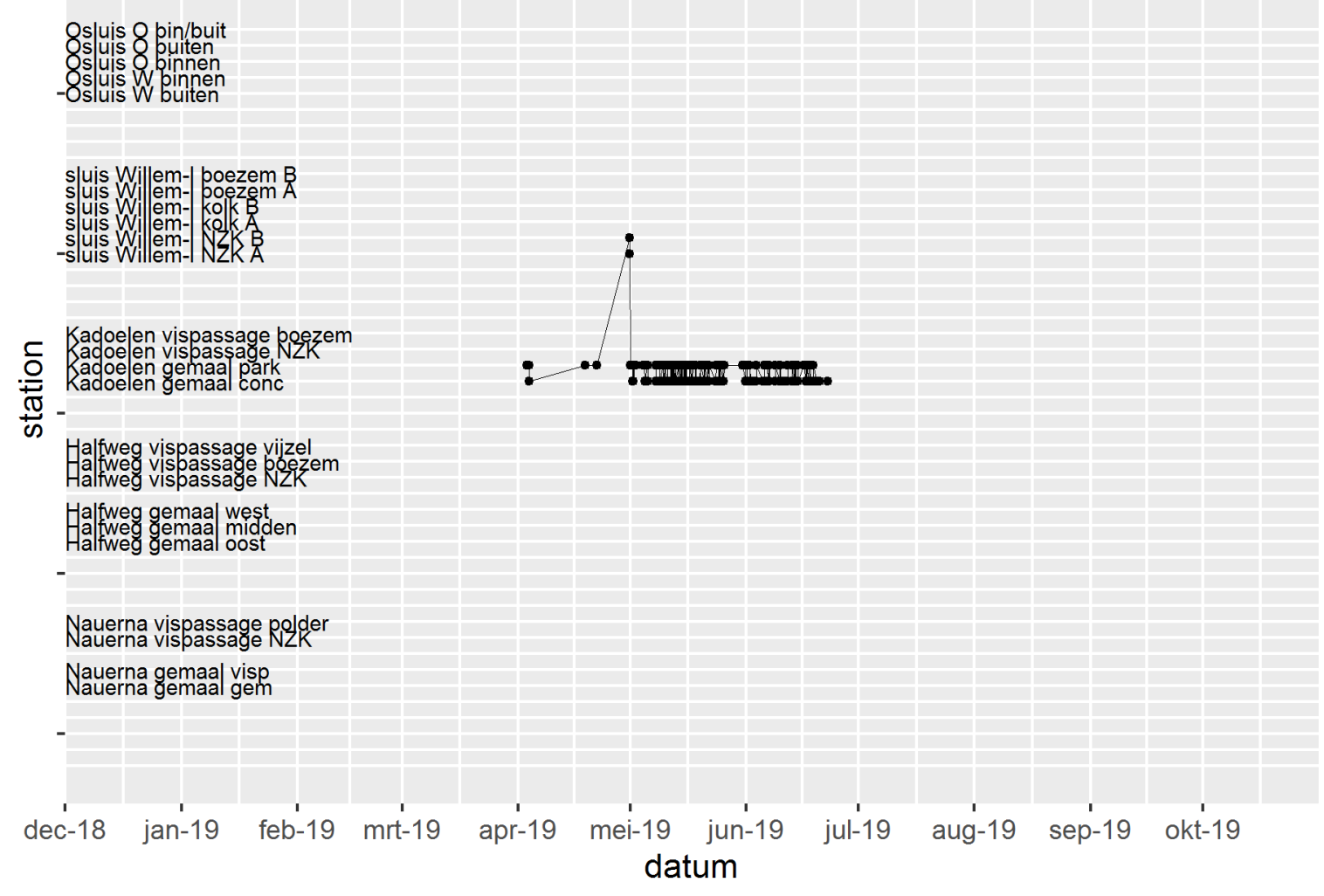

900_230000150339 Brasem 421 mm 877 gr Kadoelen 3-apr

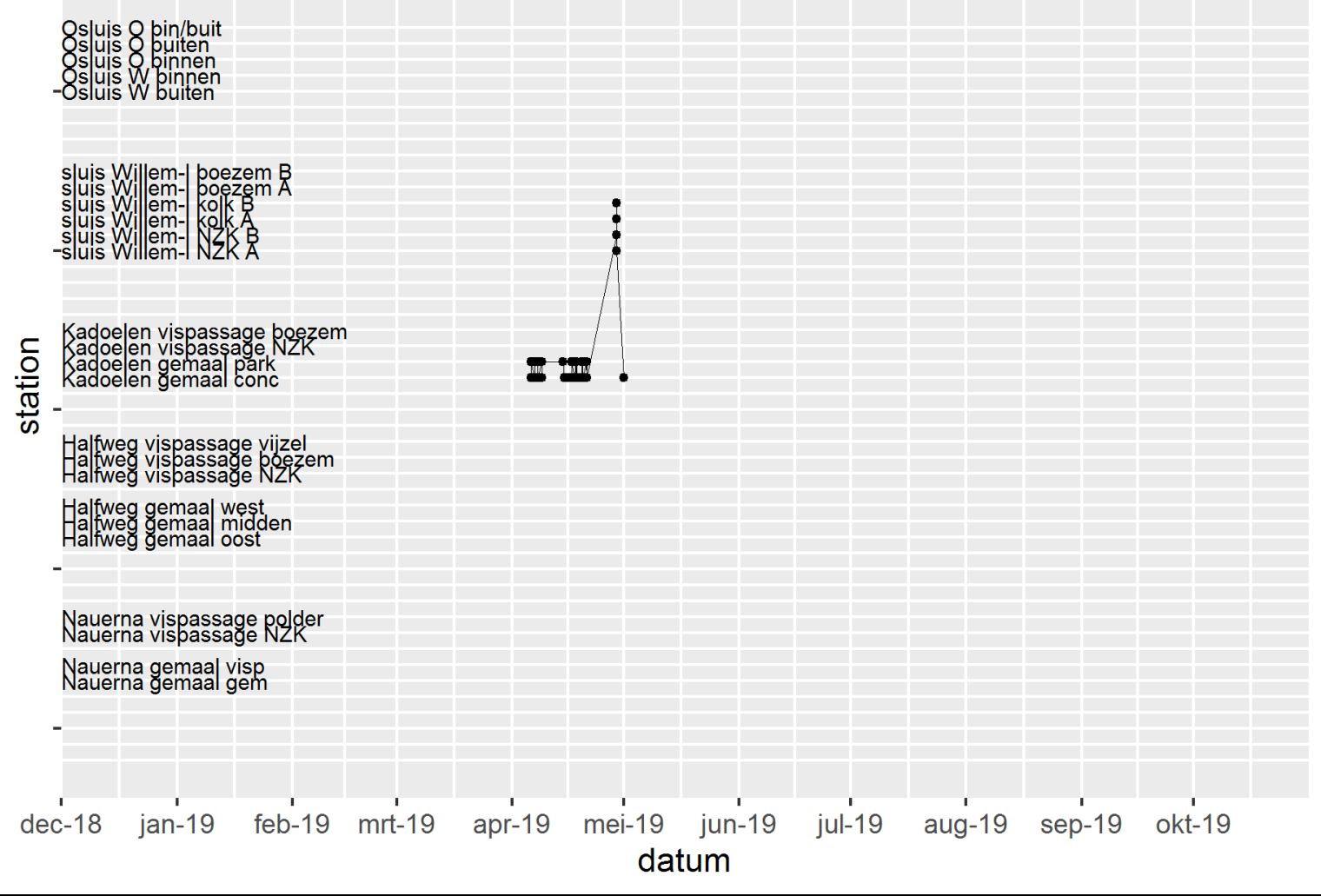


900_230000150344 Brasem 421 mm 1757 gr Kadoelen 3-apr

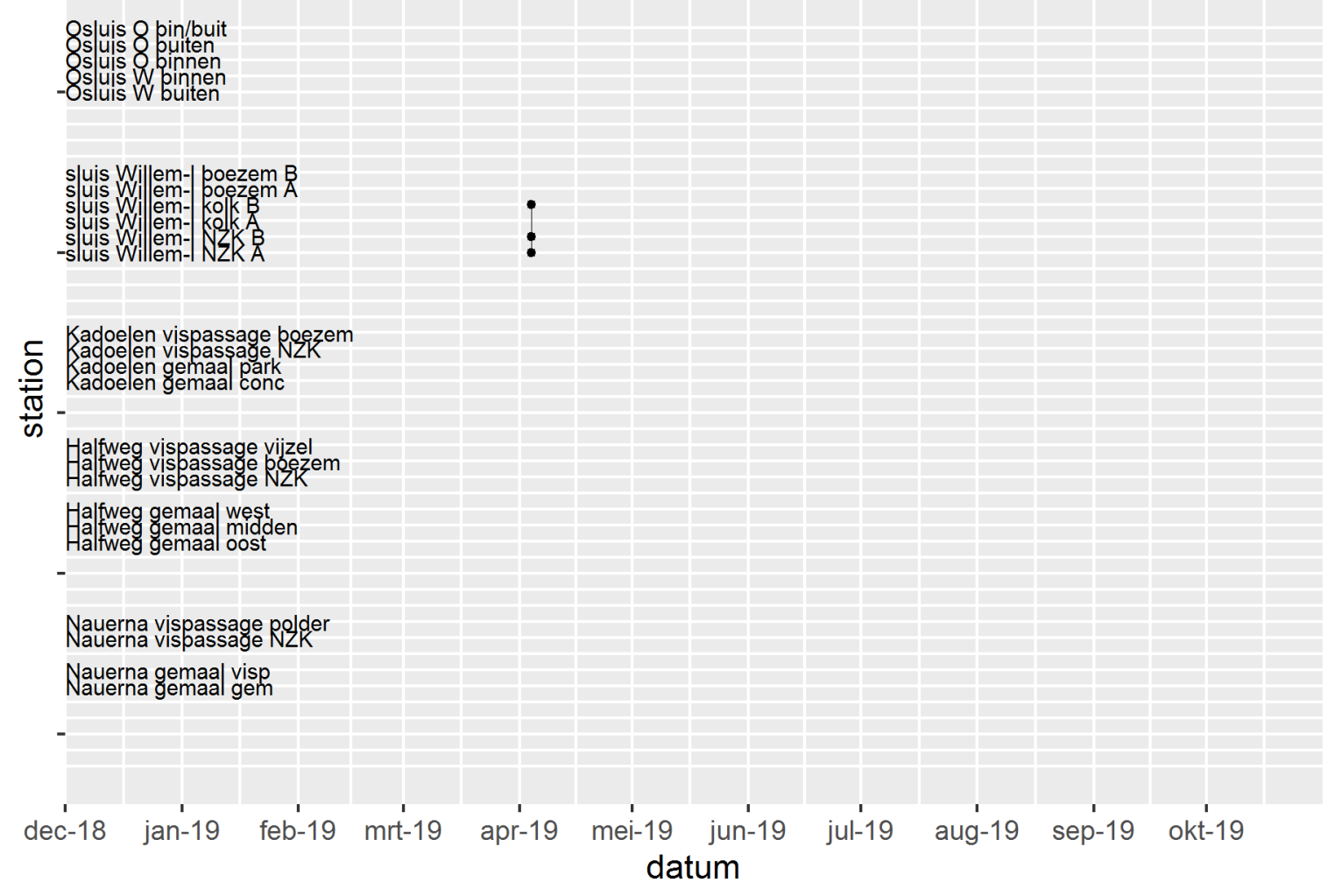

900_230000150350 Brasem 496 mm 1419 gr Kadoelen 3-apr

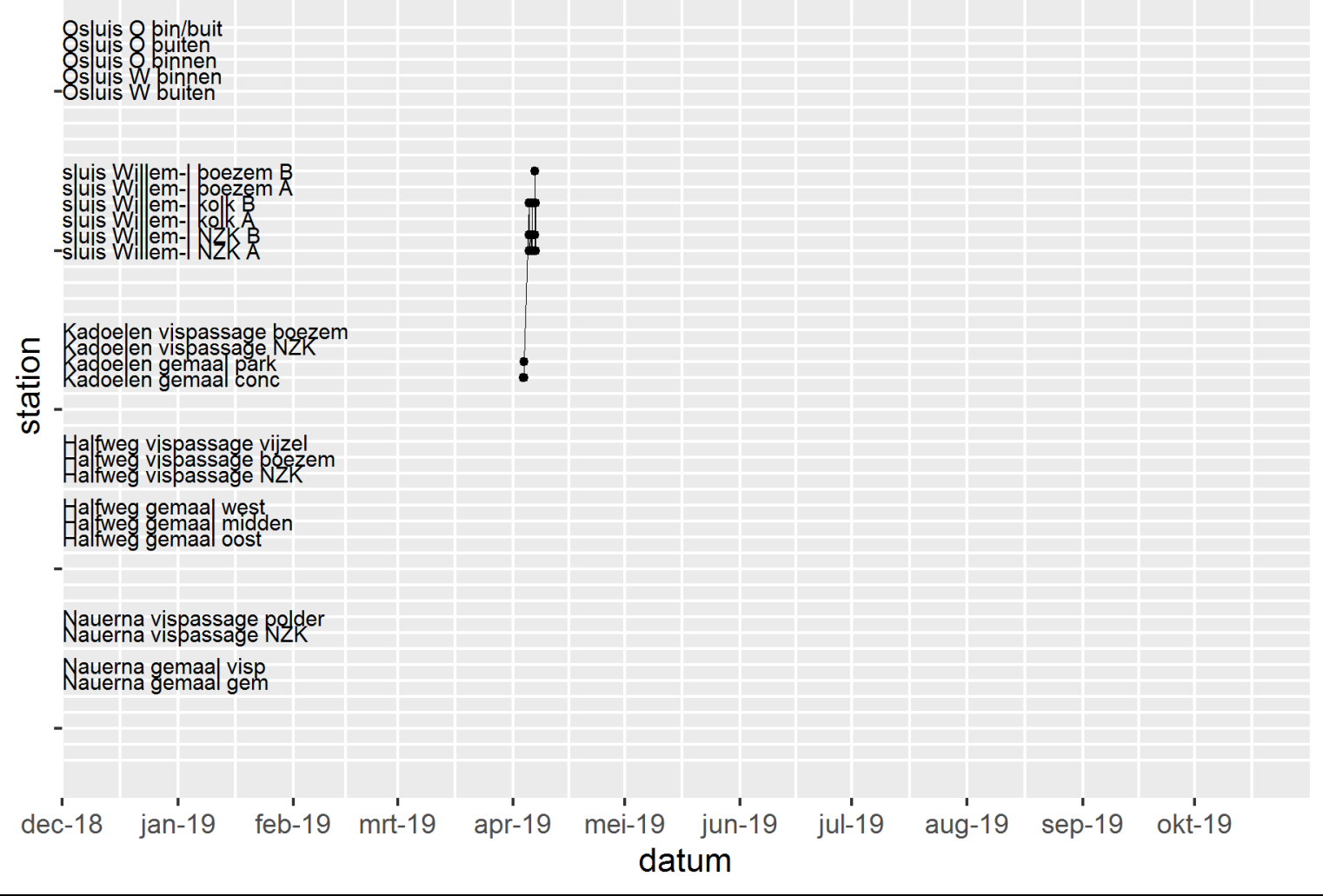


900_230000150351 Brasem 439 mm 1033 gr Kadoelen 3-apr

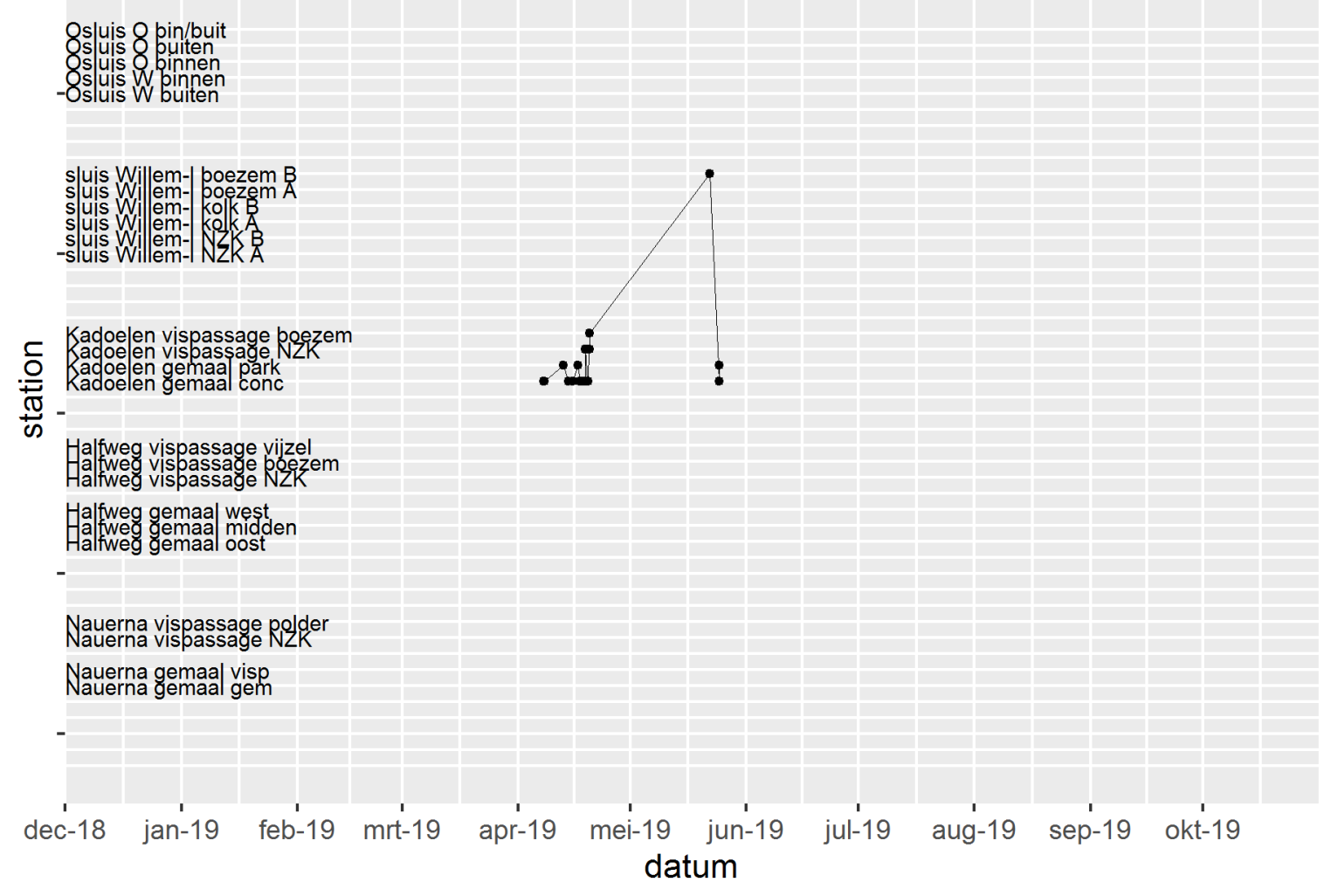

900_230000150353 Brasem 439 mm 973 gr Kadoelen 3-apr

8stuis 8 pin/buit

8s uis 8 binnen

- Osluis $W$ buiten

sluis Willem-|boezem B

uis W em- kolk

sluis Willem-1 NZK

c. Kadoelen vispassage poezem

aㅡoelen gemaal conc

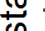

Halfweg vispassage vijzel
Ha|weg vispassage boezem
Halfweg vispassage NZK

Halfweg gemaa west

Nauerna vispassage polder

Nauerna gemaal visp

dec-18 jan-19 feb-19 mrt-19 apr-19 mei-19 jun-19 jul-19 aug-19 sep-19 okt-19 datum 
900_230000150367 Brasem 474 mm 1360 gr Kadoelen 3-apr

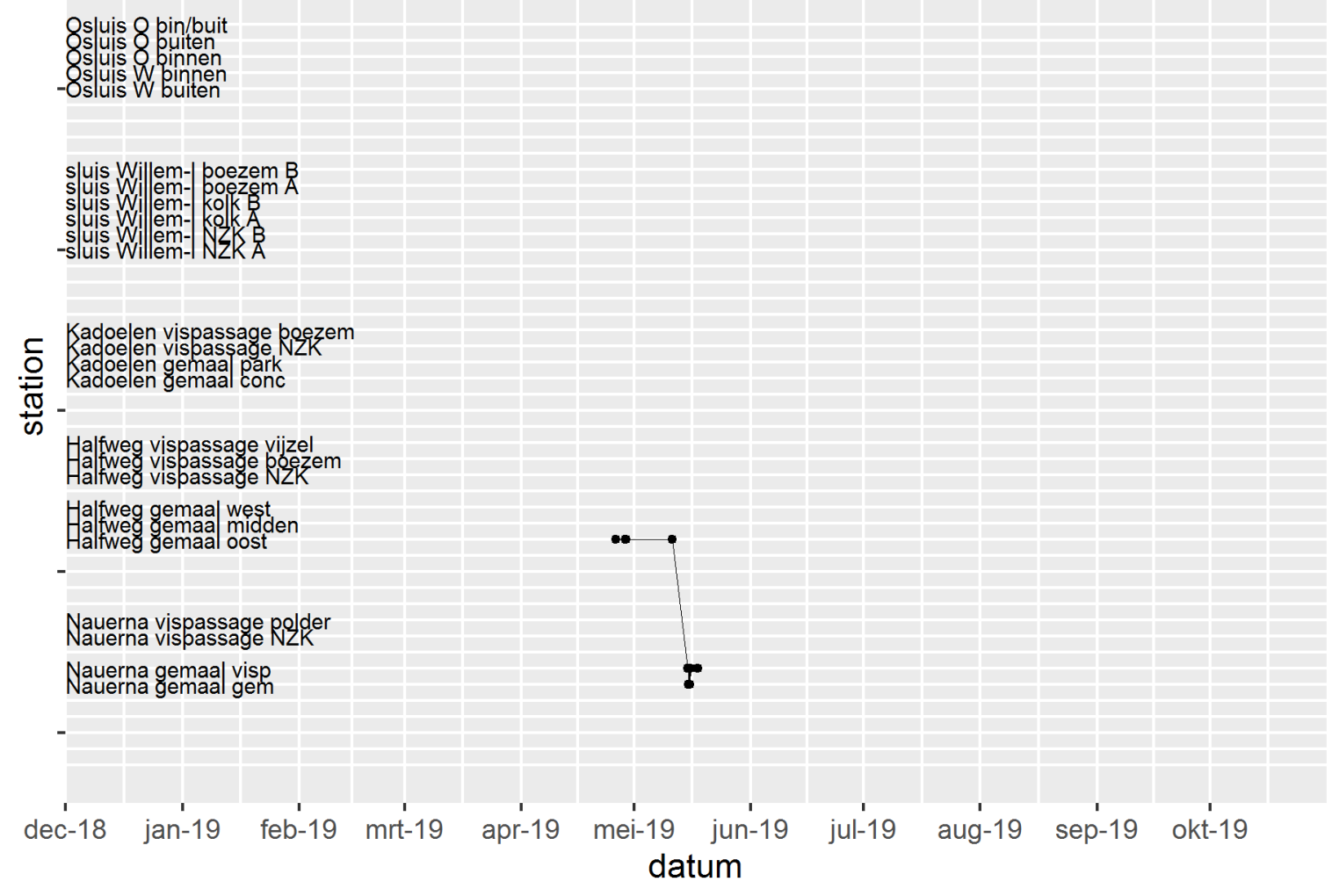

900_230000150378 Karper 745 mm NA gr Kadoelen 3-apr

8stuis 8 bin/buit

8 suis o binnen

- Osluis $W$ buiten

s|uis Willem-| poezem $B$

uns Wil em- em- koezer

-sluis Willem-1 NZK A

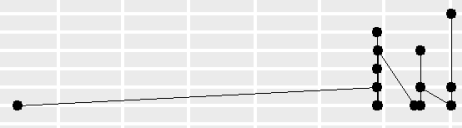

ᄃ Kadoe len vispassage boezem

으 Radoelen gemaal park

$\frac{\pi}{C}$

Halfweg vispassage vijzel

Halfweg vispassage NZK

Halfweg gemaal west

Nauerna vispassage polder

Nauerna gemaa| visp

dec-18 jan-19 feb-19 mrt-19 apr-19 mei-19 jun-19 jul-19 aug-19 sep-19 okt-19 datum 
900_230000150396 Brasem 411 mm 630 gr Kadoelen 3-apr

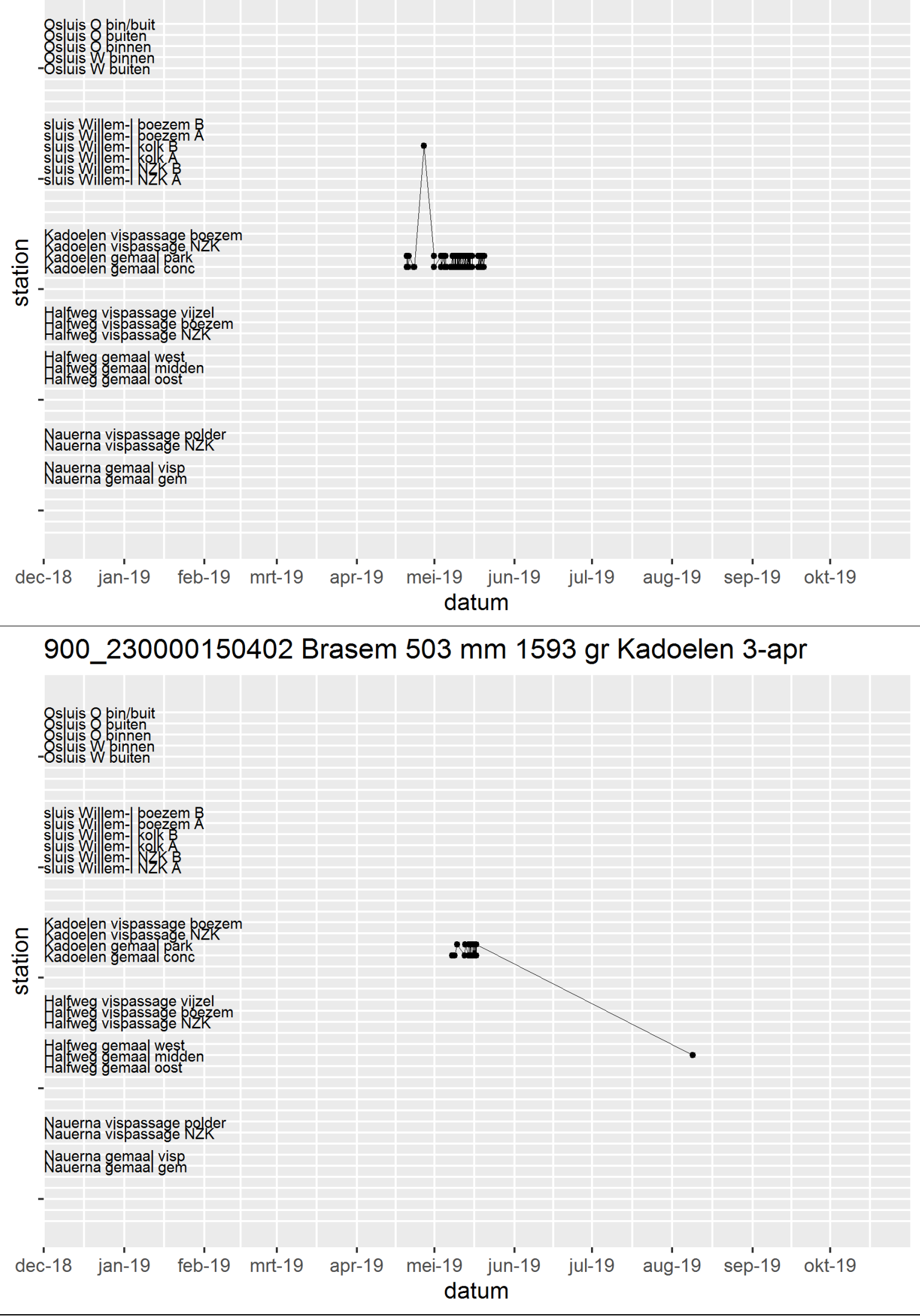


900_230000150417 Brasem 533 mm 2556 gr Kadoelen 3-apr

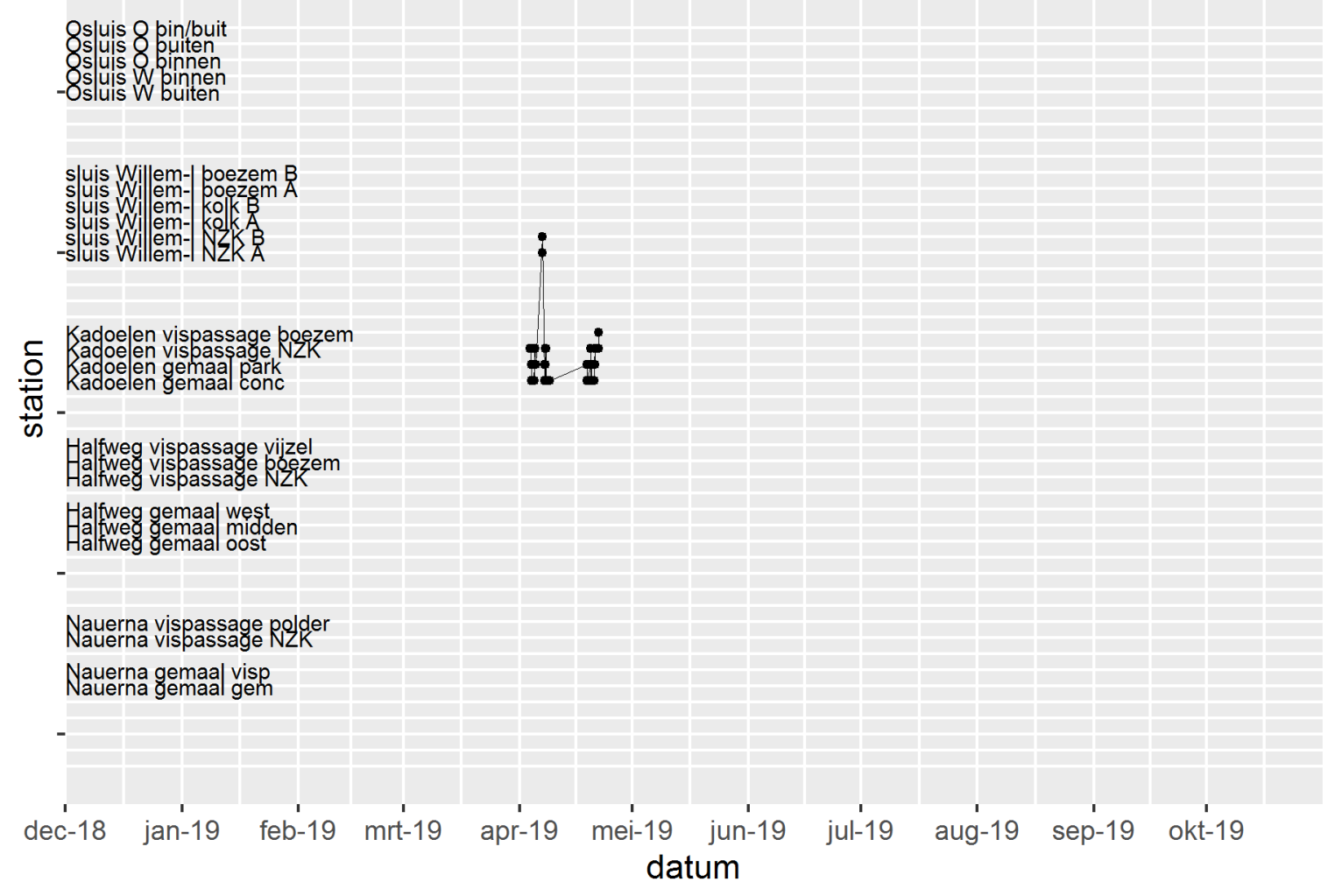

900_230000150430 Brasem 417 mm 819 gr Kadoelen 3-apr

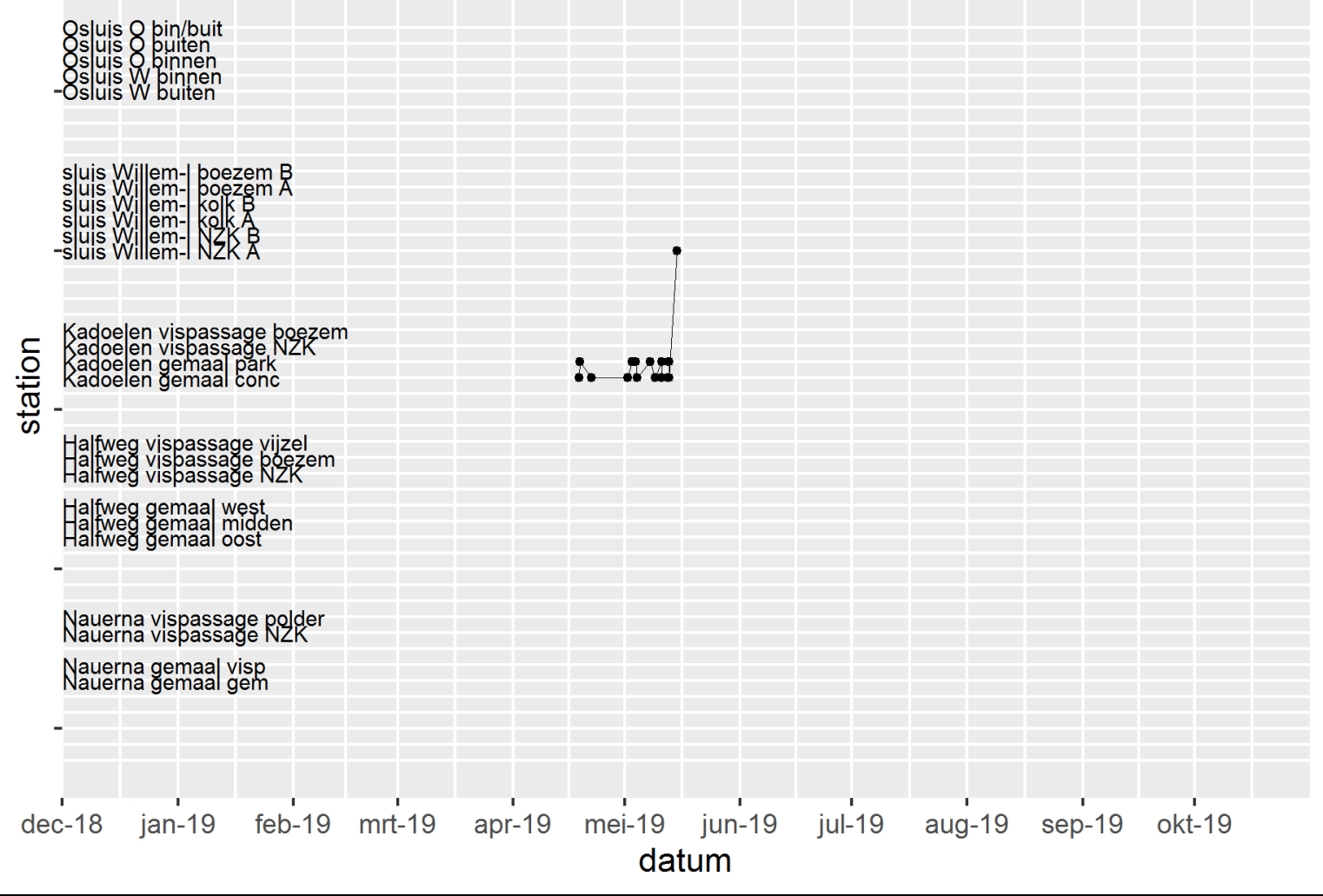


900_230000150440 Brasem 549 mm 1840 gr Kadoelen 3-apr

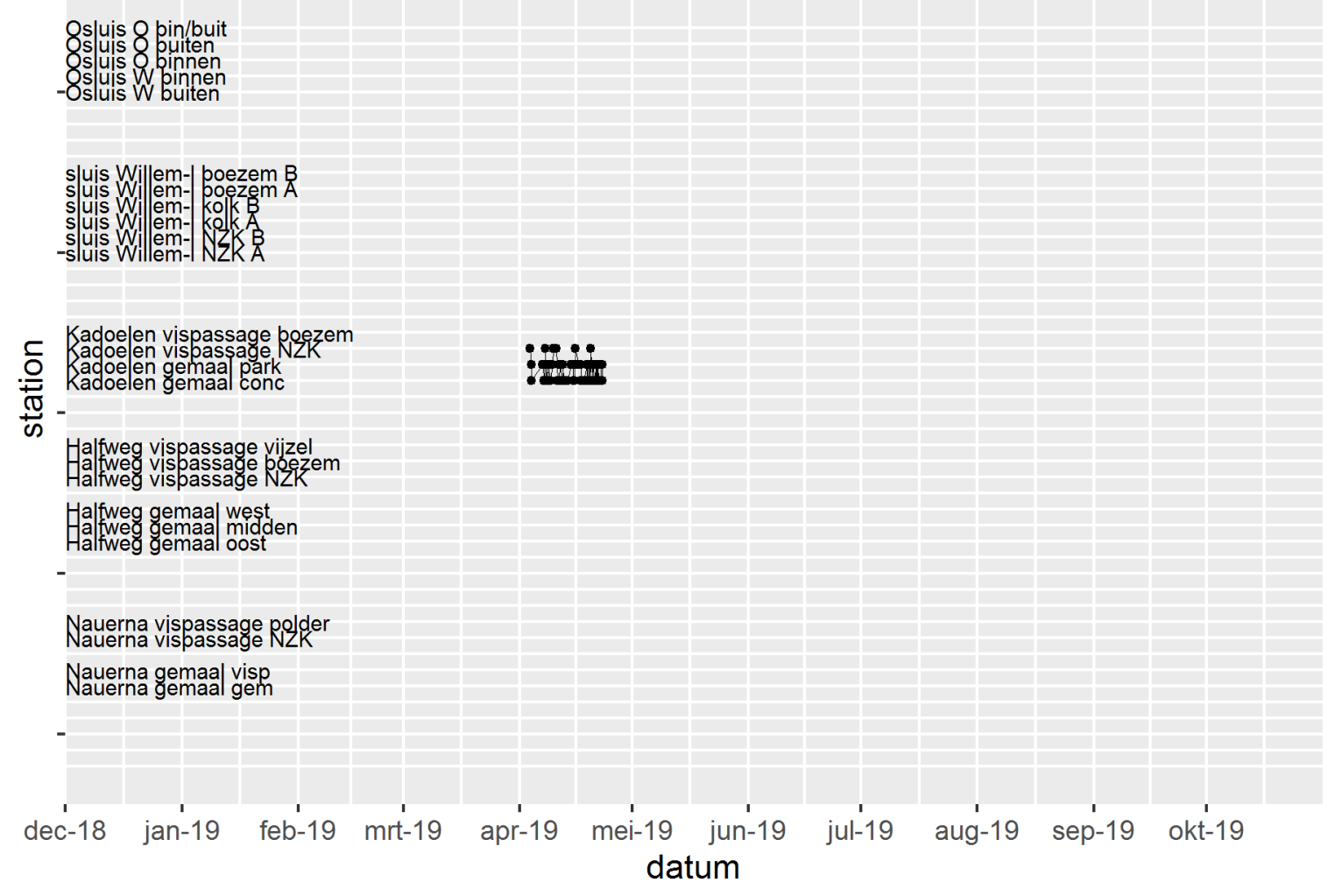

900_230000150441 Brasem 450 mm 1145 gr Kadoelen 3-apr

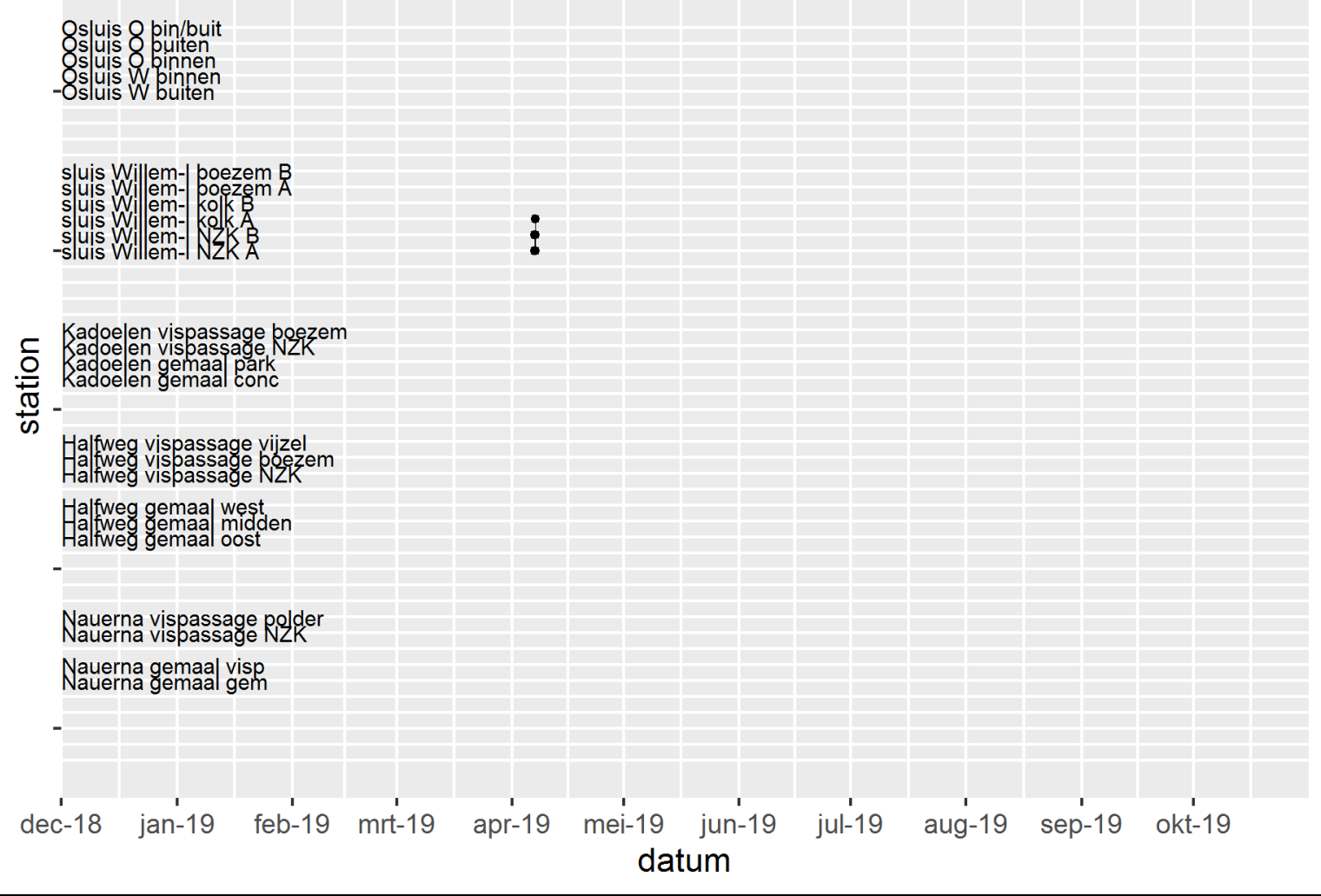


900_230000150443 Brasem 428 mm 1035 gr Kadoelen 3-apr

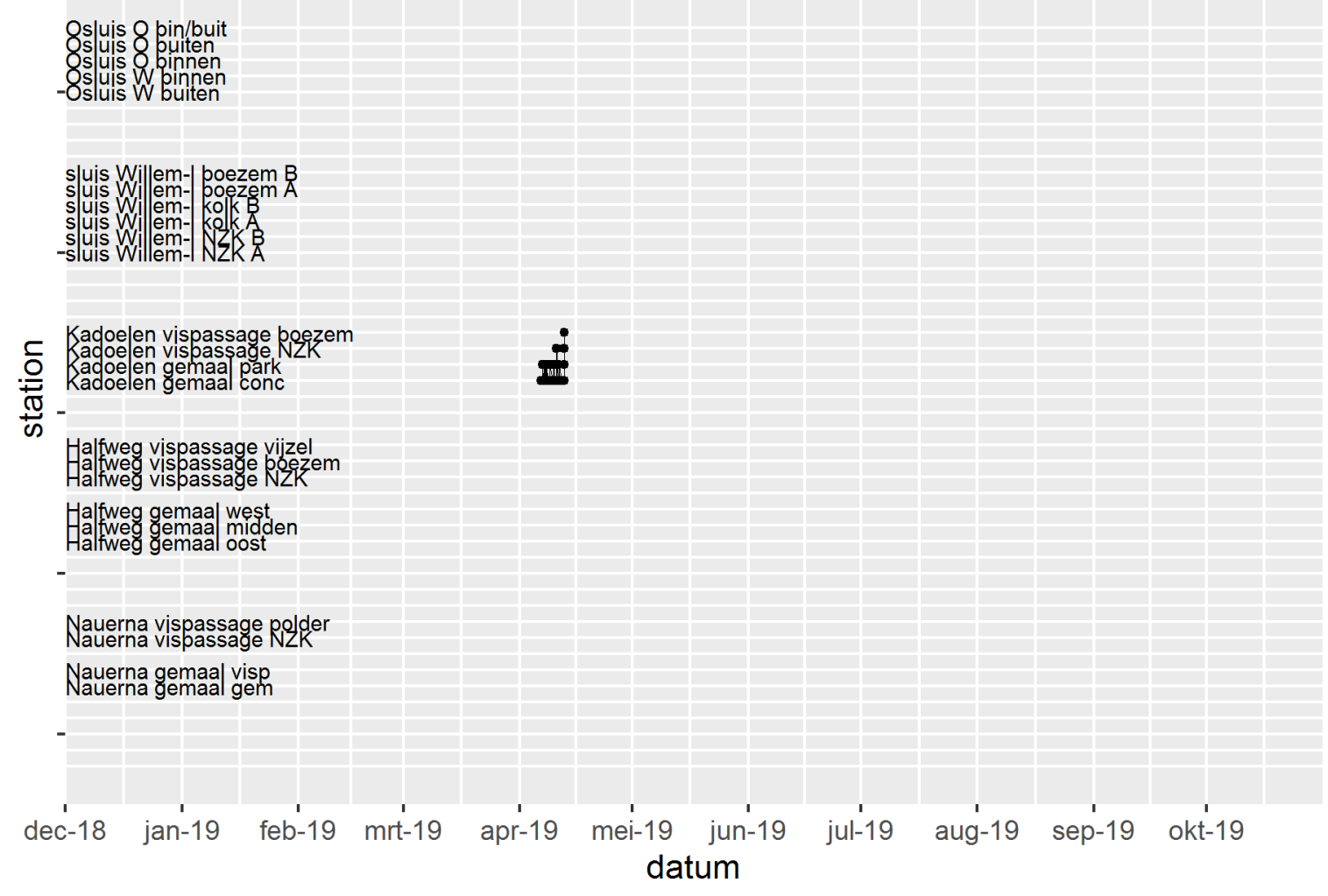

900_230000150446 Brasem 480 mm 1372 gr Kadoelen 3-apr

8stuis 8 pin/buit

8 suis binnen

- Osluis $W$ buiten

sluis Willem-|boezem B

suls Wi em- kolk

-sluis Willem-1 NZK A

ᄃ. Kadoe ${ }^{2}$ vispassage boezem

으 Kadoelen gemaal park

T)

Halfweg vispassage vijzel

Halfweg vispassage NZK

Halfweg gemaa| west

Nauerna vispassage polder

Nauerna gemaal visp

dec-18 jan-19 feb-19 mrt-19 apr-19 mei-19 jun-19 jul-19 aug-19 sep-19 okt-19 datum 
900_230000150449 Brasem 532 mm 2194 gr Kadoelen 3-apr

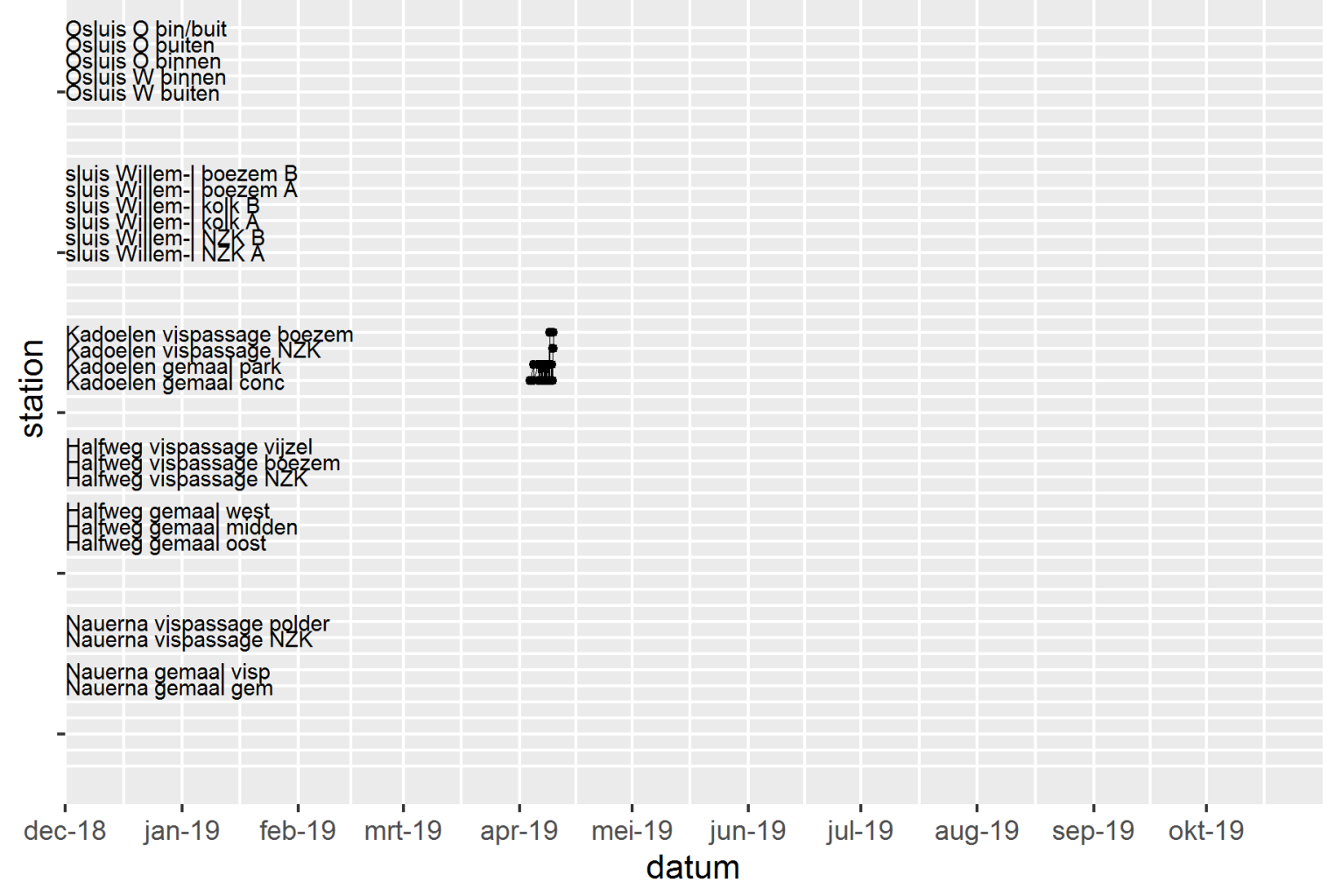

900_230000150455 Brasem 501 mm 1035 gr Kadoelen 3-apr

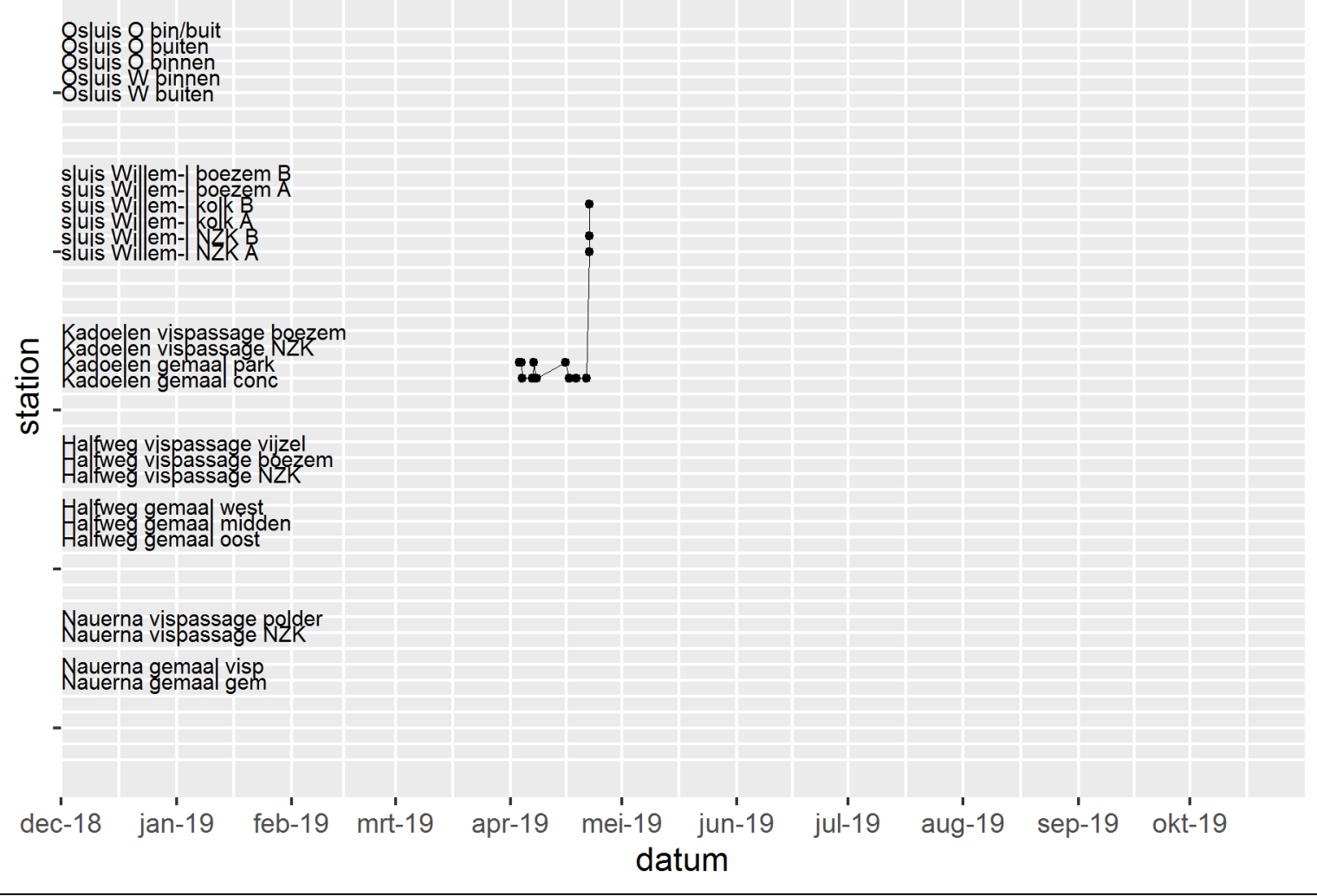


900_230000150459 Snoekbaars 590 mm 1696 gr Halfweg 8-apr

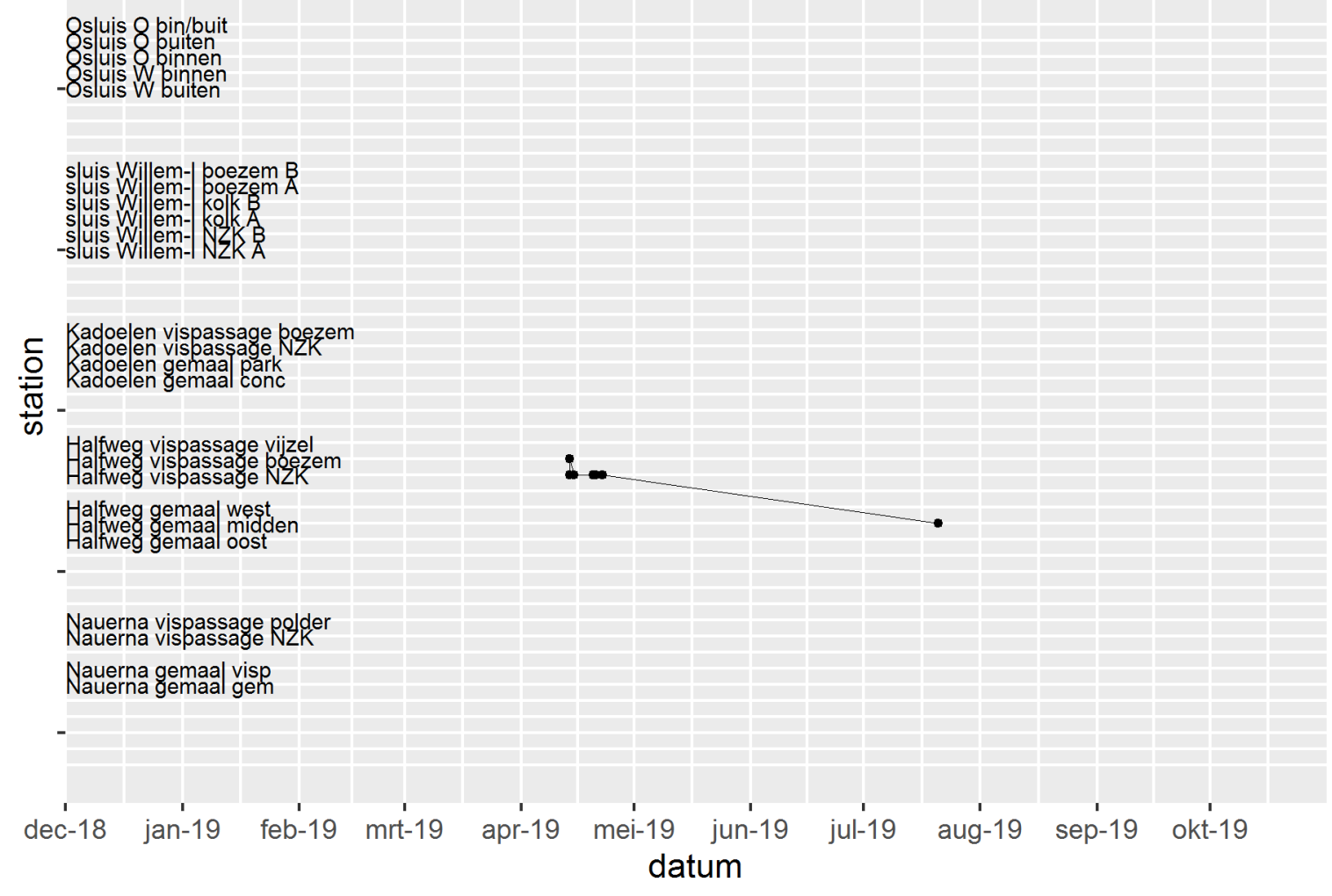

900_230000150468 Brasem 511 mm 1684 gr Kadoelen 15-apr

8s suis 8 binibuit

8 suis binnen

- Osluis $W$ buiten

sluis Willem-|boezem B

uis Wi em- kolk

-sluis Willem-1 NZK

ᄃ Kadoe Kan vispassage poezem

aㅡoelen gemaal conc

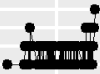

Halfweg vispassage vijzel

lalfweg vispassage NZK

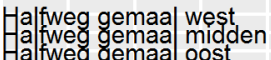

Nauerna vispassage polder

Nauerna gemaal visp

dec-18 jan-19 feb-19 mrt-19 apr-19 mei-19 jun-19 jul-19 aug-19 sep-19 okt-19 datum 
900_230000150478 Snoek 495 mm 785 gr Kadoelen 15-apr

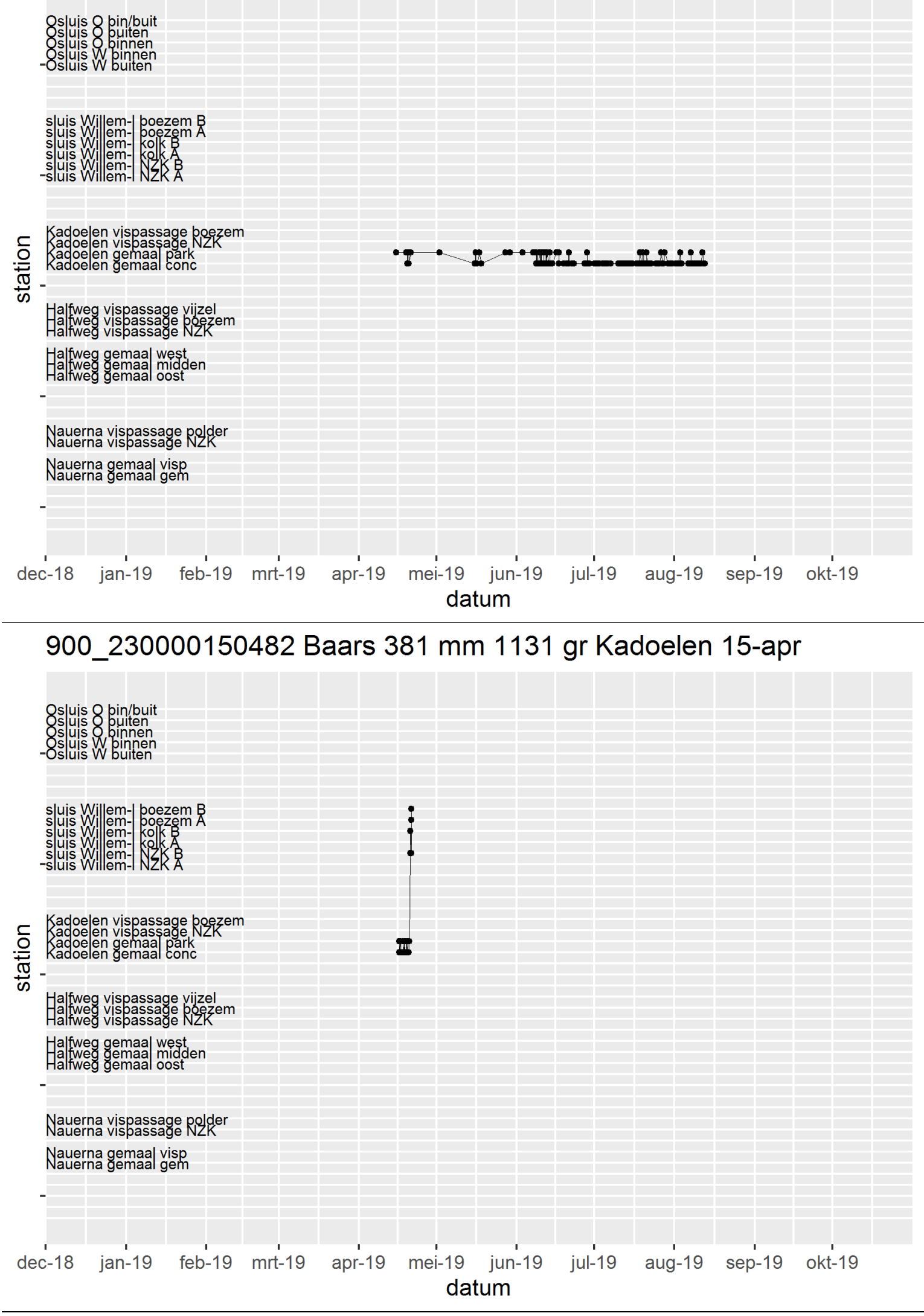


900_230000150792 Brasem 509 mm 1554 gr Nauerna 2-mei

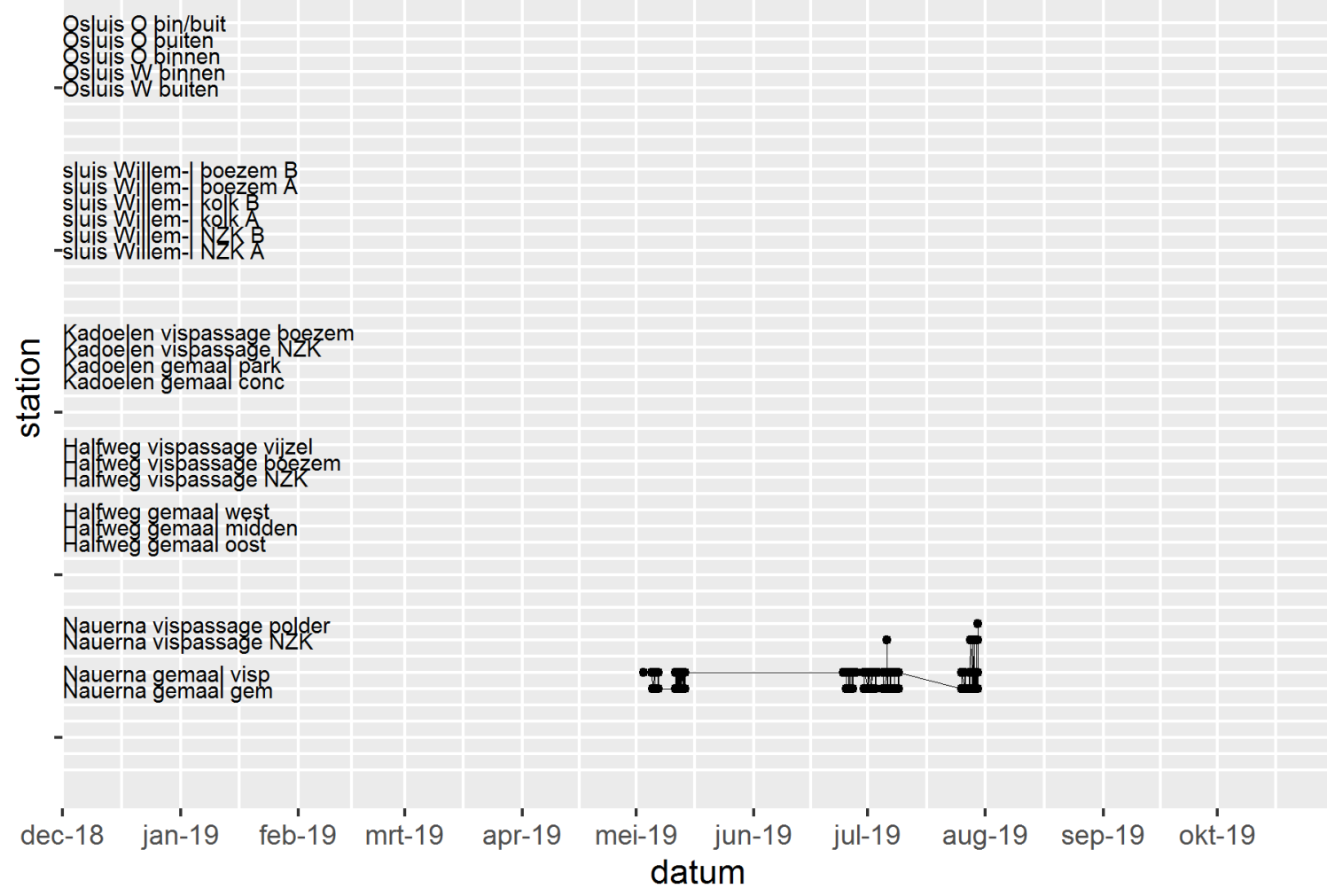

900_230000150798 Brasem 475 mm 1245 gr Nauerna 2-mei

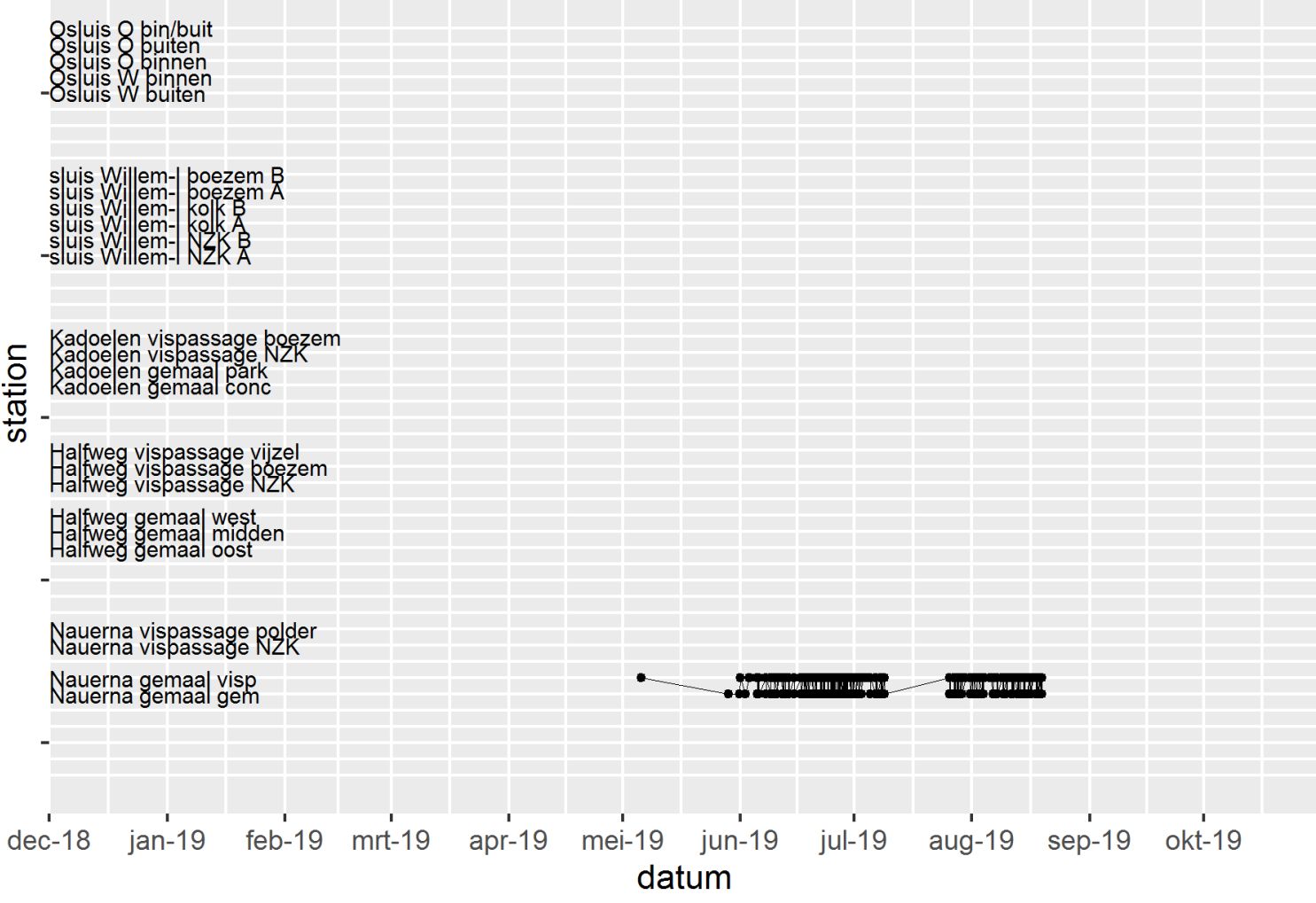


900_230000150840 Brasem 575 mm 1208 gr Nauerna 2-mei

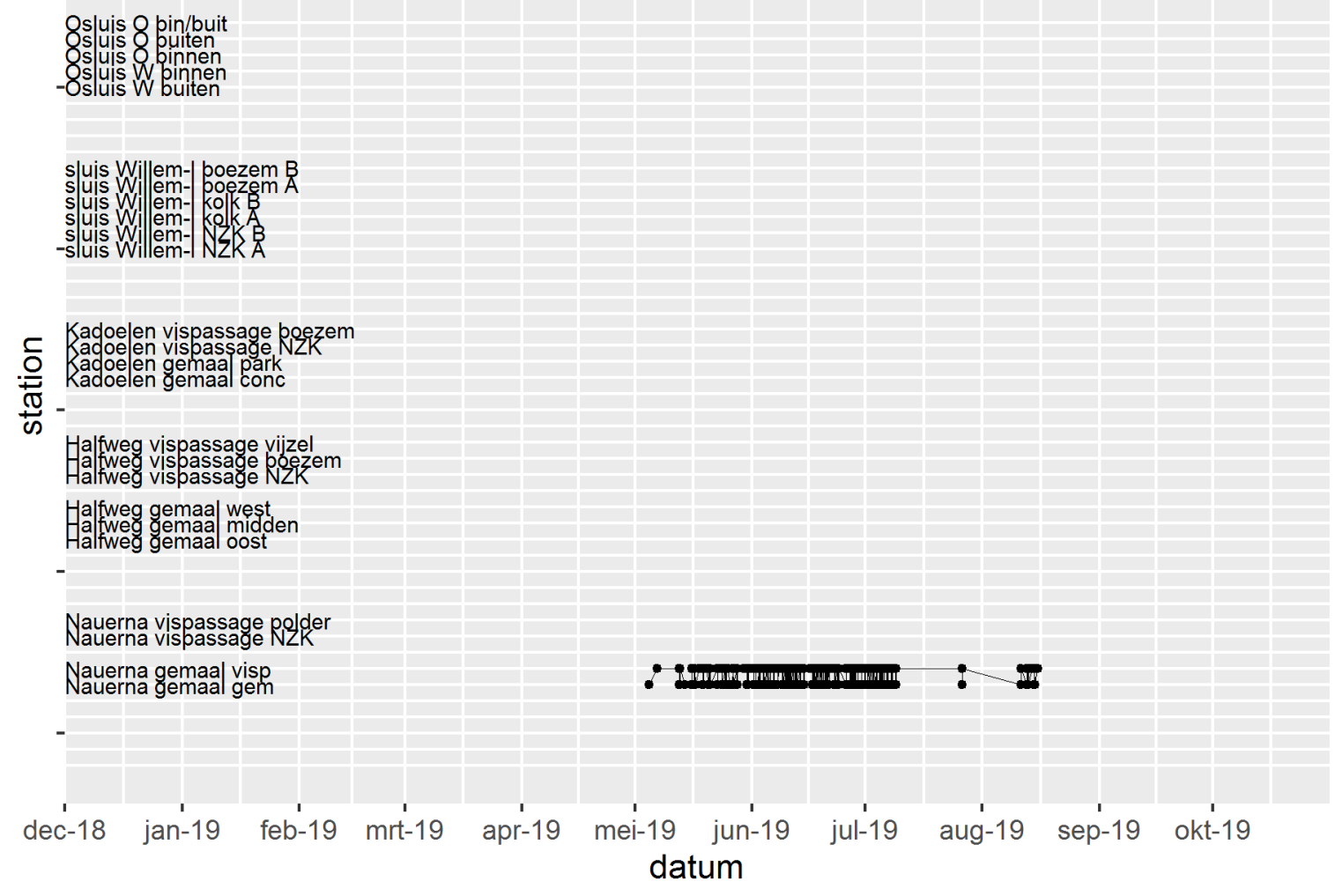

900_230000150841 Brasem 478 mm 1405 gr Nauerna 2-mei
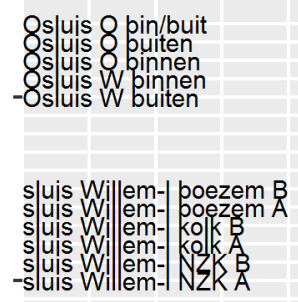

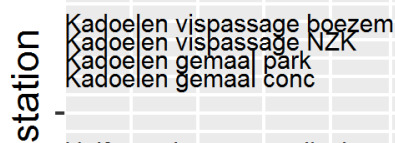

Halfweg vispassage vijzel
Haweg vispassage pejez
halfweg vispassage NŽ

Halfweg gemaa| west

Nauerna vispassage polder
Nauerna visassage NZK

Nauerna gemaa visp

7x

dec-18 jan-19 feb-19 mrt-19 apr-19 mei-19 jun-19 jul-19 aug-19 sep-19 okt-19 datum 
900_230000150843 Brasem 489 mm 1510 gr Nauerna 2-mei

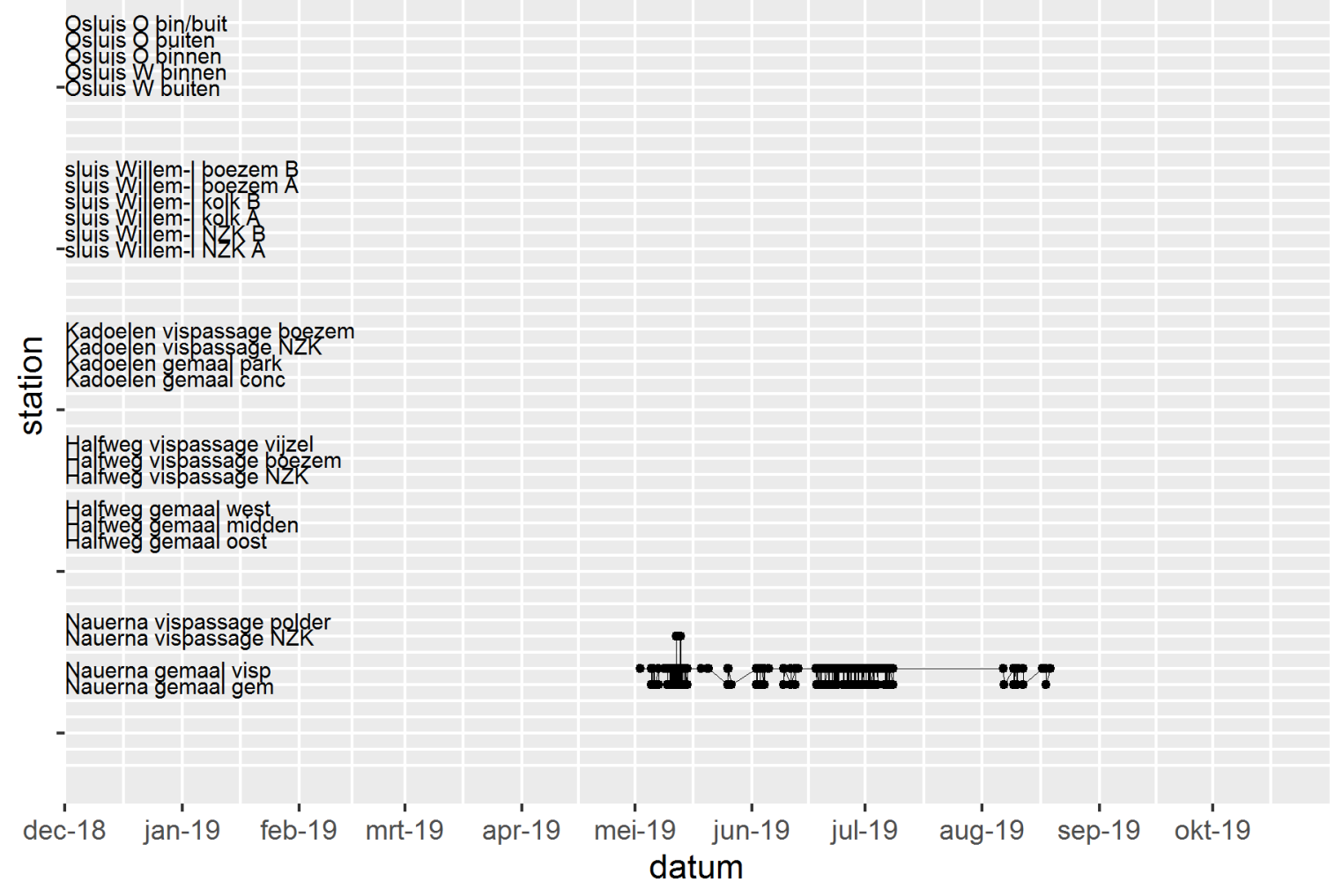

900_230000150844 Brasem 396 mm 808 gr Nauerna 2-mei

8s suis 8 binibuit

8 suls uninnen

- Osluis $W$ buiten

sluis Wil|em-| boezem B

suls W em- kolkz

-sluis Willem-1 NZK A

ᄃ Kadoeen vispassage poezem

Radoelen gemaal conc

की

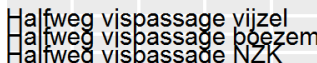

Halfweg gemaal west

Nauerna vispassage polder

Nauerna gemaa| visp

dec-18 jan-19 feb-19 mrt-19 apr-19 mei-19 jun-19 jul-19 aug-19 sep-19 okt-19 datum 
900_230000150850 Brasem 480 mm 1254 gr Nauerna 2-mei

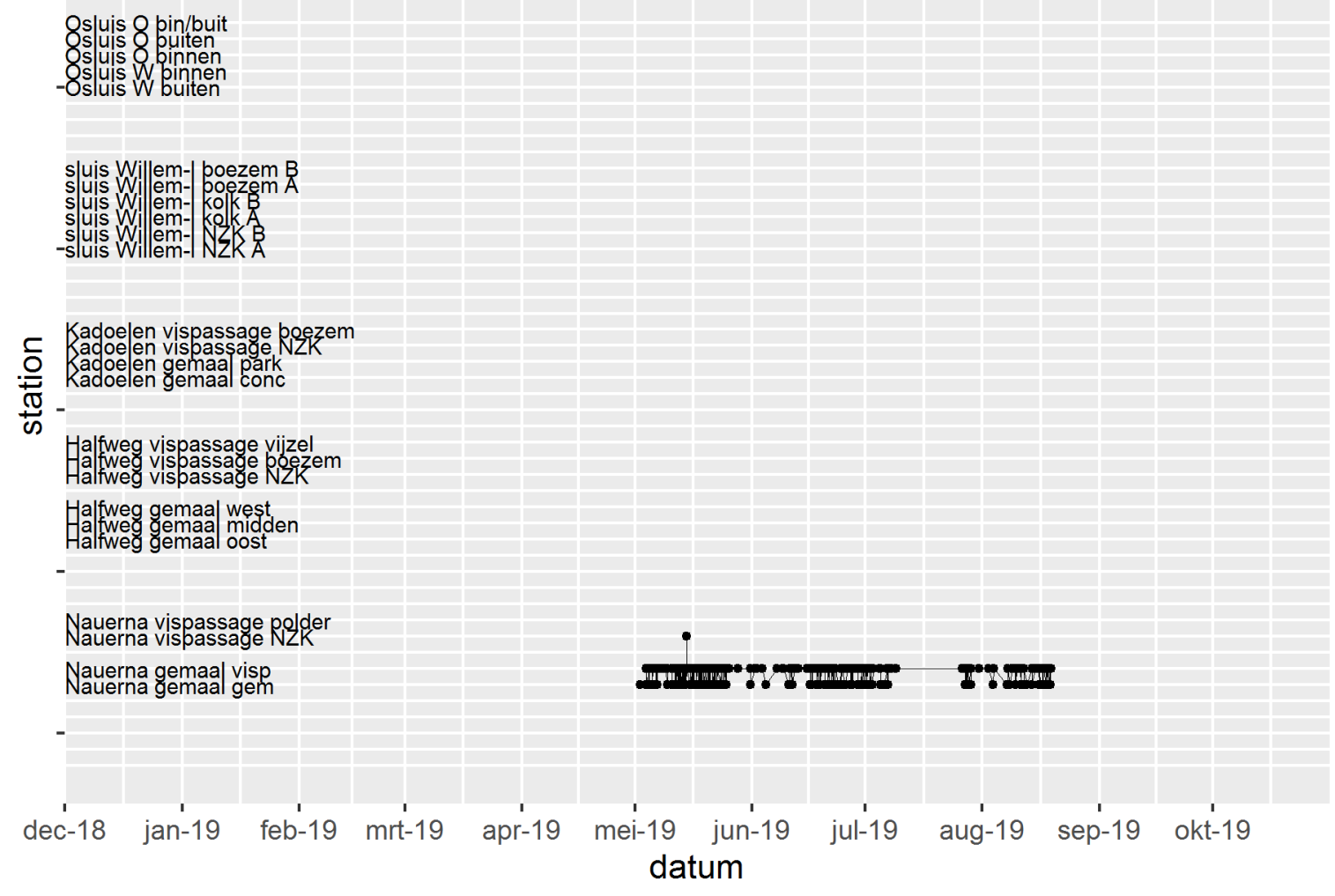

900_230000150853 Brasem 462 mm 1038 gr Nauerna 2-mei

8s suis 8 binibuit

8 suls uninnen

- Osluis $W$ buiten

sluis Wil|em-| boezem B

suls W em- kolkz

sluis Willem- NZK

c Kadoeen vispassage poezem

글 Kadoelen gemaal conc

का

Halfweg vispassage vijzel

Halfweg vispassage NZK

Halfweg gemaa| west

Nauerna vispassage polder

Nauerna gemaa| visp

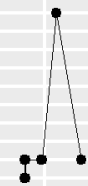

dec-18 jan-19 feb-19 mrt-19 apr-19 mei-19 jun-19 jul-19 aug-19 sep-19 okt-19 datum 
900_230000150869 Brasem 413 mm 880 gr Nauerna 7-mei

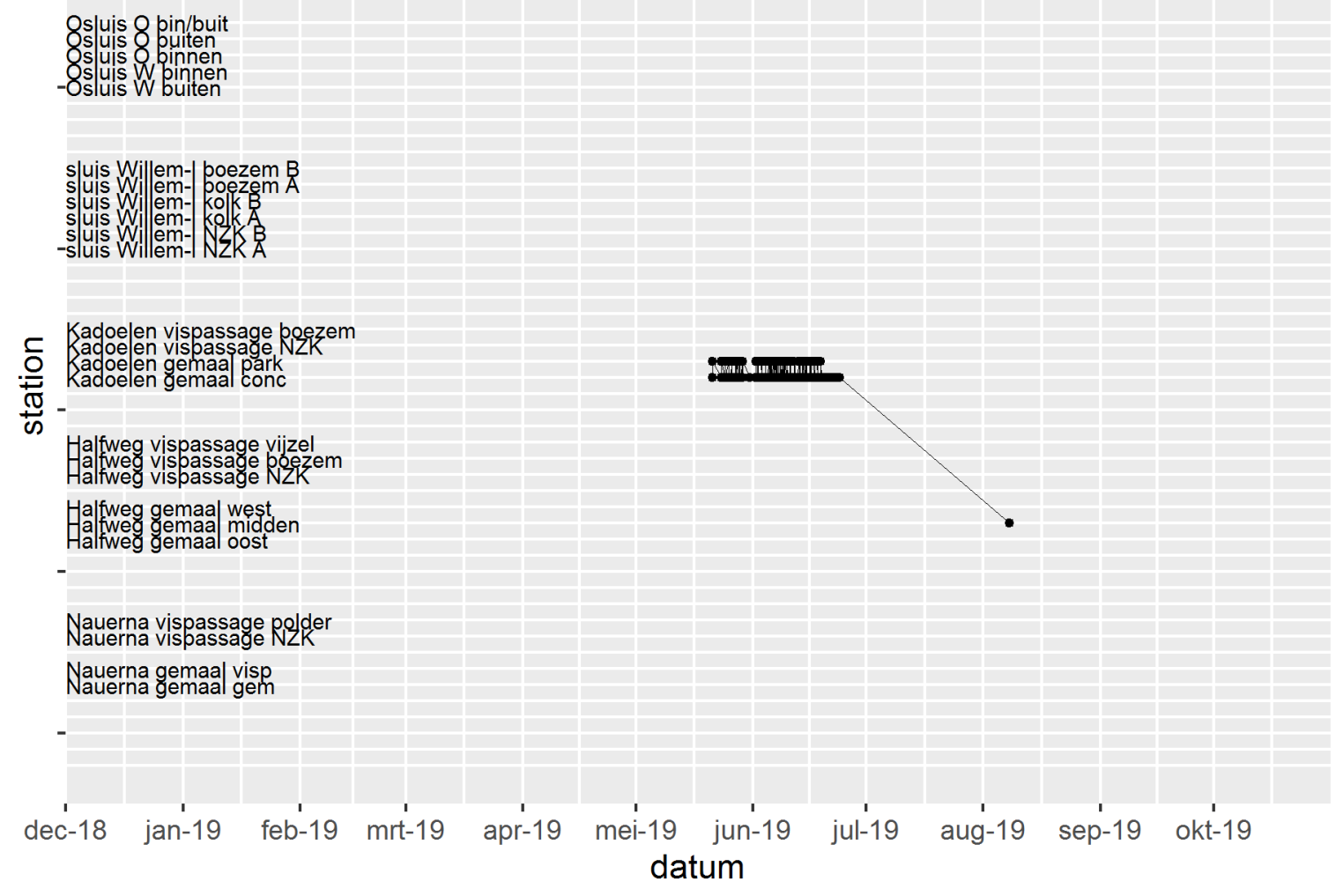

900_230000150913 Brasem 425 mm 1020 gr Kadoelen 9-mei

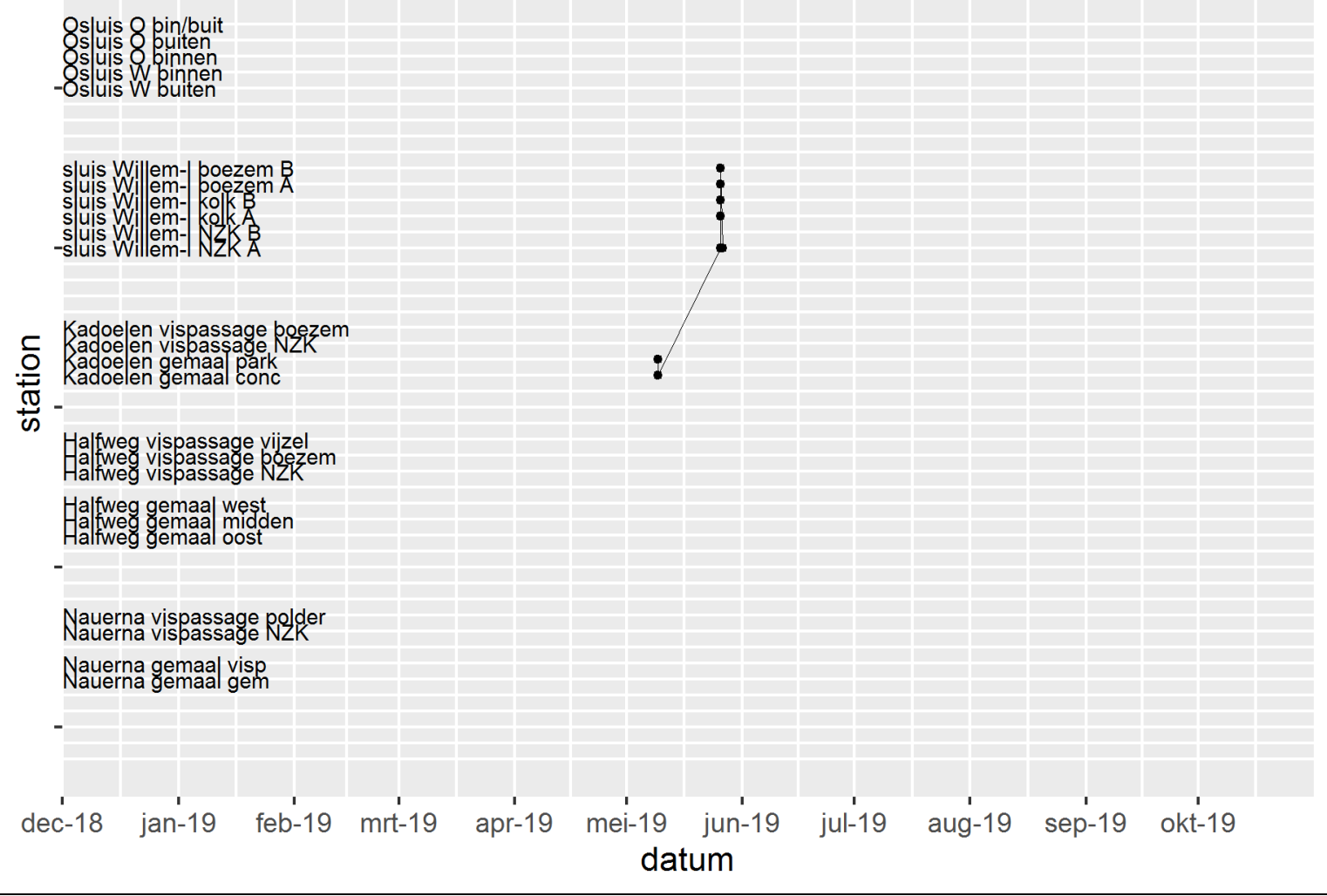


900_230000150990 Brasem 439 mm 967 gr Oranjesluizen 10-mei

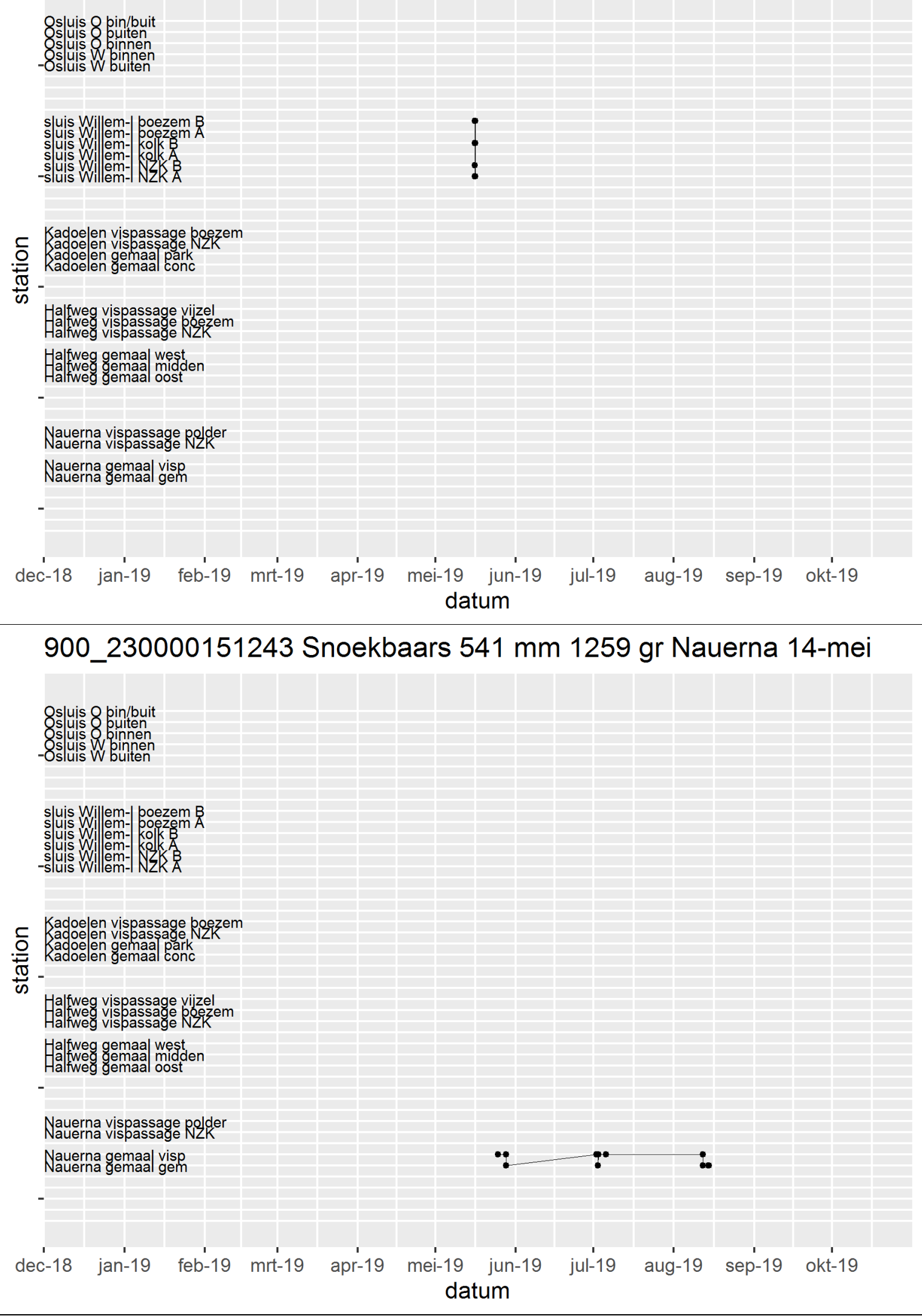


900_230000151255 Brasem 469 mm 1166 gr Nauerna 14-mei

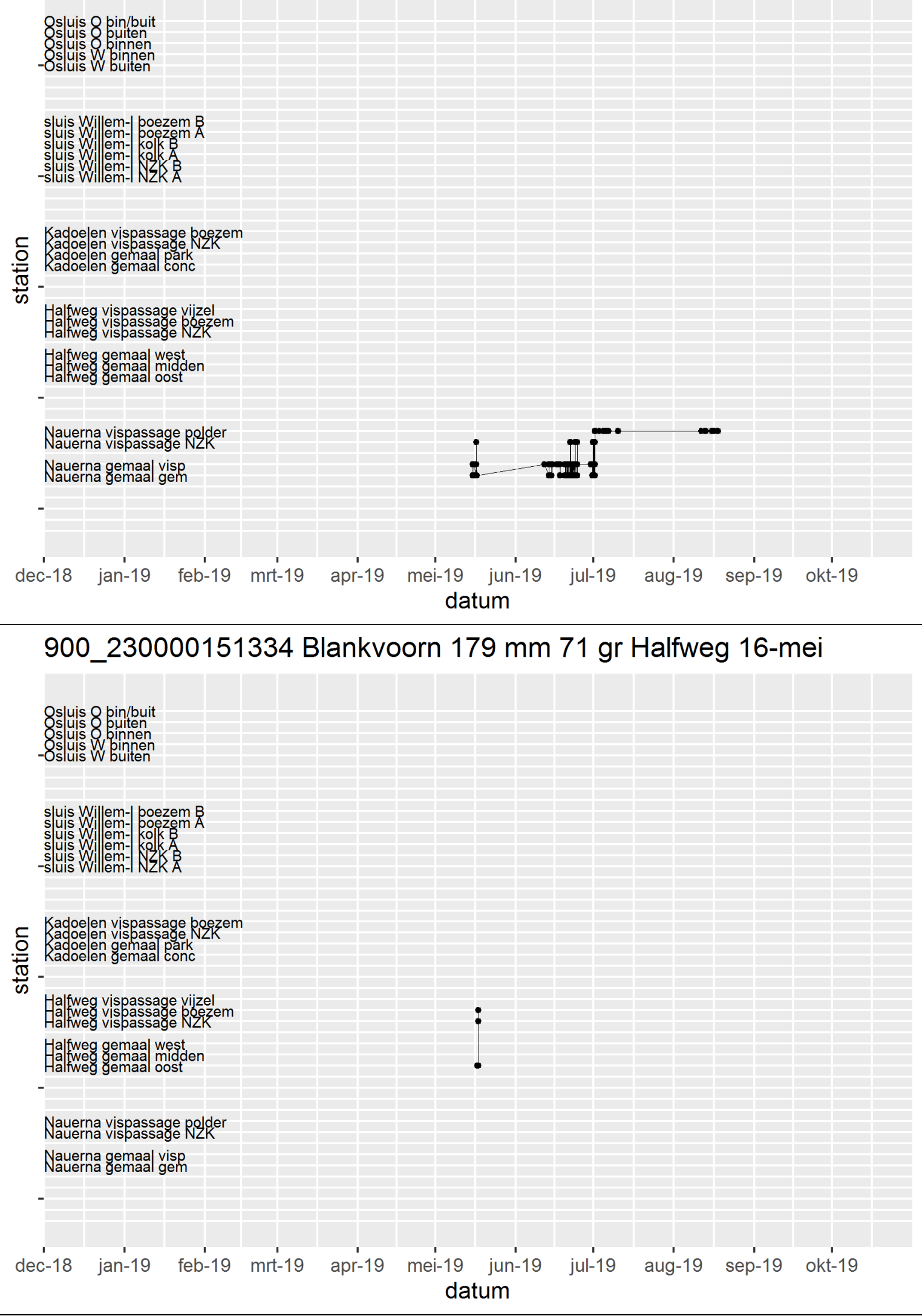


900_230000151340 Blankvoorn 164 mm 38 gr Halfweg 16-mei

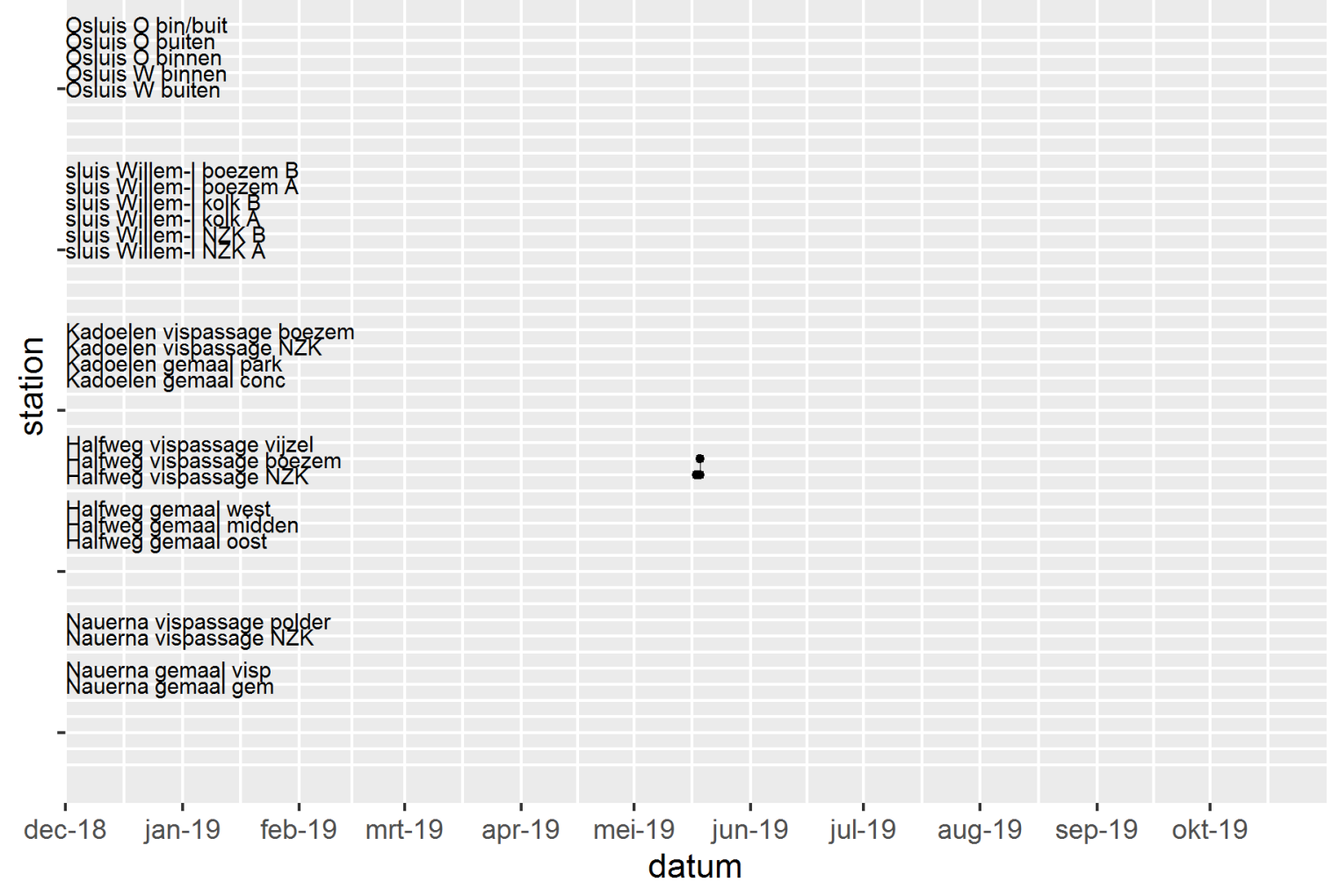

\section{0_230000151345 Baars 181 mm 62 gr Halfweg 16-mei}

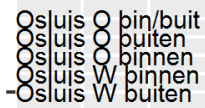

s|uis Willem-| poezem B

uis W em- poezzem

uis W em- Kolk

-sluis Willem-I NZR A

c Kadoe aden vispassage boezem

음

goe en vemaa park

$\frac{\pi}{\infty}$

Halfweg vispassage vijzel

Halfweg vispassage póngassage $\mathrm{NZK}$

Halfweg gemaal west

Nauerna vispassage polder

Nauerna gemaa| visp

dec-18 jan-19 feb-19 mrt-19 apr-19 mei-19 jun-19 jul-19 aug-19 sep-19 okt-19 datum 
900_230000151349 Blankvoorn 252 mm 201 gr Halfweg 16-mei

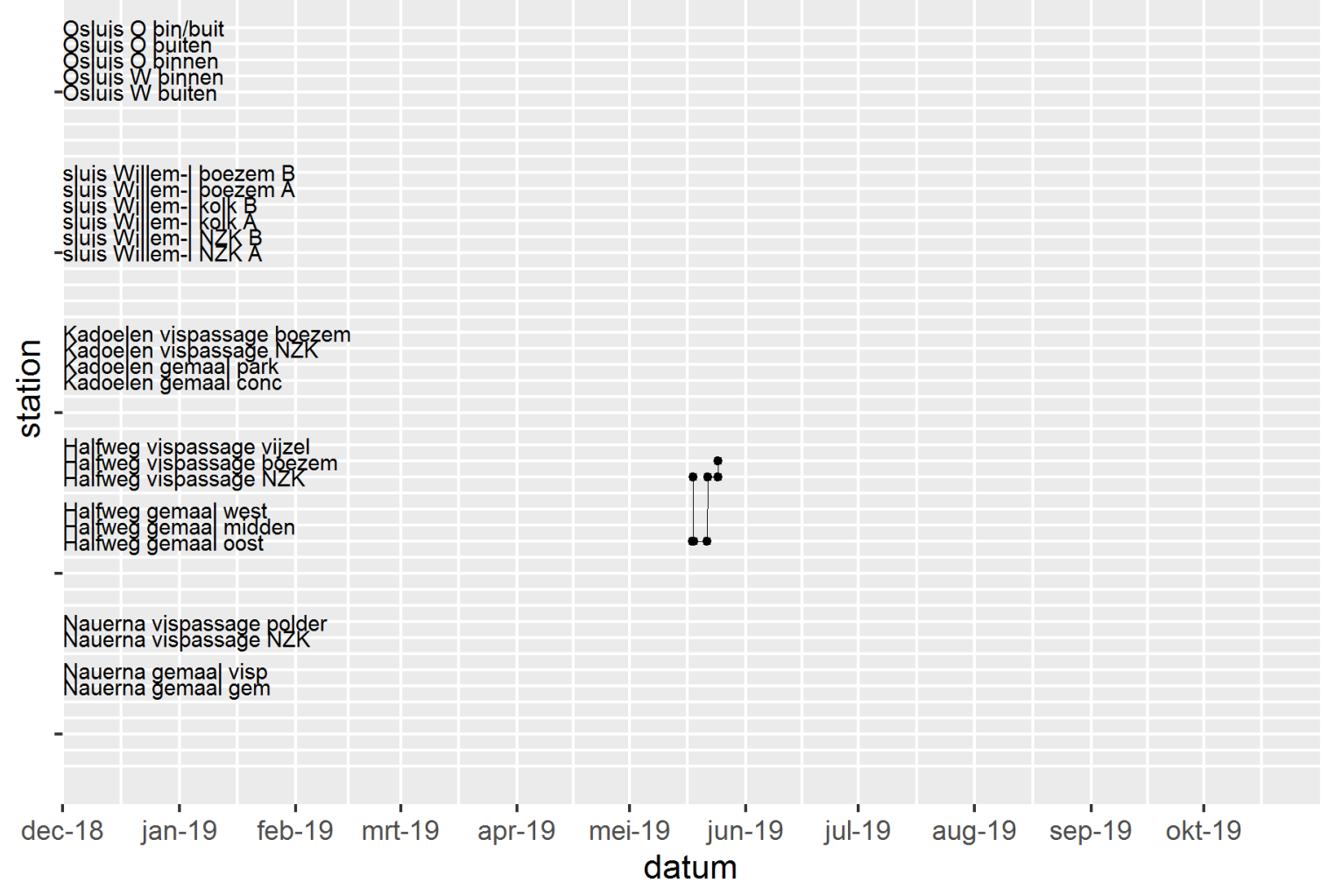

900_230000151350 Blankvoorn 227 mm 142 gr Halfweg 16-mei

8stuis 8 pin/buit

8 suls uninnen

- Osluis $W$ buiten

sluis Willem-|boezem B

uis W em- bouze

uis W em- rolk

-sluis Willem-I NZRA

ᄃ. Kadoejen vispassage boem

음

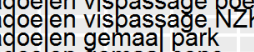

$\frac{\pi}{\infty}$

Halfweg vispassage vijzel

Halfweg vispassage NZK

Halfweg gemaal west

inIIIIII

Nauerna vispassage polder

Nauerna gemaal visp

dec-18 jan-19 feb-19 mrt-19 apr-19 mei-19 jun-19 jul-19 aug-19 sep-19 okt-19 datum 
900_230000151353 Blankvoorn 189 mm 86 gr Halfweg 16-mei

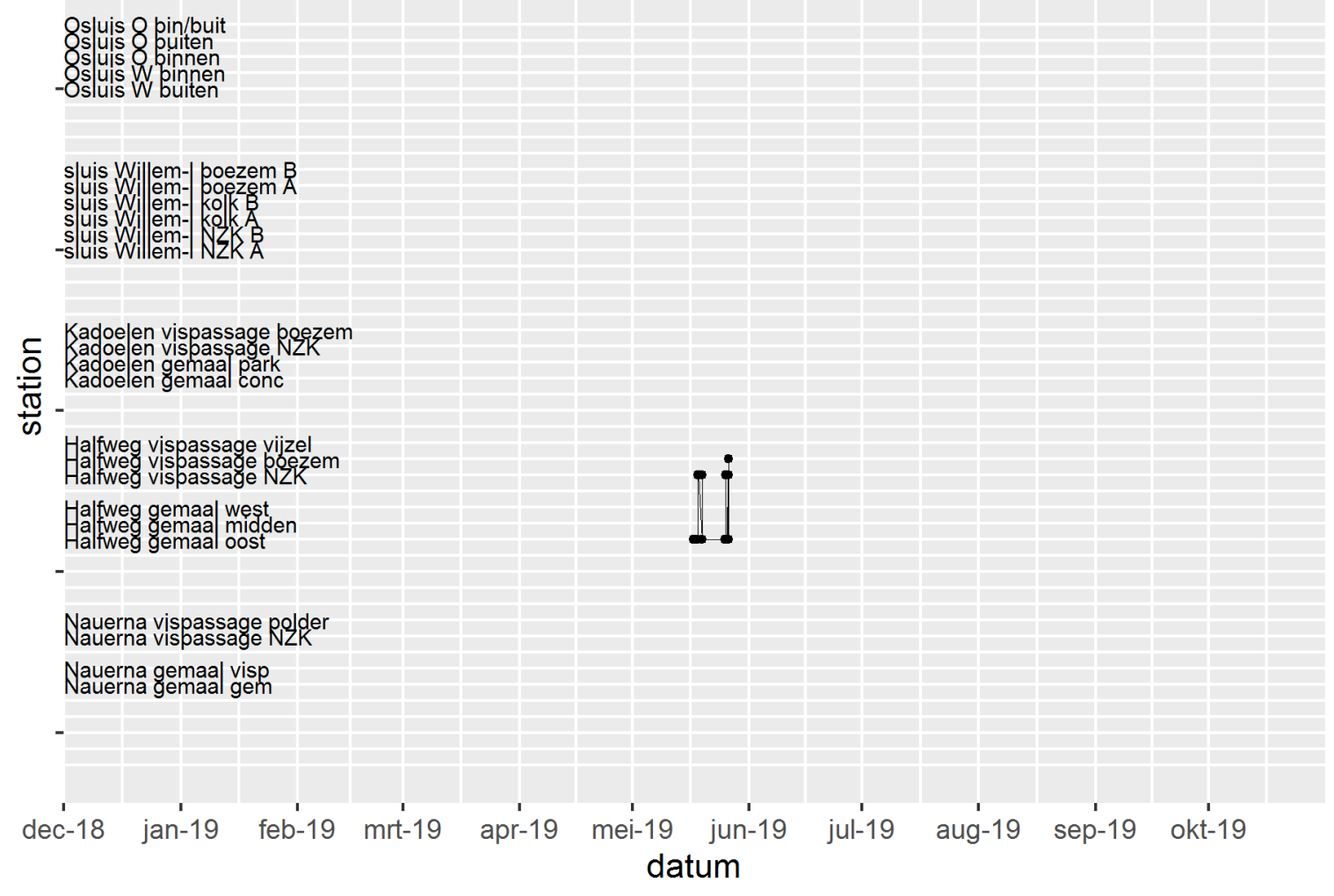

900_230000151354 Blankvoorn 220 mm 130 gr Halfweg 16-mei

8stuis 8 pin/buit

8 s uis 8 binnen

- Osluis $W$ buiten

sluis Willem-|boezem B

uis W. em- poeze

uis W em- em

-sluis Willem-I NZR A

c⿻ Kadoelen vispassage poezem

产 Radoelen gemaal conc

$+$

Halfweg vispassage vijzel
Ha|weg vispassage boezem
Halfweg vispassage NZK

Halfweg gemaa west

Nauerna vispassage polder

Nauerna gemaal visp

dec-18 jan-19 feb-19 mrt-19 apr-19 mei-19 jun-19 jul-19 aug-19 sep-19 okt-19 datum 
900_230000151355 Blankvoorn 225 mm 135 gr Halfweg 16-mei

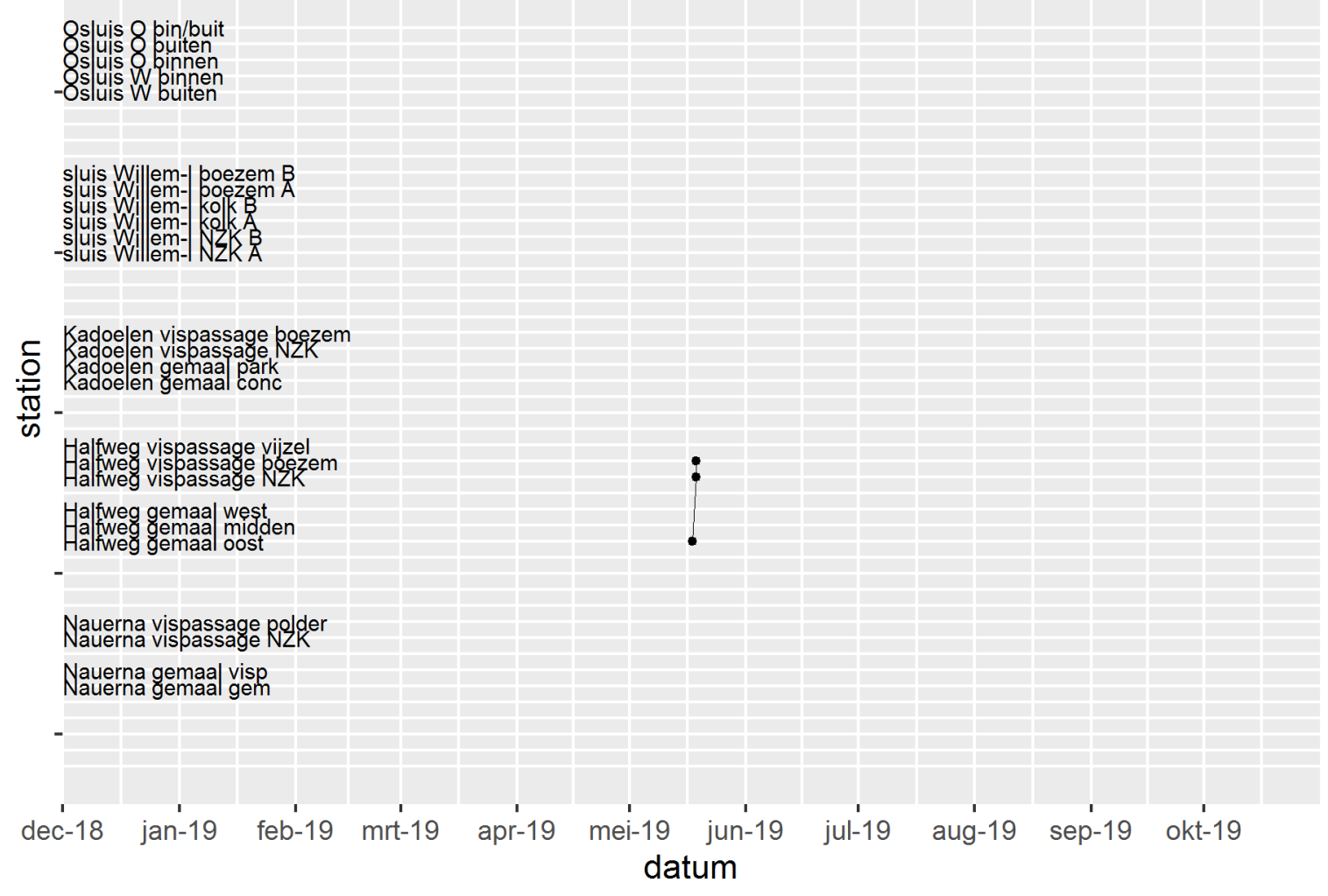

900_230000151356 Blankvoorn 287 mm 312 gr Halfweg 16-mei

8s suis 8 binibuit

8 suls uninnen

- Osluis $W$ buiten

sluis Willem-|boezem B

suls W em- kolzen

sluis Willem- NZK

c Kadoeen vispassage poezem

으 Radoelen gemaal park

$\frac{\pi}{\infty}$

Halfweg vispassage vijzel
Ha|weg vispassage boezem
Halfweg vispassage NZK

Halfweg gemaal west

Nauerna vispassage polder

Nauerna gemaal visp

dec-18 jan-19 feb-19 mrt-19 apr-19 mei-19 jun-19 jul-19 aug-19 sep-19 okt-19 datum 
900_230000151686 Kolblei 237 mm 170 gr Nauerna 28-mei

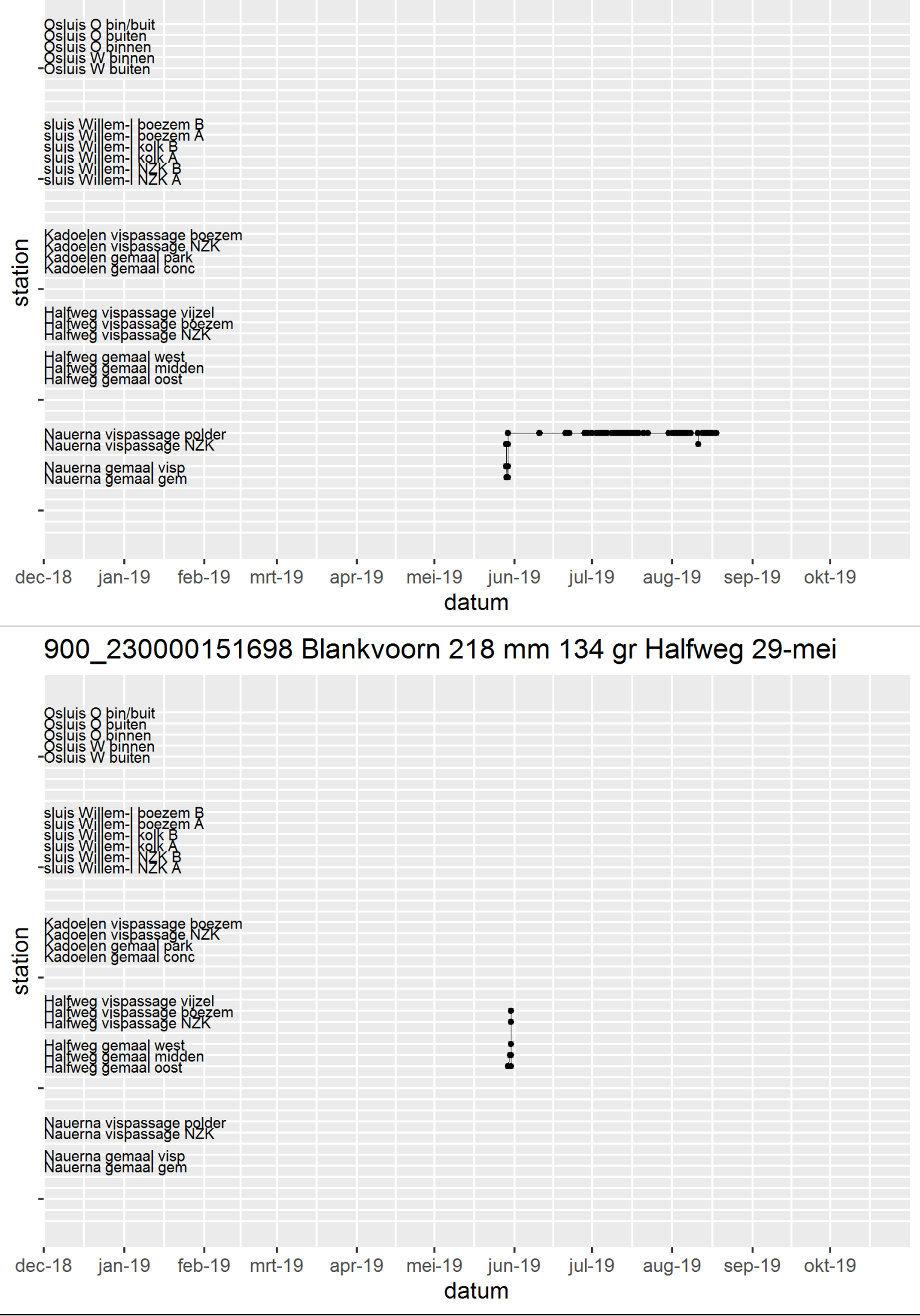


900_230000151706 Blankvoorn 202 mm 105 gr Halfweg 29-mei

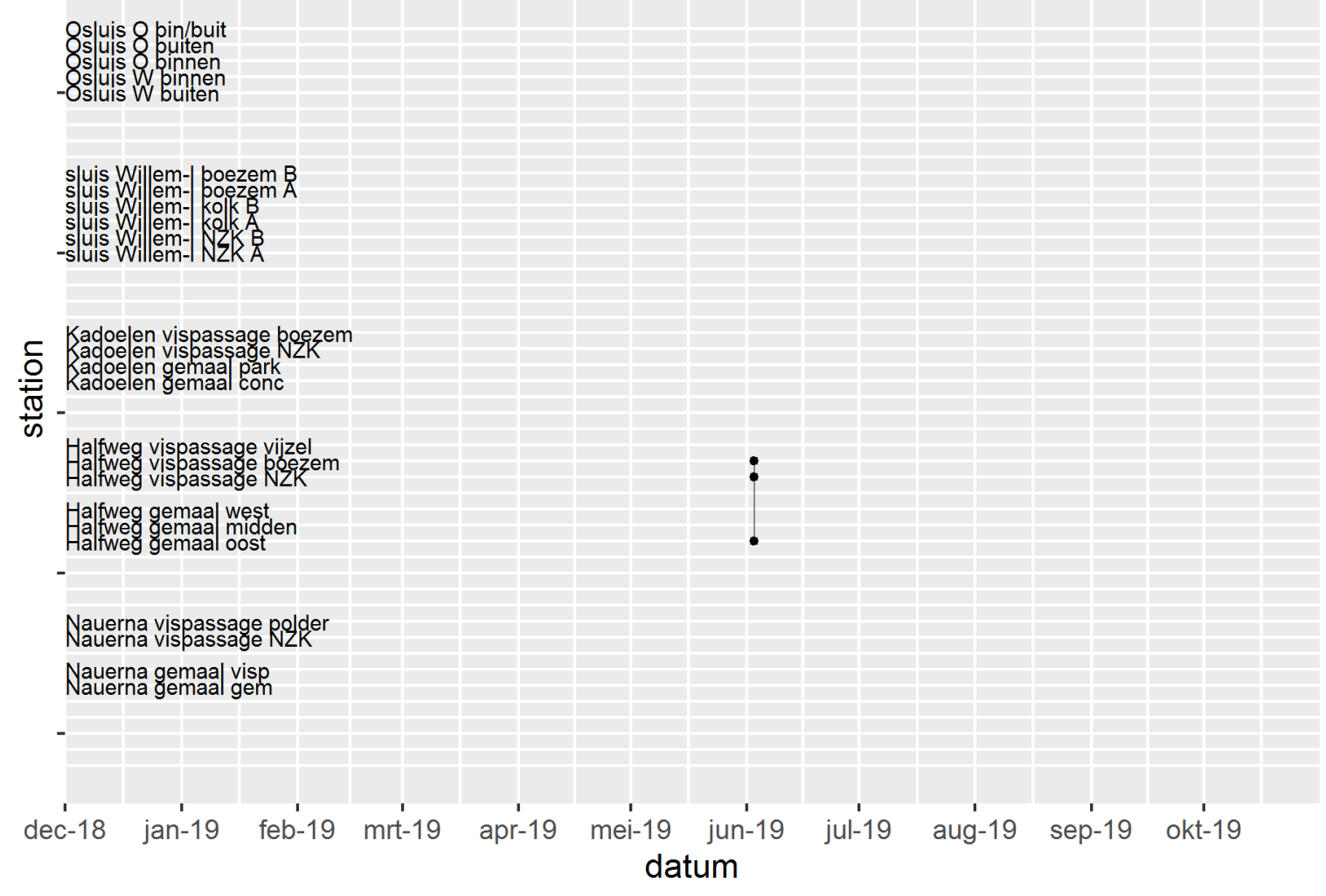

900_230000151723 Brasem 247 mm 150 gr Halfweg 29-mei

Os suis 8 pin/buit

8 suis binnen

- 8 sluis $w$ buiten

sluis Wil|em-| poezem B

us W iem- kolk

-sluis Willem-I NZKR

ᄃ Kadoelen vispassage boezem

을 Kadoelen gemaal conc

$\frac{\pi}{\infty}$.

Halfweg vispassage vijzel

Halfweg vispassage poez vispassage NZK

Halfweg gemaal west

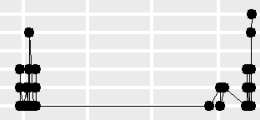

Nauerna vispassage polder

Nauerna gemaal visp

dec-18 jan-19 feb-19 mrt-19 apr-19 mei-19 jun-19 jul-19 aug-19 sep-19 okt-19 datum 
900_230000151726 Snoek 463 mm 642 gr Halfweg 29-mei

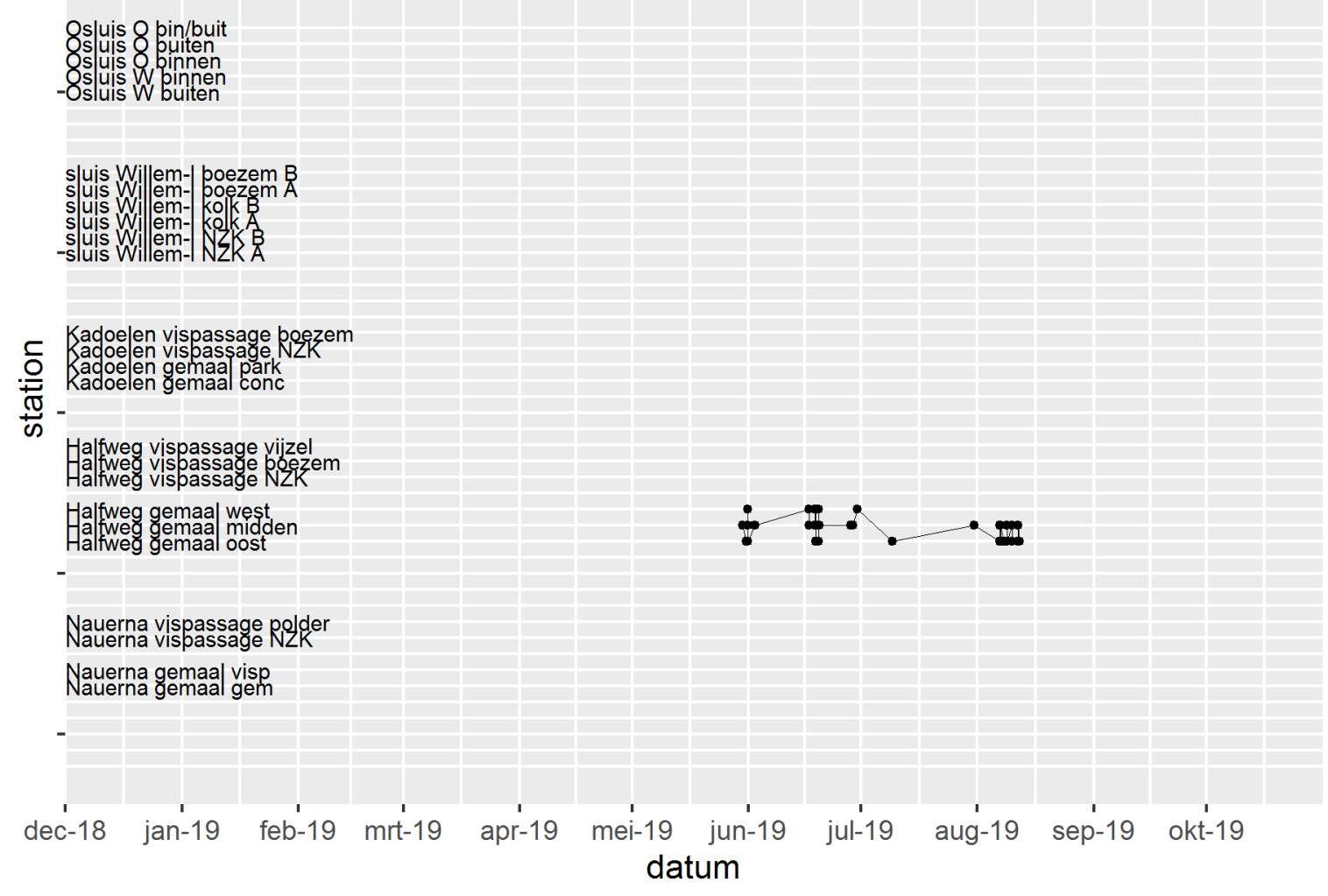

900_230000151731 Brasem 207 mm 90 gr Halfweg 29-mei
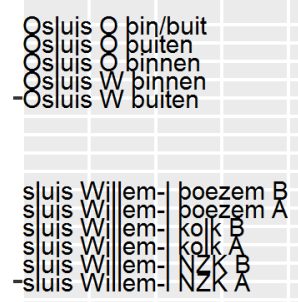

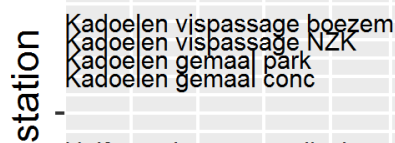

Halfweg vispassage vijzel
Halfweg vissassage boem
Halfweg vispassage NZK

Halfweg gemaa| west

Nauerna vispassage polder

Nauerna gemaa visp

dec-18 jan-19 feb-19 mrt-19 apr-19 mei-19 jun-19 jul-19 aug-19 sep-19 okt-19 datum 
900_230000151739 Baars 380 mm 814 gr Halfweg 29-mei

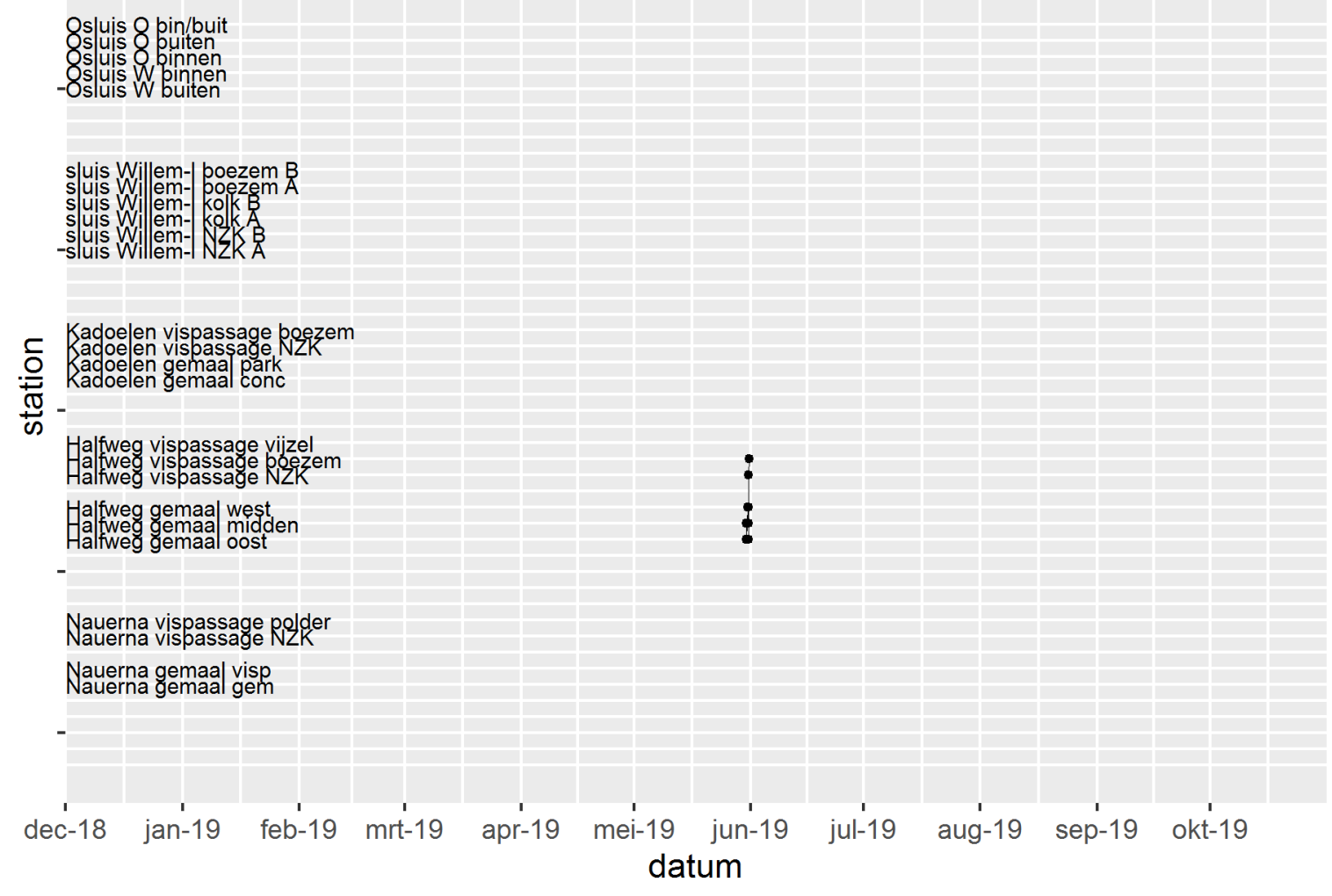

900_230000151741 Brasem 232 mm 136 gr Halfweg 29-mei

8stuis 8 pin/buit

8 s uis 8 binnen

- Osluis $W$ buiten

sluis Willem-|boezem B

uis Wi em- kolk

-sluis Willem-1 NZK

ᄃ Kadoeen vispassage poezem

으 Kadoelen gemaal park

$\frac{\pi}{\infty}$ -

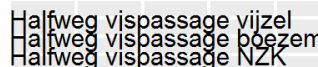

Halfweg gemaa west

Nauerna vispassage polder

Nauerna gemaal visp

dec-18 jan-19 feb-19 mrt-19 apr-19 mei-19 jun-19 jul-19 aug-19 sep-19 okt-19 datum 
900_230000151747 Blankvoorn 206 mm 114 gr Halfweg 29-mei

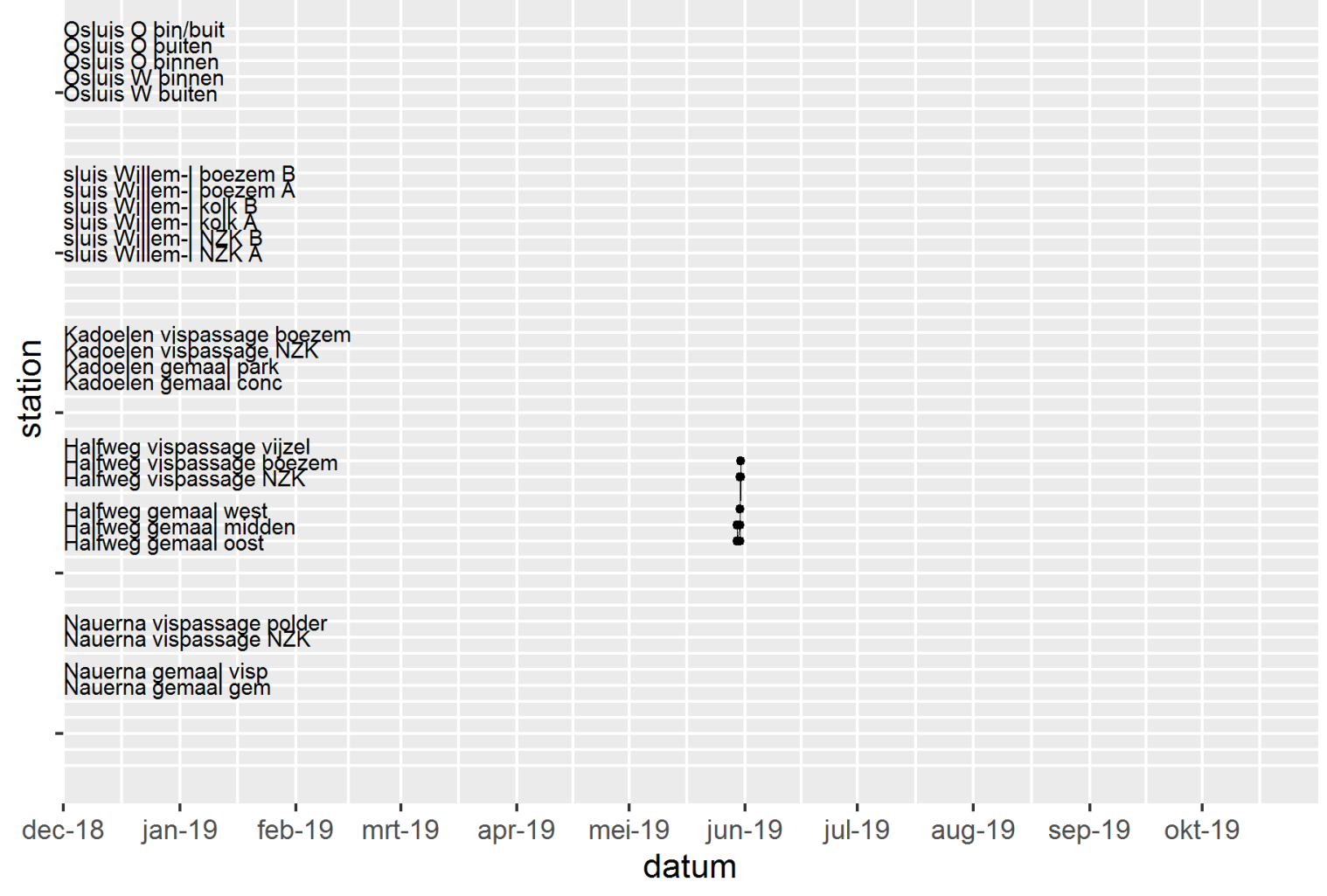

900_230000151743 Blankvoorn 286 mm 315 gr Halfweg 29-mei

8stuis 8 pin/buit

8s uis 8 binnen

- Osluis $W$ buiten

sluis Willem-|boezem B

uis W. em- kolke

uis Wi em- kolkA

-sluis Willem-I NZRA

c⿻ Kadoelen vispassage poezem

으 Kadoelen gemaal park

$\frac{\pi}{C}$

Halfweg vispassage vijzel
Ha|weg vispassage boezem
Halfweg vispassage NZK

Halfweg gemaa west

Nauerna vispassage polder

Nauerna gemaal visp

dec-18 jan-19 feb-19 mrt-19 apr-19 mei-19 jun-19 jul-19 aug-19 sep-19 okt-19 datum 
900_230000151750 Blankvoorn 221 mm 338 gr Halfweg 29-mei

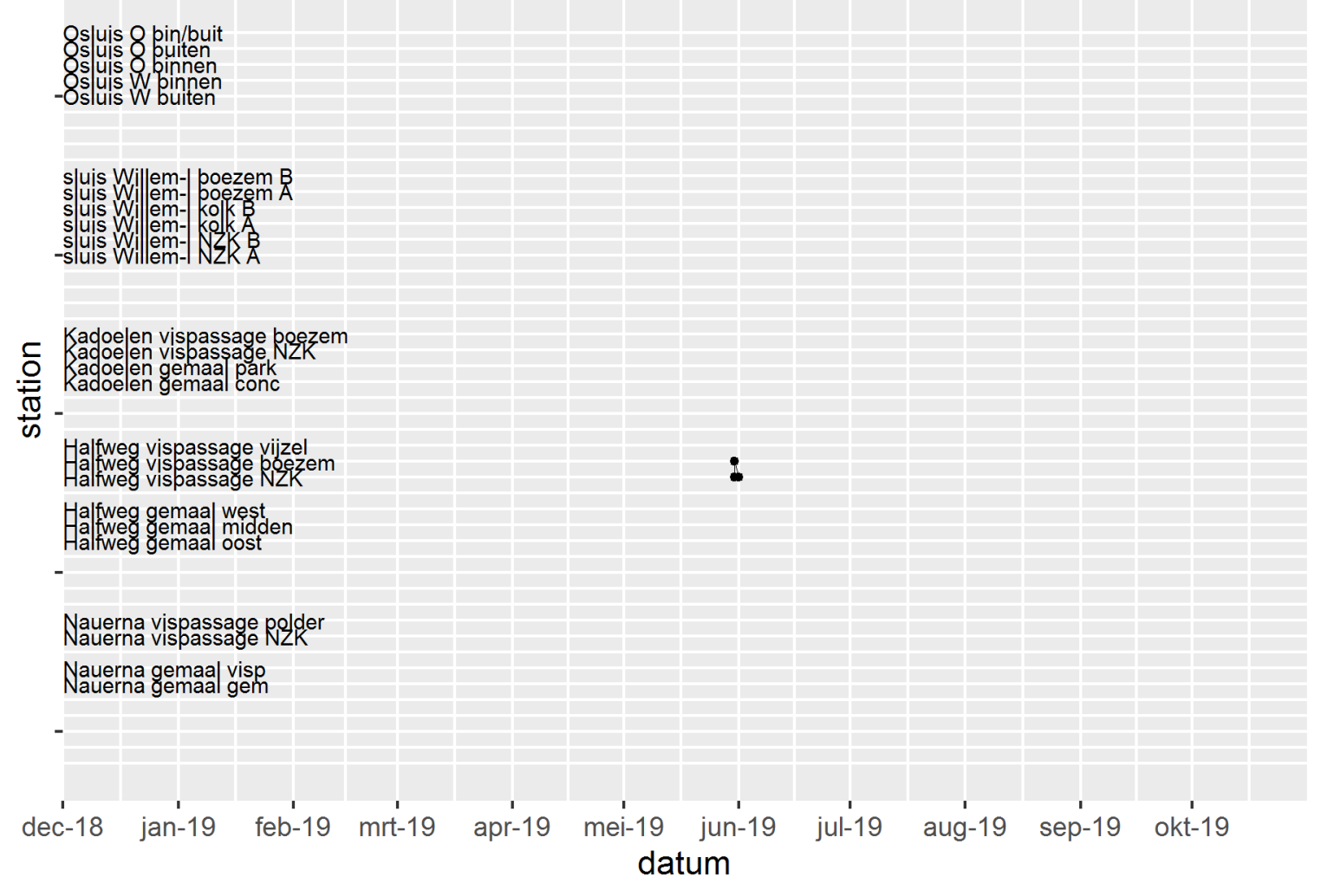

900_230000151761 Baars 360 mm 759 gr Halfweg 29-mei

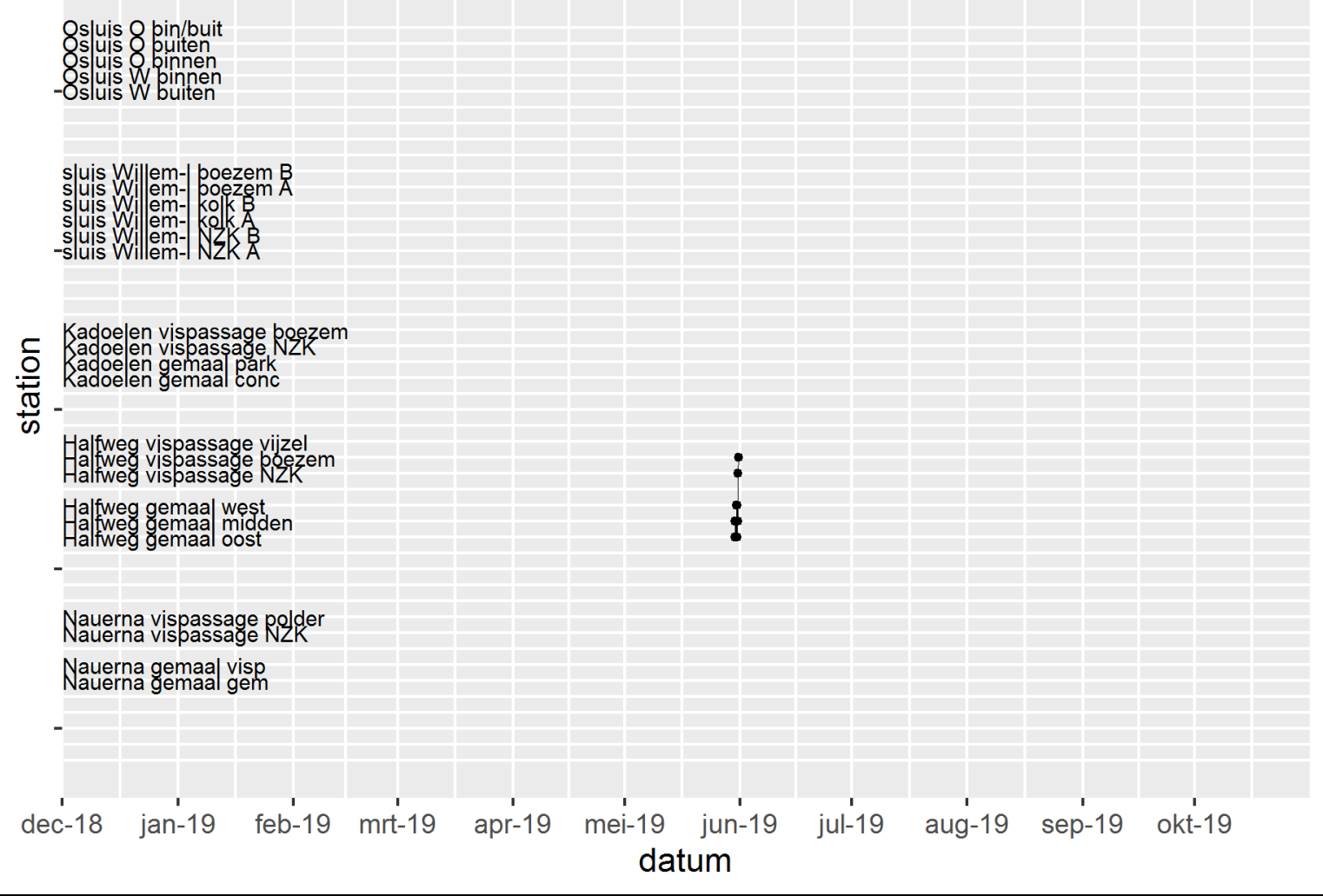


900_230000151764 Blankvoorn 239 mm 163 gr Halfweg 29-mei

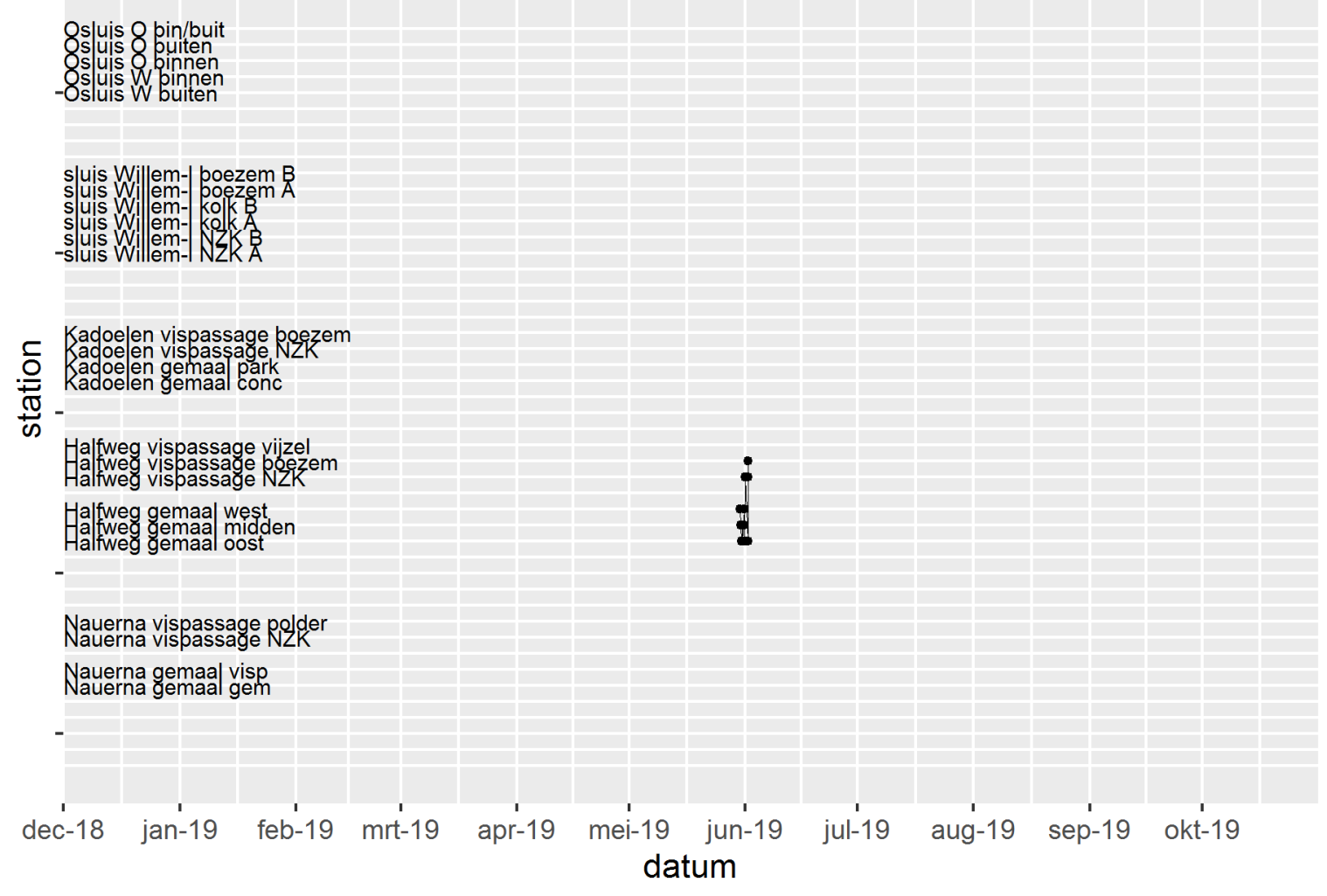

900_230000151765 Blankvoorn 198 mm 94 gr Halfweg 29-mei

8s suis 8 binibuit

8 suls uninnen

- Osluis $W$ buiten

sluis Wil|em-| boezem B

suls W em- kol em

sluis Willem- NZK

c Kadoeen vispassage boezem

은 Radoelen gemaal conc

की

Halfweg vispassage vijzel
Halfweg vispassage boezem

Halfweg gemaal west

Nauerna vispassage polder
Nauerna vispassage NZK

Nauerna gemaal visp

dec-18 jan-19 feb-19 mrt-19 apr-19 mei-19 jun-19 jul-19 aug-19 sep-19 okt-19 datum 
900_230000151766 Blankvoorn 181 mm 73 gr Halfweg 29-mei

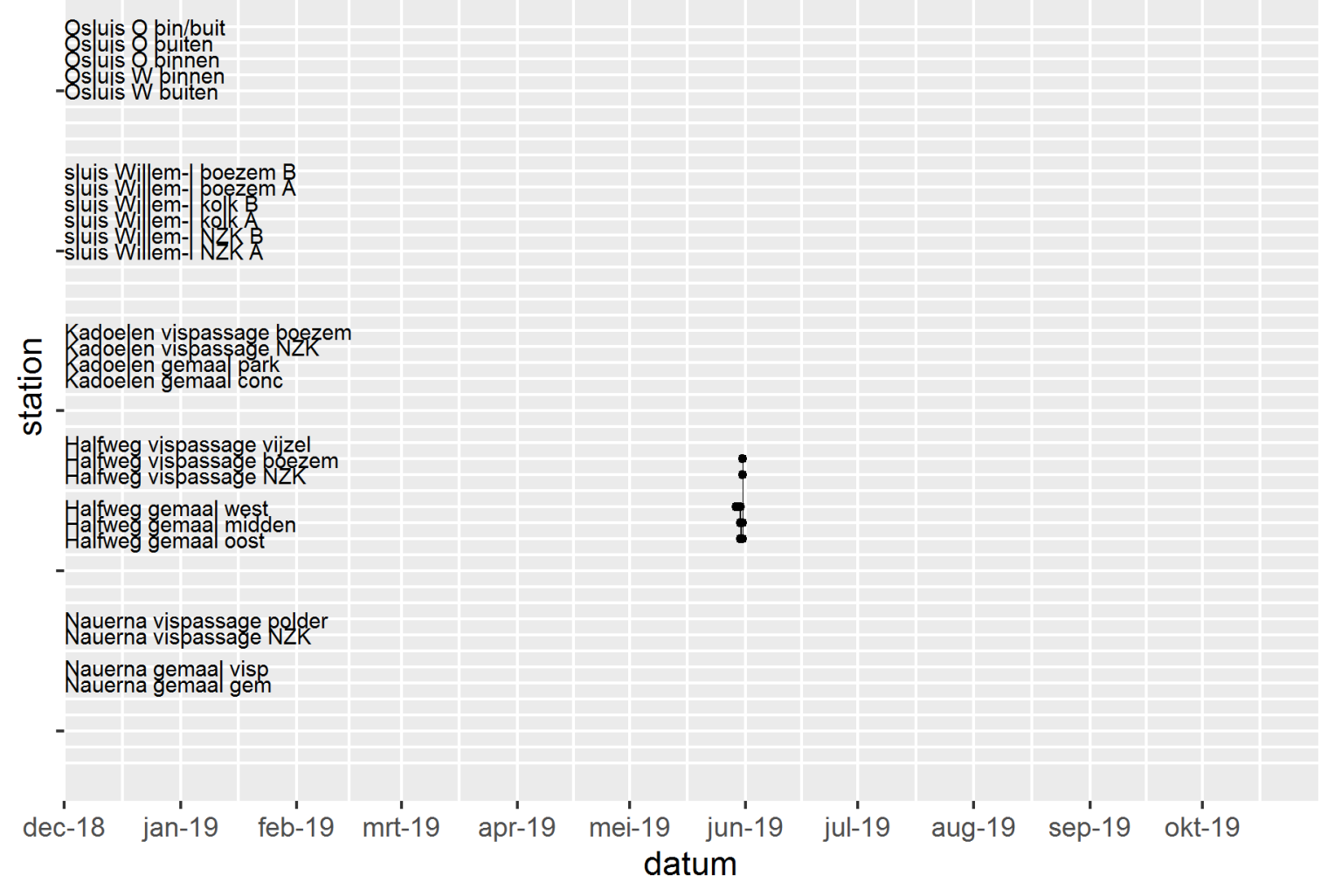

900_230000151771 Snoekbaars 700 mm 2119 gr Halfweg 29-mei

\section{8stuis 8 pin/buit \\ os üs 8 binnen \\ - Oslüis W buiten}

sluis Willem-| boezem B

suls W em- kolze

sluis Willem- NZK

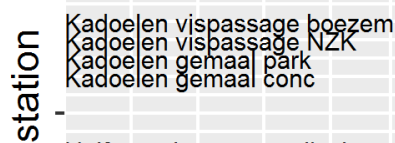

Halfweg vispassage vijzel
Halfweg vispassage pocem
Halfweg vispassage NZK

Halfweg gemaa| $\begin{aligned} & \text { west } \\ & \text { alfweg gemaa } \\ & \text { midden } \\ & \text { alfweg gemaa }\end{aligned}$

Nauerna vispassage polder
Nauerna vispassage NZKK

Nauerna gemaal visp

dec-18 jan-19 feb-19 mrt-19 apr-19 mei-19 jun-19 jul-19 aug-19 sep-19 okt-19 datum 
900_230000151774 Brasem 495 mm 1381 gr Halfweg 29-mei

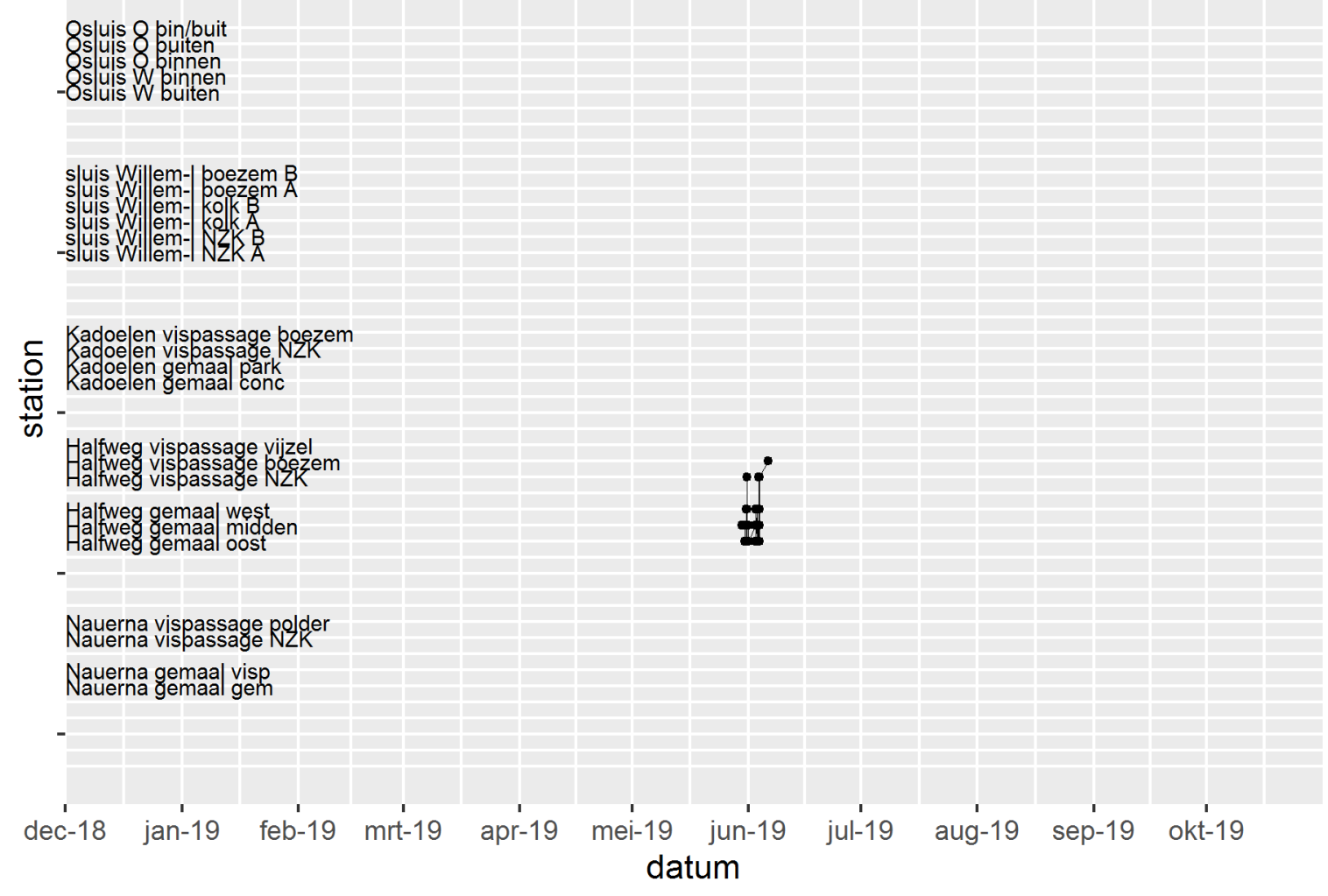

900_230000151778 Brasem 309 mm 302 gr Halfweg 29-mei

8s suis 8 binibuit

8 suls uninnen

- Osluis $W$ buiten

sluis Wil|em-| boezem B

suls W em- kol em

sluis Willem- NZK

c Kadoeen vispassage poezem

금 Kadoelen gemaal conc

का

Halfweg vispassage vijzel

Halfweg vispassage NZK

Halfweg gemaa| west

Nauerna vispassage polder

Nauerna gemaa| visp

dec-18 jan-19 feb-19 mrt-19 apr-19 mei-19 jun-19 jul-19 aug-19 sep-19 okt-19 datum 
900_230000151791 Brasem 215 mm 104 gr Halfweg 29-mei

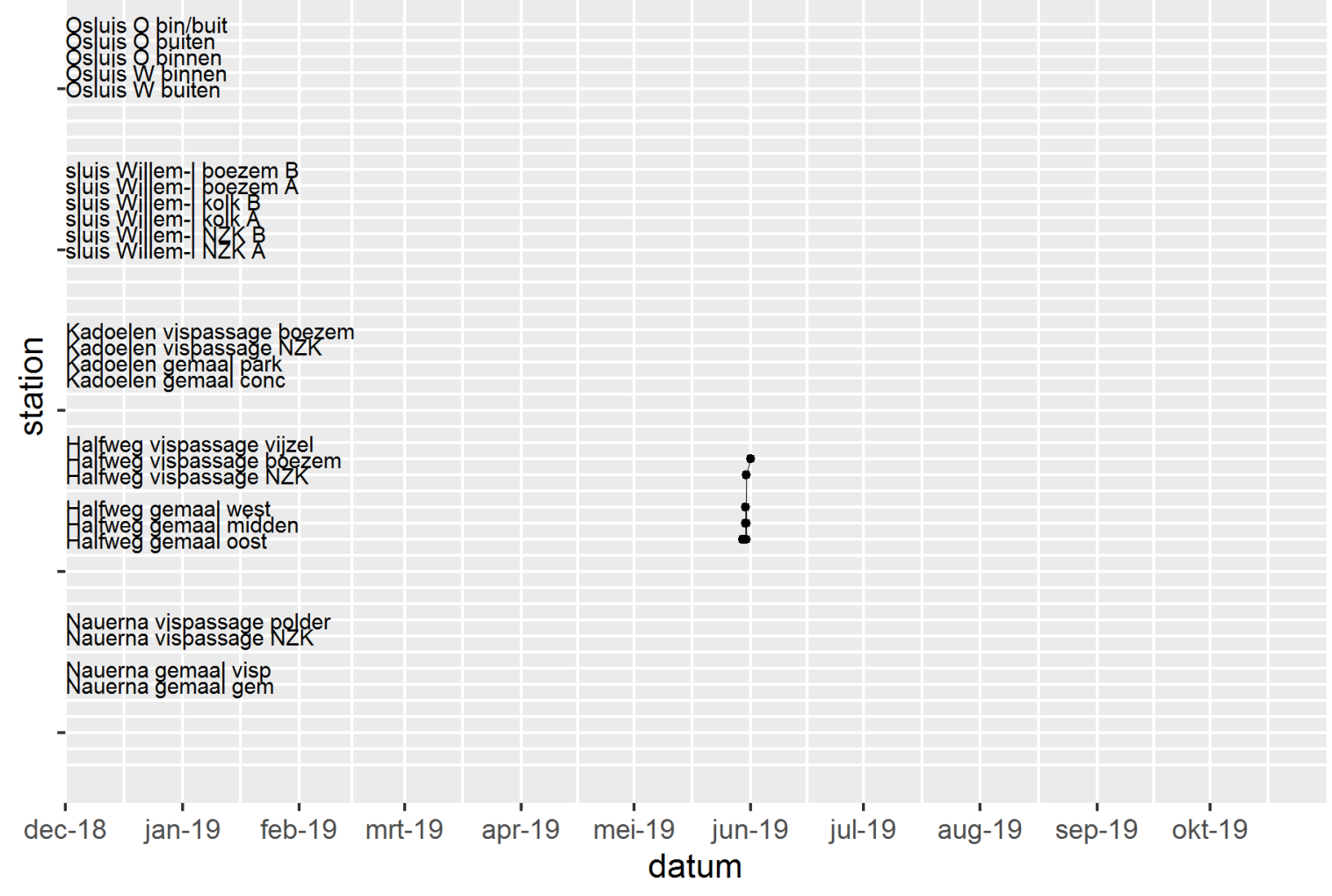

900_230000151794 Brasem 326 mm 407 gr Halfweg 29-mei

8s suis 8 binibuit

8 suls uninnen

- Osluis $W$ buiten

sluis Willem-|boezem B

suls W em- kolkz

sluis Willem- NZK

ᄃ Kadoelen vispassage poezem

으 Radoelen gemaal park

T)

Halfweg vispassage vijzel
Halfweg vispassage boezem
Halfweg vispassage NZK

Halfweg gemaal west

Nauerna vispassage polder

Nauerna gemaal visp

dec-18 jan-19 feb-19 mrt-19 apr-19 mei-19 jun-19 jul-19 aug-19 sep-19 okt-19 datum 
900_230000151799 Brasem 484 mm 1402 gr Halfweg 29-mei

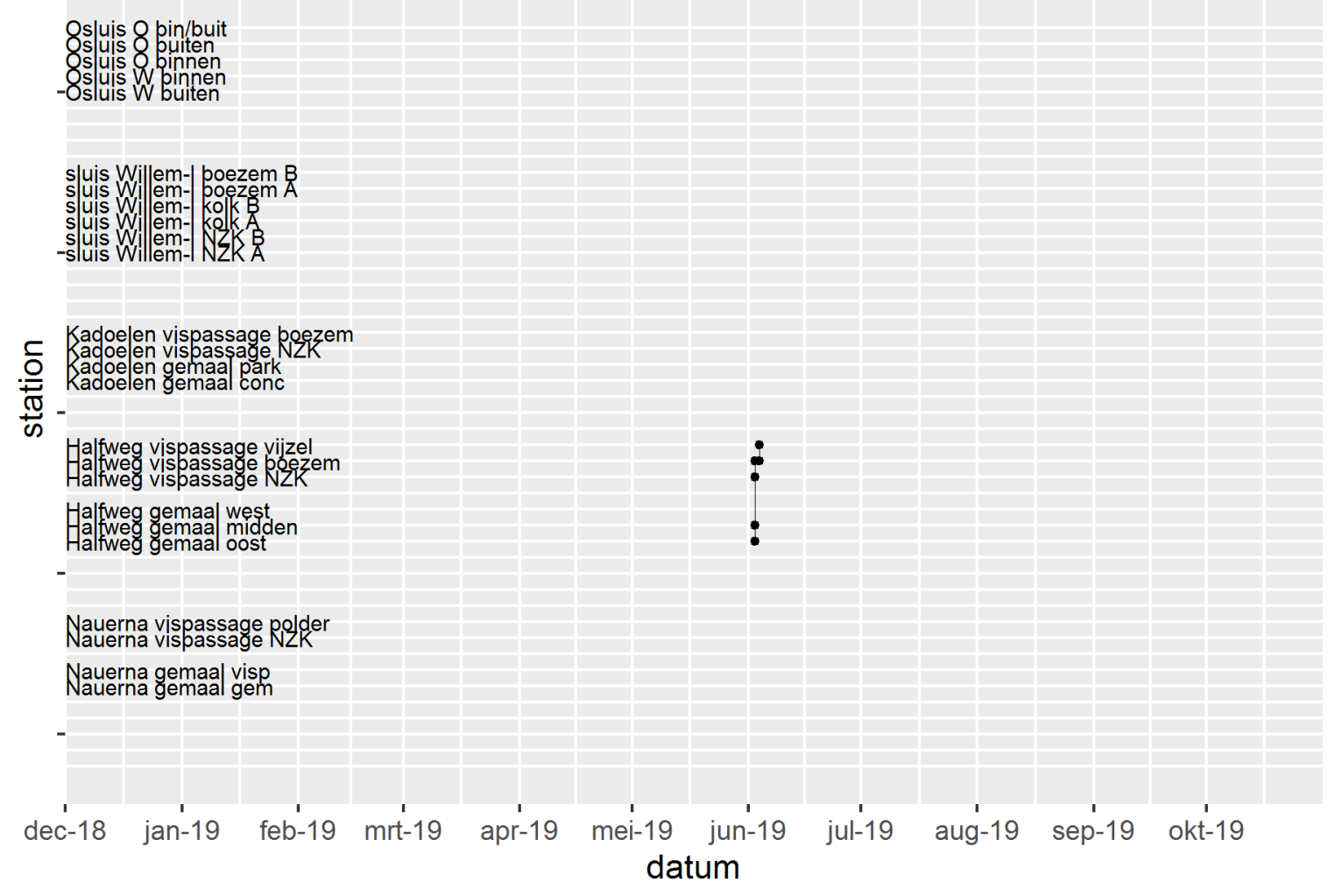

900_230000151807 Brasem 261 mm 185 gr Halfweg 29-mei

Ostuis 8 pin/buit

8 s uis 8 binnen

- - sluis $W$ buiten

sluis Wil|em-| poezem B

uis W em- kolk

-sluis Willem-1 NZK A

드 Kadoeen vispassage boezem

으 Kadoelen gemaal conc

$\frac{\pi}{\infty}$.

Halfweg vispassage vijzel
Halwweg vispassage boemzem
Halfweg vispassage NZKK

Halfweg gemaal west

Nauerna vispassage polder

Nauerna gemaal visp

dec-18 jan-19 feb-19 mrt-19 apr-19 mei-19 jun-19 jul-19 aug-19 sep-19 okt-19 datum 
900_230000151834 Blankvoorn 217 mm 125 gr Halfweg 29-mei

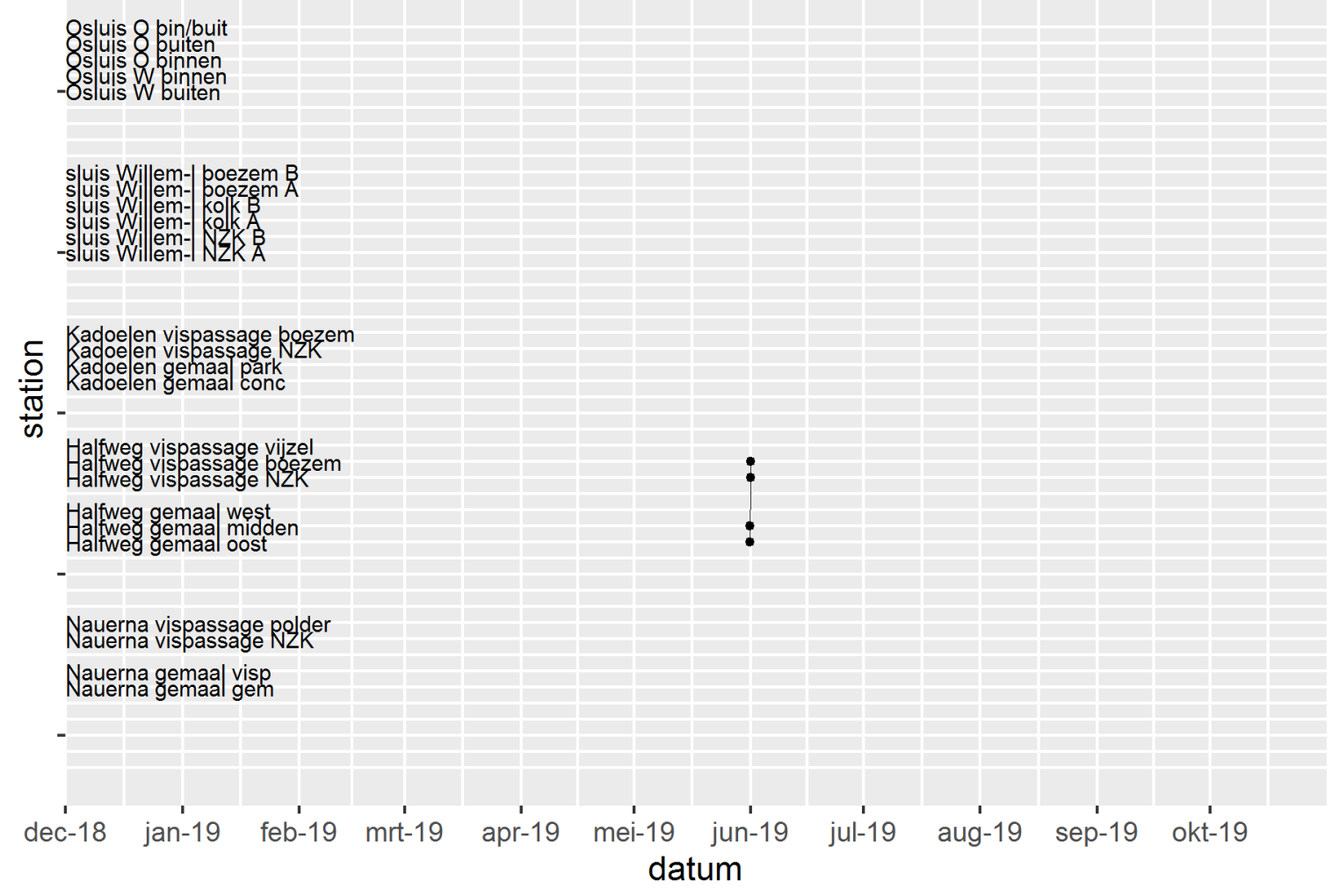

900_230000151844 Brasem 279 mm 240 gr Halfweg 29-mei

8s suis 8 binibuit

8 suls uninnen

- Osluis $W$ buiten

sluis Wil|em-| boezem B

suls W em- kolkz

sluis Willem- NZK

ᄃ Kadoelen vispassage poezem

금 Kadoelen gemaal conc

का

Halfweg vispassage vijzel

Halfweg vispassage NZK

Halfweg gemaa| west

Nauerna vispassage polder

Nauerna gemaal visp

dec-18 jan-19 feb-19 mrt-19 apr-19 mei-19 jun-19 jul-19 aug-19 sep-19 okt-19 datum 
900_230000151849 Brasem 285 mm 262 gr Halfweg 29-mei

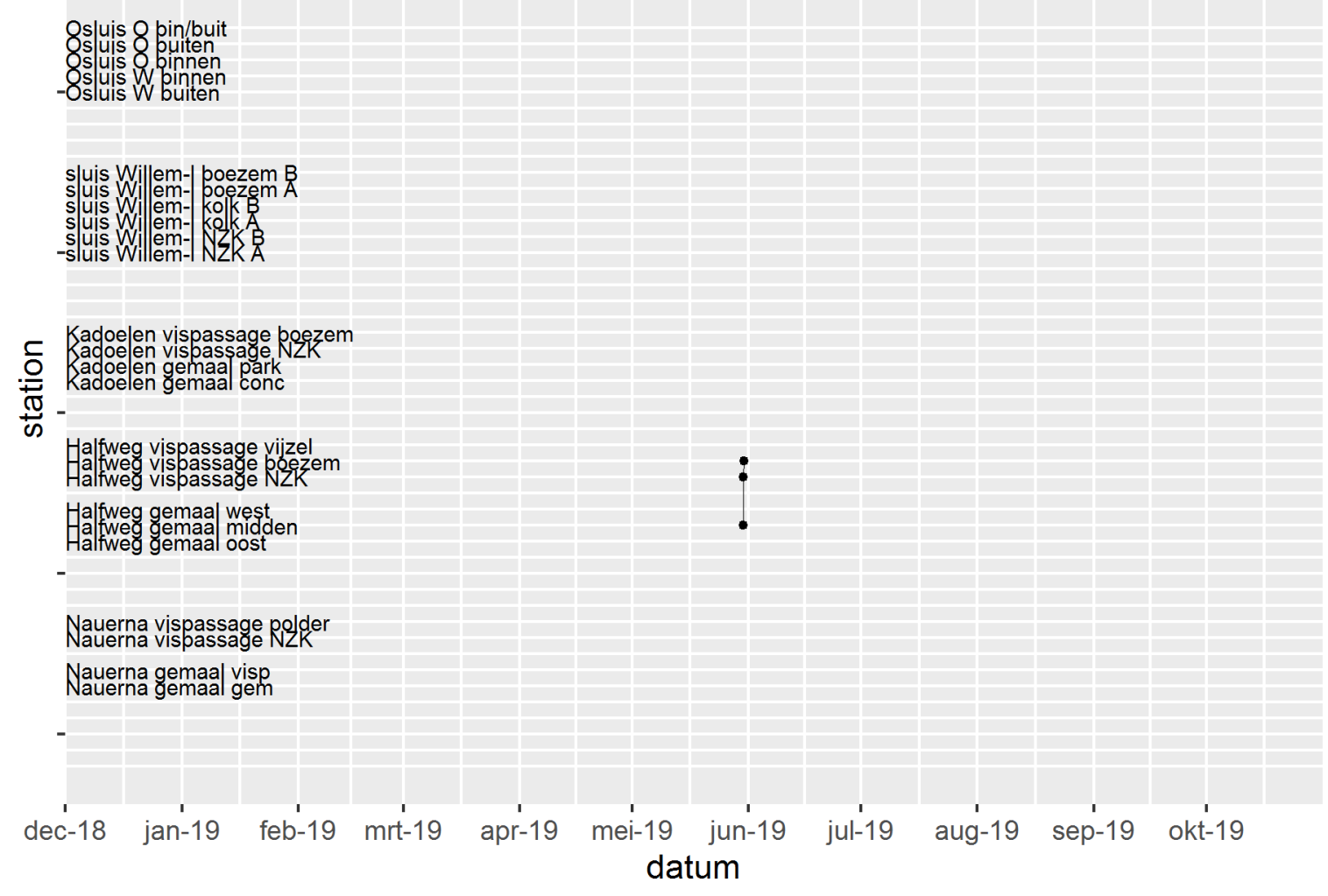

900_230000151851 Brasem 409 mm 854 gr Halfweg 29-mei

8stuis 8 pin/buit

8 suls uninnen

- Osluis $W$ buiten

sluis Willem-|boezem B

suls W em- kol em

sluis Willem- NZK

c Kadoeen vispassage poezem

음 Kadoelen gemaal conc

$\frac{\pi}{\infty}$ -

Halfweg vispassage vijzel

Halfweg vispassage $\mathrm{NZK}$

Halfweg gemaal west

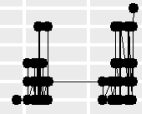

Nauerna vispassage polder

Nauerna gemaal visp

dec-18 jan-19 feb-19 mrt-19 apr-19 mei-19 jun-19 jul-19 aug-19 sep-19 okt-19 datum 
900_230000151853 Brasem 457 mm 1206 gr Halfweg 29-mei

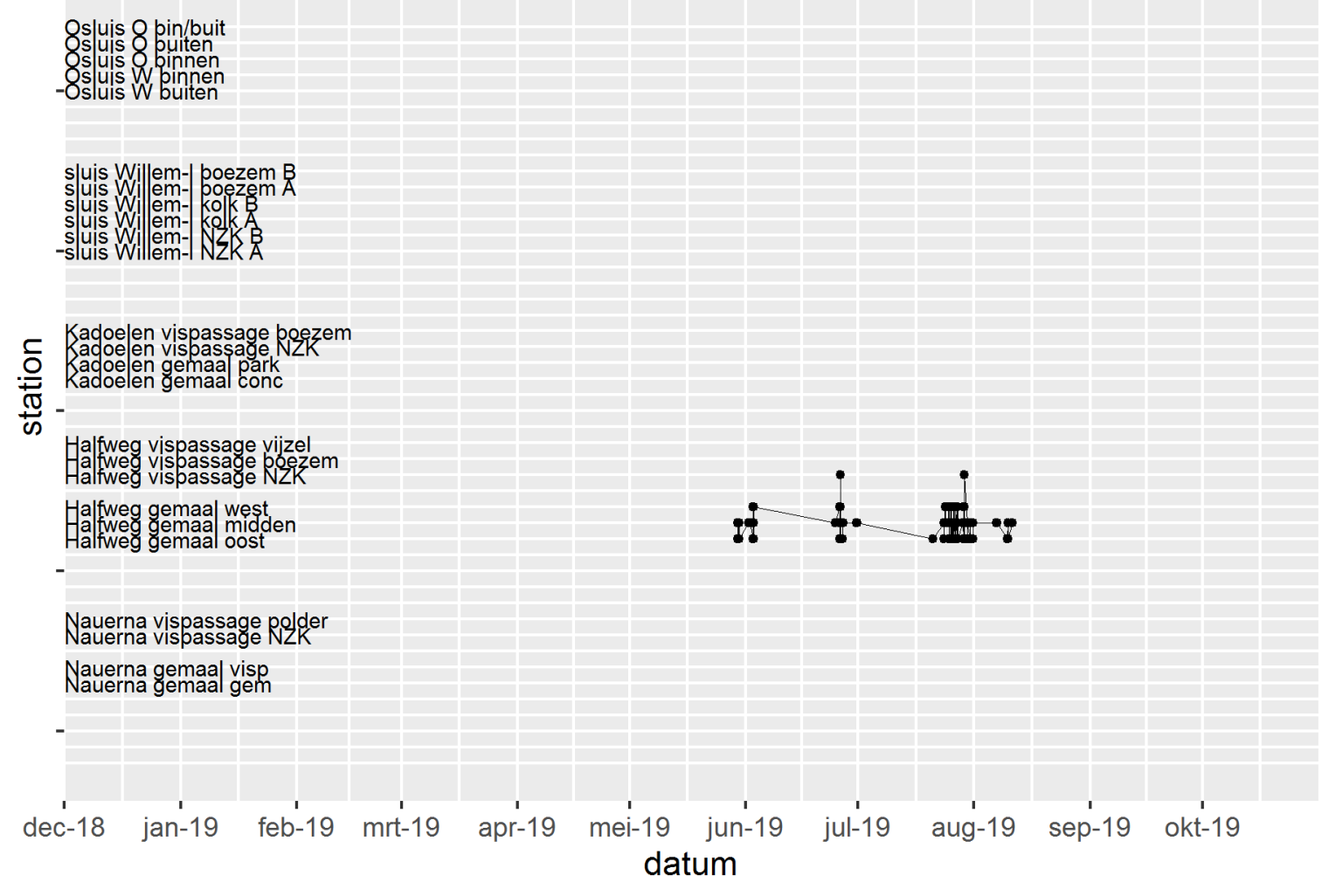

900_230000151856 Blankvoorn 230 mm 150 gr Halfweg 29-mei

8s suis 8 binibuit

8 suls uninnen

- Osluis $W$ buiten

sluis Willem-|boezem B

suls W em- kol em

sluis Willem- NZK

c Kadoeen vispassage boezem

음 Kadoelen gemaal conc

का

Halfweg vispassage vijzel

Halfweg vispassage NZK

Halfweg gemaal west

Nauerna vispassage polder
Nauerna vispassage NZZK

Nauerna gemaal visp

dec-18 jan-19 feb-19 mrt-19 apr-19 mei-19 jun-19 jul-19 aug-19 sep-19 okt-19 datum 
900_230000151871 Brasem 477 mm 1226 gr Halfweg 29-mei

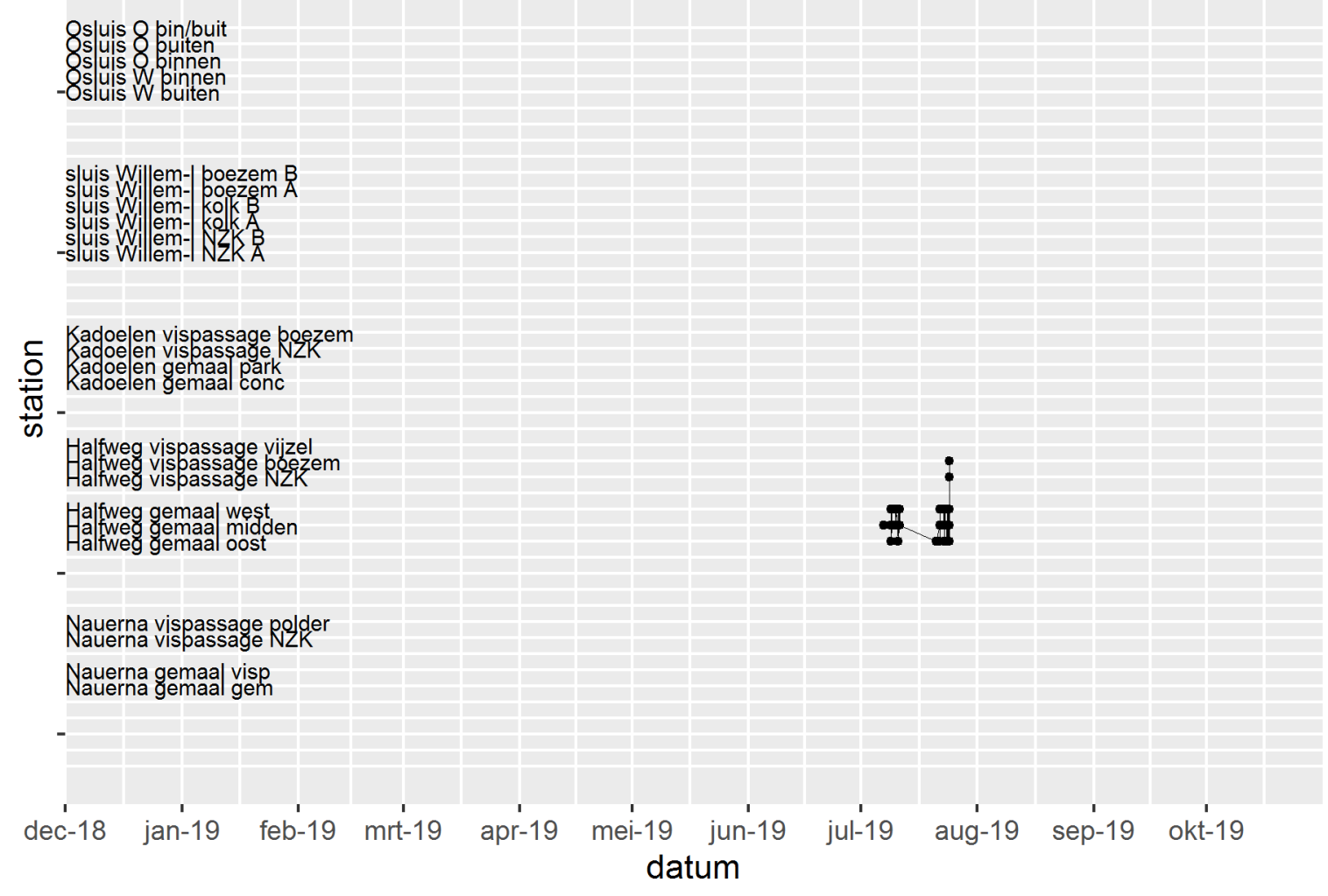

900_230000151872 Ruisvoorn 182 mm 82 gr Halfweg 29-mei

8stuis 8 pin/buit

8 suis o binnen

- Osluis $W$ buiten

s|uis Willem-| poezem $B$

uis W. em- poezem

uis W em- emz

-sluis Willem-I NZRA

ᄃ Kadoelen vispassage boezem

으 Kadoelen gemaa park

$\frac{\pi}{\infty}$

Halfweg vispassage vijzel
Halfweg vispassage boemem

Halfweg gemaal west

Nauerna vispassage polder

Nauerna gemaa| visp

dec-18 jan-19 feb-19 mrt-19 apr-19 mei-19 jun-19 jul-19 aug-19 sep-19 okt-19 datum 
900_230000151880 Brasem 210 mm 93 gr Halfweg 29-mei

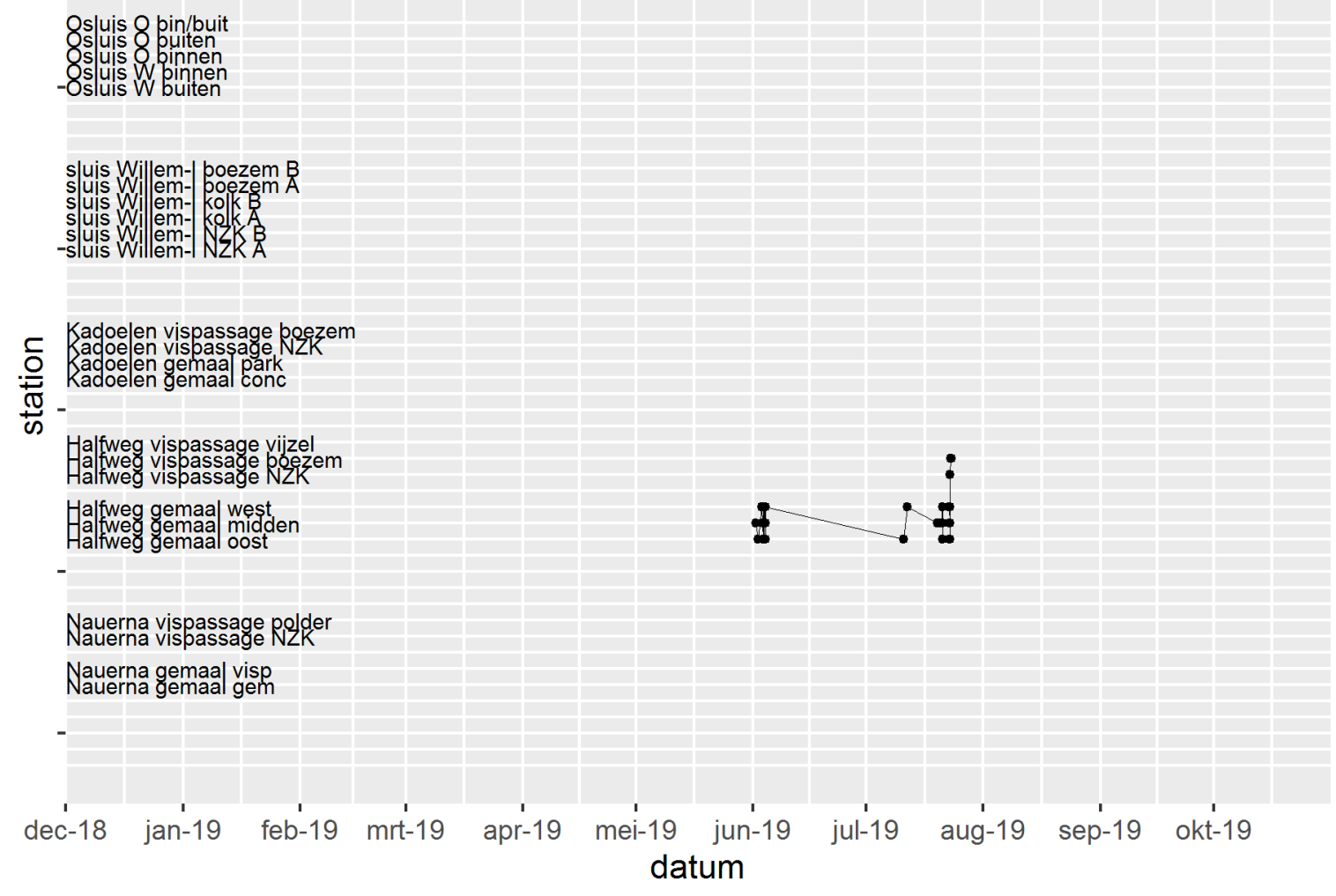

900_230000151889 Brasem 253 mm 179 gr Halfweg 29-mei

8stuis 8 pin/buit

8 suis binnen

- Osluis $W$ buiten

sluis Willem-|boezem B

uis Wi em- kolk

-sluis Willem-1 NZK

ᄃ Kadoelen vispassage poezem

을 Radoelen gemaal conc

$\frac{\pi}{C}$

Halfweg vispassage vijzel
Ha|weg vispassage boezem
Halfweg vispassage NZK

Halfweg gemaa west

Hallweg gemaal oost

Nauerna vispassage polder

Nauerna gemaal visp

dec-18 jan-19 feb-19 mrt-19 apr-19 mei-19 jun-19 jul-19 aug-19 sep-19 okt-19 datum 
900_230000151891 Brasem 433 mm 1091 gr Halfweg 29-mei

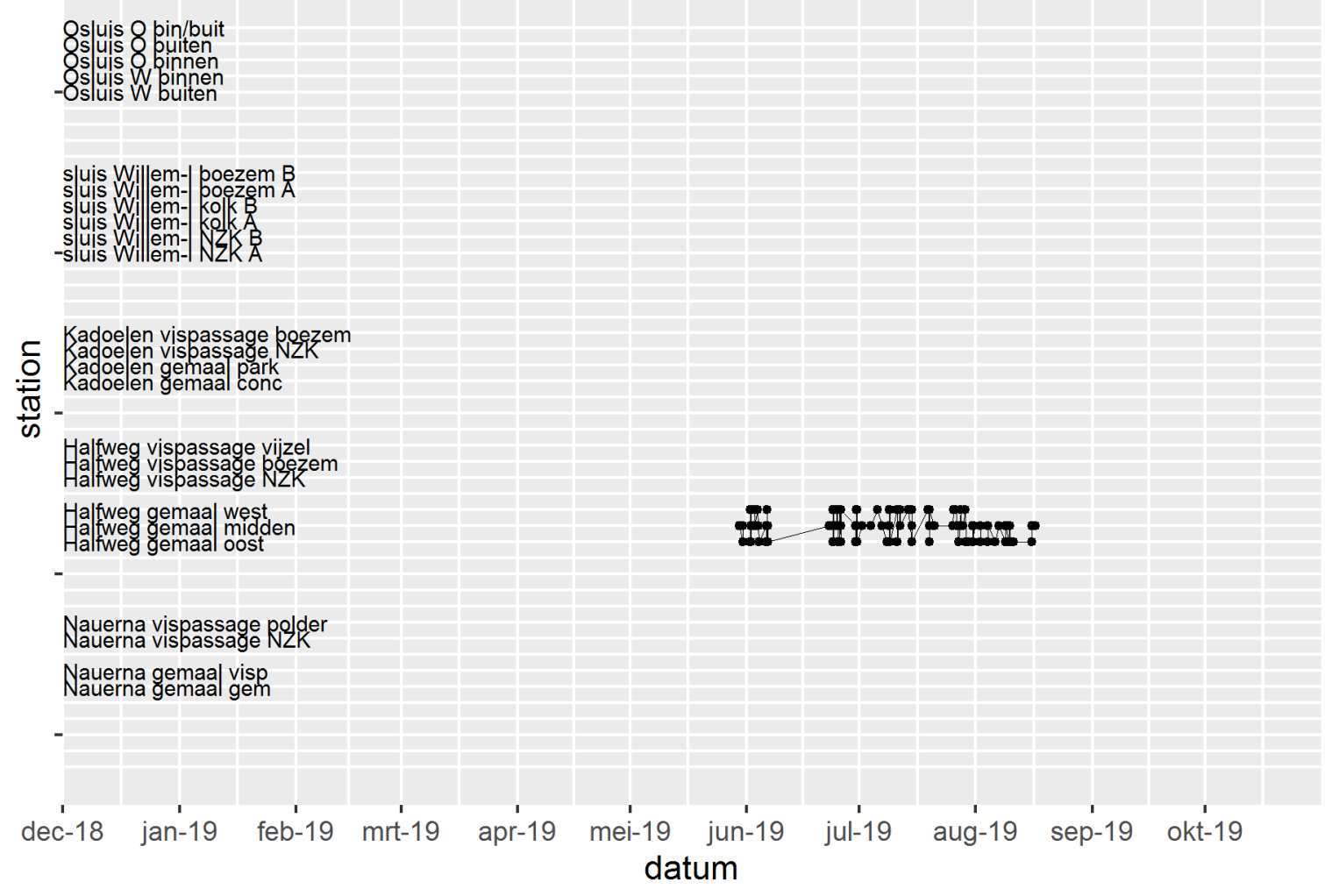

900_230000151894 Brasem 397 mm 656 gr Halfweg 29-mei

8stuis 8 pin/buit

8 suis binnen

- Osluis $W$ buiten

sluis Willem-|boezem B

uis W em- kolk en $^{\circ}$

-sluis Willem-1 NZK

c Kadoeen vispassage boezem

을 Kadoelen gemaal conc

$\frac{\pi}{\infty}$

Halfweg vispassage vijzel

Haltweg vispassage NZK

Halfweg gemaal west

Nauerna vispassage polder

Nauerna gemaal visp

dec-18 jan-19 feb-19 mrt-19 apr-19 mei-19 jun-19 jul-19 aug-19 sep-19 okt-19 datum 
900_230000151895 Blankvoorn 172 mm 71 gr Halfweg 29-mei

Os uuis 8 pin/buit

8 suis 8 binnen

- - ssluis $W$ buinnen

suis Willem- boezem B

suus Wi em- kolk

-suus Willem-I NZK

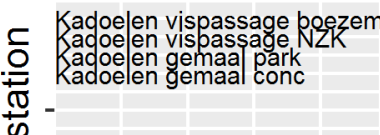

Hal|fweg vispassage vijzel
Hâweg visassage bo bem
Halfweg vispassage NZK

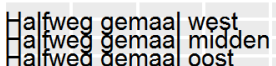

Nauerna vispassage polder

Nauerna gemaal visp

dec-18 jan-19 feb-19 mrt-19 apr-19 mei-19 jun-19 jul-19 aug-19 sep-19 okt-19 datum 
Wageningen Marine Research

T: $+31(0) 317480900$

E: marine-research@wur.nl

www.wur.nl/marine-research

Bezoekers adres:

- Ankerpark 271781 AG Den Helder

- Korringaweg 7, 4401 NT Yerseke

- Haringkade 1, 1976 CP IJmuiden
Wageningen Marine Research levert met kennis, onafhankelijk wetenschappelijk onderzoek en advies een wezenlijke bijdrage aan een duurzamer, zorgvuldiger beheer, gebruik en bescherming van de natuurlijke rijkdommen in zee-, kust- en zoetwatergebieden. 